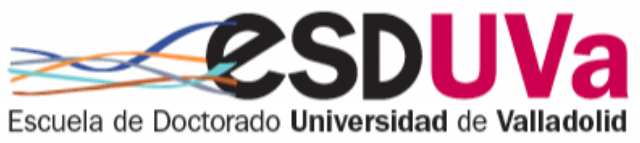

Universidad deValladolid

PROGRAMA DE DOCTORADO EN INVESTIGACIÓN EN CIENCIAS DE LA SALUD

TESIS DOCTORAL:

\title{
RED FLAGS IN THE EVALUATION OF PATIENTS WITH HEADACHE IN THE EMERGENCY DEPARTMENT: THE GOOD, THE BAD AND THE UGLY
}

Presentada por David García Azorín para optar al grado de

Doctor/a por la Universidad de Valladolid

\author{
Dirigida por: \\ Prof. Ángel Luis GUERRERO PERAL \\ Prof. Jesús PORTA ETESSAM \\ Prof. Alberto MARCOS DOLADO
}


UNIVERSIDAD DE VALLADOLID

FACULTAD DE MEDICINA

DEPARTAMENTO DE MEDICINA

\section{TESIS DOCTORAL}

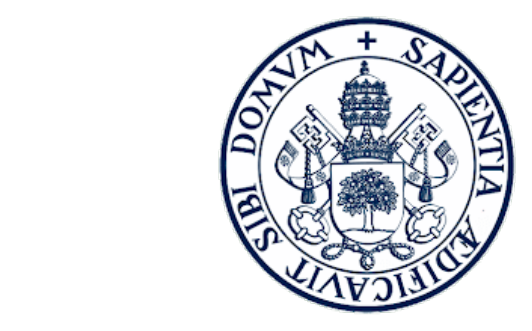

\section{UniversidaddeValladolid}

RED FLAGS IN THE EVALUATION OF PATIENTS WITH HEADACHE IN THE EMERGENCY ROOM: THE GOOD, THE BAD AND THE UGLY

DOCTORANDO: David GARCÍA AZORÍN DIRECTORES DE TESIS: Prof. Ángel Luis GUERRERO PERAL Prof. Jesús PORTA ETESSAM Prof. Alberto MARCOS DOLADO 
UNIVERSIDAD DE VALLADOLID

FACULTAD DE MEDICINA

DOCTORADO EN INVESTIGACIÓN EN CIENCIAS DE LA SALUD

DEPARTAMENTO DE MEDICINA

\section{TESIS DOCTORAL}

RED FLAGS IN THE EVALUATION OF PATIENTS WITH HEADACHE IN THE EMERGENCY ROOM: THE GOOD, THE BAD AND THE UGLY

DOCTORANDO: David GARCÍA AZORÍN DIRECTORES DE TESIS: Prof. Ángel Luis GUERRERO PERAL Prof. Jesús PORTA ETESSAM

Prof. Alberto MARCOS DOLADO

Departamento de Medicina, Universidad de Valladolid VALLADOLID, enero de 2021 


\section{Nota del autor:}

El camino hasta estas líneas no ha sido recto ni fácil. No habría sido posible sin la generosidad de quienes dieron sin esperar recibir nada a cambio, empezando por mi familia, siguiendo por mis compañeros y terminando por mis mentores. Por ello, las primeras palabras de agradecimiento deben ser para una familia que ha sacrificado su tiempo y recursos para dar siempre lo mejor. A mis padres, que siempre han dado sin pedir a cambio. A mi hermano, de quien me siento orgulloso y quien pronto seguirá mis pasos y a mi tía Lourdes, quien logró contagiarme su interés por una de sus dos carreras. Y a mi pareja, por su apoyo y comprensión durante tantas jornadas.

Quiero destacar también a unos compañeros que han sido el mejor de los ejemplos, convirtiéndose en estímulo para seguir aprendiendo y enseñando, como ellos hicieron conmigo, y para los mentores que han tenido la paciencia de corregir mis errores y transferirme su saber hacer. En este mundo en el que se gratifica tan poco la tradición docente y el aprendizaje, mi máximo agradecimiento para ellos y mis deseos para que sigan creando escuela.

El momento en el que concluye esta etapa es harto convulso a nivel sociosanitario. Un virus ha puesto de manifiesto las carencias de nuestro sistema político, económico, sanitario, afectivo e incluso personal y ha causado terribles estragos. Por ello, espero poder corresponder con todos aquellos que tanto me han dado, y seguir su ejemplo de dar sin pensar en el retorno.

Valladolid, enero de 2021

David García Azorín 


\section{Quote:}

[Sergeant Wallace and Tuco - the ugly - are at the train station, handcuffed together]

Armed Union soldier:

Hey, corporal, afraid he'll get lost? Where's the Rebel going?

\section{Sergeant Wallace:}

To hell, with a rope around his neck and a price on his head.

Tuco - the ugly:

Yeah... three thousand dollars, friend. That's a lot of money for a head.

[He flips the soldier's empty sleeve]

Tuco - the ugly:

I bet they didn't even pay you a penny for your arm. 


\section{ABSTRACT}

\section{Background}

Headache is a frequent complaint in the emergency room. The detection of patients with a secondary life-threatening cause of headache is the main priority. Due to the absence of specific biomarkers, diagnosis of secondary headache disorders is still based on the presence of red flags. In headache medicine, red flags are pieces of information whose presence increases the likelihood of having a secondary headache disorder. There are four major subgroups of red flags, elements related to: the prior history of the patient, an atypical headache phenotype, the presence of unusual symptoms or an abnormal neurological examination.

\section{Objective}

We aimed to evaluate the frequencies and types of red flags in patients who presented to the emergency room and had a confirmed diagnosis of one of the following secondary headache disorders: cerebral venous sinus thrombosis (CVST) or coronavirus disease 2019 (Covid-19). We also analyzed patients who were discharged from the emergency room with a definite diagnosis of tension-type headache (TTH).

\section{Methods}

We conducted three observational descriptive studies with cross-sectional design. The studies took place in two third-level academic hospitals and were approved by the Ethics Review Boards of both hospitals. The study population included patients with headache that visited the emergency room. Patients were excluded if another headache disorder was present or if there was some degree of uncertainty in the diagnosis. All potential cases were systematically screened for eligibility during each study period. In each case, two neurologists with expertise on headache medicine assessed for the presence of red flags in each patient who fulfilled the eligibility criteria. A pre-defined questionnaire that included the main red flags was used, based on the International Headache Society and Spanish Society of Neurology proposals. 


\section{Results}

All patients with CVST or Covid-19 presented with at least one red flag. In the case of the TTH study, red flags were also frequent in patients who received a final diagnosis of TTH in the ED discharge report. Among 31 screened patients with CVST, 19 fulfilled eligibility criteria. The most frequent red flags were related to the neurological examination (79\%), followed by the presence of other symptoms (68\%), an atypical headache phenotype (63\%) or the prior history of patients (47\%). Among 576 patients with confirmed Covid19,104 were included in the study. In this case, the most frequent red flags were the presence of systemic symptoms (100\%), followed by an atypical headache phenotype (95\%), and prior medical history (76\%). Due to the risk of contagion, patients were not physically examined by study physicians. In the third study, among 2132 patients screened, 211 received a TTH diagnosis. In this study, the most frequent red flags were the presence of other symptoms (68\%), followed by an atypical headache phenotype (26\%), elements of the prior history of patients (13\%) and an abnormal examination (7\%). Only $10 \%$ of patients fulfilled the International Classification of Headache Disorders for TTH.

\section{Conclusion}

Tension-type headache is over-diagnosed in the emergency department. Patients with a TTH diagnosis presented red flags in $80 \%$ of cases, making the TTH diagnosis incompatible. In the present studies, all patients with CVST or Covid-19 who presented to the emergency room with headache had at least one red flag. CVST must be considered in the differential diagnosis of patients with headache and red flags, so the adequate imaging modalities can be performed. In patients with new-onset headache who present with red flags during 2020-2021, the presence of a possible Covid-19 infection should be considered and evaluated. 


\section{RESUMEN EN CASTELLANO}

\section{Introducción}

La cefalea es un síntoma frecuente en urgencias. La detección de pacientes con una causa secundaria de cefalea que implique riesgo vital es la principal prioridad. Dada la ausencia de biomarcadores específicos, el diagnóstico de las cefaleas se basa todavía en la presencia de datos de alarma. En el manejo de la cefalea, los datos de alarma equivalen a elementos informativos cuya presencia aumenta la probabilidad de tener una cefalea secundaria. Existen cuatro grupos principales de datos de alarma, incluyendo elementos relacionados con: los antecedentes personales del paciente, un fenotipo de cefalea atípico, la presencia de síntomas inusuales o una exploración neurológica anómala.

\section{Objetivo}

Pretendemos evaluar la frecuencia y tipo de datos de alarma en pacientes que acudieron a urgencias y tuvieron un diagnóstico confirmado de una de las siguientes cefaleas secundarias: trombosis de senos venosos cerebrales (TSVC) o enfermedad por coronavirus 2019 (Covid-19). También analizamos pacientes que fueron dados de alta de urgencias con un diagnóstico definitivo de cefalea tipo tensión (CTT).

\section{Métodos}

Se realizaron tres estudios observacionales descriptivos con diseño transversal. Los estudios tuvieron lugar en dos hospitales académicos de tercer nivel y fueron aprobados por los comités éticos de ambos hospitales. La población de estudio incluyó pacientes con cefalea que acudieron a urgencias. Los pacientes fueron excluidos si otra cefalea distinta estaba presente o si existía incertidumbre respecto del diagnóstico. La elegibilidad de todos los posibles casos fue sistemáticamente evaluada durante cada periodo de estudio. En cada caso, dos neurólogos con experiencia en cefaleas evaluaron la presencia de datos de alarma en cada paciente que cumplió los criterios de elegibilidad. Se empleó un cuestionario predefinido que incluía los principales datos de alarma, basado en las propuestas de la Sociedad Internacional de Cefaleas y la Sociedad Española de Neurología. 


\section{Resultados:}

Todos los pacientes con TSVC o Covid-19 mostraron al menos un dato de alarma. En el caso del estudio de CTT, los datos de alarma también fueron frecuentes en pacientes que recibieron un diagnóstico final de CTT en el informe de alta de urgencias. Entre los 31 pacientes evaluados con TSVC, 19 cumplieron los criterios de elegibilidad. Los datos de alarma más frecuentes fueron relacionados con la exploración neurológica (79\%), seguidos de la presencia de otros síntomas (68\%), un fenotipo de la cefalea atípico (63\%) o los antecedentes personales de los pacientes (47\%). De 576 pacientes con infección por Covid-19 confirmada, se incluyeron 104 en el estudio. En este caso, el dato de alarma más frecuente fue la presencia de síntomas sistémicos (100\%), seguida de un fenotipo de la cefalea atípico (95\%), y elementos de los antecedentes personales (76\%). Debido al riesgo de contagio, los pacientes de este estudio no fueron examinados por los investigadores. En el tercer estudio, de 2132 pacientes evaluados, 211 recibieron un diagnóstico de CTT. En este caso, los datos de alarma más frecuentes fueron la presencia de otros síntomas (68\%), seguida de un fenotipo de la cefalea atípico (26\%), datos de los antecedentes personales de los pacientes (13\%) o una exploración anormal (7\%). Solo un 10\% de los pacientes cumplía los criterios de CTT de la Clasificación Internacional de Cefaleas.

\section{Conclusión}

La cefalea tipo tensión está sobrediagnosticada en urgencias. Los pacientes con un diagnóstico de CTT presentaron datos de alarma en un $80 \%$ de los casos, haciendo el diagnóstico de CTT incompatible. En los presentes estudios, todos los pacientes con TSVC o Covid-19 que acudieron a urgencias con cefalea tenía al menos un dato de alarma. La TSVC debe considerarse en el diagnóstico diferencial de los pacientes con cefalea y datos de alarma, para que puedan realizarse las secuencias de imagen apropiadas. En pacientes con cefalea de nueva aparición con datos de alarma durante 2020-2021, la presencia de una posible infección por Covid-19 debe ser considerada y evaluada. 


\section{ABBREVIATION LIST:}

- AION: acute inflammatory optic neuropathy

- ASDH: acute subdural hemorrhage

- CAR: C-reactive protein/albumin ratio

- CDC: centers for disease control and prevention

- CGRP: calcitonin gene-related peptide

- $\mathrm{Cl}$ : confidence interval

- CM: chronic migraine

- CNS: central nervous system

- CO: carbon monoxide

- Cross-sect: cross-sectional

- CRP: C-reactive protein

- CSF: cerebrospinal fluid

- CT: computerized tomography

- CTTH: chronic tension-type headache

- CVST: cerebral venous sinus thrombosis

- CVT: cerebral venous thrombosis

- DaT scan: dopamine transporters scan

- DAVF: dural arteriovenous fistula

- E: specificity

- ED: emergency department

- e.g.: exempli gratia, in example

- ER: emergency room

- ESR: erythrocyte sedimentation rate

- et al: et alia

- ETTH: episodic tension-type headache

- GBD: global burden of disease

- GCA: giant cell arteritis

- hs-CRP: high-sensitivity C-reactive protein

- HSV: herpes simplex virus 
- ICAM-1: intercellular adhesion molecule 1

- ICHD: international classification of headache disorders

- i.e.: id est

- IgG: immunoglobulin G

- Igiv: intravenous immunoglobulin

- IgM: immunoglobulin M

- IQR: inter-quartile range

- miRNA: micro ribonucleic acid

- MLR: monocyte-lymphocyte ratio

- $\mathrm{MOH}$ : medication overuse headache

- MRI: magnetic resonance imaging

- Multiv: multivariate

- $\quad \mathrm{N}$ : Number of subjects

- NDPH: new daily persistent headache

- NLR: neutrophil - lymphocyte ratio

- NS: not specified

- OR: odds ratio

- PACAP: pituitary adenylate cyclase-activating peptide

- PCR: polymerase chain reaction

- PLR: platelet lymphocyte ratio

- Prosp: prospective

- RCVS: reversible cerebral vasoconstriction syndrome

- Retro: retrospective

- RT-PCR: reverse transcriptase polymerase chain reaction

- S: sensitivity

- SAH: subarachnoid hemorrhage

- SARS-CoV-2: severe acute respiratory syndrome coronavirus 2

- SD: standard deviation

- STROBE: strengthening the reporting of observational studies in epidemiology

- sUPAR: soluble urokinase plasminogen activator receptor

- Syst: systematic 
- TNF-alpha: tumoral necrosis factor alpha

- TTH: tension-type headache

- UK: United Kingdom

- Univ: univariate

- USA: United States of America

- VCAM-1: vascular cell adhesion molecule 1

- VEGF-A: vascular endothelial grow factor-A

- vWF: von Willebrand factor

- YLD: years lived with disability 


\section{INDEX}

1. Introduction 20

1.1. Frequency and impact of headache 22

1.1.1. Frequency and impact of headache in the emergency room 23

1.2. Classification of headache disorders 25

1.3. Secondary headache diagnosis 26

1.3.1. Pitfalls in the diagnosis of secondary headache disorders 27

1.3.2. Sub-classification of secondary headache disorders based on the severity

1.4. Headache phenotype in secondary headache disorders

1.5. Aids in the diagnosis of headache disorders

1.5.1. Biomarkers in headache disorders

1.5.2. Concept of red flags

1.6. Pearls and pitfalls of red flags

1.6.1. Problems in secondary headache diagnosis related to the use of red flags

2. Rationale

3. Hypothesis

4. Objectives 72

5. Methods 76

$\begin{array}{ll}\text { 5.1. Study setting } & 79\end{array}$

5.2. Ethical aspects $\quad 79$

5.3. Eligibility criteria $\quad 80$

5.4. Study period and data sources $\quad 85$

5.5. Study procedures $\quad 85$ 
6. Results

6.1. Tension-type headache 90

6.2. Cerebral Venous Sinus Thrombosis

6.3. Coronavirus disease 2019 (Covid-19)

7. Discussion

7.1. Main findings of the studies

7.2. Tension-type headache

7.2.1. Epidemiology of tension-type headache

7.2.2. Diagnostic criteria for tension-type headache

7.2.3. Problems with tension-type headache diagnosis

7.2.4. Problems with tension-type headache diagnosis in the emergency department

7.5. Lessons and tips for the design of future studies assessing red flags in headache

8. Conclusions

9. References 
I. INTRODUCTION 


\section{Introduction}

\subsection{Frequency and impact of headache}

Headache is a universal experience, common in all ages, genders and races (Saylor et al, 2018). The lifetime prevalence of headache is 90-99\% (Nikiforow, 1981; Rassmussen et al, 1991; Rassmussen et al, 1992; Olofsson et al, 2000; Boardman et al, 2003), and the one-year prevalence is $79 \%$ across several different European countries (Steiner et al, 2014; Saylor et al, 2018). Tension-type headache (TTH) and migraine are the second and third most prevalent disorders worldwide (Global Burden of Disease (GBD) 2017 Disease and Injury Incidence and Prevalence collaborators, 2018). When compared with other common neurological disorders, the prevalence of migraine is ten times higher than the combined prevalence of Alzheimer's disease, Parkinson's disease, idiopathic epilepsy, and multiple sclerosis (Global Burden of Disease 2016 Neurology collaborators, 2019).

Due to their prevalence, headache disorders are an important cause of disability. They are the second leading cause of years lived with disability (YLD) worldwide (Global Burden of Disease 2016 Headache collaborators, 2018, Global Burden of Disease 2017 Disease and Injury Incidence and Prevalence collaborators, 2018, Global Burden of Disease 2019 Diseases and Injury Incidence and prevalence collaborators, 2020). Migraine is the first cause of YLD in adults between 15 and 49 years old (Global Burden of Disease 2017 Disability-adjusted life-years and Healthy Life Expectancy Collaborators, 2018; Steiner et al, 2020). This negatively affects the personal and professional development of people who suffer from headache. 


\subsubsection{Frequency and impact of headache in the Emergency Room}

Headache is also a leading complaint in the Emergency Room (ER). It is the most common neurological reason for an ER visit and the fourth most common reason for the visit when including all causes (Goldstein et al, 2006; Burch et al, 2018; Godwin et al, 2019). Data from the Centers for Disease Control and Prevention, which include 138,977 visits during 2017, showed that headache was within the top 10 reasons for an ER visit, accounting for $2.5 \%$ of all the visits and being the third leading reason in female patients aged between 15 and 64 (Centers for Disease Control and Prevention, National Hospital Ambulatory Medical Care Survey, 2017). In studies analysing the reasons for on-call neurologist consults, headache is within the main reasons but is less frequent than stroke or seizures (Table 1). Those studies that specifically analysed the proportion of headache patients in which neurologists are summoned showed that they evaluate $23 \%-28 \%$ of the patients (Matías-Guiu et al, 2016; García Azorín et al, 2020). According to the World Health Organization protocols, headache patients should be managed during first-level (i.e. primary) care whenever possible (Thakkur et al, 2015). In the ER setting, the main priority of clinicians is the detection of potential life-threatening causes of headache (Davenport 2002; Bo et al, 2008; Friedman et al, 2011). 
Table 1. Studies analysing the main reasons for consulting the on-call neurologist in the emergency department setting.

\begin{tabular}{|c|c|c|c|c|c|c|}
\hline $\begin{array}{c}\text { First } \\
\text { Author }\end{array}$ & $\begin{array}{l}\text { Year of } \\
\text { publica- } \\
\text { tion }\end{array}$ & $\begin{array}{l}\text { Study } \\
\text { design }\end{array}$ & Country & $\begin{array}{c}\text { Sample } \\
\text { size }\end{array}$ & $\begin{array}{l}\text { Headache } \\
\text { consults, } \\
\text { n (\%) }\end{array}$ & $\begin{array}{l}\text { Leading reasons for } \\
\text { consult }\end{array}$ \\
\hline De Falco & 2008 & Retro & Italy & 577279 & $\begin{array}{c}\text { NS } \\
(22 \%)\end{array}$ & $\begin{array}{ll}\text { 1. } & \text { Cerebrovascular } \\
\text { disorders }(28 \%) \\
\text { 2. } \\
\text { 3. } & \text { Dizzinesdache }(22 \%)\end{array}$ \\
\hline Rudolf & 2010 & Prosp & Greece & 5901 & $\begin{array}{c}1002 \\
(16.9 \%)\end{array}$ & $\begin{array}{ll}\text { 1. } & \text { Vertigo/dizziness } \\
(17 \%) \\
\text { 2. } & \text { Headache }(16.9 \%) \\
\text { 3. } & \text { Focal weakness } \\
& (10.6 \%)\end{array}$ \\
\hline Hansen & 2011 & Retro & USA & 500 & $\begin{array}{c}91 \\
(18.2 \%)\end{array}$ & $\begin{array}{ll}\text { 1. } & \text { Focal weakness }(22 \%) \\
\text { 2. } & \text { Headache }(18.2 \%) \\
\text { 3. } & \text { Dizziness/vertigo } \\
& (16 \%)\end{array}$ \\
\hline $\begin{array}{l}\text { Ramírez } \\
\text { Moreno }\end{array}$ & 2013 & Retro & Spain & 1458 & $\begin{array}{c}\text { NS } \\
(7.6 \%)\end{array}$ & 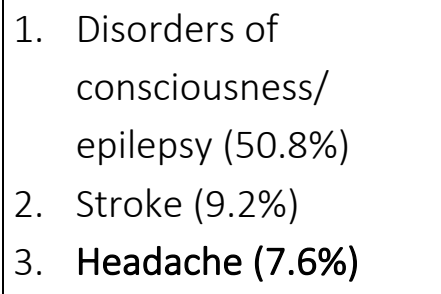 \\
\hline $\begin{array}{l}\text { Rodri- } \\
\text { guez } \\
\text { Cruz }\end{array}$ & 2014 & Prosp & Spain & 3234 & $\begin{array}{c}261 \\
(8.1 \%)\end{array}$ & $\begin{array}{ll}\text { 1. } & \text { Stroke }(34 \%) \\
\text { 2. } & \text { Epilepsy }(16 \%) \\
\text { 3. } & \text { Headache }(8.1 \%)\end{array}$ \\
\hline Hansen & 2015 & Prosp & USA & 94 & $\begin{array}{c}14 \\
(14.9 \%)\end{array}$ & $\begin{array}{ll}\text { 1. } & \text { Focal weakness } \\
& (27.7 \%) \\
\text { 2. } & \text { Dizziness }(16 \%) \\
\text { 3. } & \text { Headache }(14.9 \%)\end{array}$ \\
\hline Aller & 2017 & Retro & Spain & 472 & $\begin{array}{c}\text { NS } \\
(4.7 \%)\end{array}$ & $\begin{array}{ll}\text { 1. } & \text { Stroke }(26.9 \%) \\
\text { 2. } & \text { Epilepsy }(20.6 \%) \\
\text { 3. } & \text { Disorders of } \\
& \text { consciousness }(7.6 \%)\end{array}$ \\
\hline
\end{tabular}

Prosp: prospective design; Retro: retrospective design; NS: not specified; USA: United States of America. 


\subsection{Classification of headache disorders}

Headache disorders can be classified into primary or secondary, depending on the cause of the headache (Headache Classification committee, 2018). The International Classification of Headache Disorders (ICHD) differentiates between four groups of primary headache disorders, eight groups of secondary causes, one group of painful cranial neuropathies and other causes of facial pain, and one group of other headache disorders (Table 2).

Table 2. Main groups of the International Classification of Headache Disorders.

\begin{tabular}{|l|l|}
\hline \multicolumn{2}{|l|}{ Part One: The Primary Headaches } \\
\hline Group 1 & Migraine \\
\hline Group 2 & Tension-type headache \\
\hline Group 3 & Trigeminal autonomic cephalalgias \\
\hline Group 4 & Other primary headache disorders \\
\hline Part Two: The Secondary Headaches \\
\hline Group 5 & Headache attributed to trauma or injury to the head and/or neck \\
\hline Group 6 & Headache attributed to cranial and/or cervical vascular disorder \\
\hline Group 7 & Headache attributed to non-vascular intracranial disorder \\
\hline
\end{tabular}




\begin{tabular}{|l|l|}
\hline Group 8 & Headache attributed to a substance or its withdrawal \\
\hline Group 9 & Headache attributed to infection \\
\hline Group 10 & Headache attributed to disorder of homoeostasis \\
\hline Group 11 & $\begin{array}{l}\text { Headache or facial pain attributed to disorder of the cranium, neck, } \\
\text { structure }\end{array}$ \\
\hline Group 12 & Headache attributed to psychiatric disorder teeth, mouth or other facial or cervical \\
\hline Part Three: Painful Cranial Neuropathies, Other Facial Pain and Other Headaches \\
\hline Group 13 & \begin{tabular}{l} 
Painful lesions of the cranial nerves and other facial pain \\
\hline Group 14
\end{tabular} \\
\hline
\end{tabular}

\subsection{Secondary headache diagnosis}

Table 3 presents the core criteria for diagnosis of most secondary headache disorders. The diagnostic criteria for secondary headache disorders are based on the presence of a causative disorder and the evidence of causation (Headache Classification Subcommittee, 2004; Headache Classification committee, 2013 and 2018). In addition to biological plausibility, a close temporal relation between the onset and/or resolution of the headache and the presumed causative disorder constitutes the basic criteria for most secondary headache disorders (Headache Classification committee 2018; Olesen, 2018). However, like most headache disorders, the ICHD criteria require the phenotypic features 
of the specific cause. Lastly, the fourth criterion is related to the differential diagnosis and is stated as "not better accounted for by another ICHD diagnosis" (Headache Classification committee, 2018).

Table 3. Core criteria for secondary headache disorders.

\begin{tabular}{|l|l|}
\hline Criterion A & Phenotype of the headache \\
\hline Criterion B & Presence of a causative disorder \\
\hline Criterion C & Evidence of causation \\
\hline Criterion D & Differential diagnosis \\
\hline
\end{tabular}

\subsubsection{Pitfalls in the diagnosis of secondary headache disorders}

Diagnosis of secondary headaches can be problematic. First, in most secondary headache disorders, phenotypic criteria are scarce, relatively unspecific, or even absent. The Headache Classification committee has repeatedly encouraged researchers to contribute to this field but has seen little response (Olesen et al, 2009). For many entities, criterion A is simply stated as "Any headache fulfilling criterion C" (Headache Classification committee, 2018). In other secondary headache disorders, the phenotypic criteria may be presented under criterion C, as in the case of 9.2.2 Headache attributed to systemic viral infection (Table 4). 
Table 4. ICHD-3 criteria for 9.2.2 Headache attributed to systemic viral infection.

\begin{tabular}{|c|c|}
\hline Criterion A & Headache of any duration fulfilling criterion C \\
\hline Criterion B & $\begin{array}{l}\text { Both of the following: } \\
\text { 1. systemic viral infection has been diagnosed } \\
\text { 2. no evidence of meningeal or encephalic involvement }\end{array}$ \\
\hline Criterion C & $\begin{array}{l}\text { Evidence of causation demonstrated by at least two of the } \\
\text { following: } \\
\text { 1. headache has developed in temporal relation to onset of the } \\
\text { viral infection } \\
\text { 2. headache has significantly worsened in parallel with worsening } \\
\text { of the systemic viral infection } \\
\text { 3. headache has significantly improved or resolved in parallel with } \\
\text { improvement in or resolution of the systemic viral infection } \\
\text { 4. headache has either or both of the following characteristics: } \\
\text { a) diffuse pain } \\
\text { b) moderate or severe intensity }\end{array}$ \\
\hline Criterion D & Not better accounted for by another ICHD-3 diagnosis \\
\hline
\end{tabular}

ICHD: International Classification of Headache Disorders 
Second, the differentiation between causal and coincidental can be troublesome, in particular with headache attributed to mild injury to the head or when the ancillary tests uncover incidental radiological findings. In studies including patients with headache without neurological abnormalities, the frequency of clinically important findings from magnetic resonance imaging (MRI) ranged between 0.7-3.7\% (Jordan et al, 2000; Wang et al, 2001; Tsushima et al, 2005) and up to $18.3 \%$ in another study which showed that only age $\geq 40$ years was associated with the presence of incidental imaging findings in the multivariate analysis (Kim et al, 2020).

Third, the temporal relationship is not always evident. In several scenarios, the headache persists after the purported causative disorder resolves. This type of scenario led to a modification of the ICHD on its third version (Olesen, 2014), and resolution of the cause is no longer obligatory in most secondary headache disorders. Medication overuse headache $(\mathrm{MOH})$ is an exeption, in which withdrawal of the overused drug is indeed one of the main therapeutic approaches (Carlsen et el, 2020).

Fourth, the use of criterion D is not systematically applied. The ICHD is hierarchical, and even if a patient fulfils all of the criteria but criterion D, e.g., in the case of delayed alcohol-induced headache, that may have a migraine-like phenotype (García-Azorín et al, 2020), the secondary headache diagnosis prevails over the primary headache disorder (Headache Classification committee 2018). 


\subsubsection{Sub-classification of secondary headache disorders based on the severity}

Headache disorders, in general, are more associated with disability rather than mortality (Global Burden of Disease 2017 Disease and Injury Incidence and Prevalence collaborators, 2018; Global Burden of Disease 2017 DALY and HALE Collaborators, 2018). Primary headache disorders cause disability mainly during the acute phase of attacks, while secondary headache disorders might cause persistent disability due to sequelae, e.g., persistent visual loss, cognitive impairment, or weakness, among others (Goffaux et al, 2010). In addition, primary headache disorders should never be a cause of headacherelated mortality (Chou, 2018).

The severity of the different secondary headache disorders is highly variable. Certain secondary causes could be considered mild or relatively benign, while others might cause death or long-term sequelae (Nye et al, 2015). Those that may cause death can be subclassified as high-risk headaches or life-threatening secondary headache disorders (Filler et al, 2019, García-Azorín et al, 2020). High-risk headaches can be defined as headache disorders whose cause may be associated with significant mortality or morbidity or whose cause may be a primary headache disorder that mimic a secondary cause. This last statement is particularly relevant, since some diagnoses should be made only when other causes have been properly ruled out, as in the cases of 1.2.3 Hemiplegic migraine, 1.4.2 Persistent aura without infarction or 4.4 Primary thunderclap headache.

In other primary headache disorders, the clinical presentation might be completely "typical," but the headaches of these groups are associated with secondary causes at a 
higher frequency than would be expected by chance (de Coo et al, 2015; Burish et al, 2019). For that reason, symptomatic causes should be ruled out with imaging before confirming the diagnosis, as in the case of trigeminal autonomic cephalalgias (Gago-Veiga et al, 2020; Pareja et al, 2020) or nummular headache (García-Iglesias et al, 2020).

\subsection{Headache phenotype in secondary headache disorders}

The ICHD-3 includes 118 causes of varying life-threatening secondary headache disorders (Headache Classification committee, 2018) (Figure 1). However, the total number of causes of secondary headache might be even higher. A systematic review found 119 total causes of thunderclap headache alone, spanning 1224 articles (Devenney et al, 2014). Table 5 shows the main groups and/or subgroups of secondary causes of lifethreatening headache disorders. Since the number of possible clinical phenotypes for a headache is limited, many secondary causes may mimic a primary headache phenotype (Taylor 2014, Goffaux et al, 2010).

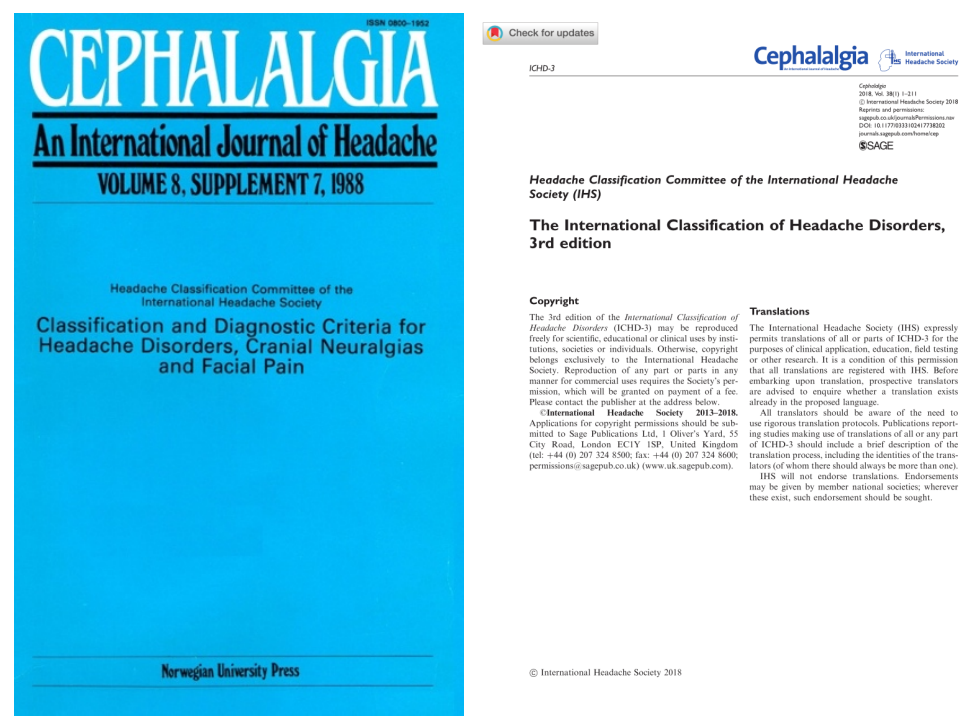

Figure 1: The cover of the International Classification of Headache Disorders, $1^{\text {st }}$ edition, 1988 (left), first page of the International Classification of Headache Disorders, $3^{\text {rd }}$ version, 2018 (right). 
Table 5. Major groups and/or subgroups of the ICHD-3 classification that include high-risk headache disorders.

\begin{tabular}{|c|c|}
\hline \multicolumn{2}{|c|}{ Part One: The Primary Headaches } \\
\hline Group 1 & $\begin{array}{l}\text { 1.2.2 Migraine with brainstem aura } \\
\text { 1.2.3 Hemiplegic migraine } \\
\text { 1.2.4 Retinal migraine } \\
\text { 1.4.2 Persistent aura without infarction } \\
\text { 1.4.4 Migraine aura-triggered seizure }\end{array}$ \\
\hline Group 2 & None \\
\hline Group 3 & None* \\
\hline Group 4 & $\begin{array}{l}\text { 4.1 Primary cough headache } \\
\text { 4.2 Primary exercise headache } \\
\text { 4.3 Primary headache associated with sexual activity } \\
\text { 4.4 Primary thunderclap headache } \\
\text { 4.9 Hypnic headache } \\
\text { 4.10 New daily persistent headache (NDPH) }\end{array}$ \\
\hline \multicolumn{2}{|c|}{ Part Two: The Secondary Headaches } \\
\hline Group 5 & $\begin{array}{l}\text { 5.1.1 Acute headache attributed to moderate or severe traumatic } \\
\text { injury to the head }\end{array}$ \\
\hline Group 6 & $\begin{array}{l}\text { 6.1 Headache attributed to cerebral ischemic event } \\
\text { 6.2 Headache attributed to non-traumatic intracranial } \\
\text { haemorrhage } \\
\text { 6.3 Headache attributed to unruptured vascular malformation } \\
\text { 6.4 Headache attributed to arteritis } \\
\text { 6.5 Headache attributed to cervical carotid or vertebral artery } \\
\text { disorder } \\
\text { 6.6 Headache attributed to cranial venous disorder } \\
\text { 6.7 Headache attributed to other acute intracranial arterial disorder } \\
\text { 6.8 Headache and/or migraine-like aura attributed to chronic } \\
\text { intracranial vasculopathy } \\
\text { 6.9 Headache attributed to pituitary apoplexy }\end{array}$ \\
\hline Group 7 & $\begin{array}{l}\text { 7.1 Headache attributed to increased cerebrospinal fluid (CSF) } \\
\text { pressure }\end{array}$ \\
\hline
\end{tabular}




\begin{tabular}{|c|c|}
\hline & $\begin{array}{l}\text { 7.2 Headache attributed to low CSF pressure } \\
\text { 7.3 Headache attributed to non-infectious inflammatory } \\
\text { intracranial disease } \\
\text { 7.4 Headache attributed to intracranial neoplasia }\end{array}$ \\
\hline Group 8 & $\begin{array}{l}\text { 8.1.3 Carbon monoxide (CO)-induced headache } \\
\text { 8.1.5 Cocaine-induced headache }\end{array}$ \\
\hline Group 9 & $\begin{array}{l}\text { 9.1 Headache attributed to intracranial infection } \\
\text { 9.2 Headache attributed to systemic infection }\end{array}$ \\
\hline Group 10 & $\begin{array}{l}\text { 10.1 Headache attributed to hypoxia and/or hypercapnia } \\
\text { 10.3 Headache attributed to arterial hypertension } \\
\text { 10.6 Cardiac cephalalgia }\end{array}$ \\
\hline Group 11 & $\begin{array}{l}\text { 11.3.1 Headache attributed to acute angle-closure glaucoma } \\
\text { 11.3.3 Headache attributed to ocular inflammatory disorder } \\
\text { 11.5.1 Headache attributed to acute or recurring rhinosinusitis }\end{array}$ \\
\hline Group 12 & $\begin{array}{l}\text { 12.1 Headache attributed to somatization disorder } \\
\text { 12.2 Headache attributed to psychotic disorder }\end{array}$ \\
\hline \multicolumn{2}{|c|}{ Part Three: Painful Cranial Neuropathies, Other Facial Pain and Other Headaches } \\
\hline Group 13 & $\begin{array}{l}\text { 13.1.1.2 Secondary trigeminal neuralgia } \\
\text { 13.1.2 Painful trigeminal neuropathy } \\
\text { 13.2.1.2 Secondary glossopharyngeal neuropathy } \\
\text { 13.2.2 Painful glossopharyngeal neuropathy } \\
\text { 13.3.1.2 Secondary nervus intermedius neuralgia } \\
\text { 13.3.2.3 Painful nervus intermedius neuropathy attributed to other } \\
\text { disease } \\
\text { 13.6 Painful optic neuritis } \\
\text { 13.7 Headache attributed to ischemic ocular motor nerve palsy } \\
\text { 13.8 Tolosa-Hunt syndrome } \\
\text { 13.9 Paratrigeminal oculosympathetic (Raeder's) syndrome } \\
\text { 13.10 Recurrent painful ophthalmoplegic neuropathy } \\
\text { 13.13 Central neuropathic pain }\end{array}$ \\
\hline Group 14 & 14.2 Headache unspecified \\
\hline
\end{tabular}

* A symptomatic cause must be ruled out in every patient with trigeminal autonomic cephalalgia. NDPH: new-daily persistent headache; CSF: cerebrospinal fluid; CO: carbon monoxide. 
Presence and type of headache is the cornerstone in the diagnosis of many of those disorders. One of the causes that should not be missed is cancer (Goldlust et al, 2010). On the one hand, headache might be the presenting symptom in many cases of systemic and craniocervical cancer (Rushton et al, 1964; Vazquez-Baquero et al, 1994). On the other hand, it is one of the most frequent symptoms, if not the most frequent, during the course of the disease (Schankin et al, 2007). Table 6 depicts the frequency of headache in the well-known published series of cancer patients.

Table 6. Frequency of headache in the well-known series of cancer patients.

\begin{tabular}{|c|c|c|c|c|c|}
\hline First Author & $\begin{array}{c}\text { Year of } \\
\text { publica } \\
\text {-tion }\end{array}$ & $\begin{array}{c}\text { Study } \\
\text { design \& } \\
\text { Period }\end{array}$ & Country & $\begin{array}{l}\text { Sample } \\
\text { size }\end{array}$ & Frequency of headache \\
\hline Rushton & 1964 & $\begin{array}{c}\text { Case series } \\
1960\end{array}$ & USA & 221 & $\begin{array}{c}59.7 \% \\
(24.9 \% \text { as first symptom) }\end{array}$ \\
\hline Forsyth & 1993 & $\begin{array}{l}\text { Case series } \\
\text { 1991-1992 }\end{array}$ & USA & 111 & $47.7 \%$ \\
\hline Suwanwela & 1994 & $\begin{array}{l}\text { Cross-sect } \\
1991-1992\end{array}$ & Thailand & 171 & $71.3 \%$ \\
\hline $\begin{array}{l}\text { Vazquez- } \\
\text { Barquero }\end{array}$ & 1994 & $\begin{array}{c}\text { Prosp } \\
1991-1993\end{array}$ & Spain & 183 & $\begin{array}{l}\text { At the moment of } \\
\text { diagnosis: }\end{array}$ \\
\hline
\end{tabular}




\begin{tabular}{|c|c|c|c|c|c|}
\hline & & & & & $\begin{array}{l}33.0 \% \text { in primary CNS } \\
\text { cancer and } 31.4 \% \text { in } \\
\text { metastases }\end{array}$ \\
\hline Counsell & 1998 & $\begin{array}{l}\text { Syst review } \\
1966-1995\end{array}$ & Worldwide & 55 & $72.1 \%$ \\
\hline Pfund & 1999 & $\begin{array}{l}\text { Case series } \\
\text { 1994-1995 }\end{array}$ & Hungary & 279 & $58.8 \%$ \\
\hline Christiaans & 2002 & $\begin{array}{c}\text { Prosp } \\
1997-2000\end{array}$ & $\begin{array}{c}\text { The } \\
\text { Netherlands }\end{array}$ & $\begin{array}{c}68 \\
\text { cancer } \\
\text { patients }\end{array}$ & $\begin{array}{l}32.4 \% \text { cancer patients with } \\
\text { new or changed headache } \\
\text { had intracranial metastasis }\end{array}$ \\
\hline Wilne & 2006 & $\begin{array}{c}\text { Retrosp } \\
1998-2001\end{array}$ & UK & $\begin{array}{c}200 \\
\text { children }\end{array}$ & $41.0 \%$ (first symptom) \\
\hline Schankin & 2007 & $\begin{array}{c}\text { Case series } \\
2002\end{array}$ & Germany & 85 & $60.0 \%$ \\
\hline Valentinis & 2010 & $\begin{array}{c}\text { Prosp } \\
2007-2008\end{array}$ & Italy & 211 & $55.0 \%$ \\
\hline Rostami & 2016 & Syst Review & Worldwide & $\begin{array}{l}14599 \\
\text { (Breast } \\
\text { cancer) }\end{array}$ & $35.0 \%$ \\
\hline
\end{tabular}

Cross-sect: Cross-sectional design; Prosp: Prospective design; Retrosp: Retrospective design; Syst: Systematic; CNS: Central nervous system, USA: United States of America; UK: United Kingdom. 
Inappropriate diagnosis of CNS cancer might have terrible consequences for the patient's prognosis, and therefore, legal implications (Singh et al, 2007; Aaronson et al, 2019). Another feared group of disorders are CNS infections. In this case, prognosis is time dependent (Van de Beek et al, 2016). Headache is one of the most frequent symptoms (Table 7).

Table 7. Frequency of headache in the well-known series of central nervous system infections.

\begin{tabular}{|c|c|c|c|c|c|c|}
\hline First Author & $\begin{array}{l}\text { Year } \\
\text { of } \\
\text { public } \\
\text { ation }\end{array}$ & Study design & Country & $\begin{array}{l}\text { Sample } \\
\text { size }\end{array}$ & $\begin{array}{l}\text { Frequency of } \\
\text { headache }\end{array}$ & $\begin{array}{l}\text { Mortality } \\
\text { rate (\%) }\end{array}$ \\
\hline \multicolumn{7}{|c|}{ Bacterial meningitis } \\
\hline Durand & 1993 & $\begin{array}{l}\text { Case series } \\
\text { 1962-1988 }\end{array}$ & USA & 493 & NS & $25.0 \%$ \\
\hline Sigurdardóttir & 1997 & $\begin{array}{l}\text { Case series } \\
\text { 1975-1994 }\end{array}$ & Iceland & 132 & NS & $19.7 \%$ \\
\hline Hussein & 2000 & $\begin{array}{l}\text { Case series } \\
\text { 1985-1996 }\end{array}$ & USA & 103 & $66.0 \%$ & $14.6 \%$ \\
\hline Van de Beck & 2004 & $\begin{array}{l}\text { Case series } \\
1998-2002\end{array}$ & $\begin{array}{l}\text { The } \\
\text { Netherland } \\
\text { S }\end{array}$ & 696 & $86.9 \%$ & $20.5 \%$ \\
\hline Thigpen & 2011 & $\begin{array}{l}\text { Case series } \\
\text { 1998-2007 }\end{array}$ & USA & 3155 & NS & $14.8 \%$ \\
\hline
\end{tabular}




\begin{tabular}{|c|c|c|c|c|c|c|}
\hline Polkowska & 2017 & $\begin{array}{l}\text { Case series } \\
1995-2014\end{array}$ & Finland & 1361 & NS & $10.3 \%$ \\
\hline \multicolumn{7}{|c|}{ Meningitis and/or encephalitis } \\
\hline Paradowska & 2016 & $\begin{array}{ll}\text { Case } & \text { series } \\
2014 & \end{array}$ & Poland & 3488 & NS & NS \\
\hline \multicolumn{7}{|c|}{ Viral meningitis } \\
\hline Whitley & 1982 & $\begin{array}{ll}\text { HSV } & \text { Case } \\
\text { series } & \end{array}$ & USA & 202 & $79.2 \%$ & NS \\
\hline Robart & 1998 & $\begin{array}{l}\text { Enterovirus } \\
\text { Case series }\end{array}$ & USA & 39 & $100 \%$ & $0 \%$ \\
\hline \multicolumn{7}{|c|}{ Brain abscess } \\
\hline Chun & 1986 & $\begin{array}{l}\text { Case series } \\
1970-1983\end{array}$ & USA & 55 & $72.1 \%$ & $40 \%$ \\
\hline Nicolosi & 1991 & $\begin{array}{l}\text { Case } \quad \text { series } \\
1935-1981\end{array}$ & USA & 38 & NS & $38 \%$ \\
\hline Berlit & 1996 & $\begin{array}{l}\text { Case series } \\
1975-1993\end{array}$ & Germany & 67 & $\begin{array}{l}19.4 \% \\
\text { (presenting } \\
\text { symptom) }\end{array}$ & $37.3 \%$ \\
\hline Grigoriadis & 1997 & $\begin{array}{l}\text { Case series } \\
\text { Streptococcu } \\
s \\
\text { pneumoniae }\end{array}$ & Worldwide & 24 & $81.0 \%$ & $34.8 \%$ \\
\hline Fica & 2006 & $\begin{array}{l}\text { Case } \quad \text { series } \\
1989-2005\end{array}$ & Chile & 30 & $58.6 \%$ & $10.0 \%$ \\
\hline Carpenter & 2007 & $\begin{array}{l}\text { Case series } \\
2000-2004\end{array}$ & UK & 49 & $49.0 \%$ & $10.2 \%$ \\
\hline
\end{tabular}

HSV: Herpes simplex virus. USA: United States of America. UK: United Kingdom. NS: Not specified. 


\subsection{Aids in the diagnosis of headache disorders}

\subsubsection{Biomarkers in headache disorders}

In contrast with other painful syndromes (Azzopardi et al, 2016; Andruchow et al, 2018; Sendama et al, 2018), headache disorders lack specific biomarkers (Schytz et al, 2016). Biomarkers are elements that lead to the diagnosis of a certain condition, or that predict prognosis. Many medical and neurological diseases have specific biomarkers, including white matter lesions in multiple sclerosis, dopamine transporters scan (DaT scan) in Parkinson's disease, electroencephalographic spikes and waves in epilepsy, hippocampal atrophy in Alzheimer's disease, polysomnography in sleep disorders, and electromyographic and electroneurographic changes in neuromuscular diseases, among others (Pascual, 2009; Zarranz, 2018). Headache medicine may be the sub-specialty of neurology in which biomarkers are the least established.

Before summarizing the existing biomarkers, it is important to consider the optimal characteristics of a biomarker (Chen et al, 2011). Table 8 lists some of the ideal features. The intended properties might vary depending on the purpose. When the main aim is diagnosis, sensitivity or specificity may be preferred depending on the frequency and severity of the condition. However, biomarkers are also used in the follow-up or to measure prognosis, the effect of the treatment, or the stage of the disease (Schuetz et al, 2015; Cardelli et al, 2018). 
Table 8. Main characteristics of a biomarker.

\begin{tabular}{|l|l|}
\hline Characteristic & Definition \\
\hline Precise & Measures what it is intended to \\
\hline Sensitive & Detects the condition whenever it is present \\
\hline Reproducible & Further determinations yield the same result \\
\hline Rapidly measurable & Provides the result quickly \\
\hline Affordable & Has an acceptable cost \\
\hline Accessible & Is available for most of the population \\
\hline Non-invasive & Is neither painful nor invasive, easily obtainable \\
\hline Early & Allows prompt and early diagnosis. Detects the condition \\
\hline early in the disease progression \\
\hline
\end{tabular}

Most of the biomarkers that have been used in headache medicine are related to the diagnosis of primary headache disorders, mainly migraine (Goadsby et al, 1990; Gallai et a,l 1995; Tuka et al, 2013) and cluster headache (Buture et al, 2019). Substantial efforts have been made in search of others, with several studies in the genetics field, imaging, electroencephalography, and laboratory studies (Schytz et al, 2016; Hadidchi et al, 2019). Despite this, there does not exist a single biomarker able to properly differentiate 
between primary and secondary headache disorders. Table 9 lists the studies that have focused on the laboratory diagnosis of headache disorders.

Table 9. Studies evaluating laboratory biomarkers for the diagnosis of headache.

\begin{tabular}{|c|c|c|c|c|c|c|}
\hline $\begin{array}{l}\text { First } \\
\text { Author }\end{array}$ & Year & Design & $\begin{array}{c}\text { Sample } \\
\text { size }\end{array}$ & Biomarker & Aim & Results \\
\hline Foroozan & 2002 & $\begin{array}{c}\text { Retrospec } \\
\text { tive case- } \\
\text { control }\end{array}$ & 91 & $\begin{array}{l}\text { Platelet } \\
\text { count }\end{array}$ & $\begin{array}{l}\text { Diagnosis of } \\
\text { GCA }\end{array}$ & $\begin{array}{l}\text { Platelet count } \\
>400 \cdot 10^{3} . \mathrm{S}: 57 \% \\
(95 \% \mathrm{Cl}: 42-72)\end{array}$ \\
\hline Costello & 2004 & $\begin{array}{l}\text { Case } \\
\text { series } \\
1985\end{array}$ & 408 & $\begin{array}{l}\text { Platelet } \\
\text { count }\end{array}$ & $\begin{array}{l}\text { Differential } \\
\text { diagnosis GCA } \\
\text { and Non- } \\
\text { Arteritic AION }\end{array}$ & $\begin{array}{c}\text { Higher platelet } \\
\text { count, better } \\
\text { when combined } \\
\text { with ESR }\end{array}$ \\
\hline $\begin{array}{l}\text { Amy Au- } \\
\text { Yong }\end{array}$ & 2007 & $\begin{array}{l}\text { Systematic } \\
\text { review }\end{array}$ & $\begin{array}{c}62 \\
\text { papers }\end{array}$ & CRP & $\begin{array}{c}\text { Negative } \\
\text { predictive value } \\
\text { in diagnosis of } \\
\text { intracranial } \\
\text { infection }\end{array}$ & $\begin{array}{l}\text { There is no } \\
\text { evidence }\end{array}$ \\
\hline $\begin{array}{l}\text { Gudmund } \\
\text {-sson }\end{array}$ & 2009 & $\begin{array}{l}\text { Case- } \\
\text { control }\end{array}$ & 7251 & $\begin{array}{l}\text { Interictal } \\
\text { CRP }\end{array}$ & $\begin{array}{c}\text { Diagnosis of } \\
\text { migraine }\end{array}$ & $\begin{array}{c}\text { No differences } \\
\text { between healthy } \\
\text { controls and } \\
\text { migraineurs }\end{array}$ \\
\hline Samaie & 2011 & $\begin{array}{l}\text { Case- } \\
\text { control }\end{array}$ & 100 & $\begin{array}{c}\text { Blood } \\
\text { magnesium } \\
\text { level }\end{array}$ & $\begin{array}{l}\text { Differential } \\
\text { diagnosis } \\
\text { migraine } \\
\text { (interictal vs. } \\
\text { ictal) vs. } \\
\text { controls }\end{array}$ & $\begin{array}{l}\text { No differences on } \\
\text { ictal vs. interictal } \\
\text { level but lower } \\
\text { than controls }\end{array}$ \\
\hline Kermani & 2012 & $\begin{array}{l}\text { Case } \\
\text { series } \\
2000- \\
2008\end{array}$ & 764 & $\begin{array}{l}\text { CRP } \\
\text { ESR }\end{array}$ & $\begin{array}{l}\text { Diagnosis of } \\
\text { temporal } \\
\text { arteritis }\end{array}$ & $\begin{array}{l}\text { S of CRP } 87 \% \\
\text { S of ESR } 84 \%\end{array}$ \\
\hline $\begin{array}{l}\text { Cernuda- } \\
\text { Morollón }\end{array}$ & 2013 & $\begin{array}{l}\text { Case- } \\
\text { control }\end{array}$ & 191 & CGRP & $\begin{array}{c}\text { Diagnosis of } \\
\text { chronic } \\
\text { migraine }\end{array}$ & $\begin{array}{c}\text { Higher interictal } \\
\text { levels of CGRP in } \\
\text { CM }\end{array}$ \\
\hline
\end{tabular}




\begin{tabular}{|c|c|c|c|c|c|c|}
\hline Yucel & 2014 & $\begin{array}{l}\text { Case- } \\
\text { control }\end{array}$ & 89 & $\begin{array}{c}\text { D-dimer } \\
\text { Galectin-3 } \\
\text { Fibrinogen }\end{array}$ & $\begin{array}{c}\text { Differential } \\
\text { diagnosis } \\
\text { migraine } \\
\text { (interictal vs. } \\
\text { ictal) vs. } \\
\text { controls }\end{array}$ & $\begin{array}{c}6.2 \% \text { higher ictal } \\
\text { value of D-dimer. } \\
\text { Other results } \\
\text { non-significant }\end{array}$ \\
\hline Al-Drawi & 2016 & $\begin{array}{l}\text { Case- } \\
\text { Control }\end{array}$ & 130 & $\begin{array}{l}\text { VCAM-1 } \\
\text { ICAM-1 }\end{array}$ & $\begin{array}{c}\text { Diagnosis of } \\
\text { SAH }\end{array}$ & $\begin{array}{l}\text { Higher levels in } \\
\text { SAH group }\end{array}$ \\
\hline $\begin{array}{c}\text { Assarzade } \\
\text { gan }\end{array}$ & 2016 & $\begin{array}{l}\text { Case- } \\
\text { control }\end{array}$ & 80 & $\begin{array}{c}\text { Serum } \\
\text { levels of } \\
\text { magnesium }\end{array}$ & $\begin{array}{c}\text { Differential } \\
\text { diagnosis } \\
\text { migraine } \\
\text { (interictal vs. } \\
\text { ictal) vs. } \\
\text { controls }\end{array}$ & $\begin{array}{l}\text { Lower levels of } \\
\text { magnesium } \\
\text { during attacks. }\end{array}$ \\
\hline Andersen & 2016 & $\begin{array}{l}\text { Case- } \\
\text { control }\end{array}$ & 24 & $\begin{array}{c}\text { miRNA } \\
\text { expression }\end{array}$ & $\begin{array}{c}\text { Differential } \\
\text { diagnosis } \\
\text { migraine } \\
\text { (interictal vs. } \\
\text { ictal) vs. } \\
\text { controls }\end{array}$ & $\begin{array}{l}\text { Upregulation of } \\
\text { miRNA-34a-5p, } \\
\text { miRNA-382-5p. }\end{array}$ \\
\hline Erygit & 2017 & $\begin{array}{l}\text { Retrosp } \\
\text { Case } \\
\text { control }\end{array}$ & 1231 & NLR & $\begin{array}{l}\text { Differential } \\
\text { SAH and } \\
\text { migraine }\end{array}$ & $\begin{array}{c}\text { SAH NLR > } \\
\text { migraine. Value } \\
\text { of 4.02: S: } 86 \% \text {, E } \\
97 \% .\end{array}$ \\
\hline Yilmaz & 2017 & $\begin{array}{l}\text { Case- } \\
\text { control }\end{array}$ & 90 & $\begin{array}{c}\text { suPAR, } \\
\text { procalcitonin } \\
\text { fibrinogen, } \\
\text { hs-CRP }\end{array}$ & $\begin{array}{c}\text { Differential } \\
\text { diagnosis } \\
\text { migraine } \\
\text { (interictal vs. } \\
\text { ictal) vs. } \\
\text { controls }\end{array}$ & $\begin{array}{l}\text { Higher levels of } \\
\text { suPAR, } \\
\text { procalcitonin and } \\
\text { fibrinogen }\end{array}$ \\
\hline Blum & 2017 & $\begin{array}{l}\text { Prosp } \\
\text { cohort }\end{array}$ & 391 & Copeptin & $\begin{array}{c}\text { Diagnosis of } \\
\text { secondary } \\
\text { headache }\end{array}$ & $\begin{array}{l}\text { Univ: OR } 2.03 \\
\begin{array}{c}\text { (95\% Cl: } 1.52- \\
2.70) \\
\text { Multiv: Not } \\
\text { significant }\end{array}\end{array}$ \\
\hline Martami & 2018 & $\begin{array}{l}\text { Case- } \\
\text { control }\end{array}$ & 83 & $\begin{array}{l}\text { CRP, TNF- } \\
\text { alpha }\end{array}$ & $\begin{array}{c}\text { Diagnosis of } \\
\text { migraine vs. } \\
\text { controls }\end{array}$ & $\begin{array}{l}\text { Higher levels of } \\
\text { TNF-alpha in } \\
\text { migraine patients }\end{array}$ \\
\hline
\end{tabular}




\begin{tabular}{|c|c|c|c|c|c|c|}
\hline Tietjen & 2018 & $\begin{array}{l}\text { Case- } \\
\text { control }\end{array}$ & 417 & $\begin{array}{l}\text { Fibrinogen, } \\
\text { factor II, D- } \\
\text { dimer, } \\
\text { hsCRP, VWF }\end{array}$ & $\begin{array}{l}\text { Diagnosis of } \\
\text { migraine vs. } \\
\text { controls }\end{array}$ & $\begin{array}{l}\text { Fibrinogen and } \\
\text { hs-CRP were } \\
\text { higher in } \\
\text { migraine }\end{array}$ \\
\hline Gürger & 2018 & $\begin{array}{l}\text { Case- } \\
\text { control }\end{array}$ & 140 & $\begin{array}{c}\text { Galectin-3, } \\
\text { hsCRP }\end{array}$ & $\begin{array}{l}\text { Diagnosis of } \\
\text { migraine vs. } \\
\text { controls }\end{array}$ & $\begin{array}{c}\text { Galectin-3: S } \\
\text { 70\%, E: 73\%. } \\
\text { hsCRP: S89\%, E: } \\
90 \%\end{array}$ \\
\hline Wicinski & 2019 & $\begin{array}{l}\text { Case- } \\
\text { Control }\end{array}$ & 130 & $\begin{array}{l}\text { VEGF-A, } \\
\text { coagulation } \\
\text { and } \\
\text { fibrinolysis } \\
\text { parameters }\end{array}$ & $\begin{array}{c}\text { Diagnosis of } \\
\text { SAH }\end{array}$ & $\begin{array}{c}\text { Only VEGF-A } \\
\text { lower in SAH. No } \\
\text { differences in the } \\
\text { rest. }\end{array}$ \\
\hline Yazar & 2019 & $\begin{array}{l}\text { Case- } \\
\text { control }\end{array}$ & 201 & $\begin{array}{c}\text { Monocyte, } \\
\text { neutrophil, } \\
\text { lymphocyte } \\
\text {, platelet } \\
\text { count, CRP, } \\
\text { albumin, } \\
\text { NLR, PLR, } \\
\text { MLR, CAR }\end{array}$ & $\begin{array}{c}\text { Differential } \\
\text { diagnosis } \\
\text { migraine } \\
\text { (interictal vs. } \\
\text { ictal) vs. } \\
\text { controls }\end{array}$ & $\begin{array}{l}\text { Increased ictal } \\
\text { levels of CRP, } \\
\text { neutrophil; ratio } \\
\text { of NLR, MLR and } \\
\text { CAR; decreased } \\
\text { albumin and } \\
\text { lymphocyte } \\
\text { count. }\end{array}$ \\
\hline Godkemir & 2020 & $\begin{array}{l}\text { Case- } \\
\text { control }\end{array}$ & 88 & Pentraxin 3 & $\begin{array}{l}\text { Diagnosis of } \\
\text { migraine with } \\
\text { aura vs. } \\
\text { controls }\end{array}$ & $\begin{array}{c}\text { S: } 93 \%, \mathrm{E}: 84 \% \\
(\mathrm{No} \mathrm{Cl})\end{array}$ \\
\hline Copeptin & 2020 & $\begin{array}{l}\text { Case- } \\
\text { control }\end{array}$ & 103 & Copeptin & $\begin{array}{l}\text { Diagnosis of } \\
\text { migraine vs. } \\
\text { controls }\end{array}$ & $\begin{array}{l}\text { S: } 59 \%(95 \% \mathrm{Cl}: \\
44-74 \%), \mathrm{E}: 61 \% \\
(95 \% \mathrm{Cl}: 50-69 \%)\end{array}$ \\
\hline
\end{tabular}

GCA: giant cell arteritis; S: sensitivity; Cl: confidence interval; AION: acute inflammatory optic neuropathy; ESR: erythrocyte sedimentation rate; CRP: C-reactive protein; CGRP: calcitonin gene-related peptide; CM: chronic migraine; NS: not significant; VCAM-1: vascular cell adhesion molecule 1; ICAM-1: intercellular adhesion molecule 1; SAH: subarachnoid haemorrhage; miRNA: micro ribonucleic acid; Retrosp: retrospective; NLR: neutrophil/lymphocyte ratio; E: specificity; sUPAR: soluble urokinase plasminogen activator receptor; hs-CRP: hypersensitive-CRP; Prosp: prospective; Univ: univariate; OR: odds-ratio; Multiv: multivariate; TNF: tumor necrosis factor; vWF: von Willebrand Factor antigen; VEGF-A: type A vascular endothelial growth factor; PLR: platelet/lymphocyte ratio; MLR: monocyte/lymphocyte ratio; CAR: C-reactive protein/albumin ratio. 
Calcitonin gene-related peptide (CGRP) was the new hope for headache diagnosis. The arrival of novel therapies targeting CGRP created great hype (Pascual, 2015), even though the first studies were conducted more than 20 years prior. In 1998, Goadsby and Edvinsson observed that CGRP was increased during the activation of the trigeminovascular system in cat models of headache (Goadsby et al, 1998). They stimulated the superior sagittal sinus and measured CGRP levels during attacks (Zagami et al, 1990) and observed the same in humans in cluster headache (Goadsby et al, 1994) and in paroxysmal hemicrania patients (Goadsby et al, 1996). The first results from Spanish authors came from the Pascual group in 2013, who observed that patients with chronic migraine exhibited higher interictal levels of CGRP when compared with episodic migraine patients, healthy controls and episodic cluster headache patients outside of a cluster (Cernuda-Morollón et al, 2013).

Most biomarker studies have focused on the identification of primary headache and not secondary headache (Table 8). Not all of the mentioned studies were done in the emergency department, where the results are most likely to be used. Validation studies of the proposed biomarkers for secondary headache disorders are even more limited. For all these reasons, to date, the diagnosis of secondary headache disorders is still based on the presence of red flags.

\subsubsection{Concept of red flags}

Red flags are pieces of information whose presence increases the likelihood of having a secondary headache disorder (Lance, 1981; Nye et al, 2015). Red flags could be related 
to either the prior history of the patient, to an atypical headache pattern, to the presence of unusual symptoms or to an abnormal neurological examination (Figure 2). There are many different proposals of red flags, but there is no clear consensus regarding which red flags should be incorporated into clinical practice (Sánchez del Río et al, 2020). Table 10 summarizes some of the main red flags.

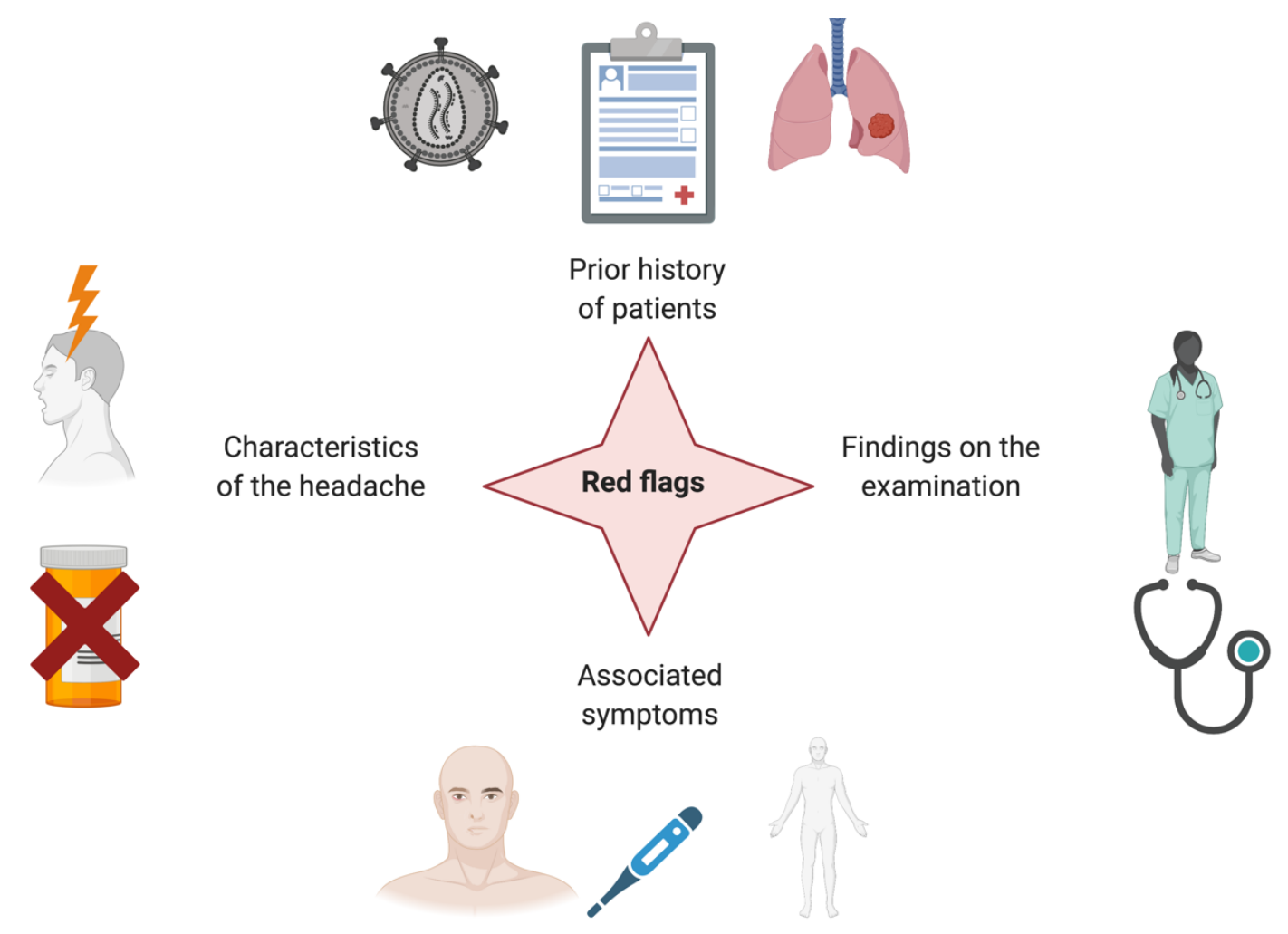

Figure 2. Main groups of red flags. Created with BioRender by David García-Azorín. 
Table 10. Main red flags of headache disorders.

\section{Group A: Red flags related to the prior history of patients}

Neoplasms in history

Immunosuppression

Cranial or cervical trauma

Drug use

Old age

Increased risk of bleeding or thrombosis

Pregnancy or puerperium

Group B: Red flags related to the phenotype of the headache

Thunderclap onset

Positional headache

Wake-up headache

Pattern change

Recent onset

Worst headache ever

Progressive headache 


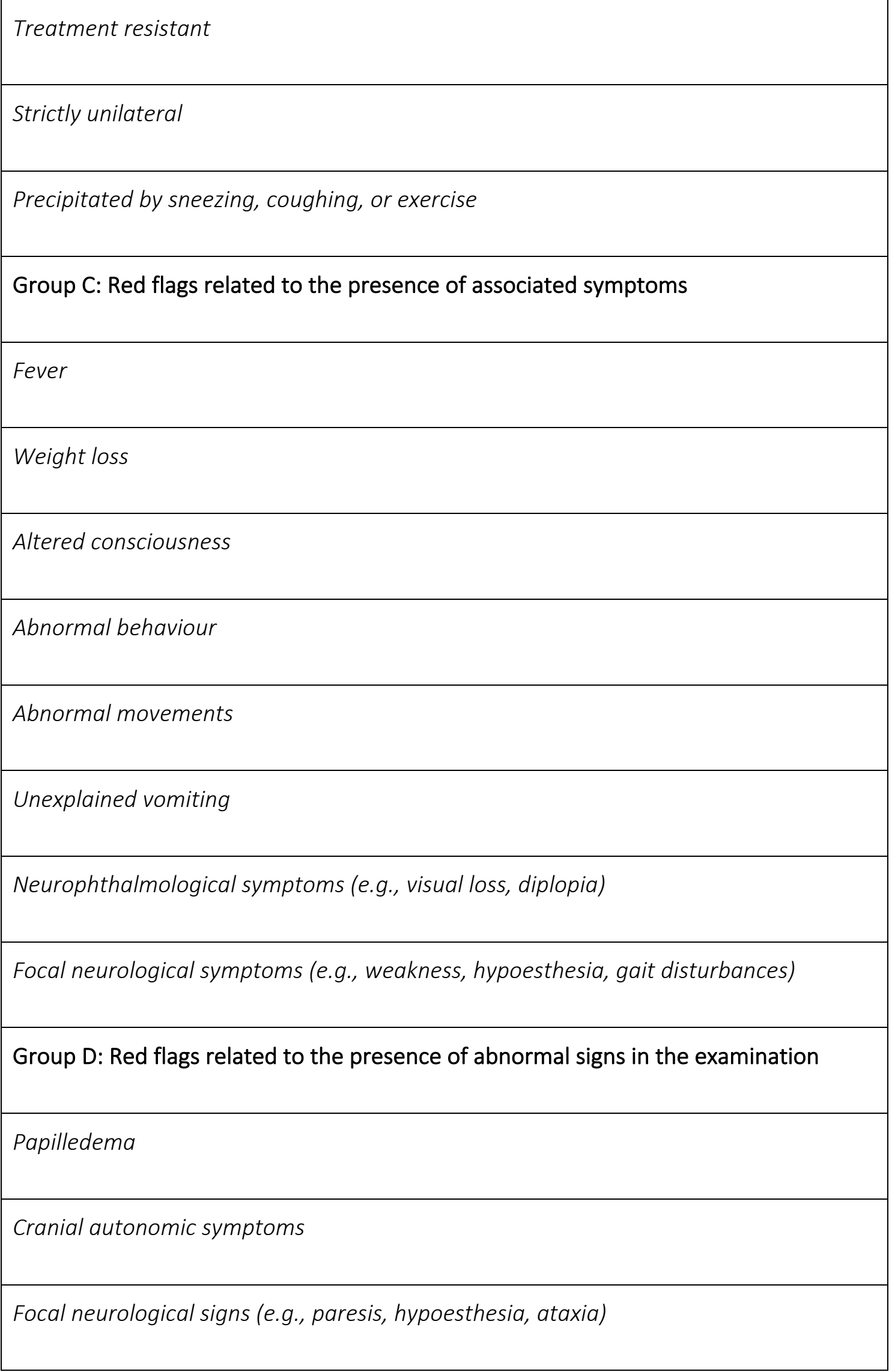


There are many studies addressing specific secondary headache disorders that describe the presence of red flags. They served as rationale for including them into the different lists of red flags. The most representative studies that describe each red flag in a group or subgroup of secondary headache disorders is listed in table 11.

Table 11. Main red flags of headache disorders and the groups or subgroups of the related secondary headache disorders.

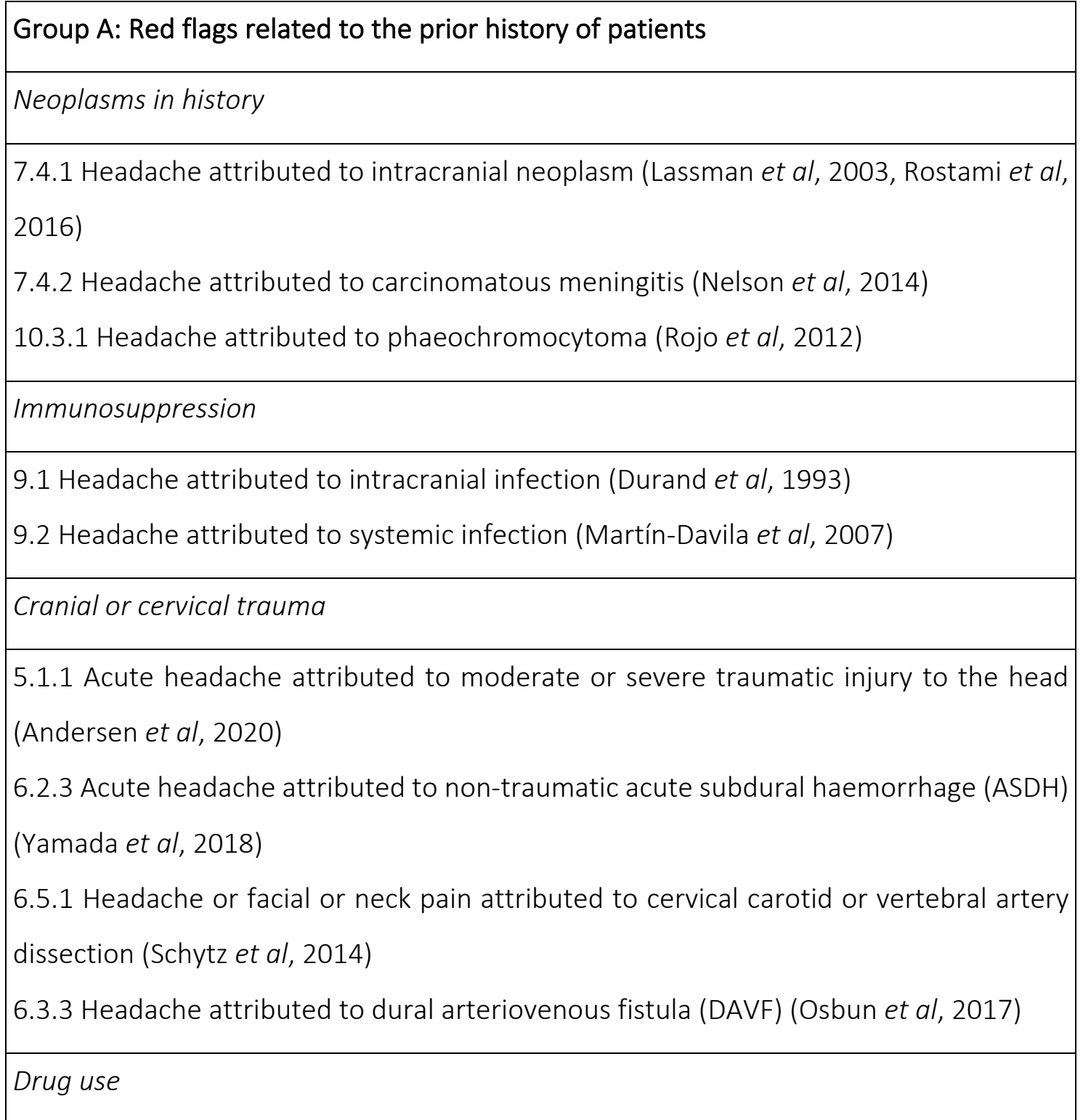


6.1 Headache attributed to cerebral ischaemic event (Sordo et al, 2014)

8.1.5 Cocaine-induced headache (Fofi et al, 2014; Farooque et al, 2020)

8.1.11 Headache attributed to use of or exposure to other substances (Zhu et al, 2020).

8.2 Medication overuse headache (Bottiroli et al, 2019)

8.3 Headache attributed to substance withdrawal (Diener et al, 2010)

Old age (Blum et al, 2017)

6.4.1 Headache attributed to giant cell arteritis (Ing et al, 2019)

7.4 Headache attributed to intracranial neoplasia (Schankin et al, 2007)

10.6 Cardiac cephalalgia (Wei et al, 2008)

Increased risk of bleeding or thrombosis

6.6.1 Headache attributed to cerebral venous thrombosis (Komro et al, 2020)

6.2 Headache attributed to non-traumatic intracerebral haemorrhage (Tabibian et al, 2018)

Pregnancy or puerperium

6.6.1 Headache attributed to cerebral venous thrombosis (Kashkoush et al, 2017)

6.9 Headache attributed to pituitary apoplexy (Piantanida et al, 2014; Galvao et al, 2017)

7.2.1 Post-dural puncture headache (Costa et al, 2019)

10.3.4 Headache attributed to pre-eclampsia or eclampsia (Fang et al, 2017)

Group B: Red flags related to the phenotype of the headache

Thunderclap onset (Blum et al, 2017)

6.1 Headache attributed to cerebral ischaemic event (Lebedeva et al, 2018)

6.2 Headache attributed to non-traumatic intracranial haemorrhage (Bo et al, 2008; Landtblom et al, 2012)

6.3.1 Headache attributed to unruptured saccular aneurysm (Day et al, 1986; Linn et al, 1994; Polmear et al, 2003, Lebedeva et al, 2020)

6.5.1 Headache or facial or neck pain attributed to cervical carotid or vertebral artery dissection (Hsu et al, 2014)

6.6.1 Headache attributed to cerebral venous thrombosis (Botta et al, 2017) 
6.7.3.1 Acute headache attributed to reversible cerebral vasoconstriction syndrome (RCVS) (Caria et al, 2019)

6.9 Headache attributed to pituitary apoplexy (Suri et al, 2019)

Positional headache

6.6 Headache attributed to cranial venous disorder (Timoteo et al, 2012)

7.1 Headache attributed to increased cerebrospinal fluid pressure (Wall et al, 2014; Yri et al, 2015)

7.2 Headache attributed to low cerebrospinal fluid intracranial hypotension (Mea et al, 2007)

7.4 Headache attributed to intracranial neoplasia (Suwanwela et al, 1994)

9.1.1.1 Acute headache attributed to bacterial meningitis or meningoencephalitis (Grände et al, 2002; Depreitere et al, 2016)

9.1.3.1 Acute headache attributed to intracranial fungal or other parasitic infection (Liu et al, 2019)

Wake-up headache

6.1 Headache attributed to cerebral ischaemic event (Tentschert et al, 2004)

6.2 Headache attributed to non-traumatic intracranial haemorrhage (Schievink et al, 1989)

6.7.3 Headache attributed to reversible cerebral vasoconstriction syndrome (Calabrese et al, 2007)

7.1 Headache attributed to increased cerebrospinal fluid pressure (Markey et al, 2016)

7.4 Headache attributed to intracranial neoplasia (Pfund et al, 1999)

Pattern change

6.2.4 Persistent headache attributed to past non-traumatic intracranial haemorrhage (Lai et al, 2018)

6.3 Headache attributed to unruptured vascular malformation (Kwon et al, 2015)

6.4 Headache attributed to arteritis (Pradeep et al, 2018)

6.5.1.2 Persistent headache or facial or neck pain attributed to past cervical carotid or vertebral artery dissection (Schytz et al, 2014) 
6.6 Headache attributed to cranial venous disorder (Metha et al, 2019)

7.1 Headache attributed to increased cerebrospinal fluid pressure (Radojicic et al, 2019)

7.2 Headache attributed to low cerebrospinal fluid pressure (Friedman, 2018)

7.3 Headache attributed to non-infectious inflammatory intracranial disease (Hanly et al, 2013; Fritz et al, 2016)

7.4 Headache attributed to intracranial neoplasia (Rushton et al, 1964)

9.1 Headache attributed to intracranial infection (Thakur et al, 2018)

Recent onset, worst headache ever

5.1 Acute headache attributed to traumatic injury to the head (Nordhaug et al, 2018)

6.1 Headache attributed to cerebral ischaemic event (Harriot et al, 2020)

6.2 Headache attributed to non-traumatic intracranial haemorrhage (Morgestern et al, 1998)

6.3 Headache attributed to unruptured vascular malformation (Linn et al, 1994)

6.4 Headache attributed to arteritis (Michiailidou et al, 2020)

6.5 Headache attributed to cervical carotid or vertebral artery disorder (Matsumoto et al, 2019)

6.6 Headache attributed to cranial venous disorder (lurlaro et al, 2004)

6.7.3 Headache attributed to reversible cerebral vasoconstriction syndrome (Singhal et al, 2011)

7.1 Headache attributed to increased cerebrospinal fluid pressure (Liu et al, 2011)

7.2 Headache attributed to low cerebrospinal fluid pressure (Schievink, 2003)

7.3 Headache attributed to non-infectious inflammatory intracranial disease (Curone et al, 2013)

7.4 Headache attributed to intracranial neoplasia (Christiaans et al, 2002)

8.2 Medication overuse headache (Mose et al, 2018)

8.3 Headache attributed to substance withdrawal (Toom et al, 2020)

9.1 Headache attributed to intracranial infection (Robart et al, 1998; van de Beck et al, 2004; Logan et al, 2008)

9.2 Headache attributed to systemic infection (De Marinis et al, 1992; Eccles et al, 2005)

10.3 Headache attributed to arterial hypertension (Arca et al, 2019)

11.3 Headache attributed to disorder of the eyes (Friedman, 2015) 
11.5 Headache attributed to disorder of the nose or paranasal sinuses (Kirsch, 2019)

Progressive headache, treatment resistant

5.2 Persistent headache attributed to traumatic injury to the head (Larsen et al, 2019)

6.2.4 Persistent headache attributed to past non-traumatic intracranial haemorrhage (Lai et al, 2018)

6.3 Headache attributed to unruptured vascular malformation (Duvall et al, 2019)

6.4 Headache attributed to arteritis (Bustamante Maldonado et al, 2004)

6.5 Headache attributed to cervical carotid or vertebral artery disorder (Matsumoto et al, 2019)

6.6 Headache attributed to cranial venous disorder (Sparaco et al, 2015)

6.7.3 Headache attributed to reversible cerebral vasoconstriction syndrome (Singhal et al, 2011)

7.1 Headache attributed to increased cerebrospinal fluid pressure (Wakerley et al, 2015) 7.2 Headache attributed to low cerebrospinal fluid pressure (Capizzano et al, 2016)

7.3 Headache attributed to non-infectious inflammatory intracranial disease (Mekinian et al, 2018)

7.4 Headache attributed to intracranial neoplasia (Pfund et al, 1999)

8.2 Medication overuse headache (Munskgaard et al, 2012)

9.1 Headache attributed to intracranial infection (Robart et al, 1998)

9.2 Headache attributed to systemic infection (Kuchar et al, 2015)

10.3 Headache attributed to arterial hypertension (Courand et al, 2016)

11.3 Headache attributed to disorder of the eyes (Nesher et al, 2014)

11.5 Headache attributed to disorder of the nose or paranasal sinuses (Kaur et al, 2013)

Strictly unilateral (Prakash et al, 2016)

6.1 Headache attributed to cerebral ischaemic event (Harriot et al, 2020)

6.2 Headache attributed to non-traumatic intracranial haemorrhage (Bazan et al, 2008) 6.3 Headache attributed to unruptured vascular malformation (Menal Muñoz et al, 2016)

6.4 Headache attributed to arteritis (Prakash et al, 2016) 
6.5 Headache attributed to cervical carotid or vertebral artery disorder (Brilla et al, 2018)

6.6 Headache attributed to cranial venous disorder (Prakash et al, 2016)

7.3 Headache attributed to non-infectious inflammatory intracranial disease (Russo et al, 2018)

7.4 Headache attributed to intracranial neoplasia (Argyriou et al, 2002)

11.3 Headache attributed to disorder of the eyes (Ramón et al, 2013)

11.5 Headache attributed to disorder of the nose or paranasal sinuses (Prakash et al, 2016)

Precipitated by sneezing, coughing, or exercise (Pascual et al, 1996)

6.3 Headache attributed to unruptured vascular malformation (Chen et al, 2009)

6.6 Headache attributed to cranial venous disorder (Timoteo et al, 2012)

6.8.3 Headache attributed to moyamoya angiopathy (Kraemer et al, 2017)

7.1 Headache attributed to increased cerebrospinal fluid pressure (Yri et al, 2015)

7.4 Headache attributed to intracranial neoplasia (Suwanwela et al, 1994)

7.7 Headache attributed to Chiari malformation type I (Mehta et al, 2015)

Group C: Red flags related to the presence of associated symptoms

Fever, weight loss

7.3 Headache attributed to non-infectious inflammatory intracranial disease (Limper et al; 2011)

7.4 Headache attributed to intracranial neoplasia (Marrodan et al, 2018)

9.1 Headache attributed to intracranial infection (Robart et al, 1998; Logan et al, 2008)

9.2 Headache attributed to systemic infection (Limper et al; 2011)

Altered consciousness, abnormal behaviour, abnormal movements

6.1 Headache attributed to cerebral ischaemic event (Henon et al, 1999)

6.2 Headache attributed to non-traumatic intracranial haemorrhage (Wang et al, 2017) 6.4 Headache attributed to arteritis (Ioannides et al, 2009)

6.5 Headache attributed to cervical carotid or vertebral artery disorder (De Reuck et al, 2009) 
6.6 Headache attributed to cranial venous disorder (Sha et al, 2018)

6.7.3 Headache attributed to reversible cerebral vasoconstriction syndrome (Singhal et al, 2011)

7.3 Headache attributed to non-infectious inflammatory intracranial disease (Amanat et al, 2019)

7.4 Headache attributed to intracranial neoplasia (Wilne et al, 2006)

8.3.2 Opioid-withdrawal headache (Jain et al, 2018)

9.1 Headache attributed to intracranial infection (Zoons et al, 2008)

Unexplained vomiting

6.2 Headache attributed to non-traumatic intracranial haemorrhage (Shigematsu et al, 2013)

6.6 Headache attributed to cranial venous disorder (Terni et al, 2015)

7.1 Headache attributed to increased cerebrospinal fluid pressure (Roy et al, 2013)

7.3 Headache attributed to non-infectious inflammatory intracranial disease (Krief et al, 2010)

7.4 Headache attributed to intracranial neoplasia (Pfund et al, 1999; Christiaans et al, 2002)

9.1 Headache attributed to intracranial infection (Robart et al, 1998)

Neurophthalmological symptoms (e.g., visual loss, diplopia)

6.4.1 Headache attributed to giant cell arteritis (Fein et al, 2019)

6.5 Headache attributed to cervical carotid or vertebral artery disorder (Song et al, 2019)

6.6.1 Headache attributed to cerebral venous thrombosis (Zhao et al, 2018)

7.1 Headache attributed to increased cerebrospinal fluid pressure (Hatem et al, 2018)

7.3 Headache attributed to non-infectious inflammatory intracranial disease (Campagna et al, 2019)

7.4 Headache attributed to intracranial neoplasia (Wilne et al, 2006)

9.1 Headache attributed to intracranial infection (Borges et al, 2018; Verma et al, 2019)

11.3 Headache attributed to disorder of the eyes (Lee et al, 2004)

Focal neurological symptoms (e.g., weakness, hypoesthesia, gait disturbances) 
6.1 Headache attributed to cerebral ischaemic event (Harriot et al, 2020)

6.2 Headache attributed to non-traumatic intracranial haemorrhage (Shinohara, 2009)

6.3 Headache attributed to unruptured vascular malformation (Tsai et al, 2004)

6.4 Headache attributed to arteritis (Salvarani et al, 2015)

6.5 Headache attributed to cervical carotid or vertebral artery disorder (Sturzenegger, 1994)

6.6 Headache attributed to cranial venous disorder (Diacinti et al, 2018)

6.7.3 Headache attributed to reversible cerebral vasoconstriction syndrome (Caria et al, 2019)

7.3 Headache attributed to non-infectious inflammatory intracranial disease (Nozaki et al, 2012)

7.4 Headache attributed to intracranial neoplasia (Argyriou et al, 2002)

9.1 Headache attributed to intracranial infection (Robart et al, 1998; Logan et al, 2008)

10.3.3 Headache attributed to hypertensive encephalopathy (Fugate et al, 2015)

Group D: Red flags related to the presence of abnormal signs in the examination

Papilledema

6.4.1 Headache attributed to giant cell arteritis (Balducci et al, 2017)

6.6.1 Headache attributed to cerebral venous thrombosis (Saadatnia et al, 2017)

7.1 Headache attributed to increased cerebrospinal fluid pressure (Radojicic et al, 2019)

7.4 Headache attributed to intracranial neoplasia (Suwanwela et al, 1994)

9.1 Headache attributed to intracranial infection (Verma et al, 2019)

11.3 Headache attributed to disorder of the eyes (Yip et al, 2019)

Cranial autonomic symptoms

6.1 Headache attributed to cerebral ischaemic event (Jin et al, 2016; Lambru et al, 2017; Lei et al, 2020)

6.2 Headache attributed to non-traumatic intracranial haemorrhage (Bazan et al, 2008) 6.5 Headache attributed to cervical carotid or vertebral artery disorder (Lai et al, 2005; Caneloro et al, 2013; Elhfnawy et al, 2017)

6.6 Headache attributed to cranial venous disorder (Park et al, 2006; Rodriguez et al, 2008) 


\begin{tabular}{|l|} 
7.3 Headache attributed to non-infectious inflammatory intracranial disease \\
(Edvardsson, 2014) \\
7.4 Headache attributed to intracranial neoplasia (Favier et al, 2007) \\
Focal neurological signs (e.g., paresis, hypoesthesia, ataxia) (Blum et al, 2017) \\
6.1 Headache attributed to cerebral ischaemic event (Moulin et al, 2019) \\
6.2 Headache attributed to non-traumatic intracranial haemorrhage (Lawton et al, \\
2017) \\
6.3 Headache attributed to unruptured vascular malformation (Lv et al, 2018) \\
6.4 Headache attributed to arteritis (Salvarani et al, 2012) \\
6.5 Headache attributed to cervical carotid or vertebral artery disorder (Engelter et al, \\
2017) \\
6.6 Headache attributed to cranial venous disorder (de Brujin et al, 2001) \\
6.7.3 Headache attributed to reversible cerebral vasoconstriction syndrome (Ducros et \\
al, 2012) \\
7.3 Headache attributed to non-infectious inflammatory intracranial disease (Kefella et \\
al, 2017) \\
7.4 Headache attributed to intracranial neoplasia (Argyriou et al, 2002) \\
9.1 Headache attributed to intracranial infection (Logan et al, 2008) \\
10.3.3 Headache attributed to hypertensive encephalopathy (Fugate et al, 2015)
\end{tabular}

When all the disorders included in a group may be related to the red flag, the entire group is listed. When only some of the disorders included in a group are related to the red flag, the specific ICHD-3 disorder is listed.

\subsection{Pearls and pitfalls of red flags}

Red flags are widely accepted. They are used in other fields of neurology and medicine, and are part of daily practice (Ramanayake et al, 2018). The evidence supporting their use is mostly based on expert opinion, which is valuable but not fully precise (Edmeads, 1990; Evans et al, 2011; Friedman et al, 2011, Do et al, 2019). Most authors agree on the fact that the presence of any single red flag requires that a 
secondary headache disorder be ruled out. Figure 3 depicts the general work-up of headache patients with red flags. The vast majority of red flags are non-specific and can be associated with several secondary causes. For that reason, the entire study should be completed in case the ancillary tests are unremarkable. The International Headache Society recommends the study of the cranial arterial and venous system, cerebrospinal fluid opening pressure and composition, and in the case of normality, detailed parenchymal assessment with MRI (Headache Classification committee, 2018).

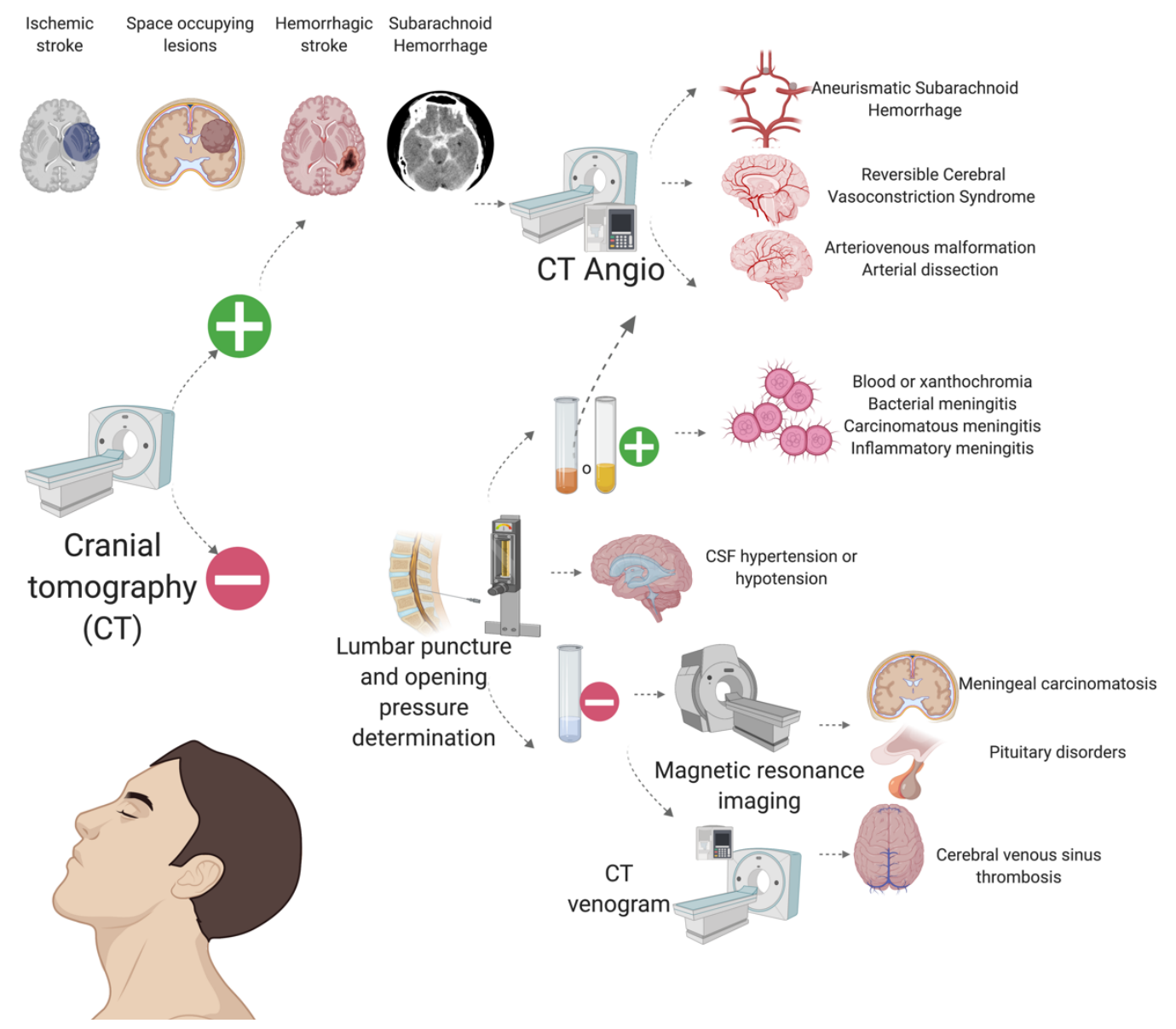

Figure 3. Work-up of patients with red flags. Created with BioRender by David GarcíaAzorín. CT: cranial computerized tomography; CSF: cerebrospinal fluid.

Within the problems related to red flags as biomarkers, probably the most striking pitfall is the lack of validation studies in non-selected patients visiting the ER for headache 
(Table 12). Red flags have been analysed frequently in disorder-specific studies, e.g., in headache attributed to subarachnoid haemorrhage (Perry et al, 2010) and headache in intracranial neoplasm (Goldust et al, 2010), so their sensitivity in those disorders can be estimated. However, the lack of validation does not imply inefficacy (Smith et al, 2003).

Table 12. Studies in which red flags have been validated.

\begin{tabular}{|c|c|c|c|c|}
\hline Author & $\begin{array}{c}\text { Sample } \\
\text { size }\end{array}$ & Design & Red flags studied & $\begin{array}{l}\text { Red flags associated with } \\
\text { secondary headache }\end{array}$ \\
\hline $\begin{array}{c}\text { Ramirez- } \\
\text { Lassepas } \\
1997\end{array}$ & 468 & $\begin{array}{c}\text { Retrosp } \\
\text { Hospitali } \\
\text { zed + non } \\
\text { hospitali } \\
\text { zed }\end{array}$ & Not pre-specified & $\begin{array}{l}\text { Abnormal examination, } \\
\text { acute onset, age >55 } \\
\text { years, occipitonuchal, } \\
\text { associated symptoms. }\end{array}$ \\
\hline $\begin{array}{l}\text { Sobri } \\
2003\end{array}$ & 111 & Retrosp & $\begin{array}{ll}\text { 1. } & \text { Onset of new or different } \\
\text { headache. } \\
\text { 2. } & \text { Nausea or vomiting. } \\
\text { 3. } & \text { Worst headache ever } \\
\text { experienced. } \\
\text { 4. }\end{array}$ & $\begin{array}{l}\text { Only } 3 \text { red flags were } \\
\text { significant in } \\
\text { multivariate regression } \\
\text { analysis: papilloedema; } \\
\text { paralysis; and } \\
\text { drowsiness, confusion, } \\
\text { memory impairment or } \\
\text { loss of consciousness. }\end{array}$ \\
\hline
\end{tabular}




\begin{tabular}{|c|c|c|c|c|}
\hline & & & $\begin{array}{l}\text { 11. Onset with exertion, } \\
\text { sexual activity or } \\
\text { coughing. } \\
\text { 12. Systemic illness. } \\
\text { 13. Numbness. } \\
\text { 14. Asymmetry of pupillary } \\
\text { response. } \\
\text { 15. Sensory loss. } \\
\text { 16. Signs of meningeal } \\
\text { irritation. } \\
\text { 17. Weight loss. } \\
\text { 18. Abnormal temporal } \\
\text { arteries. } \\
\text { 19. Lymphadenopathy. } \\
\text { 20. Persistent tinnitus. }\end{array}$ & \\
\hline $\begin{array}{c}\text { Locker } \\
2006\end{array}$ & 558 & Prosp & Not pre-specified & $\begin{array}{l}\text { Age }>50 \text { years, sudden } \\
\text { onset, abnormal } \\
\text { neurological } \\
\text { examination, } \\
\text { presentation due to } \\
\text { associated features. }\end{array}$ \\
\hline Bo 2008 & 433 & Prosp & Not pre-specified & $\begin{array}{l}\text { It is difficult to } \\
\text { distinguish between } \\
\text { primary and malignant } \\
\text { causes of headache } \\
\text { using clinical features. }\end{array}$ \\
\hline $\begin{array}{c}\text { Singh Rai } \\
2016\end{array}$ & 500 & Retrosp & Not pre-specified & $\begin{array}{l}\text { Headache with "red } \\
\text { flags" had secondary } \\
\text { causes more frequently. }\end{array}$ \\
\hline
\end{tabular}




\begin{tabular}{|c|c|c|c|c|}
\hline $\begin{array}{c}\text { Young } \\
2018\end{array}$ & 190 & Retrosp & $\begin{array}{l}\text { 1. Anticoagulation. } \\
\text { 2. Trauma. } \\
\text { 3. Systemic symptoms or } \\
\text { comorbidities. } \\
\text { 4. Neurological symptoms } \\
\text { or signs. } \\
\text { 5. Thunderclap onset. } \\
\text { 6. Onset }>50 \text { years old. } \\
\text { 7. New or different } \\
\text { headache. } \\
\text { 8. Progressively worsening } \\
\text { headache. } \\
\text { 9. Precipitation by Valsalva. } \\
\text { 10. Postural headache. } \\
\text { 11. Pregnancy. } \\
\text { 12. Awakening at night. } \\
\text { 13. Unilateral. } \\
\text { 14. Worst headache of life. } \\
\text { 15. Headache persistence. }\end{array}$ & $\begin{array}{l}\text { Imaging is justified by } \\
\text { the presence of red flags } \\
\text { in } 77 \% \text { of cases. }\end{array}$ \\
\hline $\begin{array}{l}\text { Munoz- } \\
\text { Ceron } \\
2019\end{array}$ & 244 & Prosp & $\begin{array}{l}\text { 1. } \text { Onset }>50 \text { years old. } \\
\text { 2. Onset characteristics. } \\
\text { 3. Associated symptoms. } \\
\text { 4. History of immunological } \\
\text { disorders. } \\
\text { 5. History of primary } \\
\text { headaches. } \\
\text { 6. }\end{array}$ & $\begin{array}{l}\text { History of immunological } \\
\text { disorders and age over } \\
50 . \\
\text { Green flags: History of } \\
\text { migraine and history of } \\
\text { similar episodes. }\end{array}$ \\
\hline
\end{tabular}

Prosp: prospective; Retrosp: retrospective. 


\subsubsection{Problems in secondary headache diagnosis related to the use of red flags}

i. Phenotypic heterogeneity of the disorder: The same disorder can have inconsistent clinical presentation (Sparaco et al, 2015). While there is a strong association between the location and pathophysiology of lesions and the clinical symptoms and signs (Bousser et al, 2011), headache is not a consistent symptom despite being one of the most frequent symptoms of many conditions, including infections, intracranial or subarachnoid haemorrhage, and cerebral venous sinus thrombosis (CVST) (Tables 6 and 7).

ii. Phenotypic heterogeneity of the headache: When headache is present within the clinical symptoms, the clinical phenotype of the headache might also be variable (Wasay et al, 2010). This could be related to the precise location of the neuroanatomical lesions or to the individual's predisposition (Singht et al, 2018). Subjects with a "migraine biology" might be more likely to present with migrainelike headache after certain stimuli, such as hangover (García-Azorín et al, 2020) or stimuli used in provocation studies, including cilostazol (Birk et al, 2006), CGRP (Schytz et al, 2010), pituitary adenylate cyclase-activating peptide (PACAP)-38 (Schytz et al, 2009), nitroglycerin (Karsan et al, 2020), PACAP-27 (Ghanizada et al, 2020).

iii. Lack of specificity: The same red flag can be described by patients with different secondary headache disorders, which complicates the work-up of patients (Table 11). Some of the main red flags, such as thunderclap headache, have been 
strongly associated with some individual secondary causes, as subarachnoid haemorrhage, causing that the study of those patients or the research studies are often too targeted to these causes (Cortelli et al, 2004; Locker et al, 2006; Bo et al, 2008).

iv. Verbal description: The proper classification of headache disorders relies on the patient's description. Some features of the headache can be difficult to describe (e.g., orthostatic pattern can be misdiagnosed as mechanosensitivity), can be overdiagnosed (e.g., the worst headache ever), or can be inadequately classified (e.g., stabbing quality could be underdiagnosed as throbbing when stabs occur at regular intervals) (Goadsby, 2020). Patients with severe headaches might be particularly prone to underreport certain phenotypic characteristics, because of the presence of disturbing symptoms, severe pain or speech disorders.

v. Lack of hierarchy: Not every red flag is equally important or associated with secondary causes. The specificity of red flags is generally low, and they could be associated with both primary and different secondary causes. Only one study allows for some comparability based on different odds ratios (OR), being the higher values observed with age $>50$ years (OR: 7.3$)$ and presence of any neurological abnormality on examination (OR: 6.1), (Locker et al, 2006). Clinical experience suggests that not every red flag is equally important, but this has never been proven experimentally. 
If we analyse red flags from the biomarker perspective (Table 8), a strength includes apparently high sensitivity, even if they have never been formally tested. For obvious reasons, red flags as biomarkers are accessible, non-invasive and free, but despite that, they are not always used in practice (Dobb et al, 2013). Table 13 analyses the role of red flags as biomarkers.

Table 13. Strengths and limitations of red flags as headache-related biomarkers.

\begin{tabular}{|l|l|}
\hline Characteristic & Explanation \\
\hline Precise & $\begin{array}{l}\text { They may be present in many different secondary headache } \\
\text { disorders and sometimes in primary headache disorders (i.e., } \\
\text { low precision). }\end{array}$ \\
\hline Sensitive & $\begin{array}{l}\text { Their sensitivity is unclear for most of them and does not } \\
\text { seem to be high. }\end{array}$ \\
\hline Reproducible & There are few studies of validation. \\
\hline Rapidly measurable & Most of them are rapidly measurable. \\
\hline Affordable & They have excellent affordability. \\
\hline Accessible & They can be evaluated by a physician or by using checklists. \\
\hline Non-invasive & They are not invasive. \\
\hline Early & They accelerate the diagnosis when used. \\
\hline Clinically relevant & Their relevance could be improved. \\
\hline
\end{tabular}


II. RATIONALE 


\section{Rationale}

In order to evaluate the role of red flags in the diagnosis of headache disorders, three different disorders were selected and analysed in real-world conditions. Three different entities were chosen that represent the full spectrum of headache disorders. The study was titled "the good, the bad and the ugly" based on the potential consequences of each of those disorders.

The good is tension-type headache (TTH), the most prevalent headache disorder and probably the most benign primary headache (Global Burden of Disease 2016 headache collaborators, 2018). As with every headache disorder, TTH can be disabling to patients, particularly those with chronic TTH, but in theory, it does not confer any harm or morbimortality risk for patients (Global Burden of Disease 2016 neurology collaborators, 2019). For these reasons, red flags should never be present in patients with a TTH diagnosis.

The bad is cerebral venous sinus thrombosis (CVST). This is a life-threatening cause of headache (Canhao et al, 2005). Headache is the most frequent symptom of CVST (Bousser et al, 1985; Saposnik et al, 2011). Its prognosis relies on adequate and prompt diagnosis (Ferro et al, 2004; Dentali et al, 2012; Gameiro et al, 2012). Red flags may help identify patients with CVST; however, they have never been evaluated.

The ugly is headache attributed to coronavirus disease 2019 (Covid-19). In this case, the disease is not invariably fatal (Huang et al, 2020), but inadequate diagnosis may confer risk of transmission for others and propagation of the disease (Henriquez 
et al, 2020). Headache is within the most frequent neurological symptoms in hospitalized patients with Covid-19(Romero-Sánchez et al, 2020). In this case, we aimed to evaluate if the presence of Covid-19 can be suspected in patients who do have headache based on the presence of red flags. 
III. HYPOTHESIS 


\section{Hypothesis}

The main hypothesis of the present work is that red flags can differentiate between patients with primary headache disorders and those with secondary headache disorders; thus, red flags would be useful in the diagnosis of headache disorders in clinical practice. Red flags are present in patients with secondary headache disorders. In patients with a suspected primary headache disorder, if red flags are present, diagnosis should be done only after excluding all possible secondary causes. 
IV. OBJECTIVES 


\section{Objectives}

General objectives

1. To analyse the presence of red flags in patients who were discharged from the emergency room with a definite diagnosis of TTH

2. To evaluate the frequencies and types of red flags in patients who presented to the emergency room and had a confirmed CVST diagnosis from that visit

3. To assess the frequencies and types of red flags in patients with confirmed Covid-19 infection who were hospitalized and who had headache at any point during the course of the disease

Specific objectives

i) Tension-type headache:

- To analyse if patients with a TTH diagnosis fulfilled the ICHD-3 criteria, analysing each criterion separatedly

- To evaluate if there were any data in the discharge reports that contradicted the TTH diagnosis, including elements of prior medical history, atypical symptoms or an abnormal neurological examination

- To re-classify patients according to the ICHD-3 criteria, using the information available in the discharge reports 
ii) Cerebral venous sinus thrombosis:

- To assess whether or not fundoscopic examination was completed

- To assess whether or not CVST was suspected at the moment of the neuroimaging request

- To report the time between i) the arrival of the patient and the imaging request, and ii) the arrival of the patient and the imaging completion

iii) Covid-19:

- To analyse the frequency of abnormal laboratory parameters

- To evaluate the moment when the headache occurs during the course of the disease 
$\underline{\text { V. METHODS }}$ 


\section{Methods}

To evaluate the frequencies and types of red flags in the above-mentioned three populations, three observational descriptive studies with cross-sectional designs were conducted. Two studies were retrospective and the other prospective. All three studies adhered to the Strengthening the Reporting of Observational Studies in Epidemiology (STROBE) guidelines (Von Elm et al, 2007). Figure 4 summarizes the common elements of the study designs.
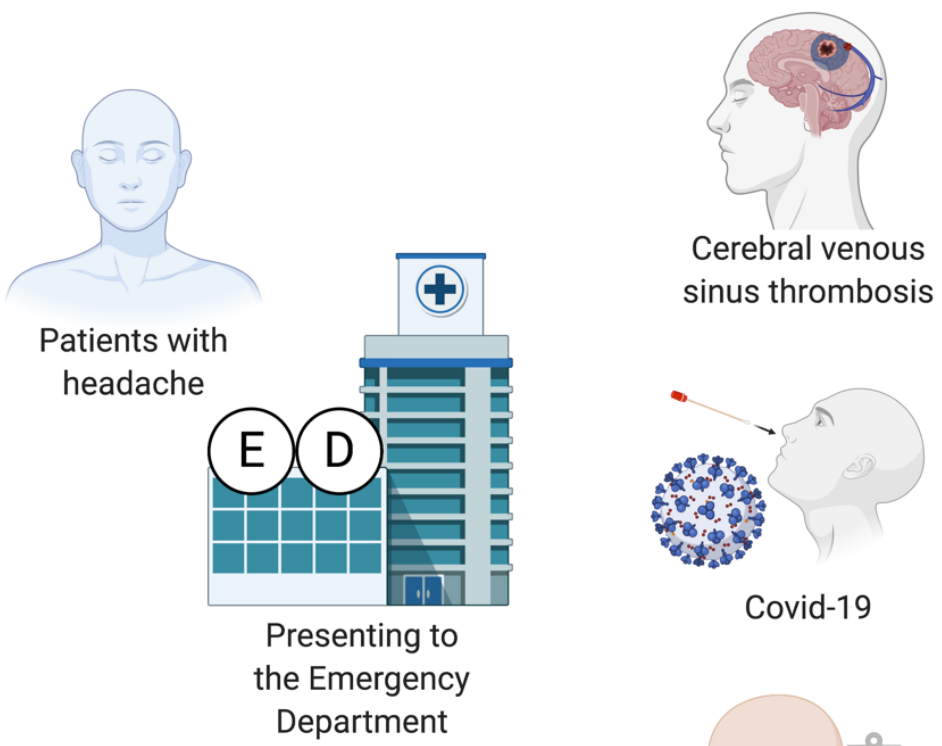

Do they have red flags?
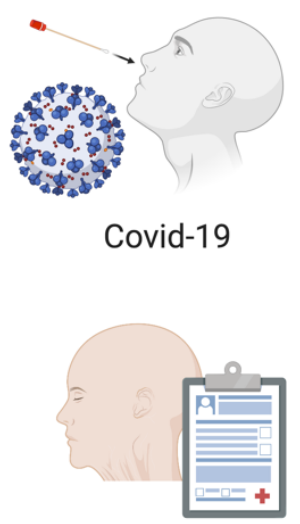

Tension-type headache

Figure 4. Common elements in the design of the three studies. Created with BioRender by David García-Azorín. 


\subsection{Study setting}

The studies that assessed CVST and TTH were done at the Hospital Clínico Universitario San Carlos, Madrid, Spain, a third level, academic, public hospital located in the metropolitan area of Madrid with a reference population of $700,000-1,000,000$ people. The reference population varied in the TTH study $(700,000)$ compared with the CVST study $(1,000,000)$ since this centre covers a larger area in its role as a stroke centre.

The study that assessed headache in Covid-19 patients was done at the Hospital Clínico Universitario de Valladolid, Valladolid, Spain, also a third level, academic, public hospital that receives patients from the eastern metropolitan area of Valladolid and 22 urban and rural primary care centres of the region. The reference population is 261,431 (Castilla y Leon Department of Health, 2020).

\subsection{Ethical aspects}

Ethics Review Boards of both hospitals approved the studies (Supplementary appendix) (CP14/425, PI 20-1738). All studies were done in accordance with Good Clinical Practice guidelines and according to the principles of the Declaration of Helsinki (International Conference on Harmonization, 1996) and the convention for bioethical principles agreed to in Oviedo (Department of State, Official Document, 1997). In the case of Covid-19, the need for written consent was waived due to the risk of contagion; 
however, patients were informed about the study aim and only those who agreed to participate were included.

\subsection{Eligibility criteria}

The common elements of the inclusion criteria for the studies were the presence of headache, the fact that patients visited the ER, and the confirmed final diagnosis. In the case of CVST and Covid-19, determination of inclusion was done after an appropriate imaging evaluation in the case of CVST or after a positive polymerase chain reaction (PCR) or immunoglobulin $\mathrm{M}(\operatorname{Ig} M)$ in serum antibody test in the case of Covid-19. In the case of $\mathrm{TTH}$, the certainty of the diagnosis came from the discharge report, where the final diagnosis was explicitly stated as TTH. Table 14 summarizes the eligibility criteria of all the studies.

Table 14. Common elements of the inclusion and exclusion criteria of the studies (Extracted from the manuscripts).

\begin{tabular}{|l|l|l|l|}
\hline \multicolumn{3}{|c|}{ Inclusion criteria } \\
\hline Criterion & Tension-type & CVST & Covid-19 \\
& headache & & \\
\hline Emergency Room & $\bullet$ Visited the ED & $\bullet$ Presented at the & $\bullet$ Were \\
\hline
\end{tabular}




\begin{tabular}{|c|c|c|c|}
\hline & & & $\begin{array}{l}\text { due to Covid- } \\
19\end{array}$ \\
\hline $\begin{array}{l}\text { Presence of } \\
\text { headache }\end{array}$ & $\begin{array}{l}\text { - The reason for } \\
\text { the ED visit was } \\
\text { headache }\end{array}$ & $\begin{array}{l}\text { - Complained of } \\
\text { headache at ED } \\
\text { presentation }\end{array}$ & $\begin{array}{l}\text { - Headache } \\
\text { occurred } \\
\text { during the } \\
\text { course of the } \\
\text { disease }\end{array}$ \\
\hline $\begin{array}{l}\text { Confirmed } \\
\text { diagnosis }\end{array}$ & $\begin{array}{l}\text { - Were classified } \\
\text { with a definite } \\
\text { diagnosis of } \\
\text { "tension-type } \\
\text { headache" in the } \\
\text { discharge report }\end{array}$ & $\begin{array}{l}\text { - Confirmed CVST } \\
\text { criteria for } \\
\text { headache } \\
\text { attributed to } \\
\text { cerebral venous } \\
\text { thrombosis }\end{array}$ & $\begin{array}{l}\text { - Confirmed } \\
\text { Covid-19 }\end{array}$ \\
\hline \multicolumn{4}{|c|}{ Exclusion criteria } \\
\hline $\begin{array}{l}\text { Other headache } \\
\text { disorders }\end{array}$ & $\begin{array}{l}\text { - Another } \\
\text { headache was } \\
\text { diagnosed at the } \\
\text { same time }\end{array}$ & $\begin{array}{l}\text { - Isolated } \\
\text { cavernous sinus } \\
\text { thrombosis } \\
\text { - Infective } \\
\text { thrombophlebitis }\end{array}$ & $\begin{array}{l}\text { - Not better } \\
\text { accounted for } \\
\text { by another } \\
\text { IHD-3 } \\
\text { diagnosis }\end{array}$ \\
\hline
\end{tabular}




\begin{tabular}{|c|c|c|c|}
\hline & & $\begin{array}{l}\text { - Isolated cortical } \\
\text { venous } \\
\text { thrombosis }\end{array}$ & \\
\hline $\begin{array}{l}\text { Unable to be } \\
\text { diagnosed }\end{array}$ & $\begin{array}{l}\text { - There was some } \\
\text { degree of } \\
\text { uncertainty in the } \\
\text { diagnosis, such as } \\
\text { "possible" or } \\
\text { "probable" }\end{array}$ & $\begin{array}{l}\text { Unclear diagnosis } \\
\text { after radiological re- } \\
\text { evaluation by an } \\
\text { experienced neuro- } \\
\text { radiologist }\end{array}$ & $\begin{array}{l}\text { - Unstable } \\
\text { medical } \\
\text { condition }\end{array}$ \\
\hline $\begin{array}{l}\text { Availability of } \\
\text { information }\end{array}$ & $\begin{array}{l}\text { - Information was } \\
\text { not available in } \\
\text { the patient chart }\end{array}$ & - Not applicable & $\begin{array}{l}\text { - } \text { Deceased } \\
\text { cognitive } \\
\text { impairment } \\
\text { - Did not agree } \\
\text { to participate }\end{array}$ \\
\hline \multicolumn{4}{|c|}{ Inclusion criteria } \\
\hline Criterion & CVST & Covid-19 & $\begin{array}{l}\text { Tension-type } \\
\text { headache }\end{array}$ \\
\hline
\end{tabular}




\begin{tabular}{|c|c|c|c|}
\hline Emergency Room & $\begin{array}{l}\text { - Presented at the } \\
\text { ED }\end{array}$ & $\begin{array}{l}\text { Were } \\
\text { hospitalized } \\
\text { due to Covid- } \\
19\end{array}$ & - Visited the ED \\
\hline $\begin{array}{l}\text { Presence of } \\
\text { headache }\end{array}$ & $\begin{array}{l}\text { - Complained of } \\
\text { headache at ED } \\
\text { presentation }\end{array}$ & $\begin{array}{l}\text { - Headache } \\
\text { occurred } \\
\text { during the } \\
\text { course of the } \\
\text { disease }\end{array}$ & $\begin{array}{l}\text { - The reason for } \\
\text { the ED visit } \\
\text { was headache }\end{array}$ \\
\hline Diagnosis & $\begin{array}{l}\text { - } \text { Confirmed CVST } \\
\text { criteria for } \\
\text { headache } \\
\text { attributed to } \\
\text { cerebral venous } \\
\text { thrombosis }\end{array}$ & $\begin{array}{l}\text { - Confirmed } \\
\text { Covid-19 }\end{array}$ & $\begin{array}{l}\text { - Were } \\
\text { classified with } \\
\text { diagnosis of } \\
\text { "tension-type } \\
\text { headache" in } \\
\text { the discharge } \\
\text { report }\end{array}$ \\
\hline \multicolumn{4}{|c|}{ Exclusion criteria } \\
\hline $\begin{array}{l}\text { Other headache } \\
\text { disorders }\end{array}$ & $\begin{array}{l}\text { Isolated cavernous } \\
\text { sinus thrombosis }\end{array}$ & $\begin{array}{l}\text { - Not better } \\
\text { accounted for } \\
\text { by another }\end{array}$ & $\begin{array}{l}\text { - Another } \\
\text { headache was }\end{array}$ \\
\hline
\end{tabular}




\begin{tabular}{|c|c|c|c|}
\hline & $\begin{array}{l}\text { - Infective } \\
\text { thrombophlebitis } \\
\text { - Isolated cortical } \\
\text { venous } \\
\text { thrombosis }\end{array}$ & $\begin{array}{l}\text { IHD-3 } \\
\text { diagnosis }\end{array}$ & $\begin{array}{l}\text { diagnosed at } \\
\text { the same time }\end{array}$ \\
\hline $\begin{array}{l}\text { Unable to be } \\
\text { diagnosed }\end{array}$ & $\begin{array}{l}\text { - Unclear diagnosis } \\
\text { after radiological } \\
\text { re-evaluation by } \\
\text { an experienced } \\
\text { neuro-radiologist }\end{array}$ & $\begin{array}{l}\text { - Unstable } \\
\text { medical } \\
\text { condition }\end{array}$ & $\begin{array}{l}\text { - There was } \\
\text { some degree } \\
\text { of uncertainty } \\
\text { in the } \\
\text { diagnosis, } \\
\text { such "possible" or } \\
\text { "probable" }\end{array}$ \\
\hline $\begin{array}{l}\text { Availability of } \\
\text { information }\end{array}$ & - Not applicable & $\begin{array}{l}\text { - Deceased } \\
\text { - Psychiatric or } \\
\text { cognitive } \\
\text { impairment } \\
\text { - Did not agree } \\
\text { to participate }\end{array}$ & $\begin{array}{l}\text { - Information } \\
\text { was not } \\
\text { available in } \\
\text { the patient } \\
\text { chart }\end{array}$ \\
\hline
\end{tabular}

CVST: Cerebral Venous Sinus Thrombosis; Covid-19: coronavirus disease 2019; ED: emergency department; ICHD-3: the International Classification of Headache Disorders $3^{\text {rd }}$ edition. 


\subsection{Study period and data sources}

For CVST, considering the rarity of the disorder, all patients who received a diagnosis of CVST in the centre between January 2009 and May 2015 were screened. All potential cases were systematically assessed across three different databases, including the Hospital General database, the Emergency Department database and the Department of Radiology database.

In the case of TTH, the final diagnoses of all patients who visited the emergency department (ED) between January 2012 to July 2014 were systematically screened. The ED database was evaluated, and every single case was individually reviewed.

In the case of Covid-19, all consecutive patients who were hospitalized due to Covid19 (i.e., from patient number 1 to patient number 576) between March 2020 and April 2020 were screened. In those patients, the presence of headache was screened for in primary care records, ED records and hospitalization records. Patients were contacted and interviewed about the presence of red flags.

\subsection{Study procedures}

In each study, two neurologists with expertise on headache medicine screened for the presence of red flags in each patient who fulfilled the eligibility criteria. To do this, a pre-defined questionnaire that included the main red flags was used (supplementary 
appendix). The International Headache Society's Secondary Headache Special Interest Group proposal (Do et al, 2019) and the list of red flags present in the Headache Study Group of the Spanish Society of Neurology (Ezpeleta et al, 2015) were used to screen patients. Despite that the study periods were between 2009 and 2015 in two of the studies, data were re-analysed after the publication of those manuscripts. In the CVST and TTH studies, health records were retrospectively reviewed. In the Covid-19 study, patients were interviewed after the onset of symptoms.

\subsection{Statistical aspects}

All three studies were mainly descriptive. Qualitative nominal variables and quantitative ordinal variables are presented as frequencies and percentages. Quantitative continuous variables are presented as mean and standard deviation if the distribution was normal, after evaluating normality with Kolmogorov-Smirnov tests or QQ plots; or by median and inter-quartile range if the distribution was not normal.

For hypothesis testing, chi-squared tests or Fisher's exact tests were used when variables were qualitative. When continuous variables were tested for differences, Student's t-tests or Mann-Whitney $U$ tests were used, depending on the type of distribution. To identify correlations between continuous variables, Pearson's test was used. Multiple comparisons were adjusted for by using the Bonferroni method. The statistical significance threshold was set to $P<0.05$. The statistical analysis was done by using SPSS (IBM Corp. Armonk, NY). All the statistical analysis was done by David García Azorín. 
VI. RESULTS 


\section{Results}

All patients with CVST and Covid-19 presented with at least one red flag. The types of red flags differed between the disorders. In the case of the TTH study, red flags were frequent in patients who received a final diagnosis of TTH in the ED discharge report. Figure 5 summarizes the frequency of red flags within the studied groups.

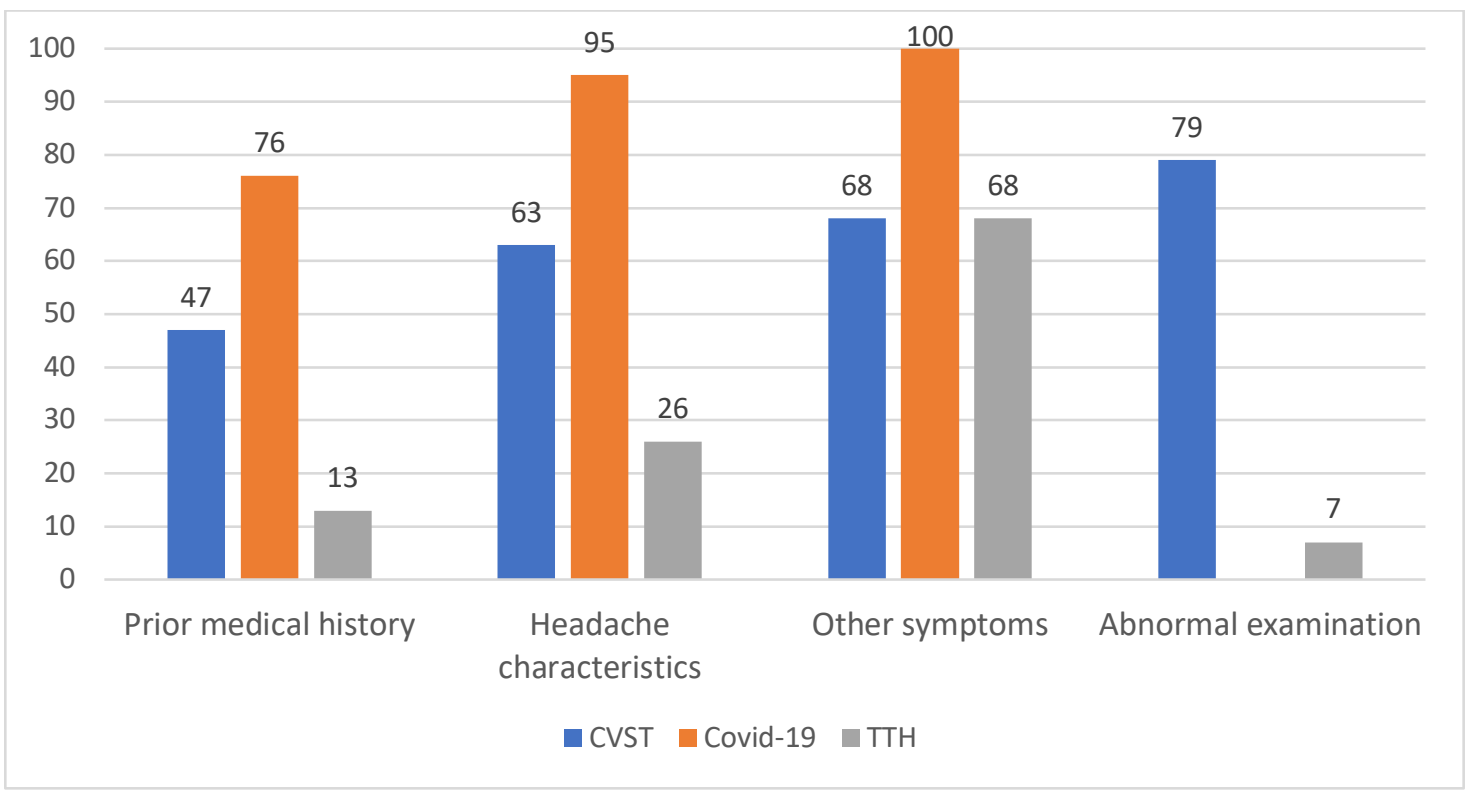

Figure 5. Frequency of red flags in CVST, Covid-19 and TTH groups separated by category of red flag. CVST: cerebral venous sinus thrombosis; Covid-19: coronavirus disease 2019; TTH: tension-type headache. Created with Excel by David García-Azorín.

\subsection{Tension-type headache}

Of the 2132 patients screened, 211 (9.9\%) received a TTH diagnosis. For the first objective, it was observed that only 5/211 (2.4\%) fulfilled the ICHD-3 criteria for TTH. The 
criterion that was fulfilled most frequently was criterion $B$, related to the headache phenotype, in $74 \%$ of patients.

Second, when looking for discrepancies in the TTH diagnosis, errors in the diagnosis were observed to be related to anamnesis in $87 \%$ of patients. In particular, there were red flags related to the headache phenotype in $26 \%$ of cases, related to the presence of systemic symptoms in $27 \%$ of cases, to other neurological symptoms in $41 \%$ of cases, and related to prior medical history of secondary headache disorders in $13 \%$ of patients (Figure 5).

When patients were re-classified according to the ICHD-3 criteria, only 21 (9.9\%) patients fulfilled ICHD-3 criteria for TTH. In 50\% of patients, headache was better accounted for by another ICHD-3 diagnosis, being a secondary headache disorder in 30\% of those cases and being a high-risk headache in $6 \%$.

\subsection{Cerebral Venous Sinus Thrombosis}

During the study period, 31 patients were screened and 19 fulfilled eligibility criteria. The most frequent types of red flags were related to the neurological examination, which was abnormal in $79 \%$ of cases, followed by the presence of other symptoms in $68 \%$, headache-specific red flags in $63 \%$, and red flags related to prior medical history in $47 \%$ (Figure 5). 


\subsection{Covid-19}

During the study period, 576 patients were screened, with headache observed to have no specific cause in 130 (22.6\%) of them, and 104 patients were included in the study. The most frequent red flags were the presence of systemic symptoms, in the category "other symptoms", which were observed in all (100\%) cases (Figure 5). In addition, red flags related to an atypical headache phenotype were frequent (95\%) and those related to prior medical history were observed in most cases as well (76\%). In this study, due to the risk of contagion, patients were not physically examined by the study physicians, so red flags related to an abnormal examination were not assessed further. For the Covid-19-specific objective, laboratory parameters were altered in $94 \%$ of patients at the moment of the ED visit. 


\section{Manuscript 1:}

Tension-type headache in the Emergency Department Diagnosis and misdiagnosis: The TEDDi study. García-Azorín D, Farid-Zahran M, Gutiérrez-Sánchez M, González-García MN, Guerrero AL, PortaEtessam J. Sci Rep 2020;10(1):2446. Published: February 12, 2020. 


\section{Tension-type headache in the Emergency Department Diagnosis}

\section{and misdiagnosis: The TEDDi study}

David García-Azorín, Mariam Fahrid-Zahram², María Gutiérrez-Sánchez¹, Nuria González-García ${ }^{3}$, Ángel L. Guerrero, 4, 5, Jesus Porta-Etessam³.

Author contribution statement:

All authors participated in the design of the study. DGA and MF created the questionnaire, and $A L G, J P E, M G$ and $N G G$ reviewed the questionnaire. MF and DGA reviewed all cases, and NGG and MG solved disputes. DGA wrote the first draft, and all the authors reviewed and approved the final draft.

\section{Declarations:}

- Ethics approval and consent to participate: The Clinical Research Ethics Committee of Hospital Clínico San Carlos approved the study. Informed consent forms were obtained from the participants.

- Consent for publication: All authors gave their consent for publication.

-Availability of data and material: Study material and supplementary material are available upon request from the corresponding author. 
-Competing interests: The authors declare no conflicts of interest.

-Funding: All the authors declare that no specific Funding was received.

-Authors contributions: All authors participated in the design of the study. DGA and MF created the questionnaire, and ALG, JPE, MG and NGG reviewed the questionnaire. MF and DGA reviewed all cases, and NGG and MG solved disputes. DGA wrote the first draft, and all the authors reviewed and approved the final draft.

-Acknowledgements: We acknowledge our emergency department colleagues for all their support.

-Authors' information: We assure that this study represents original work. The present work was partially presented at the $2^{\text {nd }}$ European Academy of Neurology Congress. 
Tension-type headache in the Emergency Department Diagnosis and misdiagnosis: The TEDDi study

\section{ABSTRACT:}

Headache is a common reason to visit the emergency department (ED). Tension-type headache $(\mathrm{TTH})$ is the commonest headache. The diagnosis of TTH implies a mild condition, with no need for special tests. We evaluated the use of the International Classification of Headache Disorders (ICHD) criteria for TTH in the ED. We performed a cross-sectional study including all ED patients with a definite TTH diagnosis in their discharge report for 2.5 years. We evaluated whether the ICHD criteria for TTH were referenced and met. We analysed discrepancies concerning anamnesis or prior history and reclassified patients.

A total of 211 out of 2132 patients fulfilled the criteria (9.9\%). Only five patients fulfilled TTH criteria. Criteria A-D were referenced in $60-84 \%$ of patients and met in $16-74 \%$ of these patients. Anamnesis was discrepant in $87.5 \%$ as was prior history in $20.8 \%$. After re-reclassification, 21 patients fulfilled the criteria for TTH (five) or probable TTH (16). In 106 patients, another headache was diagnosed, with migraine in 40 (18.9\%), secondary headache in 64 (30.3\%), and a life-threatening disorder in 13 (6.1\%). In our sample, TTH was overdiagnosed. Only a minority of patients fulfilled the ICHD criteria. Inconsistencies in prior medical history or anamnesis were frequent.

Keywords:

Headache disorders; Tension-type headache; Emergency department; diagnosis. 


\section{INTRODUCTION:}

Tension-type headache (TTH) is the most common primary headache disorder ${ }^{1,2}$. The prevalence of TTH is estimated to be between 30 and $70 \%$ of the general population according to different studies ${ }^{2}$. The diagnostic criteria proposed by the International Classification of Headache Disorders (ICHD) have remained unaltered since the first edition in $1988^{3-6}$. The criteria are based on bilateral, oppressive and mild pain, without typical migraine features and with no better explanation ${ }^{6}$. Given the mild nature of the disorder, few patients seek assistance, and in headache unit-based series, it is not a frequent diagnosis, accounting for $16 \%$ of all diagnoses ${ }^{7}$. On the other hand, it is not uncommon for migraine patients to be erroneously diagnosed with $\mathrm{TTH}^{8}$.

Headache is one of the main reasons for consultation in the emergency department (ED). It seems remarkable that in some ED-based series, TTH diagnosis accounts for up to 25$33 \%$ of all headache visits ${ }^{9}, 10$; particularly when other series are performed by neurologists or using ICHD criteria diagnosis, TTH represents only 1-6\% of total headache patients ${ }^{11-15}$. In the ED setting, secondary headache detection represents the main priority. TTH is particularly threatening, as its typical phenotype is relatively unspecific, and many secondary headaches may mimic it.

The use and knowledge of the ICHD criteria in the ED setting may be difficult. Most clinicians use red flag lists to rule out secondary headaches ${ }^{16}$. However, we hypothesize that TTH is probably overdiagnosed in the ED setting, which might represent a risk for 
patients with nondetected secondary headaches. Establishing TTH diagnosis might be dangerous, as it implies that the patient has a harmless disorder.

In this study, the first objective was to analyse the percentage of patients who fulfilled the $\mathrm{ICHD}^{6}$ criteria for tension-type headache and the percentage of patients presenting each of the different criteria. The second objective was to analyse the presence of data in the discharge reports that contradicted TTH diagnosis, such as relevant prior medical data, atypical symptoms or abnormal findings in the examination. The third objective was to analyse whether patients could be re-classified as having other headache disorders by using the ICHD-3 criteria.

\section{PATIENTS AND METHODS:}

This is an observational study with a cross-sectional design. Our study population included patients who visited the emergency department due to headache. The study was performed according to the Strengthening the Reporting of Observational Studies in Epidemiology (STROBE) guidelines ${ }^{17}$.

The study took place at the ED of the Clínico San Carlos University Hospital, Madrid (Spain), a third-level hospital with a reference population of 700.000 people. The study period was between January 2012 and July 2014.

\section{Eligibility:}

The inclusion criteria were as follows: 1) patients visiting the ED because of headache and 2) patients with a definite diagnosis of "tension-type headache" in the ED discharge 
report. We excluded patients with 1) some degree of uncertainty in the diagnosis, such as "possible" or "probable"; 2) another headache diagnosed at the same time; and 3) no available information in the patient chart.

We screened all the patients who visited the ED during the study period because of headache by using the ED database, which codifies patients by initial reason for consultation. We reviewed the digitalized reports and gathered the information from the discharge reports. We did not review any additional sources, and we did not evaluate any patients. The rationale for this was that we aimed to see if with the information present in the ED reports, TTH diagnosis was appropriate or not.

The included demographic variables were sex; age; and relevant prior medical history, including current or past cancer, pathology of the immune system, and prior headache history. Clinical variables included headache description, with special attention to the presence of any red flag, neurological examination and abnormal focal signs, vital signs and general examination.

Study objectives:

For the first objective, we reviewed the ICHD criteria for $\mathrm{TTH}^{4-6}$ (table 1 ). We analysed whether each criterion was referenced in the report and if it was fulfilled or not. Criterion A, alluding to the number of episodes, was considered to be met for an infrequent tension-type headache diagnosis if the patient had a minimum of 10 episodes. We did not differentiate the ICHD edition in the manuscript, given that there were no differences 
between the TTH ICHD criteria in the second, third beta and third editions of the classification ${ }^{4-6}$ (Supplementary material).

Table 1: The International Classification of Headache Disorders criteria for Tension-type headache.

\begin{tabular}{|l|l|l|}
\hline Criterion & Feature & Specific criterion \\
\hline episodes & Number of & At least 10 episodes of headache. \\
\hline B & $\begin{array}{l}\text { Episode } \\
\text { duration }\end{array}$ & Lasting from 30 minutes to seven days \\
\hline Characteristics & $\begin{array}{l}\text { 1. Bilateral location } \\
\text { symptoms }\end{array}$ & $\begin{array}{l}\text { 2. Pressing or tightening (non-pulsating) quality } \\
\text { 3. no nausea or vomiting }\end{array}$ \\
\hline D & 2. no more than one of photophobia or phonophobia \\
& 4. Not aggravated by routine physical activity, such as \\
& walking or climbing stairs \\
\hline
\end{tabular}


For the second objective, we analysed discrepancies concerning both anamnesis and prior medical history. Anamnesis discrepancies were classified into five groups:

1: Presence of symptoms highly suggestive of another headache disorder, including pulsating quality, presence of both photophobia and phonophobia, worsening with exercise, cervical topography, neuralgiform pain, or highly localized pain.

2: Presence of abnormal neurological symptoms or signs, such as aphasia, dysarthria, sensory disturbances, paresis, visual symptoms, vertigo, instability, and papilledema.

3: Presence of red flags related to the headache description, such as thunderclap onset, severe intensity (>9/10), progressive worsening, recent onset, worsening with Valsalva manoeuvre, precipitation by exercise, and refractoriness to appropriate treatment.

4: Systemic symptoms, such as fever, chest pain, abdominal pain, arthralgia, diarrhoea, urethral syndrome, and localized ocular pain.

5: Close temporal relation with an event able to produce headache, including cranial trauma, high blood pressure, lumbar puncture, and cranial surgery.

Discrepancies in prior medical history included prior headache disorders, cancer affecting encephalic structures, sinus disease, ophthalmological diseases able to produce ocular pain, sleep apnoea syndrome, and any other intra- or extracranial conditions able to produce headache.

For the third objective, two headache specialists (NGG, DGA) independently reviewed each case and analysed the information present in the discharge reports. With that information, when possible, patients were re-assessed according to ICHD-3 (77). In case of discrepancies, a third headache specialist (JPE) solved the disputes. 
We also evaluated the management of patients. We determined the total duration of the emergency department stay, from when the patient was admitted to discharge. We analysed whether patients had been examined, specifically reviewing whether fundoscopy had been done. Complementary exam referrals were also addressed, including lumbar puncture, cranial tomography (CT), X-ray, and laboratory exams. Management at discharge was reviewed, inspecting if any treatment had been prescribed and if patients were referred to the neurological department. We compared whether patients who had undergone neurological exams or complementary exams had a longer stay and if they were more often diagnosed correctly.

The local ethics committee board approved the study. The study was performed according to the principles of the Declaration of Helsinki. Informed consent was obtained from all the participants.

\section{Statistics:}

Qualitative variables are presented as frequencies and percentages. Quantitative variables are presented as the means and standard deviations (sds) or medians and interquartile ranges (IQRs) in the case of a nonnormal distribution. Normality was tested by using the Kolmogorov-Smirnov test. The first three endpoints did not include statistical analysis and were based on descriptive qualitative data. As we analysed only patients with a definite TTH diagnosis, we only determined the positive predictive value of TTH diagnosis. In the analysis of the management of patients, for the comparison of qualitative variables, we used the chi squared test. When comparing two continuous variables, we used Student's t test if a normal distribution was shown in the Kolmogorov- 
Smirnov test, and we used the Kruskal-Wallis test if the data were not normally distributed. We considered a p-value as significant if it was lower than 0.05 and specified degrees of freedom (df). In case of missing data, we performed complete-case analysis. We did not anticipate any sample size a priori but included all possible patients during the study period.

\section{RESULTS:}

During the study period, 2132 patients visited the ED because of headache. The inclusion/exclusion criteria were satisfied by 211 patients ( $9.9 \%$ of the total sample), and these patients were included in the study. The median age of the patients was 42.6 years [30.9-57.3], and $75.6 \%$ were female.

Tension-type headache criteria:

Only five patients fulfilled all ICHD criteria for TTH (2.4\% of the included patients). The frequencies at which each criterion was referenced were as follows: criterion A was referenced in $81 \%$ of patients and fulfilled in $16 \%$ of patients, criterion B was referenced in $84 \%$ of patients and fulfilled in $74 \%$ of patients, criterion C was mentioned in $72 \%$ of patients and fulfilled in $43 \%$ of patients, and criterion $D$ was referenced in $60 \%$ of patients and fulfilled in $56 \%$ of patients. Figure 1 shows the percentage of patients who fulfilled each criterion. 


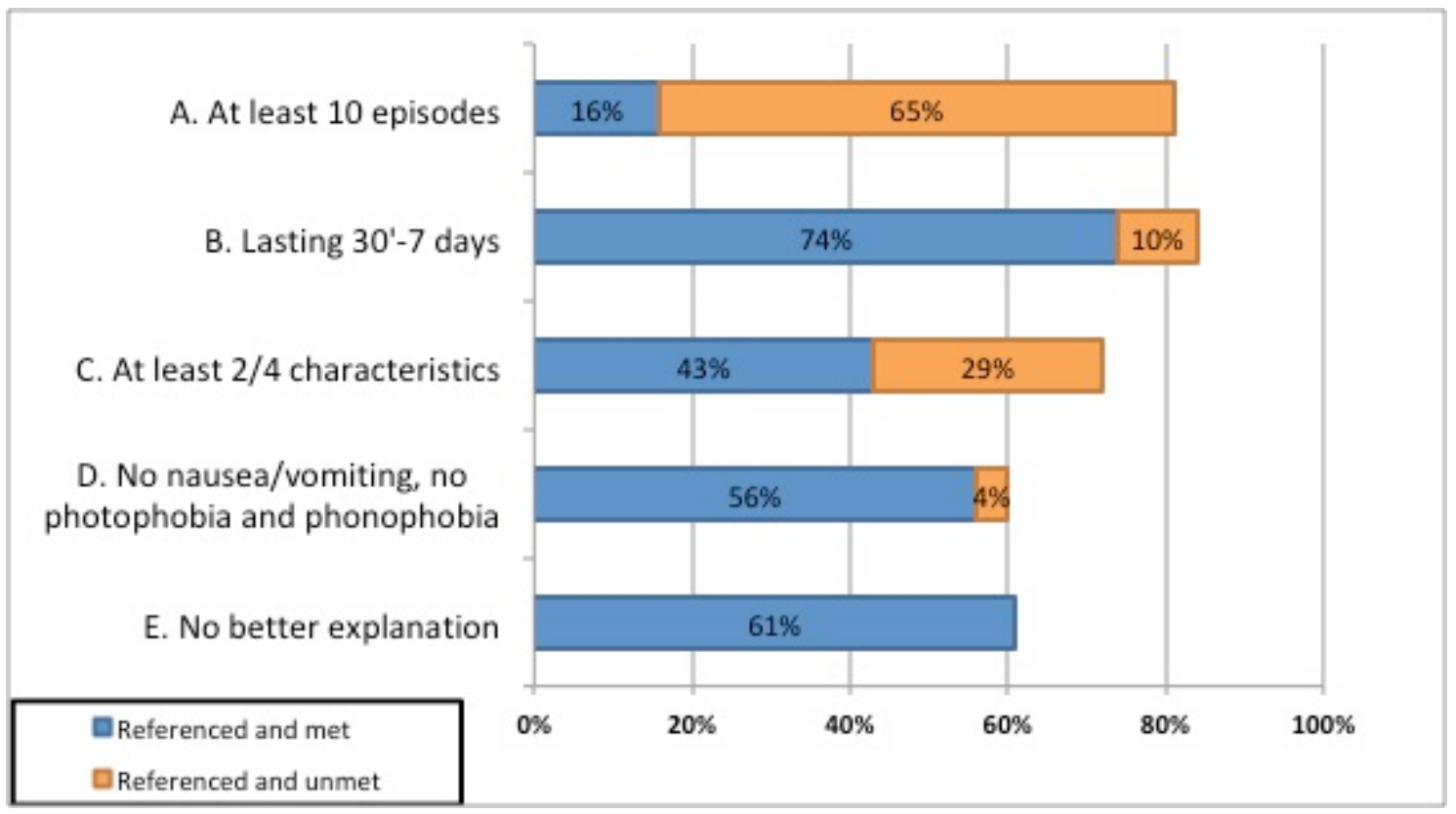

Figure 1: Percentage of patients in which every criterion is referenced; in blue referenced and met; in orange, referenced but unmet.

Discrepancies in TTH diagnosis:

There was at least one discrepancy in regard to anamnesis in 184 patients (87.2\%). Symptoms suggestive of another headache disorder were present in 131 subjects (62.1\%); 87 patients (41.2\%) described other neurological symptoms; red flags were identified in 55 patients (26.1\%); 57 subjects (27.0\%) also reported systemic symptoms; and in 31 patients (14.6\%), an event able to produce headache was described.

Concerning events related to headache onset, in 12 patients, traumatic injury to the head had occurred in the prior 7 days and was mentioned by patients; in 11 patients, an acute increase in blood pressure (BP) over 180/140 was documented, with cessation of headache after proper BP management; in three patients, headache started after dental 
manipulation with no prior history of headache; in two patients, headache began after the use of corticosteroids or amisulpride and olanzapine; in two patients, headache started after lumbar puncture; and in one patient, an intracranial aneurism was embolized the same day the headache started.

Regarding prior medical history, 44 patients $(20.85 \%)$ had some condition able to produce headache. In 17 patients, a prior history of migraine was present. Those patients referred to an unchanged headache phenotype that was resistant to treatment; nine patients had acute sinusitis, four patients had painful ophthalmological conditions (glaucoma in two, ophthalmic herpes in one and acute uveitis in one), three patients had cerebral and arteriovenous malformation, two patients had a recent history of subarachnoid haemorrhage, two patients had a history of intracranial cerebrospinal fluid (CSF) hypotension, one patient had cerebellar haemangioblastoma, one patient had Erdheim-Chester disease, one patient had a history of temporal arteritis, one patient had a history of occipital neuralgia, one patient had sleep apnoea, one patient had intracranial aneurism and one patient had polycythaemia vera with hyperviscosity syndrome.

Re-classification according to ICHD-3:

After reviewing all the discharge reports, only 21 patients (9.9\% of the included sample, 0.98\% of the total sample) fulfilled the ICHD-3 criteria for tension-type headache (five) or probable tension-type headache (16). The positive predictive value of TTH diagnosis was 0.099. In 106 patients, another ICHD-3 diagnosis was met (50.2\% of patients). In 64 patients, a secondary headache was the final diagnosis (30.3\%), with 13 having high-risk 
secondary headaches (6.1\%). Figure 2 and Table 2 show the number of patients encoded in each classification group and the specific diagnoses.

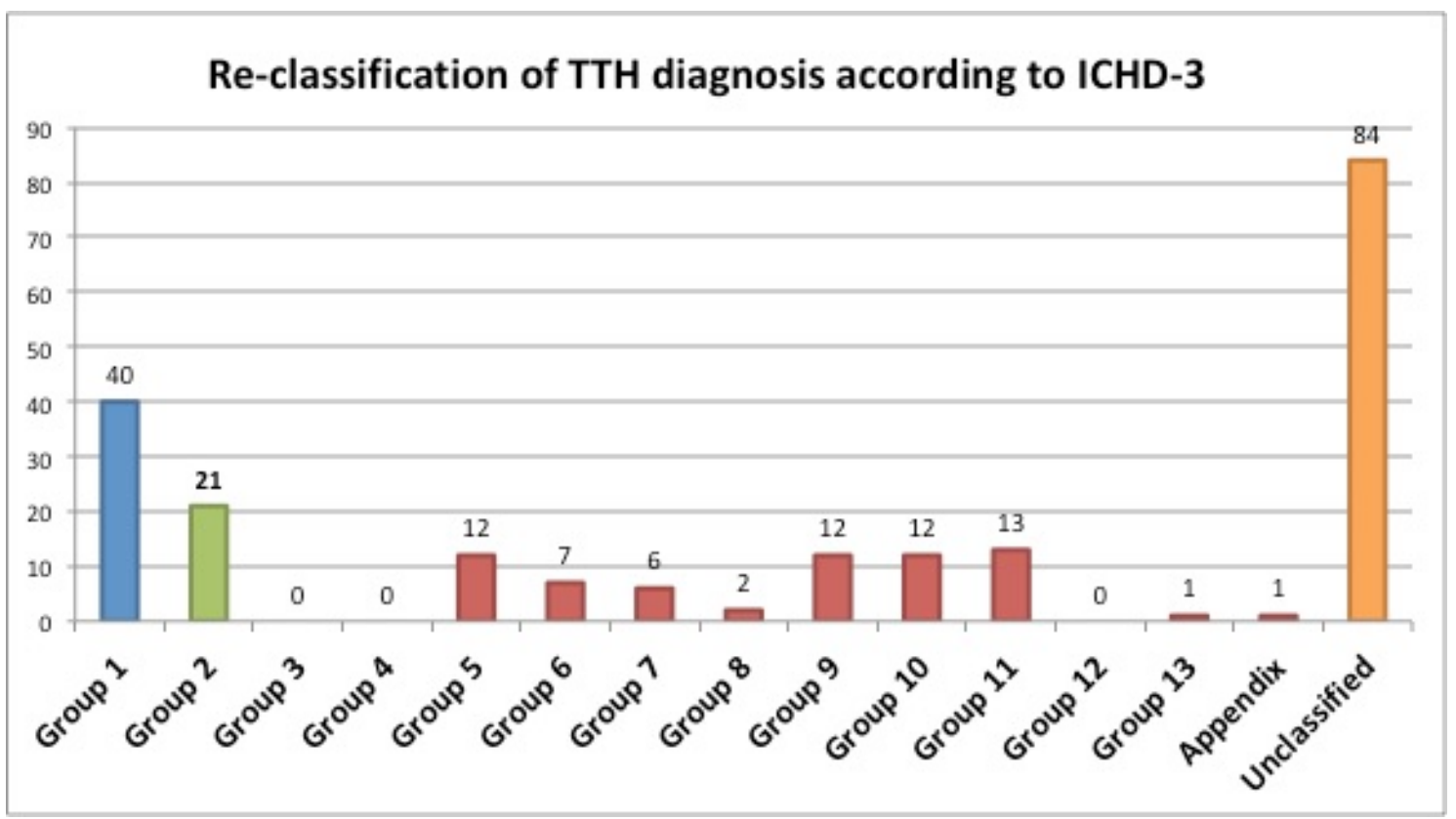

Figure 2: Number of patients re-classified to each ICHD-3 group. On the right column, patients unable to be re-classified.

Table 2: Number and percentage of patients re-classified into each of the ICHD-3 diagnostic groups with specific diagnosis and codes.

\begin{tabular}{|c|c|c|}
\hline Headache group & $\begin{array}{l}\text { Number of } \\
\text { cases (\%) }\end{array}$ & Subtype \\
\hline 1. Migraine & $40(18.9 \%)$ & $\begin{array}{l}\text { 1.1 Migraine without aura (5) } \\
\text { 1.2 Migraine with aura (1) } \\
\text { 1.3 Chronic migraine (3) } \\
\text { 1.5 Probable migraine (31) }\end{array}$ \\
\hline
\end{tabular}




\begin{tabular}{|c|c|c|}
\hline 2. Tension-type headache & $21(10.0 \%)$ & $\begin{array}{l}\text { 2.2 Frequent tension-type } \\
\text { headache ( } 3 \text { ) } \\
2.3 \text { Chronic tension-type } \\
\text { headache (2) } \\
\text { 2.4 Probable tension-type } \\
\text { headache (16) }\end{array}$ \\
\hline $\begin{array}{l}\text { 3. Trigeminal autonomic } \\
\text { cephalalgias }\end{array}$ & 0 & 0 \\
\hline $\begin{array}{l}\text { 4. Other primary headache } \\
\text { disorders }\end{array}$ & 0 & 0 \\
\hline $\begin{array}{l}\text { 5. Headache attributed to trauma } \\
\text { injury to the head and/or neck }\end{array}$ & $12(5.7 \%)$ & $\begin{array}{l}\text { Acute headache attributed to } \\
\text { traumatic injury to the head (11) } \\
\text { Acute headache attributed to } \\
\text { whiplash (1) }\end{array}$ \\
\hline $\begin{array}{l}\text { 6. Headache attributed to cranial } \\
\text { and/or cervical vascular disorder }\end{array}$ & $7(3.3 \%)$ & $\begin{array}{l}\text { 6.2.4.2 Persistent headache } \\
\text { attributed to past non-traumatic } \\
\text { subarachnoid haemorrhage ( } 2 \text { ) } \\
6.3 .2 \text { Headache attributed to } \\
\text { arteriovenous malformation } \\
\text { (AVM) (3) }\end{array}$ \\
\hline
\end{tabular}




\begin{tabular}{|c|c|c|}
\hline & & $\begin{array}{l}\text { 6.7.1 Headache attributed to an } \\
\text { intracranial endarterial } \\
\text { procedure (1) } \\
6.4 .1 \text { Headache attributed to } \\
\text { giant cell arteritis (1) }\end{array}$ \\
\hline $\begin{array}{l}\text { 7. Headache attributed to non- } \\
\text { vascular intracranial disorder }\end{array}$ & $6(2.8 \%)$ & $\begin{array}{l}\text { 7.2.1 Post-dural puncture } \\
\text { headache (2) } \\
7.2 .3 \text { Headache attributed to } \\
\text { spontaneous intracranial } \\
\text { hypotension (2) } \\
\text { 7.4.1 Headache attributed to } \\
\text { intracranial neoplasm (2) }\end{array}$ \\
\hline $\begin{array}{l}\text { 8. Headache attributed to a } \\
\text { substance or its withdrawal }\end{array}$ & $2(0.9 \%)$ & $\begin{array}{l}\text { 8.1.9 Headache attributed to } \\
\text { occasional use of non-headache } \\
\text { medication (2) }\end{array}$ \\
\hline 9. Headache attributed to infection & $12(5.7 \%)$ & $\begin{array}{l}\text { 9.2.2.1 Acute headache } \\
\text { attributed to systemic viral } \\
\text { infection (12) }\end{array}$ \\
\hline $\begin{array}{l}\text { 10. Headache attributed to } \\
\text { disorder of homeostasis }\end{array}$ & $12(5.7 \%)$ & $\begin{array}{l}\text { 10.3.2 Headache attributed to } \\
\text { hypertensive crisis without }\end{array}$ \\
\hline
\end{tabular}




\begin{tabular}{|c|c|c|}
\hline & & $\begin{array}{l}\text { hypertensive encephalopathy } \\
\text { (11) } \\
\text { 10.1.4 Sleep apnoea headache } \\
\text { (1) }\end{array}$ \\
\hline $\begin{array}{l}\text { 11. Headache or facial pain } \\
\text { attributed to disorder of the } \\
\text { cranium, neck eyes, nose, sinuses, } \\
\text { mouth or other facial or cervical } \\
\text { structure }\end{array}$ & $13(6.2 \%)$ & $\begin{array}{l}11.3 \text { Headache attributed to } \\
\text { disorder of the eyes ( } 2 \text { ) } \\
\text { 11.3.3 Headache attributed to } \\
\text { ocular inflammatory disorder (2) } \\
11.6 \text { Headache attributed to } \\
\text { disorder of the teeth } \\
\text { 11.5.1 Headache attributed to } \\
\text { acute rhinosinusitis (3) } \\
\text { 11.5.2 Headache attributed to } \\
\text { chronic or recurring } \\
\text { rhinosinusitis (6) }\end{array}$ \\
\hline $\begin{array}{l}\text { 12. Headache attributed to } \\
\text { psychiatric disorder }\end{array}$ & 0 & 0 \\
\hline $\begin{array}{l}\text { 13. Painful lesions of the cranial } \\
\text { nerves and other facial pain }\end{array}$ & $1(0.5 \%)$ & Occipital neuralgia (1) \\
\hline Appendix & $1(0.5 \%)$ & $\begin{array}{l}\text { A10.8.2 Headache attributed to } \\
\text { other metabolic or systemic }\end{array}$ \\
\hline
\end{tabular}




\begin{tabular}{|l|l|l|}
\hline & & $\begin{array}{l}\text { disorder (polycythaemia vera, } \\
\text { viscosity syndrome) (1) }\end{array}$ \\
\hline Not classifiable & $84(39.8 \%)$ & \\
\hline
\end{tabular}

Management of patients:

The total duration of the ED visits, from admission to discharge, had a median length of 3.59 hours [IQR: 2.5-5.1], with a range between 0.35 and 19.10 hours. Neurological examination was described in the reports of $90.5 \%$ of patients and was abnormal in $6.8 \%$ of these patients. When the neurological exam was done, the duration of the ED visit was 4.0 hours vs. 3.9 hours when it was not done (Student's t test, $22 \mathrm{df}, \mathrm{p}=0.87$ ). Fundoscopy was performed in $10.9 \%$ of patients, and the results were normal in all cases.

The diagnosis was more often appropriate in patients who underwent fundoscopy (chisquare test, $1 \mathrm{df}, \mathrm{p}=0.004)$.

Regarding complementary exams, laboratory exams were performed in $32.6 \%$ of patients. Laboratory exams including erythrocyte sedimentation rate (ESR) or C-reactive protein (CRP) were performed in $48.6 \%$ of patients older than 65 years old. Cranial CT was performed in $11.3 \%$ of patients, and cervical or sinus X-ray was performed in $12.7 \%$ of patients. Only 2 CT exams were abnormal, one exhibiting a vascular malformation and the other with acute inflammation of the frontal sinuses. Figure 3 summarizes the percentage of patients who underwent each examination. 


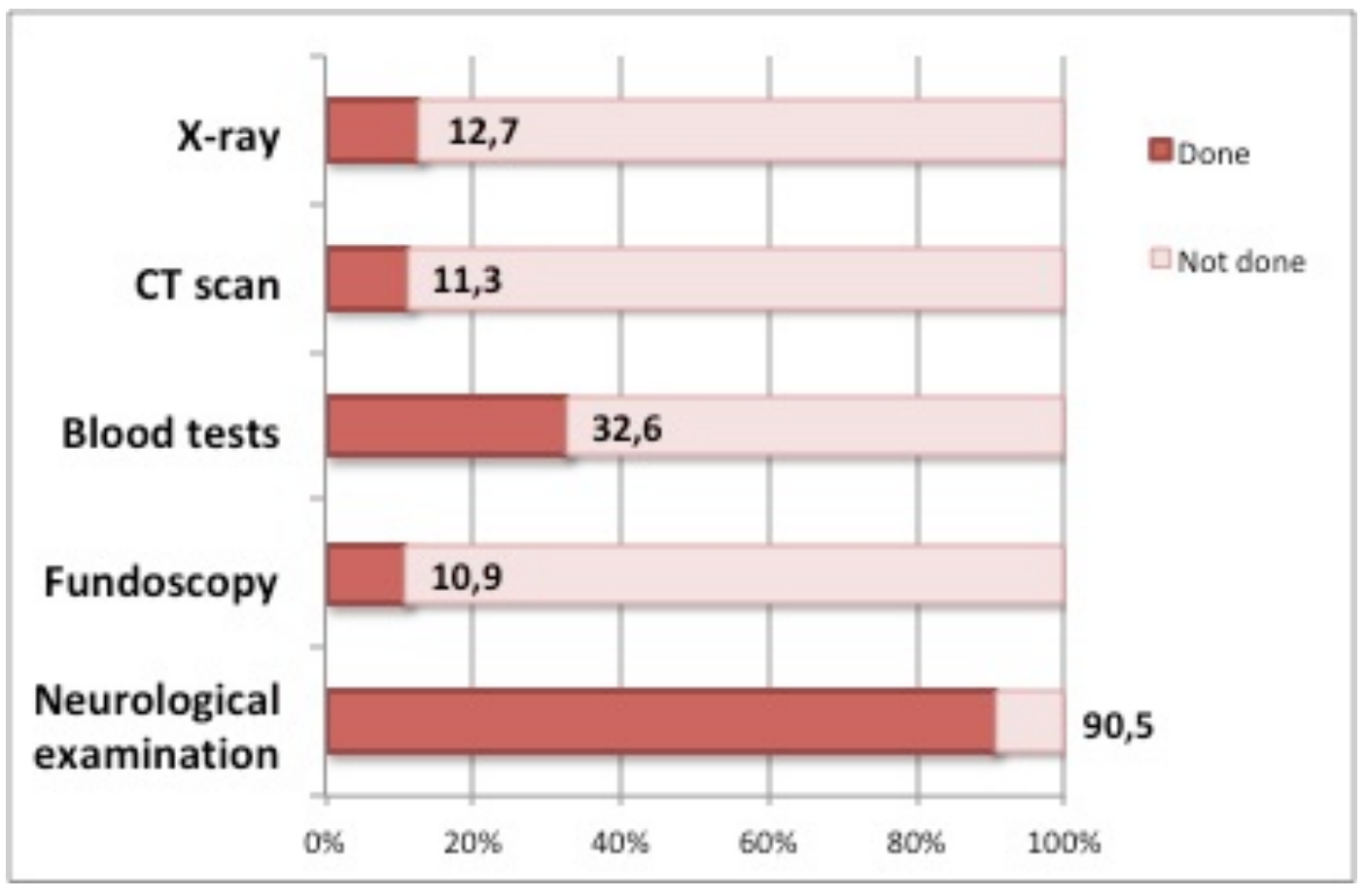

Figure 3: Percentage of patients that underwent each examination. CT scan (Cranial Tomography).

When complementary exams were performed, the mean duration of the stay increased from 3.28 to 4.94 hours (Student's t test, $217 \mathrm{df}, \mathrm{p}<0.001$ ). Requests for complementary exams were not associated with a higher probability of proper diagnosis (chi-square, $1 \mathrm{df}$, $p=0.71$ ). At discharge, $21.3 \%$ of patients were referred for a neurological examination. In $90 \%$ of the discharge reports, some acute medications were prescribed.

\section{DISCUSSION:}

The present study was performed in the emergency department setting. We systematically analysed a series of patients with definite TTH diagnosis according to whether the diagnostic criteria were mentioned and fulfilled in the discharge report. We screened the reports for the presence of data that would contradict TTH diagnosis, and finally, we tried to reclassify patients based on the information provided in the reports. 
The main findings of our study were that only a minority of patients, only $2.4 \%$ of the whole sample, fulfilled the ICHD criteria for TTH. In over $80 \%$ of patients, a discrepancy was found in the anamnesis, and in one-fifth of patients, prior medical history made TTH diagnosis unlikely. Finally, when we tried to reclassify patients, migraine diagnosis was two-times more frequent than TTH diagnosis. In almost $40 \%$ of patients, the information was not sufficient for a diagnosis, so in the best possible scenario, only half of patients with TTH diagnosis would have this condition, leading to a total percentage of $4.9 \%$ of the whole sample.

Concerning the ICHD criteria ${ }^{6}$, the most frequently mentioned criterion was duration, followed by number of episodes and phenotype. The most surprising data were that criterion $\mathrm{A}$, describing the number of episodes, was mentioned in $81 \%$ of cases, but it was only fulfilled in $16 \%$ of cases. This fact may reflect the idea that many patients visit the emergency department due to recent-onset headaches. New onset headache and progressive worsening are two of the main red flags ${ }^{18}$. In patients with primary headaches, a previous history of similar unchanged attacks might constitute a green flag.

The ICHD Criteria for TTH, unchanged since the first edition ${ }^{3}$, attempt to differentiate TTH from the other main primary headache, migraine. The criteria include positive, negative and exclusion criteria. The positive criteria describe the typical characteristics of TTH: bilateral, pressing, and relatively mild. The negative criteria rule out the presence of typical migraine features, such as nausea, vomiting, photophobia and phonophobia or worsening as a result of activity. Finally, as in every ICHD diagnosis, the condition should 
not be better described by any other diagnosis. In the literature, some series have diagnosed TTH in 53\% of patients with nausea ${ }^{19}$. Other series included patients who were diagnosed with TTH who had pulsating (23.8\%) and hemicranial headaches $(20.1 \%)^{20}$.

The typical TTH phenotype is probably the most unspecific, and many conditions might have similar features, such as migraine, hemicrania continua, primary cough headache, primary exercise headache, primary headache associated with sexual activity, externalpressure headache, hypnic headache, new daily persistent headache and the vast majority of secondary headache disorders ${ }^{6,8}$. Misdiagnosis might be related to the classification of patients based on pain phenotype; however, headache diagnosis should be performed by integrating prior medical history, headache anamnesis, presence of other symptoms and neurological examination, not solely by headache phenotype ${ }^{8,21}$.

The confusion surrounding TTH diagnosis might be partly influenced by the many names that have been used to describe this condition: tension headache, muscle contraction headache, psychomyogenic headache, stress headache, ordinary headache, essential headache, idiopathic headache, or psychogenic headache ${ }^{3-6}$. Some of these names may suggest a psychogenic cause. Currently, we consider stress and affective disorders a cause of worsening or a trigger rather than the cause of headache 22,23 .

Medical attention at the emergency department usually prioritizes the detection of lifethreatening conditions. The frequent saturation, rush and wide variety of conditions complicate the thorough and meticulous anamnesis that headache disorders require. In our sample, $30 \%$ of patients had a secondary headache, and $5 \%$ of patients had a 
secondary headache with potential morbimortality. In a previous series, up to $10 \%$ of patients diagnosed with TTH had an abnormal examination ${ }^{18}$.

One of the biggest needs in the headache field is the development of reliable biomarkers. Unlike other painful syndromes, such as chest or abdominal pain, we still base our diagnosis on anamnesis and neurological examination ${ }^{18}$. Some rules ${ }^{16}$ and lists of red flags have been proposed to detect secondary headaches ${ }^{24}$. CT and lumbar puncture, although frequently requested $18,25,26$, do not always rule out many entities, such as cerebral venous sinus thrombosis, intracranial space-occupying lesions, or cerebrospinal fluid pressure disorders.

Headache is one of the leading reasons for consultation, accounting for $2.3 \%$ of all ED visits $^{14,15,18}$; therefore, all ED physicians should be trained in headache medicine. In our sample, just a minority of patients underwent fundoscopy, and in many cases, even plain X-ray was requested. The use of lab tests was not properly selected for elderly patients, as less than half of the patients had an ESR or CRP exam.

Sometimes an accurate diagnosis cannot be made; in our study, up to $38 \%$ of patients had an unspecific diagnosis, with this figure reaching $38-45 \%$ in the literature ${ }^{24,27}$. In those cases, it is important to note that declaring a primary headache disorder without certainty might implicate the end of the diagnostic work-up and a higher risk of complications. In case of doubt, final diagnosis should be "possible" or "headache not otherwise specified"11,13, 24 . 
The consequences of inaccurate diagnosis are the risk of morbimortality among patients, inappropriate use of diagnostic resources, and the potential cost of establishing the proper diagnosis. Treatment of different secondary headaches differs widely, and in many conditions, prognosis is correlated with a prompt and proper treatment, as in the case of temporal arteritis, cerebral venous sinus thrombosis, or central nervous system infections ${ }^{13}$.

Although tension-type headache is supposed to be the most prevalent primary headache disorder ${ }^{28,29}$, it is seldom treated in headache outpatient clinics $^{30}$, and some authors even suggest that patients diagnosed with TTH suffer from improperly diagnosed migraines in at least one-third of the cases $^{31,32}$. Research on TTH and knowledge about its pathophysiology are also scarcer than those of other primary headaches, such as cluster headache or migraine $e^{2,33}$.

In many cases, TTH has been related to psychosocial factors ${ }^{22}$, and when patients complain of stress or mood disorders, TTH diagnosis is often made. It is well known that primary headache disorders are associated with significant personal, societal and familiar burdens ${ }^{30}$.

The pre-test probability of having $\mathrm{TTH}$ is $60-70 \% 1,2$ in the general population, but in the ED setting, it is important to clarify whether the headache that motivated the consult has changed, worsened progressively, resisted treatment or had new features. With regard to prior medical history, in our sample, one-fifth of the patients had conditions able to produce headaches, and $8 \%$ of the subjects were migraineurs. It is well known that chronic migraine exhibits a less typical phenotype, and some of the episodes might 
resemble TTH episodes ${ }^{34}$. In the diagnosis of chronic migraine, only 8 out of the minimum 15 headaches per month are needed to fulfil the migraine without or with aura criteria ${ }^{6}$.

The main limitations of the present study are the participation of a single centre, which might affect the generalizability of the results. Because of the design of the study, some data could have been asked and evaluated but not written; however, from a legal perspective, non-written data did not "occur". The re-classification was performed without evaluating patients; therefore, there was potential for misclassification, and we used the current ICHD instead of the two editions valid during the study period (ICHD-2 and ICHD-3 beta). We did not follow up with patients to confirm the final diagnosis. The strengths of the study are the thorough review of every patient chart, the participation of headache experts and the three different analyses performed.

\section{CONCLUSION:}

In our sample, TTH was overdiagnosed in an emergency department, as only $2.4 \%$ of the patients fulfilled all ICHD criteria for TTH. Inconsistencies in prior medical history or anamnesis were present in the discharge reports in one-fifth and four-fifths of patients, respectively. Our analysis of medical records allowed us to reclassify these patients as having other primary or secondary headaches. Efforts to improve knowledge on headache disorders and ICHD are needed among ED physicians.

\section{List of abbreviations:}

Tension-type headache (TTH), the International Classification of Headache Disorders (ICHD), emergency department (ED), Strengthening the Reporting of Observational 
Studies in Epidemiology (STROBE), cranial tomography (CT), degrees of freedom (df), blood pressure (BP), cerebrospinal fluid (CSF), erythrocyte sedimentation rate (ESR), Creactive protein (CRP), standard deviation (sd), inter-quartile range (IQR).

\section{Declarations:}

- Ethics approval and consent to participate: The Clinical Research Ethics Committee of Hospital Clínico San Carlos approved the study.

- Consent for publication: All authors gave their consent for publication.

-Availability of data and material: Study material and supplementary material are available upon request from the corresponding author.

-Competing interests: The authors declare no conflicts of interest.

-Funding: All the authors declare that no specific Funding was received.

-Authors contributions: All authors participated in the design of the study. DGA and MF created the questionnaire, and ALGP, JPE, MG and NGG reviewed the questionnaire. MF and DGA reviewed all cases, and NGG and MG solved the disputes. DGA wrote the first draft, and all the authors reviewed and approved the final draft.

-Acknowledgements: We acknowledge our emergency department colleagues for all their support.

-Authors' information: We assure that this study represents original work. The present was been partially presented at the $2^{\text {nd }}$ European Academy of Neurology Congress. 


\section{REFERENCES:}

1. Jensen, R. H. Tension-type headache - the normal and most prevalent headache. Headache. 58(2):339-345 (2018).

2. Bendtsen, L., Jensen, R. Tension-type headache: the most common, but also the most neglected, headache disorder. Curr. Opin. Neurol. 19:305-309 (2006).

3. Headache Classification Committee of the International Headache Society. Classification and diagnostic criteria for headache disorders, cranial neuralgias and facial pain. Cephalalgia. 8:suppl7:1-96 (1988).

4. Headache Classification Subcommittee of the International Headache Society. The International Classification of Headache Disorders, $2^{\text {nd }}$ Edition. Cephalalgia. 24,supl 1:9-160 (2004).

5. Headache Classification Committee of the International Headache Society (IHS). The International Classification of Headache Disroders, $3^{\text {rd }}$ edition (beta version). Cephalalgia. 33(9):629-808 (2013).

6. Headache Classification Committee of the International Headache Society (IHS). The International Classification of Headache Disorders, 3rd edition. Cephalalgia. 38:1211 (2018).

7. Guerrero, A. L. et al. Characteristics of the first 1000 headaches in an outpatient headache clinic registry. Headache. 51(2):226-31 (2011).

8. Crystal, S. C. Robbins, M. S. Tension-type headache mimics. Curr. Pain. Headache. Rep. 15:459-466 (2011).

9. Maizels, M. Headache evaluation and treatment by primary care physicians in an emergency department in the era of triptans. Arch. Intern. Med. 161:1969-1973 (2001). 
10. Dermitzakis, E. V. et al. Headache patients in the emergency department of a Greek tertiary care hospital. J. Headache. Pain. 11:123-128 (2010).

11. Sahai-Srivastava, S., Desai, P., Zheng, L. Analysis of headache management in a busy emergency room in the United States. Headache. 48:931-938 (2008).

12. Friedman BW, et al. Applying the International Classification of Headache Disorders to the Emergency Department: An assessment of reproducibility and the frequency with which unique diagnosis can be assigned to every acute headache presentation. Ann. Emerg. Med. 49:409-419 (2007).

13. Relja, G. et al. Nontraumatic headache in the Emergency Department: a survey in the province of Trieste. J. Headache. Pain. 6:290-300 (2005).

14. Barton CW. Evaluation and treatment of headache patients in the emergency department: A survey. Headache. 34:91-94 (1994).

15. Munoz-Ceron, J., Marin-Careaga, V., Peña, L., Mutis, J., Ortiz, G. Headache at the emergency room: etiologies, diagnostic usefulness of ICHD-3 criteria, red and green flags. PLoS One. 14(1):e0209728 (2019).

16. Do, T.P. et al. Red and orange flags for secondary headaches in clinical practice. SNNOOP10 list. Neurology. 92:134-144 (2019).

17. Vandenbroucke, J.P. et al. Strengthening the Reporting of Observational Studies in Epidemiology (STROBE): Explanation and elaboration. PLoS Med. 4(10):e297 (2007).

18. Locker, T., Mason, S., Rigby, A. Headache management- Are we doing enough? An observational study of patients presenting with headache to the emergency department. Emer. Med. J. 21:327-332 (2004). 
19. Bo, S. H., Davidsen, E. M., Guldbrandsen, P., Dietrichs, E. Acute headache: a prospective work-up of patients admitted to a general hospital. Eur. J. Neurology. 15:1293-1299 (2008).

20. Li, X., Zhou, J., Tan, G., Wang, Y., Ran, L., Chen, L. Clinical characteristics of tensiontype headache in the neurological clinic of university hospital in China. Neurol. Sci. 33:283-287 (2012).

21. Kaniecki, R.G., Tension-type headache. Continuum Lifelong Learning Neurol. 18(4):823-834 (2012)

22. Kaynak Key, F.N., Donmez, S., Tuzun, U. Epidemiological and clinical characteristics with psychosocial aspects of tension-type headache in Turkish college students. Cephalalgia. 24:669-674 (2004).

23. Ashina, S., Bendtsen, L., Buse, D.C., Lyndberg, A.C., Lipton, R., Jensen, R. Neuroticism, depression and pain perception in migraine and tension-type headache. Acta Neurol. Scand. 136:470-476 (2017).

24. Chu, K.H. et al. Acute headache presentations to the Emergency Department: A statewide cross-sectional study. Acad. Emerg. Med. 24(1):53-62 (2017).

25. Morgenstern, L.B. et al. Headache in the emergency department. Headache. 41:537$541(2001)$

26. Goldstein, J.N., Camargo Jr, C.A., Pelletier, A.J., Edlow, J.A. Headache in United States Emergency Departments: demographics, work-up and frequency of pathological diagnoses. Cephalalgia. 26:684-690 (2006).

27. Ruiz, F.B., Santos, M.S., Siqueira, H.S., Cotta, U.C. Clinical features, diagnosis and treatment of acute primary headaches at an emergency center. Acta Neuropsiquiatr. 65(4-B):1130-1133 (2007). 
28. Stovner, L.J. et al. The global burden of headache: a documentation of headache prevalence and disability worldwide. Cephalalgia. 27:193-210 (2007).

29. Sahler, K. Epidemiology and cultural differences in Tension-type headache. Curr. Pain Headache Rep. 16:525-532 (2012).

30. Rasmussen, B.K., Jensen, R., Olesen, J. Impact of headache on sickness absence and utilisation of medical services: a Danish population study. J Epidemiol. Community Health. 46(4):443-446 (1992).

31. Lipton, R.B., Cady, R.K, Stewart, W.F., Wilks, K., Hall, C. Diagnostic lessons from the Spectrum Study. Neurology. 58(suppl6):S27-S31 (2002).

32. Blumenfeld, A., Schim, J., Brower, J. Pure tension-type Headache versus Tension-type headache in the migraneur. Curr. Pain Headache Rep. 14:465-469 (2010).

33. Fernandez-de-las-Peñas, C., Arendt-Nielsen, L. Improving understanding of trigger points and widespread pressure pain sensitivity in tension-type headache patients: clinical implications. Expert Rev. Neurother. 17(9):933-939 (2017).

34. Turkdogan, D., Cagirici, S., Soylemez, D., Sur, H., Bilge, C., Turk, U. Characteristic and overlapping features of Migraine and Tension-Type Headache. Headache. 46:461468 (2006). 


\section{FIGURE LEGEND:}

Table 1: The International Classification of Headache Disorders criteria for Tension-type headache.

Figure 1: Percentage of patients in which every criterion is referenced; in blue referenced and met; in orange, referenced but unmet.

Figure 2: Number of patients re-classified to each ICHD-3 group. On the right column, patients unable to be re-classified.

Table 2: Number and percentage of patients re-classified into each of the ICHD-3 diagnostic groups with specific diagnosis and codes.

Figure 3: Percentage of patients that underwent each examination. CT scan (Cranial Tomography). 


\section{Manuscript 2:}

Presence of red flags in patients with cerebral venous sinus thrombosis admitted to the emergency department because of headache: A STROBE compliant cohort-study. García-Azorín D, Monje MHG, González-García N, Guerrero AL, Porta-Etessam J. Medicine (Baltimore) 2020;99(29)e20900. Published: July 17, 2020. 


\section{Presence of red flags in patients with cerebral venous sinus}

thrombosis admitted to the Emergency Department because of headache. A STROBE compliant cohort-study.

Authors: David García-Azorín, MD¹, Mariana HG Monje MD²,3, Nuria González-García $\mathrm{MD}^{4}$, Ángel L Guerrero MD, PhD ${ }^{1,5}$, Jesús Porta-Etessam MD, $\mathrm{PhD}^{4}$.

\section{Authors affiliation:}

${ }^{1}$ Headache Unit, Neurology Department. Hospital Universitario Clínico de Valladolid. Valladolid, Spain.

${ }^{2}$ HM-CINAC, HM Puerta del Sur University Hospital, Móstoles, Madrid, Spain.

${ }^{3}$ Anatomy, Histology and Neuroscience Department. Faculty of Medicine. Universidad Autónoma de Madrid, Madrid, Spain.

${ }^{4}$ Headache Unit, Neurology Department. Hospital Universitario Clínico San Carlos, Madrid.

${ }^{5}$ Institute for Biomedical Research of Salamanca, IBSAL, Salamanca, Spain.

\section{Corresponding author:}

David García-Azorín

Headache Unit. Neurology Department. Hospital Clínico Universitario de Valladolid, Valladolid, Spain.

Ramon y Cajal avenue, 5.

Phone: +34665872228 
47003 Valladolid, Valladolid, Spain.

Spain

E-mail: davilink@hotmail.com

Conflict of interest: The Authors declare that there is no conflict of interest.

Funding: This research received no specific grant from any funding agency in the public, commercial, or not-for-profit sectors.

\section{Keywords:}

Headache Disorders, secondary; sinus thrombosis, intracranial; venous thrombosis; diagnosis.

\section{Abbreviations:}

Cerebral venous Sinus Thrombosis (CVST), Secondary Headaches (SH), the International Classification of Headache Disorders, $3^{\text {rd }}$ edition (ICHD-3), Emergency Department (ED), the Strengthening the Reporting of Observational in Epidemiology (STROBE) guidelines, Computed Tomography (CT), Standard deviation (SD), Inter-Quartile Range (IQR), Tension-type headache (TTH). 


\section{Abstract}

Introduction:

Cerebral Venous Sinus Thrombosis (CVST) is a cause of secondary headache with substantial morbimortality. Headache dominates the clinical presentation, but no typical phenotype has been described. We aim to evaluate the presence of red flags in headache in patients with confirmed CVST at the moment of emergency department (ED) presentation.

Patients and methods:

Retrospective STROBE compliant cohort study including patients with confirmed CVST that consulted because of headache at the ED. We analyzed presence and type of red flags at the moment of consult. We evaluated if CVST was suspected at the moment of imaging request and analysed delay in the diagnosis.

Results:

Nineteen patients fulfilled inclusion and exclusion criteria. Mean age was 48.5 years, 47.4\% were female. All the studied patients exhibited at least one red flag, being abnormal neurological examination the most frequent (79\%), followed by the presence of other neurological symptoms (68\%), alarm data related with headache phenotype (63\%) or risk factors concerning prior medical history (47\%). Temporal pattern of the headache was acute in $42.1 \%$, thunderclap in $31.6 \%$ and subacute in $26.3 \%$. In none patient CVST was the specific suspicion when imaging was requested. Median time since headache onset and ED presentation were 84 hours, being different in patients with associated symptoms (48 hours) when compared with isolated headache patients (168 hours). Time since ED presentation and the diagnosis also differed between the two groups, being more prolonged in patients with an isolated headache at presentation. 
Conclusion:

Headache attributed with CVST did not exhibit any distinctive phenotype, but all the patients presented some red flag, being abnormal neurological examination the most frequent. 
Presence of red flags in patients with cerebral venous sinus thrombosis admitted to the Emergency Department because of headache. A STROBE compliant cohort-study.

\section{Introduction}

Cerebral venous Sinus Thrombosis (CVST) is a rare cause of stroke ${ }^{1}$. Its incidence is 1.32 cases per 100.000 patients/year but increases in middle-aged women, among which it might affect up to $2.78 / 100.000$ patients/year ${ }^{2}$. The epidemiological picture of CVST is a middle-aged woman, being $73.7 \%$ of patients female aged 39.1 years in mean ${ }^{3,4}$. Its prognosis with no adequate treatment is gloomy, with a mortality rate around $7.7 \%$ $8.3 \%^{3,4}$. Given the availability and efficacy of anticoagulation, diagnosis should be done as soon as possible $e^{4,5}$.

Diagnostic delay is common, around 3 days between hospital admission and diagnosis ${ }^{3,}$ ${ }^{4}$, probably related with the clinical heterogeneity, the lack of awareness and the need of specific radiological imaging sequences for its adequate diagnosis $3,4,6,7$. Clinical presentation of CVST is variable, begin considered as one of the "great mimickers" of Neurology. Phenotype might influence by the topography of the affected sinus ${ }^{6}$, the existence of intracranial hypertension and the presence of complications such as subarachnoid hemorrhage of venous infarcts ${ }^{6,7}$.

Headache is, by far, the most frequent symptom at onset, present in $88.8 \%$ of patients ${ }^{6-}$

13. It is usually accompanied by other neurological symptoms, but in $22.7-45.0 \%$ of the patients represents the sole symptom ${ }^{6,8-10}$. Headache phenotype is polymorph, sometimes even mimicking "benign" headaches. Tension-Type Headache is a common misdiagnosis, as pain can be continuous in $88 \%$, throbbing in $76 \%$ and progressive in $64 \%^{12}, 13$, nevertheless, the needed number prior episodes contradicts it. The 
International Classification of Headache Disorders, $3^{\text {rd }}$ edition (ICHD-3) does not require any specific headache phenotype for the diagnosis ${ }^{14}$. When headache is the only presenting symptom, the diagnostic delay might prolong up to 13.1 days d2, $^{15-16}$. Secondary headaches $(\mathrm{SH})$ are those produced by a cause able to originate headache ${ }^{17}$. The temporal relation with the onset, aggravation or improvement is required in the causation assumption ${ }^{14}$. Due to the lack of specific biomarkers for headache in the Emergency Department (ED), the detection of secondary headache is still based on the presence of red flags. Presence of red flags in headache attributed to CVST have been partially described $^{9,13}$, however presence of identifiable red flags at the ED admission has not been analyzed yet.

In this study, we aim to evaluate if a secondary headache can be suspected due to the presence of any red flag at the moment of ED consultation in a series of CVST patients. Due to the needed index of suspicion and specific imaging modalities, we also pretend to evaluate if suspicion of CVST changes the study work-up and reduces the time to diagnosis.

\section{Material and methods}

We conducted an observational retrospective study. Our study population included patients with confirmed CVST that consulted at the ED because of headache. Our inclusion criteria were: 1) CVST confirmed by Magnetic Resonance Venography, Cranial Tomography Venography or Angiography; 2) Presenting at the Emergency Department;

3) Complaining because of headache at ED presentation; 4) Fulfilling ICHD-3 criteria for headache attributed to cerebral venous thrombosis ${ }^{18}$. Exclusion criteria were: 1) Isolated Cavernous Sinus Thrombosis; 2) infective thrombophlebitis; 3) Isolated Cortical venous 
thrombosis; 4) Unclear diagnosis after radiological re-evaluation from an experienced Neuro-radiologist.

The study took place in University Hospital Clinico San Carlos from Madrid, a third level public hospital with a reference population of 1 million inhabitants. The study period was between January 2009 and May 2015. We followed retrospectively all the patients since the ED presentation until the confirmation of the diagnosis.

We screened all the available cases from the Hospital General Database, the Emergency Department specific database, and the Radiology Department database by ICD codes. Two different researchers reviewed the cases for eligibility and a third neurologist solved the disputes. We tried to avoid selection bias by doing a wide search and reviewing a high number of records.

Data extraction:

We carefully reviewed clinical information from the emergency department charts, evaluating demographical information such as age and gender. Information was obtained from computerized medical records.

Two headache specialists evaluated the clinical data analyzing the presence of red flags at the moment of Emergency Department Visit. We classified the clinical data into four categories depending on the possible red flag. We adapted the classification of red flags to the CVST setting considering prior authors publications ${ }^{1,6,7,13,17}$. (Figure 1). The first category was related with prior medical history conditions that could be associated with CVST. The second category was the presence of red flags related to headache description 
and phenotype. The third group included red flags due to the existence of other neurological or systemic symptoms other than headache. We described nausea and vomiting presence by separate because they can be present both in primary and secondary headache disorders. The last group was the presence of abnormal neurological signs detected in the neurological examination. In those red flags that could be either a symptom or a sign, for example neuro-ophthalmological red flags, we considered symptoms if they were referred by patients and signs if they were observed during the examination. The components of each category are detailed in Figure 1

[insert Figure 1]

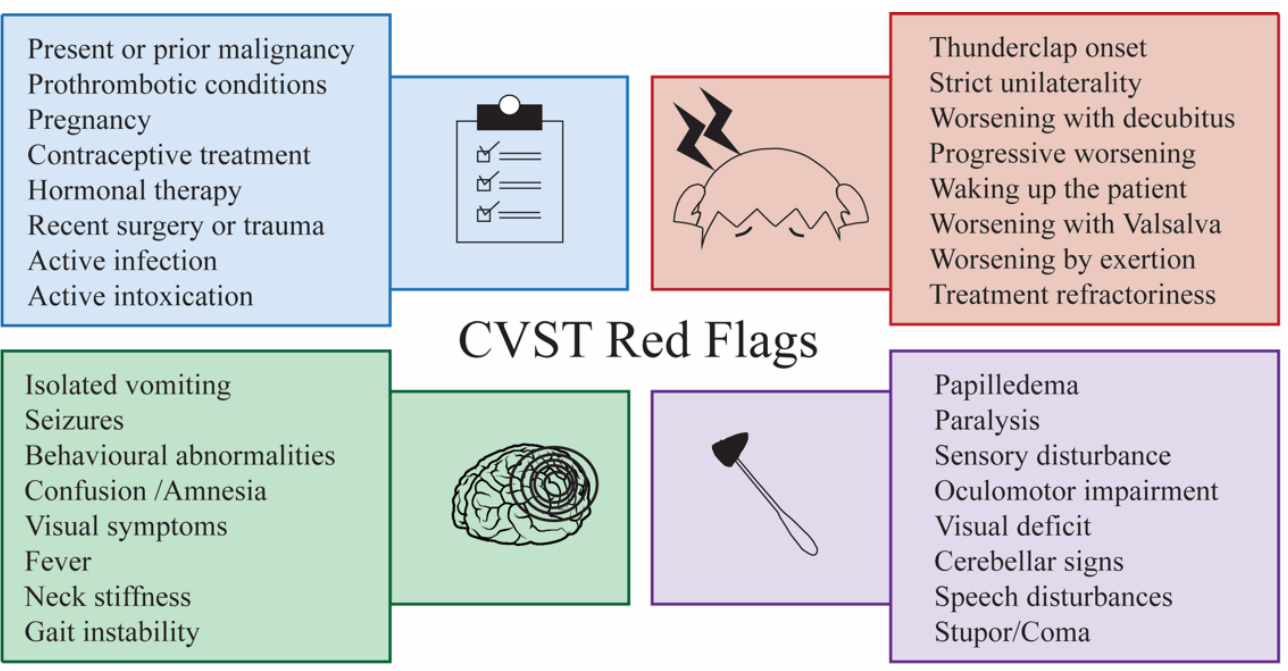

Figure 1. Red flags in cerebral venous sinus thrombosis. Classification of red flags in patients with cerebral venous thrombosis adapted considering prior authors publications $s^{1,6,7,13,17,19}$

We classified patients based on the presence of only headache or existence of other symptoms. According previous studies $6,7,9,11$, we defined isolated headache if at the moment of presentation, the patient did not complain about other neurological or 
systemic symptoms. If the patient reported other symptoms, it was defined as headache plus patient. In line with prior studies $6,7,9,11$ we differentiated three temporal patterns of headache depending on the time between the onset and the moment of maximal intensity: i) thunderclap, if the most severe intensity was reached within the first minute, ii) acute, if it took less than 24 to reach the maximum intensity, and iii) progressive, if it was after 24 hours $^{12}$.

Concerning diagnosis, we evaluated if fundoscopy was done. We also analyzed the time between the onset of the symptoms, ED presentation, first radiological exam and final diagnosis. We considered if CVST was suspected as the secondary cause producing the headache at the moment of the Cranial Tomography (CT) petition. We reviewed which imaging exam was done after the first imaging depending the results.

Local ethics committee board approved the study (CP14/425-E). The study followed the Strengthening the Reporting of Observational in Epidemiology (STROBE) guidelines ${ }^{19}$.

\section{Statistical analysis:}

The primary endpoint of the study was to evaluate the presence and type of any red flags at the moment of ED presentation. Secondary endpoints were to analyse: a) if funduscopic examination was done in all cases; b) if CVST was suspected at the moment of neuroimaging request and c) if delay in the consultation and diagnosis changed between the groups.

Qualitative variables are presented as frequency and percentage. Continuous variables are presented as mean and standard deviation (SD) in case of normal distribution or median and inter-quartile range (IQR) in case of non-normality. Normal distribution was 
evaluated with Kolmogorov-Smirnov test. In the case that some item was not detailed at the report, missing data was managed by doing Complete Case Analysis. We used ChiSquared test or Fisher exact test for the contrast of qualitative variables, Student test when comparing qualitative and quantitative variables or U-Mann Whitney test if distribution was not normal distribution and Pearson test in the comparison of quantitative variables, with Bonferroni correction in case of multiple comparisons. We considered an alpha level of 5\%. Statistical analysis was performed with SPSS v20.0 (IBM Corp, Armonk, NY).

\section{Results}

During the study period, 31 patients were diagnosed of CSVT but 7 did not presented headache at onset. We excluded three patients because of isolated cavernous sinus thrombosis and two because of infective thrombophlebitis. Finally, 19 patients fulfilled both inclusion and exclusion criteria. Mean age of our sample was 48.5 years (SD: 20.7) and $47.4 \%$ of patients were female. Six patients complained only about headache and thirteen described other symptoms as well (Table 1).

Table 1. Summary of the demographic and clinical variables. SD: Standard deviation. IQR: inter-quartile range. ED: Emergency Department.

\begin{tabular}{|l|l|}
\hline Variable & Value \\
\hline Mean age & 48.5 years (SD: 20.7) \\
\hline Female patients & $9(47.4 \%)$ \\
\hline Presence of red flags at the moment of ED presentation & $19(100 \%)$ \\
\hline
\end{tabular}




\begin{tabular}{|l|l|}
\hline Red flags related with prior medical history & $9(47.4 \%)$ \\
\hline Red flags related with headache characteristics & $12(63.2 \%)$ \\
\hline Red flags related with abnormal examination & $13(68.4 \%)$ \\
\hline Median time since headache onset and ED presentation & 84 hours (IQR:48-312) \\
\hline Median time between consultation and the first imaging & 36 hours (IQR:24-192) \\
\hline exam & \\
\hline Median time between first imaging exam and diagnosis & 48 hours (IQR:24-96) \\
\hline
\end{tabular}

SD: Standard deviation. IQR: inter-quartile range. ED: Emergency Department.

Headache characteristics:

Headache temporal pattern is represented in the Figure 2. The most frequent pain pattern was pressing (63.2\%). It was described as holocranial in 11 patients (57.9\%), five (26.3\%) as hemicranial, two as occipital, and in one single case frontal. Intensity was severe in 12 patients (63.2\%) and moderate in seven (36.8\%). No patient referred headache intensity as mild.

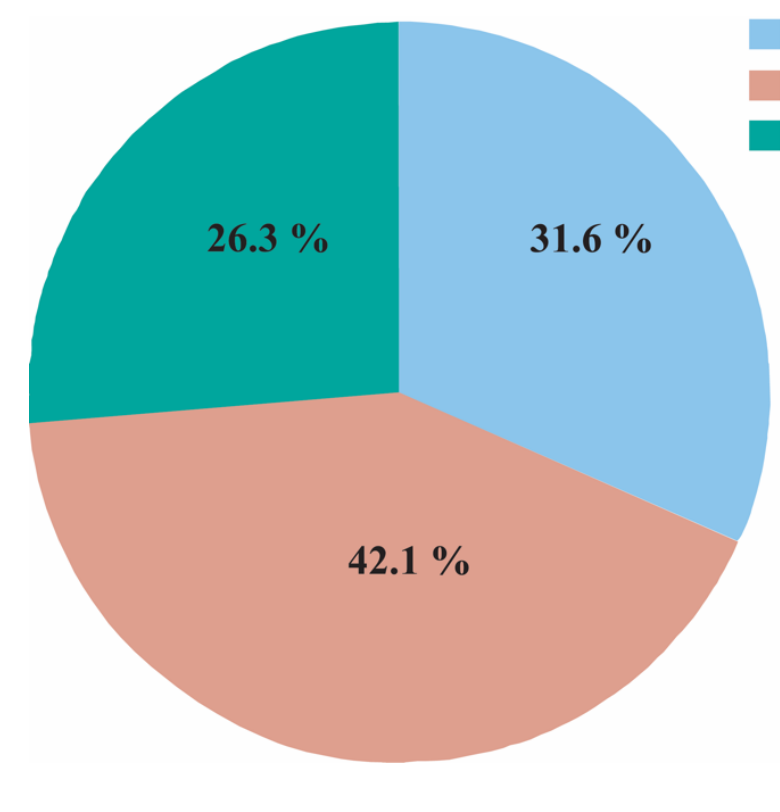

\author{
Thunderclap \\ Acute $(<24$ hours $)$ \\ Progressive ( $>24$ hours)
}


Figure 2. Temporal pattern of headache at presentation of patients with cerebral venous sinus thrombosis. Note how the high percentage of patients presented with thunderclap pattern of headache.

Red flags presence:

All the patients exhibited at least one red flag at the moment of ED presentation. Distribution of the different red flags within the 4 proposed categories is presented in figure 3.

Figure 3. Reg Flags exhibited by patients with cerebral venous sinus thrombosis. All the patients have some red flags. Note how the presence of red flags in headache characteristics are present in more than half of the patients.

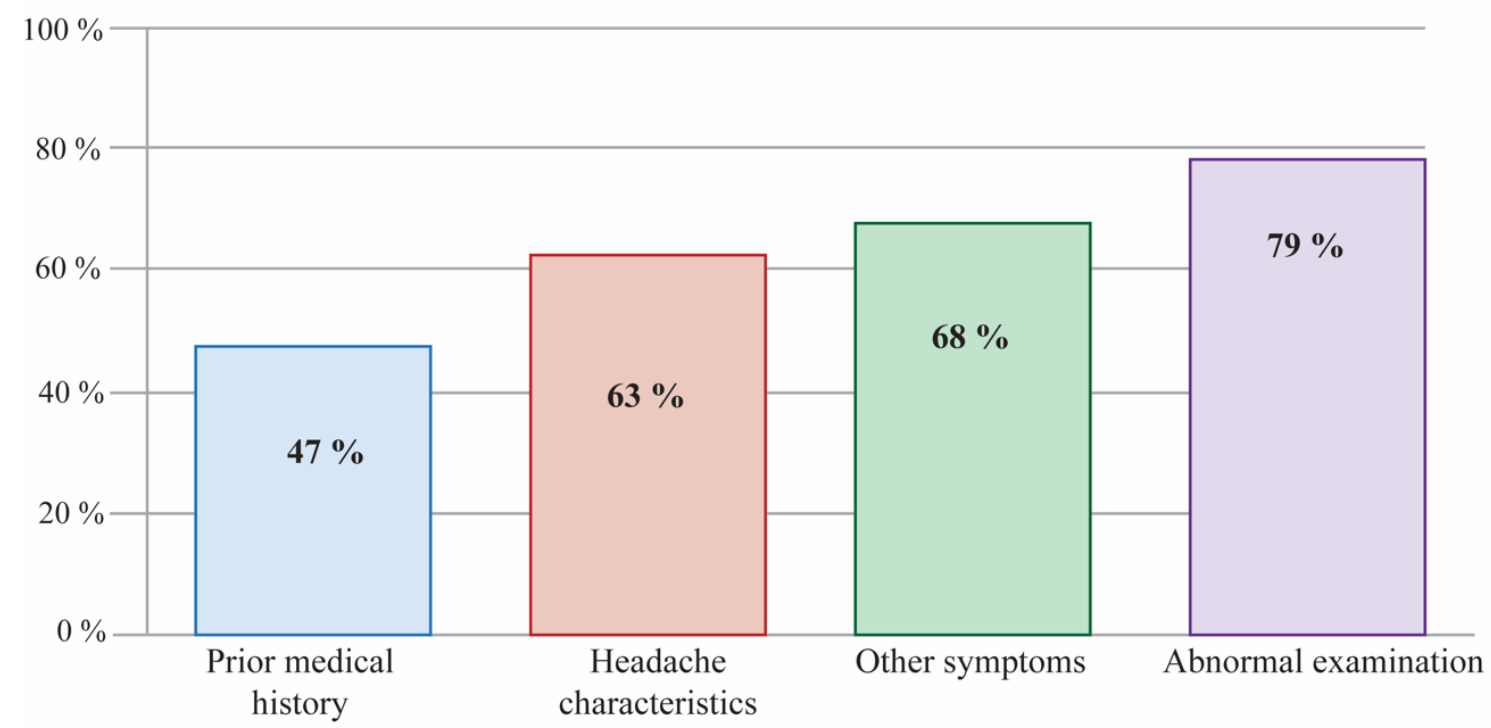

In nine patients (47.4\%) there were some recognizable alarm data about their prior medical conditions at presentation: four had previous active malignancy (21.1\%), four 
reported prior venous thromboembolic events $(21.1 \%)$ and one patient was under hormonal replacement treatment (5.3\%).

Twelve patients (63.2\%) described some alarm data related with headache characteristics. The most frequent was the progressive worsening of headache in seven patients (36.8\%), followed by thunderclap onset (six patients, 31.6\%), interruption of sleep (six, 31.6\%), resistance to symptomatic treatment (five, 26.3\%), worsening with decubitus (five, 26.3\%) and aggravation with Valsalva maneuvers (four, 21.1\%).

Thirteen patients (68.4\%) referred other abnormal neurological symptoms. The most prevalent were neuro-ophthalmologic symptoms (seven cases, 36.8\%), followed by motor weakness (five, 26.3\%), abnormal consciousness level (four, 21.1\%), behavioral disturbances (four, 21.1\%), fever (three, 15.8\%), seizures (two, 10.5\%), speech disturbances and gait instability in one patient each (5.3\%). Nausea and vomiting was present in eight patients (42.1\%).

Neurological examination was abnormal in 15 patients (78.9\%). The most frequently found signs were paresis (eight cases, $42.1 \%$, seven cases of hemiparesis and one case of facial palsy), neuro-ophthalmologic signs (seven, 36.8\%), sensory deficits (five, 26.3\%) and aphasia or decreased level of consciousness (two patients each, 10.5\%).

\section{Funduscopic examination:}

Funduscopy was performed in only 12 patients (63.2\%). It was more frequently done in patients with isolated headache (75\%) than in those with headache plus other symptoms 
(54.5\%). In 10 cases (83.3\% of the examined) papilledema was present. All patients with isolated headache at presentation exhibited papilledema.

\section{CVST index of suspicion:}

When the first imaging exam was ordered, a secondary headache was suspected in all the cases. However, in none of the requests, "CVST", "venous examination" or "thrombosis" was mentioned. In the first CT, 11 cases presented some abnormal finding, but only one case was considered highly suggestive of CVST. In patients with a first abnormal CT scan, a second urgent neuroimaging with vascular evaluation was requested in $77.8 \%$ of cases, whereas in patients with a first normal CT scan, another urgent neuroimaging with vascular evaluation was done only in $27.2 \%$ of patients.

Delay in diagnosis:

Median time since headache onset and ED presentation was 84 hours (IQR:48-312). Patients with headache plus other symptoms at presentation consulted earlier than those with isolated headache (48 vs. 168 hours, $\mathrm{p}<0.05$ ). Median time between consultation and the first imaging exam was 36 hours (IQR:24-192) and between first exam and diagnosis 48 hours (IQR:24-96). Time between ED consult and first imaging examination and time between first imaging examination and diagnosis tended to be shorter in patients with headache plus than patients with isolated headache, albeit differences were not statistically significant ( $p=0.1$ in both), (Figure 4). 


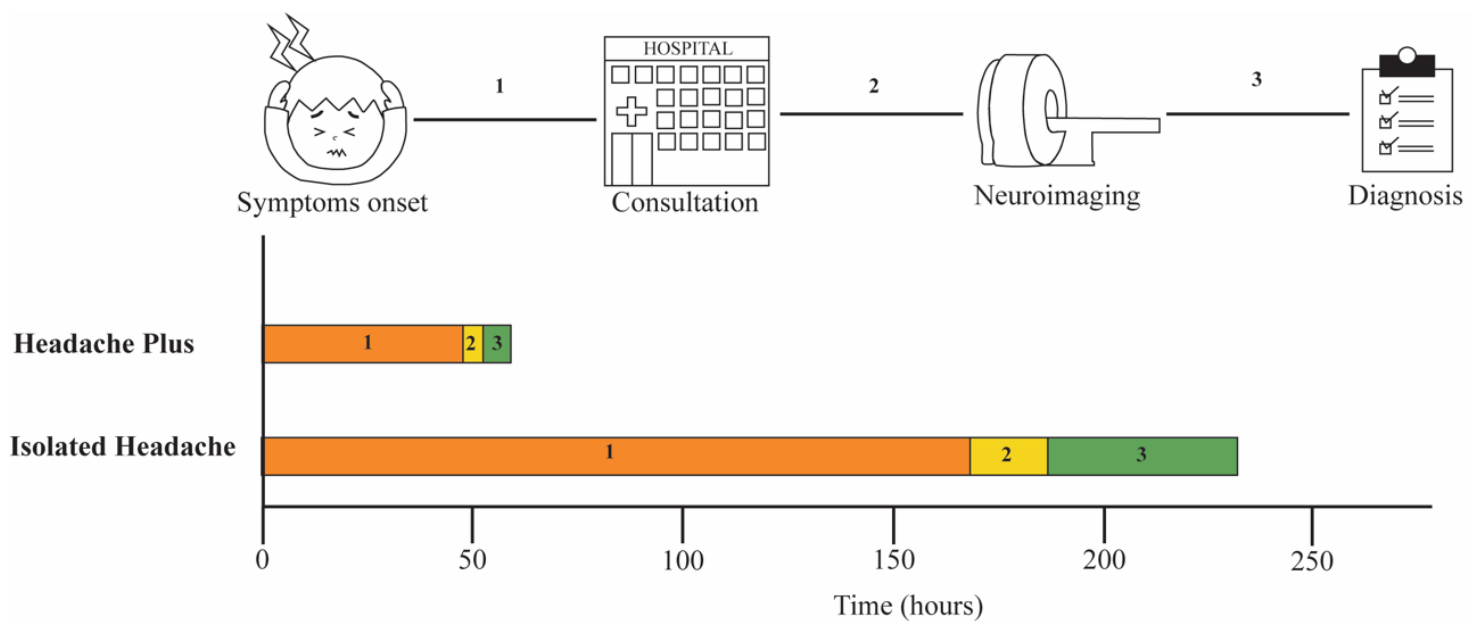

Figure 4. Graphical representation of the timing sequence since de clinical symptoms' onset and the diagnosis of cerebral venous sinus thrombosis. Isolated headache clinical manifestation patients (yellow) has a more considerable time from symptoms onset to consultation (1) compared to a headache plus patients (red) $(p<0.05)$. The time between consultation and first neuroimaging (2) and the time between first neuroimaging and diagnosis (3) was shorter in headache plus patients, although it did not reach significant statistical difference $(p=0.1)$.

\section{Discussion}

In this study we analyzed if CVST can be suspected in the ED because of the presence of red flags. We also analyzed which red flag group is more frequently abnormal and the impact of red flags presence in the diagnostic work-up and delay.

At the moment of ED presentation, all the patients presented at least one red flag and a secondary headache was suspected in all cases. Despite its potential consequences, CVST was not specifically mentioned in any patient. However, we found that diagnosis was delayed in many cases and specific imaging modalities were requested seldom. 
During the study period, 31 patients were diagnosed of cerebral venous sinus thrombosis. After excluding those patients with infective thrombophlebitis or isolated cavernous sinus thrombosis, headache was the most frequent symptom of presentation in CVST patients in our sample, present at ED admission in 19/26 cases (73.0\%). Many previous authors have highlighted the importance of headache as the key symptom in CVST diagnosis ${ }^{6-13}$.

In our sample, all the patients had red flags at the moment of ED presentation. The most frequent red flags were encoded in the group of abnormal signs in the neurological examination, presents in $78.9 \%$ of patients. In $68.4 \%$ of patients, headache description contained some alarm characteristic and in $68.4 \%$ other alarm symptoms other than headache were present. Finally, some medical condition increasing the risk of a secondary headache was identified at ED presentation in $47.4 \%$ of patients.

The clinical presentation may be related with CSVT extension. Venous sinus thrombosis is a dynamic process, so if venous drainage remains obstructed the intracranial hypertension is expected to rise. This may lead to a worsening of symptoms due to intracranial hypertension, venous infarcts and even hemorrhagic infarcts or subarachnoid haemorrhage ${ }^{8}$. The presence of hemorrhage has been also associated with seizures and the involvement of the deep venous system with decreased level of consciousness. Additionally, some authors described that the distension of the transverse sinus may be responsible of the lateralized pain ${ }^{11,12}$. 
History and examination can give some clues about the underlying pathophysiological process $^{20,21}$. Symptoms such as worsening with decubitus, morning predominance, vomiting without prior nausea or blurred vision; or signs such as papiledema or sixth nerve palsy can reflect intracranial hypertension. Seizures or focal signs might suggest venous infarcts or subarachnoid hemorrhage. The most useful manoeuvre in our sample was neurological examination, which should be always performed and might include fundus examination.

Neither us nor other authors have found any specific pattern of headache ${ }^{22}$; the main "chameleon" is tension-type headache. Nevertheless, in our sample at least two thirds of patients described red flags about headache description, which would contradict TTH diagnosis. It is typical that there is not any distinctive phenotype, but in our sample, all patients exhibited some red flag, so primary headache disorders should be diagnosed only if no better explanation can be found ${ }^{8,9,12}$.

Among the possible prior medical history, attention should be focused on conditions that may predispose to suffer a CVST. Classically it has been classified depending on which part of the Virchow triad was altered ${ }^{23,24}$ : hypercoagulability, hemodynamic changes or endothelial injury. The most frequent ones are changes in the composition of the blood, such as acquired hypercoagulability states, mainly secondary to oral contraceptives, pregnancy, puerperium, but also inherited ones, as prothrombin mutation G20210A, Factor V Leyden, Protein C and protein S deficiency. Second, the susceptibility to CVST can be related to endothelial damage: secondary to infections, inflammatory diseases, malignancies, mechanical causes, or trauma. Last but not least, hemodynamic changes 
with stasis of the blood might contribute to the problem, as it frequently happens in dehydration and secondarily in intracranial hypertension ${ }^{23}$.

Local causes of endothelial damage are less frequent in CVST than in other organ specific thrombosis (34\% compared with $73-88 \%$ as it is found in portal, renal or pulmonary veins thrombosis), so systemic entities that may predispose to thrombosis should be considered $^{23}$. Some of these conditions can be identified in history. Attention should be paid, not only because it may support the diagnosis, but also because some of these conditions could precise a specific and prompt treatment, as in the case of Behçet disease.

In our sample, a secondary entity was suspected in all the patients when neuroimaging was ordered. Despite of that, diagnosis was deferred in many cases. It has previously described that diagnosis in patients with isolated headache may be delayed ${ }^{12}$. Theoretically, if secondary headache is suspected, even if basal CT is normal, a contrastenhanced CT or MRI should be done. If CSVT diagnosis is a possibility, venous sequences should be included in the study.

In light with our findings, CVST should be considered also in the differential diagnosis of thunderclap headache. Venous specific imaging sequences should be included, because about a third of CVST patients in our sample and prior studies had a sudden onset of headache ${ }^{9}$.

Potential limitations of our work are the: the small sample size; the retrospective nature of the study, which could underreport some symptoms that were not identified in the 
medical records and with higher interobserver variability; the participation of a single center; the risk of biases. Among the strengths of our study, it is the first study that specifically analyzed presence of red flags in CVST patients; we adapted the classification of red flags to this condition and we avoided false diagnosis by the specific review of all imaging sequences.

\section{Conclusions}

Headache is the most frequent presenting symptom in patients with CVST, but it is not universal. CVST related headache typically has not a distinctive phenotype. All the patients of our sample presented some red flag in the prior medical history, clinical presentation or neurological examination. Imaging of the cerebral venous system should be considered in patients with headache and red flags. 


\section{References}

1. Einhäupl K, Stam J, Bousser MG, et al. EFNS guideline on the treatment of cerebral venous and sinus thrombosis in adults patients. Eur J of Neurology 2010; 17: 12291235.

2. Coutinho JM, Zuurbier SM, Aramideh M, Stam J. The incidence of cerebral venous thrombosis. A cross-sectional study. Stroke 2012; 43: 3375-3377.

3. Dentali F, Poli D, Scoditti U, et al. Long-term outcomes of patients with cerebral vein thrombosis: a multicenter study. J of Thromb and Haemostasis 2012; 10: 12971302.

4. Ferro JM, Canhao P, Stam J, Bousser MG, Barrinagarrementeria F. Prognosis of cerebral vein and dural sinus thrombosis. Results of the international study on cerebral vein and dural sinus thrombosis. Stroke 2004; 35: 664-670.

5. Canhao P, Ferro JM, Lindgren AG, et al. Causes and predictors of death in cerebral venous thrombosis. Stroke 2005; 36: 1720-1725.

6. Bousser MG, Chiras J, Bories J, Castaigne P. Cerebral venous thrombosis - a review of 38 cases. Stroke 1985; 16 (2): 199-213.

7. Saposnik G, Barrinagarrementeria F, Brown RD, et al. Diagnosis and management of cerebral venous thrombosis. A statement for healthcare professionals from the American Heart Association/American Stroke Association. Stroke 2011; 42: 11581192.

8. Crassard I, Bousser MG. Céphalées au cours des thrombosis veineuses cérébrales. Rev Neurol (Paris) 2005; 6-7: 706-708.

9. Sparaco M, Feleppa M, Bigal ME. Cerebral venous thrombosis and headache - a case series. Headache 2015; 55: 806-814. 
10. Damak M, Crassard I, Wolff V, Bousser MG. Isolated lateral sinus thrombosis. a series of 62 patients. Stroke 2009; 40: 476-481.

11. Singh RJ, Saini J, Varadharajan S, Baburao Kulkarni G, Veerendrakumar M. Headache in cerebral venous sinus thrombosis revisited: exploring the role of vascular congestion and cortical vein thrombosis. Cephalalgia 2018; 38 (3): 503510.

12. Cumurciuc R, Crassard I, Sarov M, Valade D and Bousser MG. Headache as the only neurological sign of cerebral venous thrombosis: a series of 17 cases. J Neurol Neurosurg Psychiatry 2005; 76: 1084-1087.

13. Wasay M, Kojan S, Dai Al, et al. Headache in cerebral venous thrombosis: Incidence, pattern and location in 200 consecutive patients. J Headache Pain 2010; 11: 137139.

14. Headache Classification Committee of the International Headache Society (IHS). The International Classification of Headache Disorders, 3rd edition. Cephalalgia 2018; 38:1-211.

15. Gameiro J, Ferro JM, Canhao P, et al. Prognosis of cerebral vein thrombosis presenting as isolated headache: early vs. late diagnosis. Cephalalgia 2012; 32(5):407-412.

16. Iurlaro S, Beghi E, Massetto N, et al. Does headache represent a clinical marker in early diagnosis of cerebral venous thrombosis? A prospective multicentric study. Neurol Sci 2004;25(Suppl3): S298-S299.

17. Friedman BW, Lipton RB. Headache emergencies: diagnosis and management. Neurol Clin 2012; 30:43-59. 
18. Headache Classification Committee of the International Headache Society (IHS). The International Classification of Headache Disorders, 3rd edition (beta version). Cephalalgia 2013;33:629-808.

19. Vandenbroucke JP, von Helm E, Altman D et al. Strengthening the Reporting of Observational Studies in Epidemiology (STROBE): Explanation and elaboration. PLoS Med 2007;4(10):e297.

20. Do TP, Remmers A, Schytz HW, et al. Red and orange flags for secondary headaches in clinical practice. SNOOP10 list. Neurology 2019;92:134-144.

21. Mehta A, Danesh J, Kuruvilla D. Cerebral Venous Thrombosis Headache. Curr Pain Headache Rep 2019;23(7):47.

22. Agostoni E. Headache in cerebral venous thrombosis. Neurol Sci 2004;25:S206S210.

23. McBane II RD, Tafur A, Wysokinski WE. Acquired and congenital risk factors associated with cerebral venous sinus thrombosis. Thrombosis Res 2010;126:8187.

24. Weimar C. Diagnosis and treatment of cerebral venous and sinus thrombosis. Curr Neurol Neurosci Rep 2014;14; 417.

25. Terni E, Giannini N, Chiti A, et al. Cerebral sinus venous thrombosis: clinical and pathogenetic perspectives from Tuscany. Blood Coag and Fibrinolysis 2015; 26: 505-508. 


\section{Figures legends:}

Figure 1. Red flags in cerebral venous sinus thrombosis. Classification of red flags in patients with cerebral venous thrombosis adapted considering prior authors publications ${ }^{1,6,7,13,17,19}$

Table 1. Summary of the demographic and clinical variables. SD: Standard deviation. IQR: inter-quartile range. ED: Emergency Department.

Figure 2. Temporal pattern of headache at presentation of patients with cerebral venous sinus thrombosis. Note how the high percentage of patients presented with thunderclap pattern of headache.

Figure 3. Reg Flags exhibited by patients with cerebral venous sinus thrombosis. All the patients have some red flags. Note how the presence of red flags in headache characteristics are present in more than half of the patients.

Figure 4. Graphical representation of the timing sequence since de clinical symptoms' onset and the diagnosis of cerebral venous sinus thrombosis. Isolated headache clinical manifestation patients (yellow) has a more considerable time from symptoms onset to consultation (1) compared to a headache plus patients (red) $(p<0.05)$. The time between consultation and first neuroimaging (2) and the time between first neuroimaging and diagnosis (3) was shorter in headache plus patients, although it did not reach significant statistical difference $(p=0.1)$. 


\section{Manuscript 3:}

Frequency and type of red flags in patients with Covid-19 and headache: a series of 104 hospitalized patients. García-Azorín D*, Trigo J, Talavera B, Martínez-Pías E, Sierra A, Porta-Etessam J, Arenillas JF, Guerrero AL. Headache 2020;60(8):1664-1672. Published: August 18, 2020. 


\section{Frequency and type of red flags in patients with Covid-19 and headache: a series of 104 hospitalized patients}

David García-Azorín ${ }^{1},{ }^{2} \mathrm{MD}$, Javier Trigo ${ }^{1}$ MD, Blanca Talavera ${ }^{1} \mathrm{MD}$, Enrique Martínez-Pías ${ }^{1}$ MD, Álvaro Sierra ${ }^{1}, \mathrm{MSci}_{\text {, Jesús Porta-Etessam }}^{3,4}$ MD, PhD, Juan F Arenillas ${ }^{1,5,6}, \mathrm{MD}, \mathrm{PhD}$, Ángel L Guerrero ${ }^{1,2}$,, $\mathrm{MD}$, PhD.

1. Headache Unit, Department of Neurology. Hospital Clínico Universitario de Valladolid, Valladolid, Spain.

2. Institute for Biomedical Research of Salamanca (IBSAL), Salamanca, Spain.

3. Headache Unit, Department of Neurology, Institute of Neurosciences, Hospital Clínico San Carlos, IdISSC. Madrid, Spain.

4. Department of Medicine, Universidad Complutense de Madrid, Madrid, Spain.

5. Neurovascular Research Laboratory. Instituto de Biología y Genética Molecular. Universidad de Valladolid - Consejo Superior de Investigaciones Científicas, Madrid, Spain.

6. Department of Medicine, School of Medicine, Universidad de Valladolid, Valladolid, Spain. 


\section{Correspondence:}

Dr. David García-Azorín

Headache Unit, Neurology Department, Hospital Clínico Universitario de Valladolid. Avenida Ramón y Cajal 3.

47005 Valladolid. SPAIN, Telephone: +34 665872228, Fax: +34 983257511

Email: davilink@hotmail.com, dgazorin@ucm.es

Orcid-ID identifier: 0000-0002-3132-1064

\section{Keywords:}

Covid-19, Neurology, Headache, coronavirus, diagnosis.

\section{Declarations:}

All the authors declare that they did not receive any specific funding.

Authors declare no conflict of interest.

All the patients read or heard and signed informed consent or agreed to participate.

\section{List of abbreviations:}

Covid-19: Coronavirus disease.

$\mathrm{Cl}$ : Confidence interval.

RT-PCR: real-time reverse-transcriptase-polymerase-chain-reaction.

mRS: Modified Rankin scale.

ACEi: Angiotensin-converting enzyme inhibitors.

AT-II: Angiotensin-II receptor blockers.

ADRS: Acute distress respiratory syndrome. 
RV: Reference value.

LDH: Lactate dehydrogenase.

INR: International normalized ratio.

CRP: C-reactive protein.

PCT: Procalcitonin.

SD: Standard deviation.

IQR: inter-quartile range.

\section{Acknowledgements:}

We thank the patients for their collaboration and all the people who faced Covid-19. 


\section{Abstract:}

\section{Objective:}

In this study we aimed to evaluate the frequency of the main red flags in patients with headache who do have Covid-19.

\section{Background:}

Headache is one of the most frequent neurologic symptoms of Coronavirus disease 2019 (Covid-19). Diagnosis of secondary headache disorders is still based on the presence of red flags.

\section{Design and methods:}

Cross-sectional study of hospitalized patients with confirmed Covid-19 disease. We interrogated every patient about the presence of headache and if so, a headache expert conducted a structured interview assessing the presence and type of the main red flags. We evaluated the presence of laboratory abnormalities on admission.

\section{Results:}

We screened 576 consecutive patients, 130/576 (22.6\%) described headache, and 104 were included in the study. Mean age of patients was 56.7 (standard deviation: 11.2) and 66/104 (63.4\%) were female. Red flags concerning prior medical history were present in 79/104 (76.0\%) cases, and those related to the headache itself were observed in 99/104 (95.2\%) patients. All patients 104/104 (100\%) described systemic symptoms and 86/104 (82.7\%) some neurologic symptoms. Laboratory results were abnormal in 98/104 (94.2\%) 
cases. The most frequent red flags were fever, in 93/104 (89.4\%) patients, cough, in 89/104 (85.6\% cases), and increased C-reactive protein in 84/100 (84.0\%) cases.

\section{Conclusion:}

In patients with Covid-19 that described headache red flags were present in most cases.

There was not any universal red flag, being necessary the comprehensive evaluation of all of them. 


\section{Introduction:}

The pandemic caused by the Coronavirus disease 2019 (Covid-19) has changed our lives and the way in which we treat our patients ${ }^{1}$. Now that the situation gradually improves ${ }^{2}$, we will have to assure both the quality in the assistance and the protection of healthcare workers $^{3-5}$. One of the presenting symptoms of Covid-19 is headache, described in around $13 \%$ of hospitalized patients ${ }^{6-9}$. Thus, it seems pertinent to question how the Covid-19 presence can be suspected in patients that complain of headache.

Covid-19 diagnosis is based on microbiological confirmation ${ }^{10,11}$. The main problems associated with this are the need of laboratory facilities, the delay in the confirmation of the results, the possible false negative result in the first days of the disease, and the risk of false positives, particularly high in the case of rapid tests ${ }^{11,12}$. In the clinical setting, diagnosis of secondary headache disorders is still based on the presence of red flags ${ }^{13-15}$. The above-mentioned are elements of the prior medical history, anamnesis or examination that associate with a secondary headache disorder with a higher frequency than the expected by chance. Some of the red flags refer to systemic symptoms, older age or new onset of the headache ${ }^{15}$, which might be frequent in Covid-19 patients ${ }^{7,8}$.

Now that the situation caused by Covid-19 gradually improves and the discontinuation of the lockdown permits to resume consultation activity, clinicians might be exposed to headache patients infected by Covid-19. We hypothesized that red flags or laboratory abnormalities might be ubiquitous in patients with headache and Covid-19 disease. In this study we aimed to evaluate the frequency and type of red flags in patients with 
headache who do have Covid-19. We also analyzed the frequency of abnormal laboratory parameters in Covid-19 in patients with headache.

\section{Methods:}

This is an observational descriptive study with a cross-sectional design. The study was done according to the STROBE guidelines ${ }^{16}$. The study population was patients with headache and confirmed Covid-19 disease. The study setting was the Hospital Clinico, tertiary university public hospital from Valladolid, Spain. The study was approved by the Ethics Review Board (ERB) of Valladolid East health area (code: PI 20-1738). Written or oral informed consent was obtained from each participant, after explaining the aim the study, the approval by the ERB, the duration of the study and the implications of the participation. Only participants that explicitly agreed to participate were included. This was the primary analysis of the data regarding hospitalized Covid-19 patients with headache. All the hospitalized patients were studied but the information about the whole series is not published yet. This is the first analysis of these data.

\section{Eligibility criteria:}

We included patients with confirmed Covid-19 disease that were hospitalized and described headache during the course of the disease. We excluded patients if they were deceased at the time of the evaluation, they had a poor medical condition that did not allow to enquiry about the headache, had psychiatric or cognitive impairment that difficulted the evaluation, or if they did not agree to participate. We screened all consecutive cases since March $8^{\text {th }}$ to April $11^{\text {th }}, 2020$. 
We did not restrict the headache to those that fulfilled the International Classification of Headache Disorders, $3^{\text {rd }}$ version (ICHD-3), criteria for specific secondary headaches ${ }^{13}$ and every patient that described headache during the course of the disease was included. Diagnosis of Covid-19 was done with real-time reverse-transcriptase-polymerase-chainreaction (RT-PCR) assay (LightMIx Modular SARS-CoV (COVID19) E-gene and LightMIx Modular SARS-CoV (COVID19) RdRP, Roche Diagnostics S.L.) from oropharyngealnasopharyngeal swab, sputum or lower respiratory tract sample; or by the presence of anti-SARS-CoV-2 IgM+lgA antibodies (COVID-19 ELISA IgM+lgA; Vircell, S.L. Granada, Spain) in serological test in patients with clinical symptoms ${ }^{11,12}$.

\section{Exposure:}

We screened the electronic records of the patients that had a positive result of Covid-19 and were hospitalized. In those in which the presence of headache was not described, we contacted by phone and enquired about it. We invited all the patients with headache to participate in the study. In those who agreed, a neurologist with expertise on headache medicine and involved in the management of Covid-19 patients conducted a pre-defined structured interview, either by phone or by physical consult. All the interviews took place within 45 days since the admission. We collected additional data from primary care medical records, emergency department charts and hospitalization reports.

\section{Variables:}

We assessed demographic variables, including age, sex, prior history of hypertension, diabetes, smoking habit (current or in the preceding six months), cardiovascular diseases, chronic pulmonary diseases, cancer (except for cutaneous epidermoid and basal cell 
carcinoma), and immunocompromised conditions. We analyzed the prior history of headache and family history of headache. Baseline performance was described by using the modified Rankin Scale (mRS) ${ }^{17}$. The gathered the use of Angiotensin-convertingenzyme inhibitors (ACEi), angiotensin-II receptor blockers (AT-II), and systemic steroids.

We counted the percentage of patients that were diagnosed by RT-PCR and by serology ${ }^{10}$ 11. We describe the percentage of patients that had an abnormal result in chest imaging, either x-ray or computerized tomography scan. We graded the severity of the disease according to the American Thoracic Society guidelines for community-acquired pneumonia in mild disease, pneumonia, severe pneumonia and acute distress respiratory syndrome $(A D R S)^{18}$ (supplementary materials). Patients were treated according to the national guidelines for Covid-19 management ${ }^{12}$.

Red flags concerning prior medical history included onset of the headache after 50 years, current or prior history of cancer, or presence of immune compromised states. Red flags regarding the headache included thunderclap onset (defined as abrupt onset of severe headache that reaches the maximum intensity within one minute and lasts for at least five minutes), recent onset of the headache (defined by coincidental with Covid-19 symptoms onset or within the preceding two weeks of the diagnosis), change in the pattern in patients with pre-existent headache (defined by the patient as a similarity equal or lower to $30 \%$ in a $0-100 \%$ scale, compared with the preceding headache), treatment resistance (defined as the complete lack of response to acute medications), precipitation of the headache by sneezing, coughing or exercise; progressive worsening of the headache, ocular pain (defined as pain localized in the eye-ball), presence of cranial 
autonomic features (including lacrimation, nasal congestion, conjunctival injection, rhinorrhea, eyelid edema, ear fullness or ptosis), positional pattern (defined as worsening or improvement after sitting upright, after standing or after lying horizontally), interruption of the sleep (if the patient declares to be woken up by the headache and not solely with the headache), worst headache ever experienced, and strict unilaterality. We describe how many days after the first Covid-19 symptom did the headache start, and if it was already present at the moment of the ED visit.

We analyzed also general and neurologic symptoms. Red flags concerning general symptoms included arthralgias, asthenia, chest pain, cough, cutaneous rash, diarrhea, dyspnea, emesis, expectoration, fever, generalized weakness, light-headedness, odynophagia, and rhinorrhea. With regards to neurologic symptoms, we assessed the presence of anosmia, myalgia, loss of consciousness, visual disturbances, speech disorders, focal or generalized weakness, hypoesthesia, vertigo, ataxia, altered mental status, and seizures.

We analyzed the frequency of typical Covid-19 laboratory abnormalities ${ }^{19}$ on the first laboratory determination, including abnormal leukocyte count (reference value (RV): 410 cell count $\times 10^{9} / \mathrm{L}$ ), Iymphopenia (RV $>900$ cells $\times 10^{9} / \mathrm{L}$ ), increased lactate dehydrogenase $(\mathrm{LDH})(\mathrm{RV}>250 \mathrm{U} / \mathrm{L})$, increased international normalized ratio (INR) (RV $<1.3$ ), increased D-dimer (RV $<500 \mathrm{ng} / \mathrm{dL}$ ), increased C-reactive protein (CRP) $(\mathrm{RV}<5 \mathrm{mg} / \mathrm{L})$, and increased procalcitonin $(P C T)(R V<5 \mathrm{ng} / \mathrm{mL})$. 
Statistical analysis:

We present data nominal variables regarding sex, frequency of comorbidities, prior headache history, prior treatment, red flags, frequency of abnormal laboratory parameters and frequency of general symptoms as frequency and percentage. We describe ordinal variables as Rankin as median and standard deviation (SD) and severity of Covid-19 disease as frequency and percentage per group. Continuous variables as age were presented mean and standard deviation (SD) or median and inter-quartile range (IQR) if the distribution was not normal, determined by Q-Q plots. We did not calculate sample size in advance and the analysis proceeded on the available data. We describe the proportion of patients with headache and Covid-19 that presented each red flag or laboratory abnormality. We compared demographic variables in patients in which headache was the first symptom and the rest of the sample by using Fisher's exact test and independent Student's T-test. In all comparisons, tests were two-tailed and statistical significance was accepted if the $p$ value was $<0.05$. We analyzed the number of days after the first Covid-19 symptom in which headache started by the Kaplan-Meier one minus survival curve. The analysis of the data of this study was preplanned. We used SPSS v.26 (IBM Corp. Armonk, NY) for the statistical analysis. We managed missing data by complete case analysis.

\section{Results:}

During the study period, 576 patients had a positive Covid-19 test. Headache was described by 130 (22.6\%) of them. We excluded eight patients because we were not able to reach them, eight patients because of decease, five because of poor medical condition, three because of cognitive impairment, and two patients rejected to participate. The final 
sample included 104 patients, 66/104 (63.5\%) female, with a mean age of 56.7 (SD: 11.2; minimum 25, maximum 83).

The number of patients with each comorbidity was 36/104 (34.6\%) for hypertension, 12/104 (11.5\%) for diabetes, $12 / 104$ (11.5\%) for smoking habit, 9/104 (8.7\%) for cardiovascular disorders, 24/104 (23.1\%) for pulmonary disorders, 13/104 (12.5\%) for cancer, 5/104 (4.8\%) for immune compromised states. Prior history of headache disorders was described by 60/104 (57.7\%) patients, being migraine in 17/104 (16.3\%) of cases and tension-type headache in 30/104 (28.8\%). In the rest of the cases, diagnosis was not specified. Family history of headache was described by 39/104 (37.5\%) patients. Patients were under chronic treatment with ACEi or AT-II in 30/104 (28.8\%) cases, and steroids in 5/104 (4.8\%) patients. The mean score mRS was 0.1 (SD: 0.4).

Mean time between the onset of symptoms and the ED presentation was 8.8 (SD: 6.4) days. Headache was the first Covid-19 symptom in 27/104 (26.0\%) patients. We did not find differences in demographic variables in patients in whom headache was the first Covid-19 symptom (Table 1). In 91/104 (87.5\%) patients the headache was present at the moment of emergency department visit. The figure 1 shows the Kaplan Meier one minus survival curve showing the onset of the headache over the course of Covid-19. Chest imaging was abnormal in 99/104 (95.2\%) cases. Diagnosis was based on oropharyngeal RT-PCR in 100/104 (96.1\%) cases, sputum RT-PCR in 1/104 (0.96\%) case and serology in $34 / 104(32.7 \%)$. The severity of the disease corresponded to a mild disease in 5/104 (4.8\%) cases, pneumonia in 46/104 (44.2\%) cases, severe pneumonia in 45/104 (43.3\%) and ADRS in 8/104 (7.7\%). Oxygen therapy was needed in 52/104 (50.0\%) patients, non- 
invasive ventilation in 3/104 (2.9\%) patients and invasive ventilation in 3/104 (2.9\%) additional cases.

Table 1. Comparison of demographic variables and prior history between patients in whom headache was the first symptom and the rest of the sample.

\begin{tabular}{|c|c|c|c|}
\hline Variable & $\begin{array}{l}\text { Headache as the } \\
\text { first symptom } \\
\quad(n=27)\end{array}$ & $\begin{array}{l}\text { Rest of the sample } \\
\qquad(n=77)\end{array}$ & $p$-value \\
\hline $\begin{array}{l}\text { Female sex }(n, \%) \\
\qquad(n=104)\end{array}$ & 20/27 (74.1\%) & 46/77 (59.7\%) & $0.247^{\dagger}$ \\
\hline $\begin{array}{l}\text { Age (years) (mean, } \\
\text { SD) }(n=104)\end{array}$ & $67.6(12.2)$ & 56.4 (10.9) & $0.634^{\ddagger}$ \\
\hline $\begin{array}{l}\text { Hypertension (n, \%) } \\
\qquad(n=104)\end{array}$ & 9/27 (33.3\%) & $27 / 77$ (35.1\%) & $>0.999^{\dagger}$ \\
\hline $\begin{array}{l}\text { Diabetes }(n, \%) \\
\qquad(n=104)\end{array}$ & $2 / 27(7.4 \%)$ & 10/77 (13.0\%) & $0.727^{+}$ \\
\hline $\begin{array}{l}\text { Smoking }(n, \%) \\
(n=104)\end{array}$ & $1 / 27(3.7 \%)$ & $11 / 77(14.3 \%)$ & $0.178^{+}$ \\
\hline $\begin{array}{c}\text { Cardiac disorders (n, } \\
\text { \%) }(n=104)\end{array}$ & $3 / 27(11.1 \%)$ & $6 / 77$ (7.8\%) & $0.693^{\dagger}$ \\
\hline
\end{tabular}




\begin{tabular}{|c|c|c|c|}
\hline $\begin{array}{l}\text { Pulmonary disorders } \\
\qquad(\mathrm{n}, \%)(\mathrm{n}=104)\end{array}$ & $4 / 27(14.8 \%)$ & $20 / 77(26.0 \%)$ & $0.296^{\dagger}$ \\
\hline Cancer $(n, \%)(n=104)$ & $1 / 27(3.7 \%)$ & $12 / 77(15.6 \%)$ & $0.176^{+}$ \\
\hline $\begin{array}{l}\text { Immunocompromised } \\
\text { states }(n, \%)(n=104)\end{array}$ & $1 / 27(3.7 \%)$ & $4 / 77(5.2 \%)$ & $>0.999^{\dagger}$ \\
\hline $\begin{array}{l}\text { Prior history of } \\
\text { headache }(n, \%) \\
(n=104)\end{array}$ & $16 / 27(59.2 \%)$ & $44 / 77(57.1 \%)$ & $>0.999^{\dagger}$ \\
\hline $\begin{array}{c}\text { ACE-I / AT-2 use }(n, \%) \\
(n=104)\end{array}$ & $10 / 27(37.0 \%)$ & $20 / 77(26.0 \%)$ & $0.326^{+}$ \\
\hline $\begin{array}{l}\text { Steroids use }(n, \%) \\
\qquad(n=104)\end{array}$ & $2 / 27(7.4 \%)$ & $3 / 77(3.9 \%)$ & $0.609^{\dagger}$ \\
\hline
\end{tabular}

${ }^{\dagger}$ Fisher two-tailed exact test. ${ }^{\ddagger}$ Independent Student T-test. SD: Standard deviation.

Figure 1: Headache onset in the course of Covid-19 disease. Number of days after the first Covid-19 symptom in which headache started. Kaplan-Meier one minus survival curve $(n=104)$. 


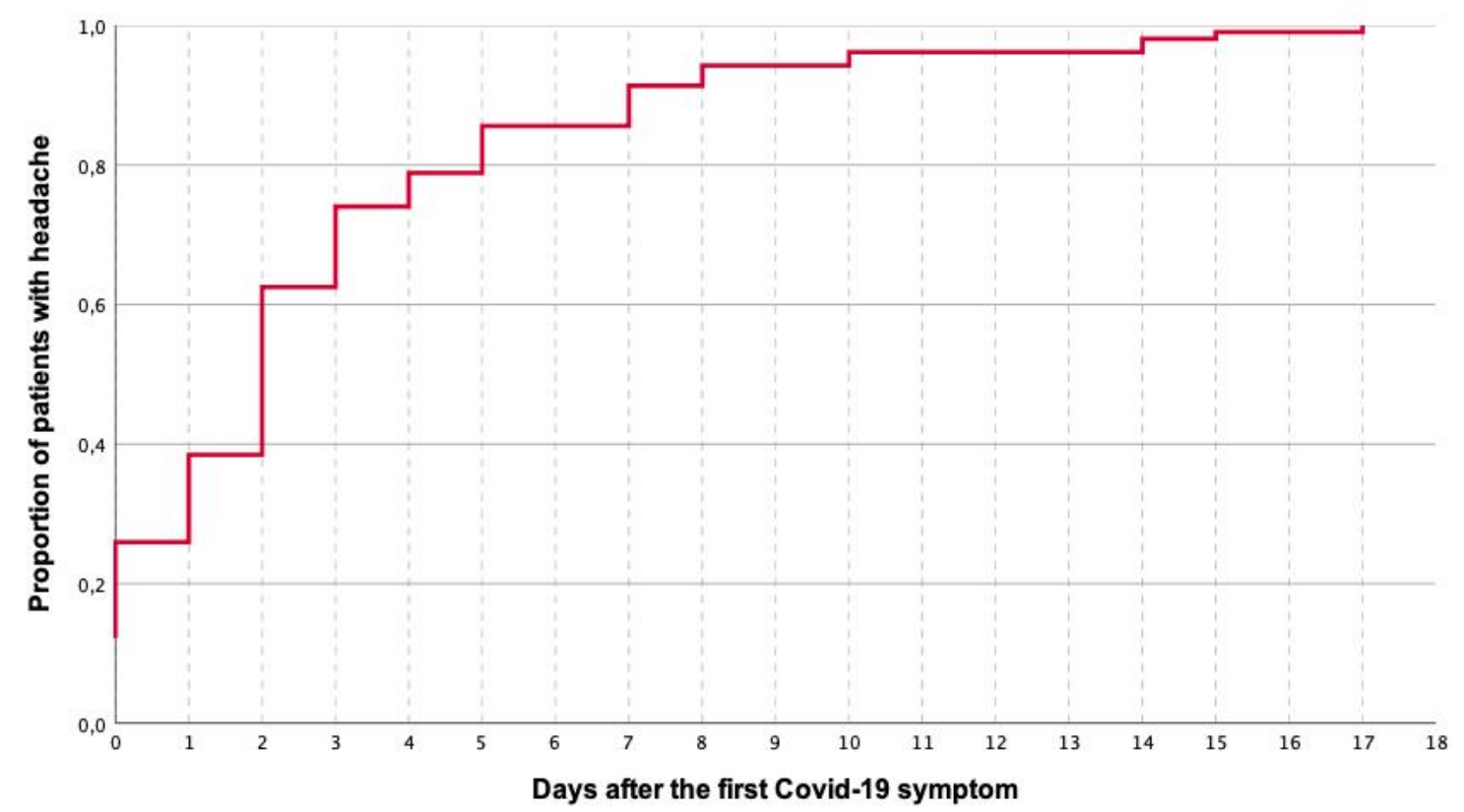

Frequency and type of red flags:

Red flags concerning prior medical history were present in 79/104 (76.0\%) patients. In 99/104 (95.2\%) cases, red flags regarding the headache were present, however, no single red flag was present in more than half of the patients, being the most frequent the change in the pattern of a pre-existent headache, in 51/104 (49.0\%) cases. Table 2 shows the frequency and type of each red flag.

Table 2: Frequency and type of red flags related with prior medical history and related to the headache phenotype.

\begin{tabular}{|c|c|}
\hline \multicolumn{2}{|c|}{ Red flags related to prior medical history } \\
\hline Variable & Frequency (\%) \\
\hline Prior medical history $(n=104)$ & $79 / 104(76.0 \%)$ \\
\hline
\end{tabular}




\begin{tabular}{|c|c|}
\hline Age $>50(n=104)$ & $75 / 104(72.1 \%)$ \\
\hline Neoplasm in history $(n=104)$ & $13 / 104(12.5 \%)$ \\
\hline Pathology of the immune system $(n=104)$ & $5 / 104(4.8 \%)$ \\
\hline \multicolumn{2}{|c|}{ Red flags related to the headache } \\
\hline Variable & Frequency (\%) \\
\hline Pattern change $(n=104)$ & $51 / 104(49.0 \%)$ \\
\hline Recent onset $(n=104)$ & $44 / 104(42.3 \%)$ \\
\hline Worst headache $(n=104)$ & $39 / 104(37.5 \%)$ \\
\hline $\begin{array}{l}\text { Precipitated by sneezing, coughing or exercise } \\
\qquad(n=104)\end{array}$ & $39 / 104(37.5 \%)$ \\
\hline Painful eye ( $n=104)$ & $32 / 104(30.8 \%)$ \\
\hline Progressive headache $(n=104)$ & $18 / 104(17.3 \%)$ \\
\hline Wake up $(n=104)$ & $17 / 104(16.3 \%)$ \\
\hline Strict unilaterality $(n=104)$ & $16 / 104(15.4 \%)$ \\
\hline Treatment resistant $(n=104)$ & $15 / 104(14.4 \%)$ \\
\hline Autonomic features $(n=104)$ & $6 / 104(5.8 \%)$ \\
\hline Positional headache (n=104) & $7 / 104(6.7 \%)$ \\
\hline Sudden onset $(n=104)$ & $5 / 104(4.8 \%)$ \\
\hline
\end{tabular}


The presence of systemic symptoms was described in 104/104 (100\%) patients and neurologic symptoms were described by $86 / 104$ (82.7\%), patients. Table 3 presents the frequency and type of general and neurologic symptoms. There were not any case of visual disturbance, speech disorder, focal weakness, hypoesthesia, ataxia or seizures.

Table 3: Frequency and type of red flags related to the presence of systemic symptoms and the presence of neurologic symptoms.

\begin{tabular}{|c|c|}
\hline \multicolumn{2}{|c|}{ Red flags related to systemic symptoms } \\
\hline Variable & Frequency (\%) \\
\hline Systemic symptoms $(n=104)$ & $104 / 104(100 \%)$ \\
\hline Asthenia $(n=104)$ & $54 / 104(51.9 \%)$ \\
\hline Arthralgia $(n=104)$ & $13 / 104(12.5 \%)$ \\
\hline Chest pain $(n=104)$ & $28 / 104(26.9 \%)$ \\
\hline Cough $(n=104)$ & $89 / 104(85.6 \%)$ \\
\hline Cutaneous Rash ( $n=104)$ & $4 / 104(3.8 \%)$ \\
\hline Diarrhoea $(n=104)$ & 49/104 (47.1\%) \\
\hline Dyspnoea $(n=104)$ & $52 / 104(50.0 \%)$ \\
\hline Emesis $(n=104)$ & $11 / 104(10.6 \%)$ \\
\hline Expectoration $(n=104)$ & $16 / 104(15.4 \%)$ \\
\hline Fever $(n=104)$ & $93 / 104(89.4 \%)$ \\
\hline
\end{tabular}




\begin{tabular}{|c|c|}
\hline Generalized weakness ( $n=104)$ & $23 / 104(22.1 \%)$ \\
\hline Light-headedness ( $n=104)$ & $15 / 104(14.4 \%)$ \\
\hline Odynophagia $(n=104)$ & $18 / 104(17.3 \%)$ \\
\hline Rhinorrhoea $(n=104)$ & 2/104 (1.9\%) \\
\hline \multicolumn{2}{|c|}{ Red flags related to neurologic symptoms } \\
\hline Variable & Frequency (\%) \\
\hline Neurologic symptoms $(n=104)$ & $86 / 104(82.7 \%)$ \\
\hline Anosmia $(n=104)$ & $67 / 104(64.4 \%)$ \\
\hline Myalgia $(n=104)$ & $44 / 104(42.3 \%)$ \\
\hline Altered mental status $(n=104)$ & $10 / 104(9.6 \%)$ \\
\hline Weakness ( $n=104)$ & $2 / 104(1.9 \%)$ \\
\hline Vertigo ( $n=104)$ & $3 / 104$ (2.9\%) \\
\hline Loss of consciousness $(n=104)$ & $6 / 104(5.8 \%)$ \\
\hline
\end{tabular}

Laboratory parameters:

In the first laboratory determination, there was at least one abnormal laboratory value in 98/104 (94.2\%) cases, being the most frequently abnormal CRP, in 84/100 (84.0\%) of cases. Table 4 shows the frequency of each laboratory parameter abnormality. The figure 2 represents the most frequent red flags within the sample. 
Table 4: Frequency of laboratory parameter abnormalities.

\begin{tabular}{|c|c|}
\hline Variable & Frequency (\%) \\
\hline Abnormal leukocyte count $(n=104)$ & $20 / 104(19.2 \%)$ \\
\hline Lymphopenia ( $=104)$ & $22 / 104(21.1 \%)$ \\
\hline Increased LDH ( $=102)$ & $49 / 102(48.0 \%)$ \\
\hline Increased INR $(n=103)$ & $9 / 102(8.7 \%)$ \\
\hline Increased D-dimer $(n=100)$ & $54 / 100(54.0 \%)$ \\
\hline Increased CRP $(n=100)$ & $84 / 100(84.0 \%)$ \\
\hline Increased PCT $(n=79)$ & $3 / 79(3.8 \%)$ \\
\hline
\end{tabular}

LDH: Lactate dehydrogenase, INR: international normalized ratio. CRP: C-reactive protein. PCT: Procalcitonin. 


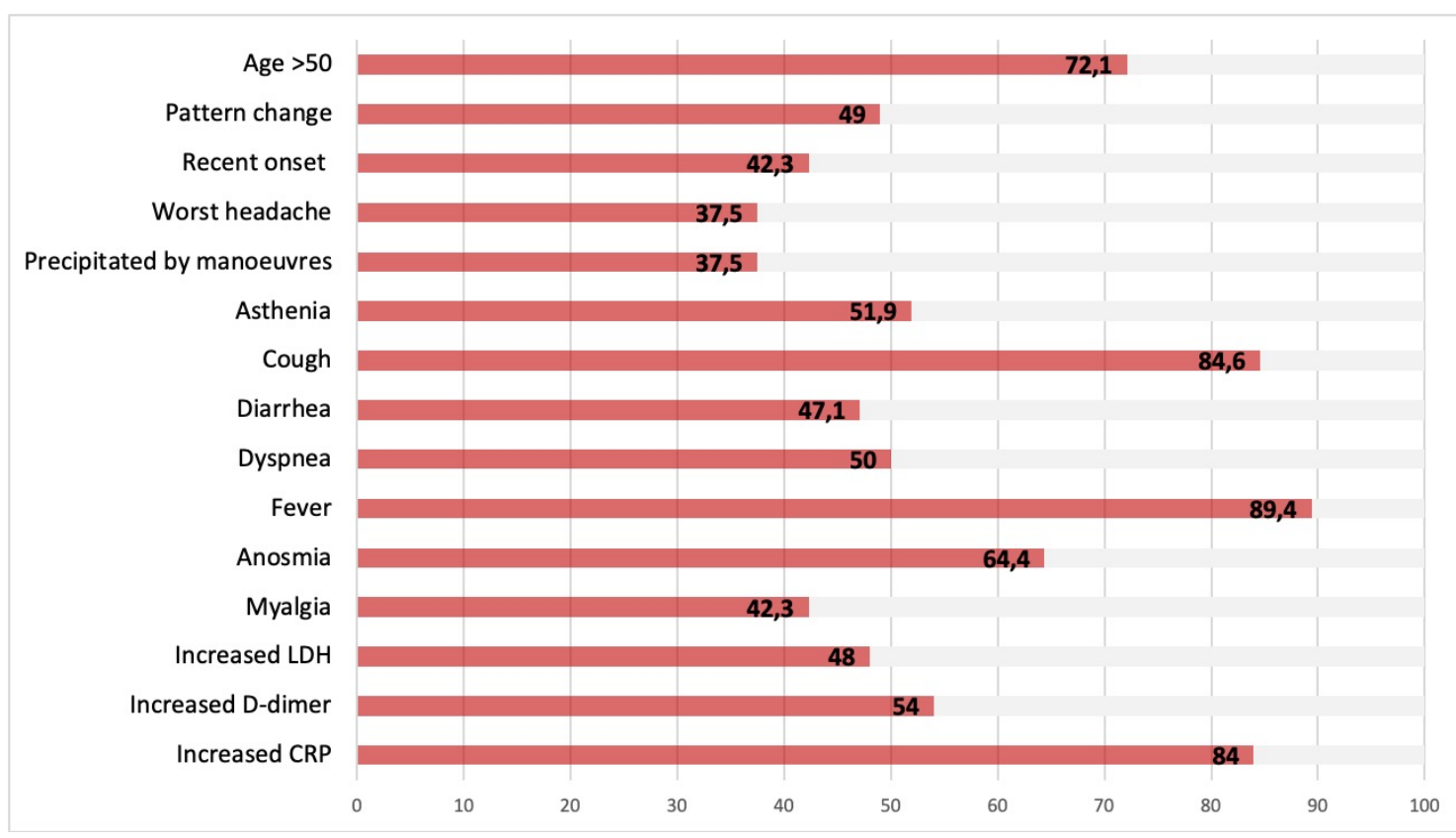

Figure 2: Most common red flags in hospitalized patients with Covid-19 disease and headache.

\section{Discussion:}

In the present study, we analyzed the frequency and type of headache red-flags in patients with Covid-19. We assessed if the presence of Covid-19 in headache patients could be suspected by the presence of other typical Covid-19 symptoms, red flags related with the headache or laboratory abnormalities. For this, we systematically tested the main red flags in a series of patients with confirmed Covid-19 infection. In our sample, red flags were common, but there was not a single, perfect, red flag. This reinforces how important the anamnesis is, and in particular in headache medicine ${ }^{13}$.

There are many different lists of red flags ${ }^{14,15,20,21}$. The secondary headache Special Interest Group of the International Headache Society recently did a comprehensive review that included the main red and orange flags ${ }^{15}$. In the case of headache in Covid- 
19 patients, items like the presence of systemic symptoms, including fever, the precipitation by sneezing or coughing and the recent onset or change in the pattern were particularly frequent.

We focused on the frequency of red flags, while the sensitivity in the detection of a potentially life-threatening condition, should be the priority ${ }^{22,23}$. Future studies should analyze the specificity of the red flags with regards to primary headache or compared with other secondary headache disorders. Mean age of our patients notably exceeded the typical age of primary headache patients ${ }^{24,25}$. Median age of the confirmed cases in Spain is 60 (IQR: 46-78) ${ }^{26}$. The role of cancer or immunosuppression as red flags in Covid19 is disputable, but the Covid-19 diagnosis in those patients cannot be missed.

Concerning the headache, our study was not focused on the phenotypic characterization of the acute headache attributed to Covid-19 infection 9,13 , but to the presence of atypical presentations of the headache. A remarkable result of our study was the fact that the red flag "recent onset of headache" was not as frequent as expected, being present in $42 \%$ of the patients. This could be related with the high frequency of prior history of headache, in $57 \%$ of the patients, a prevalence that exceeds the estimated prevalence of primary headache disorders 24,25 . This fact probably increased the frequency of the red flag "change in the pattern", in $49 \%$ of the cases. We deem this hypothesis reinforced by the frequency of "worst headache ever" frequency, in 37\% of patients. Therefore, clinicians must be aware of new onset headache or changes of headache pattern in patients with previous primary headache disorders. 
Another finding that deserves further interpretation is the frequency of "treatment resistance". The potential risk of non-steroidal anti-inflammatory drugs and ACE inhibitors became popular since the first stages of the pandemic, despite the evidence at that time was scarce ${ }^{27}$. Some patients might be reluctant to acute medication. Given the disability that severe headache poses ${ }^{24}$, they should be adequately counselled ${ }^{28}$.

The prevalence of headache in our sample was $22 \%$, almost two-fold than the previously reported in the literature ${ }^{7-9}$. This could be explained because we enquired every patient about the presence of headache, but the real prevalence of headache in Covid-19 might be underestimated ${ }^{6}$. Studies that systematically analyzed the prevalence of olfactory disorders reported a higher prevalence ${ }^{29-31}$ than the first general series ${ }^{7,8}$ as well.

The present study has important limitations. The first is the possible selection bias: we studied hospitalized patients and therefore the severity of the disease in these patients might be worse. In our sample, 95\% of the patients had pneumonia and $7.7 \%$ developed ADRS, in contrast with the $53.9 \%$ and $6.7 \%$ reported frequency in the nation-wide surveillance reports ${ }^{26}$. Due to the shortage of reactive and protective equipment, at the onset of the pandemic only the severest cases were tested, so further studies should analyze the sensitivity of red flags including patients managed in primary care. Another limitation is that on the other extreme, we could not test thirteen patients due to decease or poor medical condition. This could underestimate the frequency of some other red flags, as laboratory parameters, expected to be worse in the most severely affected patients ${ }^{19}$. 
The external validity of the study should be contextualized to the setting, a public hospital. Given the disparity in the reports across the nations, multicentric and multinational studies should be performed to clarify if the headache presentation is uniform or not. Another relevant point is that the Covid-19 headache phenotype might be defined not only by the presence of red flags, but also with a distinct headache phenotype. Future studies should characterize it and evaluate if there is any specific presentation. The frequency and type of red flags in patients who present with headache as the initial symptom of Covid-19 should also be analyzed in future studies. Both sensitivity and specificity of red flags in Covid-19 patients should be properly studied. We hope that the estimations observed in our study might help in the design of future specific studies.

\section{Conclusion:}

In patients with Covid-19 that described headache, red flags were frequent. There was not any universal red, being necessary the integration of them. Systemic symptoms were present in all cases, red flags concerning the headache were described in almost all cases and red flags related with prior medical history or the presence of neurological symptoms were also common. Laboratory parameters were abnormal in most cases, being the most frequently abnormal parameter the C-reactive protein. 


\section{References:}

1. World Health Organization. Director-General's opening remarks at the media briefing on COVID-19. 11 March 2020. World Health Organization. https://www.who.int/dg/speeches/detail/who-director-general-s-openingremarks-at-the-media-briefing-on-covid-19---11-march-2020 Accessed on May $21^{\text {st }}, 2020$.

2. World Health Organization. Coronavirus disease (COVID-19). Situation report 121. https://www.who.int/docs/default-source/coronaviruse/situationreports/20200520-covid-19-sitrep-121.pdf?sfvrsn=c4be2ec6 2 Accessed on May $21^{\text {st }}, 2020$

3. Klein BC, Busis NA. COVID-19 is catalyzing the adoption of teleneurology. Neurology 2020, 10.1212/WNL.0000000000009494.

4. Chowdhury D, Datta D. Managing migraine in the times of COVID-19 Pandemi. Ann Indian Acad Neurol 2020;23(suppl 1):S33-S39.

5. Silvestro M, Tessitore A, Tedeschi G, Russo A. Migraine in the time of COVID-19. Headache 2020;60(5):988-989.

6. Belvis R. Headaches during COVID-19: My clinical case and review of the literature. Headache 2020. Doi: 10.1111/head.13841.

7. Guan W, Ni Z, Hu Y, et al. Clinical characteristics of coronavirus disease 2019 in China. N Engl J Med 2020;382(18):1708-1720.

8. Mao L, Jin H, Wang $M$, et al. Neurologic manifestations of hospitalized patients with coronavirus disease 2019 in Wuhan, China. JAMA Neurol 2020; e201127.

9. Bolay H, Gül A, Baykan B. COVID-19 is a Real Headache. Headache 2020. Doi:10.1111/head.13856. 
10. World Health Organization. Clinical management of severe acute respiratory infection when novel coronavirus (2019- nCoV) infection is suspected: interim guidance. January 28, 2020. https://www.who.int/docs/defaultsource/coronaviruse/ clinical-management-of-novel-cov.pdf. Accessed on May $21^{\text {st }}, 2020$.

11. World Health Organization. Coronavirus disease (COVID-19) technical guidance: laboratory testing for 2019-nCoV in humans https://www.who.int/emergencies/ diseases/novel-coronavirus-2019/technical $\quad$-guidance/laboratory-guidance. Accessed May 16, 2020.

12. Ministry of Health. Technical documents. Hospital management of COVID-19. $\begin{array}{lll}\text { Version } & \text { March } & 2020 .\end{array}$ https://www.mscbs.gob.es/profesionales/saludPublica/ccayes/alertasActual/nC ov-China/documentos/Protocolo manejo clinico ah COVID-19.pdf. Accessed on May $21^{\text {st }}, 2020$.

13. Headache Classification Committee of the International Headache Society (IHS). The International Classification of Headache Disorders, 3rd edition. Cephalalgia 2018;38:1-211.

14. Nye BL, Ward TN. Clinic and emergency room evaluation and testing of headache. Headache 2015;55(9):1301-1308.

15. Do TP, Remmers A, Schytz HW, et al. Red and orange flags for secondary headaches in clinical practice. SNNOOP10 list. Neurology 2019;92:134-144.

16. Von Elm E, Altman DG, Egger $M$, et al. The Strengthening the Reporting of Observational Studies in Epidemiology (STROBE) statement: guidelines for reporting observational studies. PLoS Med 2007;4(10):e296. 
17. Quinn TJ, Dawson J, Walters MR, Lees KR. Reliability of the modified Rankin Scale: a systematic review. Stroke 2009;40(10):3393-3395.

18. Metlay JP, Waterer GW, Long AC, et al. Diagnosis and treatment of adults with community-acquired pneumonia: an official clinical practice guideline of the American Thoracic Society and Infectious Disease Society of America. Am J Respir Crit Care Med 2019;200(7):e45-e67.

19. Lippi G, Plebani M. Laboratory abnormalities in patients with COVID-19 infection. Clin Chem Lab Med 2020. Doi: 10.1515/cclm-2020-0198.

20. Filler L, Akhter M, Nimlos P. Evaluation and management of emergency department headache. Semin Neurol 2019;39:20-26.

21. Giamberardino MA, Affiaitati G, Costantini R, et al. Acute headache management in emergency department. A narrative review. Intern Emerg Med 2015(1):109117.

22. Chassé M, Fergusson DA. Diagnostic accuracy studies. Semin Nucl Med 2019;49(2):87-93.

23. Godwin SA, Cherkas DS, Panagos PD, et al. Clinical policy: critical issues in the evaluation and management of adult patients presenting to the emergency department with acute headache. Ann Emerg Med. 2019;74:e41-e74.

24. GBD 2016 Neurology Collaborators. Global, regional, and national burden of neurological disorders, 1990-2016: a systematic analysis for the Global Burden of Disease Study 2016. Lancet Neurol 2019;18:459-480.

25. Atlas 2018 about the impact and situation of migraine in Spain. Editorial Universidad de Sevilla 2018. ISBN: 978-84-472-2832-4. 
26. National Epidemiologic Surveillance Network. Daily report on the COVID-19 situation. Report number 31, March $14^{\text {th }}, 2020$. Available on: https://www.isciii.es/QueHacemos/Servicios/VigilanciaSaludPublicaRENAVE/Enf ermedadesTransmisibles/Documents/INFORMES/Informes\%20COVID19/Informe\%20n-\%2031.\%20Situación\%20de\%20COVID19\%20en\%20España\%20a\%2014\%20de\%20mayo\%20de\%202020.pdf Accessed on May $19^{\text {th }}, 2020$.

27. Giollo A, Adami G, Gatti D, et al. Coronavirus disease 19 (Covid-19) and nonsteroidal anti-inflammatory drugs (NSAID). Ann Rheum Dis 2020;annrheumdis2020-217598.

28. Maassen Van den Brink A, de Vries T, Jan Danser AH. Headache medication and the COVID-19 pandemic. J Headache Pain 2020;21(1):38.

29. Lechien JR, Chiesa-Estomba CM, de Siati DR, et al. Olfactory and gustatory dysfunctions as a clinical presentation of mild-to-moderate forms of the coronavirus disease (COVID-19): a Multicenter European Study. Eur Arch Otorhinolaryngol 2020; 1-11.

30. Beltrán-Corbellini A, Chico-García JL, Martínez-Poles J, et al. Acute-onset smell and taste disorders in the context of COVID-19: a pilot multicentre polymerase chain reaction based-control study. Eur J Neurol 2020. Doi:10.1111/ene.14273.

31. Angelo Vaira L, Deiana G, Fois AG, et al. Objective evaluation of anosmia and ageusia in COVID-19 patients: single-center experience on 72 cases. Head Neck 2020. Doi: $10.1002 /$ hed.26204. 


\section{Figure legend:}

Table 1: Comparison of demographic variables and prior history between patients in whom headache was the first symptom and the rest of the sample.

Table 2: Frequency and type of red flags related with prior medical history and related to the headache phenotype.

Table 3: Frequency and type of red flags related to the presence of systemic symptoms and the presence of neurologic symptoms.

Table 4: Frequency of laboratory parameter abnormalities. LDH: Lactate dehydrogenase, INR: international normalized ratio. CRP: C-reactive protein. PCT: Procalcitonin.

Figure 1: Headache onset in the course of Covid-19 disease. Number of days after the first Covid-19 symptom in which headache started. Kaplan-Meier one minus survival curve $(n=104)$.

Figure 2: Most common red flags in hospitalized patients with Covid-19 disease and headache. 


\section{Supplementary materials:}

Supplementary table 1:

Severity of Covid-19 disease according to the American Thoracic Society guidelines for community-acquired pneumonia.

\begin{tabular}{|c|c|}
\hline Severity & Description \\
\hline Mild illness & $\begin{array}{l}\text { Patients with uncomplicated upper respiratory tract viral } \\
\text { infection symptoms and have non-specific symptoms such } \\
\text { as fever, fatigue, cough (with or without sputum } \\
\text { production), anorexia, malaise, muscle pain, sore throat, } \\
\text { dyspnea, nasal congestion, diarrhea, nausea or vomiting } \\
\text { or }\end{array}$ \\
\hline Pneumonia & $\begin{array}{l}\text { Presence of pneumonia but no signs of severe pneumonia } \\
\text { and no need for supplemental oxygen. } \\
\text { CURB scale } \leq 1 \text {. }\end{array}$ \\
\hline $\begin{array}{l}\text { Severe } \\
\text { pneumonia }\end{array}$ & $\begin{array}{l}\text { Confirmed respiratory infection, plus one of the following: } \\
\text { 1) Respiratory rate }>30 \text { breaths/min. } \\
\text { 2) Severe respiratory distress. } \\
\text { 3) } \mathrm{SpO} 2 \leq 93 \% \text { on room air. }\end{array}$ \\
\hline $\begin{array}{l}\text { Acute } \\
\text { respiratory }\end{array}$ & $\begin{array}{l}\text { Onset: within } 1 \text { week of a known clinical insult or new or } \\
\text { worsening respiratory symptoms. }\end{array}$ \\
\hline
\end{tabular}




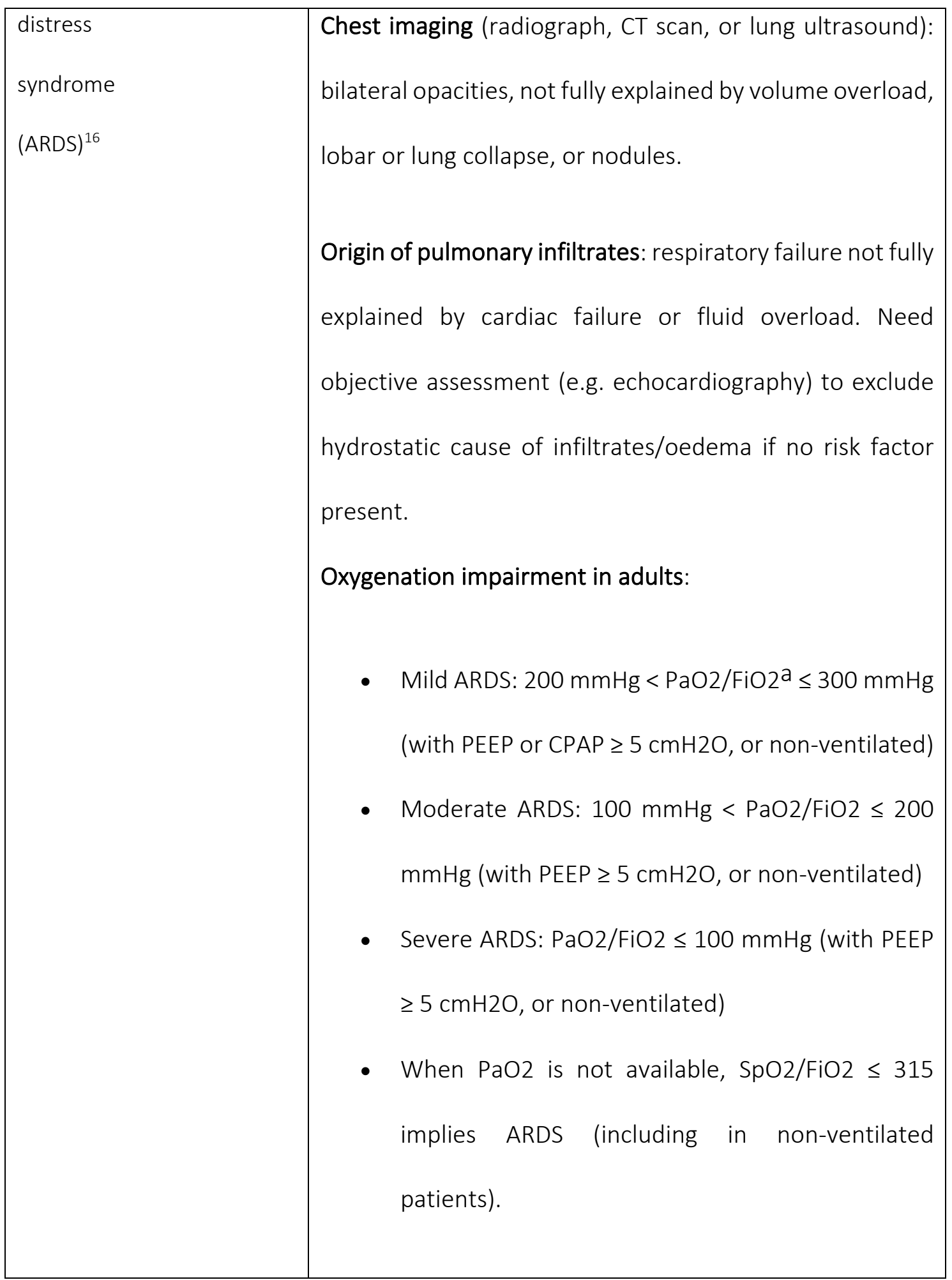

Sp: Saturation percentage. ADRS: Acute Distress Respiratory Syndrome. CT: Cranial Tomography. PaO2: Partial pressure of Oxygen. FiO2: Fraction of inspired Oxygen. PEEP: Positive end-expiratory pressure. CPAP: Continuous positive airway pressure.

Adapted from: 
32. Metlay JP, Waterer GW, Long AC, et al. Diagnosis and treatment of adults with community-acquired pneumonia: an official clinical practice guideline of the American Thoracic Society and Infectious Disease Society of America. Am J Respir Crit Care Med 2019;200(7):e45-e67. 
VII. DISCUSSION 


\section{Discussion}

\subsection{Main findings of the studies}

In the present dissertation project, red flags were characterized in three conditions that represent the full spectrum of headache disorders, from the most benign primary headache disorder (i.e., TTH) to a life-threatening condition (i.e., CVST). The main common result is that red flags can be helpful in the management of headache patients in the ED. In our study, red flags were present in patients with selected secondary causes: CVST and headache attributed to Covid-19. In contrast, red flags were also present in some patients with an incorrect diagnosis of TTH, suggesting that education in headache disorders should still be improved for ED physicians and triage staff.

The aim of this study was to assess how frequent red flags were among people with each of the three predefined diseases or diagnoses. An important application of this study is the use of red flags as tests in which a high degree of sensitivity is required. The definition of sensitivity, or true positive rate, is the proportion of people with a disease who have a positive test result. Considering the four possible results of a test (Table 15), sensitivity is the proportion of those detected as "diseased" (A) divided by the total number of patients with the disease $(A+C)$ (Parikh et al, 2008). 
Table 15. Evaluation of sensitivity and specificity of a test.

\begin{tabular}{|c|c|c|}
\hline & Disease present & Disease absent \\
\hline Test positive & A (True positive) & B (False positive) \\
\hline Test negative & C (False negative) & D (True negative) \\
\hline
\end{tabular}

When represented with a formula, the sensitivity of a test is as follows:

$$
\text { Sensitivity }=\frac{\text { Patients } \text { with the disease detected by the test }}{\text { Patients } \text { with the disease }}
$$

Sensitivity can then be represented by using the four categories from Table 15:

$$
\text { Sensitivity }=\frac{A \text { (True positive })}{A \text { (True positive })+C(\text { False negative })}
$$

In the case of red flags, sensitivity can be represented by the following formula:

$$
\text { Sensitivity }=\frac{\text { Patients with the disease detected by the red flag }}{\text { Patients } \text { with the disease }}
$$

In the present study, the frequency of red flags in patients with CVST, Covid-19 or presumed TTH were estimated. In the first two cases, all of the patients included in the study had the disease; therefore, the total number of patients included makes up the denominator. It was not possible to estimate the specificity of the red flags with the current data, given that, for that purpose, patients who do not have the disease would need to be included in the sample: 


$$
\text { Specificity }=\frac{D(\text { True negative })}{B(\text { False positive })+D(\text { True negative })}
$$

Because of the design of these studies, patients were not included if they did not have the disease. Sensitivity was prioritized over specificity because the main purpose of the ED physicians is to detect patients with serious or life-threatening disorders, and not to properly classify patients (Godwin et al, 2019).

Considering the design of this and other similar studies, the sensitivity of red flags may be underestimated. CVST, Covid-19 and many other secondary headache disorders are evolving conditions (Singh et al, 2018). Red flags may not be present at the precise moment of ED presentation but may appear later during the course of the disease (Cumurciur et al, 2005). In the case of CVST, the moment of ED presentation was studied because it is the setting where red flags are most clinically relevant.

\subsection{Tension-type headache}

Red flags were assessed in TTH because this disorder is supposed to be the most benign and innocuous primary headache disorder (Jensen, 2018). Ironically, this is probably what makes it dangerous: a TTH diagnosis implies a benign headache with no need for further testing, which makes TTH misdiagnosis particularly harmful. Given the lack of specific criteria for most secondary headache disorders (Headache Classification committee, 2018) and the fact that many secondary headache disorders, including CVST 
(Metha et al, 2019) and Covid-19 (Trigo et al, 2020), may mimic the TTH phenotype (Cristal et al, 2011), TTH diagnosis should not be misplaced.

\subsubsection{Epidemiology of tension-type headache}

TTH is the second most prevalent disease in the world and the most prevalent headache disorder (Global Burden of Disease 2017 Disease and Injury Incidence and Prevalence collaborators, 2018). Its prevalence also seems to be increasing. A Danish study observed that in 2001, prevalence was 87\%, compared with 79\% in 1989 (Lyngberg et al, 2005). In that sample, 84\% of patients studied in 1989 experienced better outcomes, when comparing the frequency of episodes in 1989 and 2001 . The factors that were associated with a poor outcome were coexisting migraine, not being married, and sleep disorders (Lyngberg et al, 2005). In studies done in students, dissatisfaction with studies and depressed mood were associated with the presence of TTH in males and females, respectively (Lebedeva et al, 2017). The prevalence of TTH varies depending on the study, and it is frequently underreported in hospital-based and outpatient clinicbased series, as most TTH patients do not see a doctor for the headache (Crystal et al, 2010). Despite that the prevalence of TTH is between two and four times higher than migraine, the number of scientific publications is ten times higher for migraine $(40,868$ vs. 3,908). Figure 6 shows the number of scientific publications on PubMed.gov from inception to November 11, 2020 (National Library of Medicine, National Center for Biotechnology Information, 2020). 


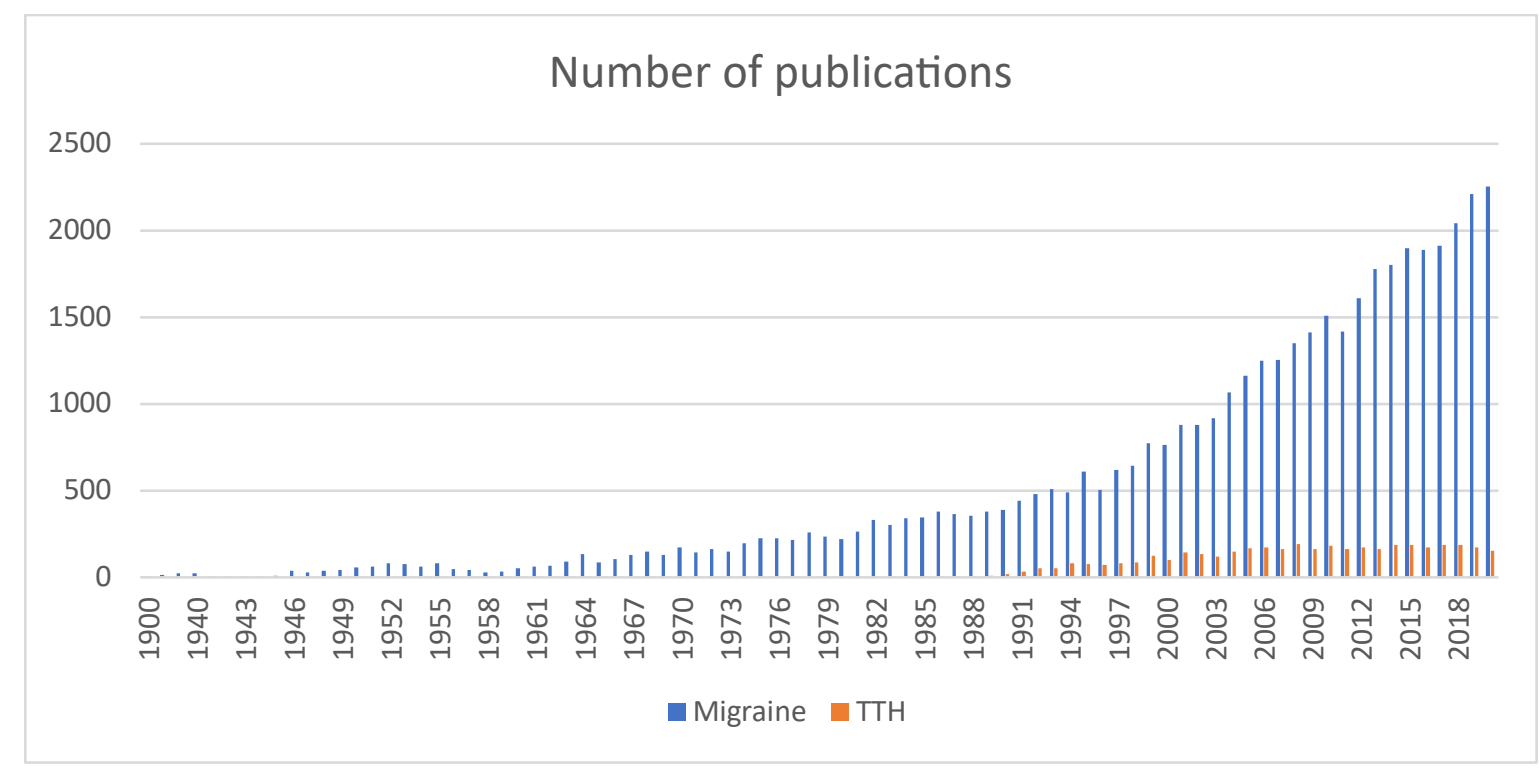

Figure 6. Number of publications per year related to migraine (blue) or tension-type headache (TTH) (orange) indexed in PubMed.gov from inception to November 11, 2020. Created with Excel by David García-Azorín.

Despite the higher severity of migraine attacks, compared with TTH episodes, there might exist publication bias related to commercial interests. The 10:1 proportion is not expected to change in the near future. According to the number of planned or ongoing studies on ClinicalTrials.gov, there are 12 times more studies focusing on migraine compared with TTH (1,051 vs. 82) (United States National Library of Medicine, ClinicalTrials.gov). Another remarkable example is that in 2011, the World Health Organization created the Atlas of Headache Disorders (World Health Organization, 2011); however, in Spain in 2018, the publication was named the Atlas of Migraine (Garrido Cumbera et al, 2018). 


\subsubsection{Diagnostic criteria for TTH}

The ICHD-3 differentiates between episodic and chronic TTH (CTTH), similarly to episodic and chronic migraine, based on the frequency of the episodes in the three months preceding diagnosis. In addition, episodic TTH (ETTH) is sub-divided into infrequent and frequent, depending on the annual and monthly frequency. Despite the terms "low-frequency episodic migraine" and "high-frequency migraine" are frequently used, they are not defined in the ICHD-3 (Headache Classification committee, 2018).

According to the ICHD-3, the only phenotypic difference between ETTH and CTTH is that mild nausea is accepted in patients with CTTH but not in ETTH patients. Table 16 summarizes ICHD-3 criteria for TTH.

Table 16. ICHD-3 criteria for 2. Tension type headache.

\begin{tabular}{|l|l|}
\hline Criterion A & $\begin{array}{l}\text { Infrequent episodic tension-type headache: At least } 10 \text { episodes of } \\
\text { headache occurring on }<1 \text { day/month on average ( }<12 \text { days/year) } \\
\text { and fulfilling criteria B-D } \\
\text { Frequent episodic tension-type headache: At least } 10 \text { episodes of } \\
\text { headache occurring on 1-14 days/month on average for }>3 \text { months } \\
(\geq 12 \text { and }<180 \text { days/year) and fulfilling criteria B-D } \\
\text { Chronic tension-type headache: Headache occurring on } \geq 15 \\
\text { days/month on average for } 3 \text { months ( } \geq 180 \text { days/year), fulfilling } \\
\text { criteria B-D }\end{array}$ \\
\hline
\end{tabular}




\begin{tabular}{|l|l|}
\hline Criterion B & $\begin{array}{l}\text { Lasting from } 30 \text { minutes to seven days } \\
\text { 1. bilateral location } \\
\text { 2. pressing or tightening (non-pulsating) quality } \\
\text { 3. mild or moderate intensity }\end{array}$ \\
4. not aggravated by routine physical activity such as walking or \\
climbing stairs \\
Both of the following: \\
1. no nausea or vomiting* \\
2. no more than one of photophobia or phonophobia \\
\hline Criterion E
\end{tabular}

*In chronic TTH, mild nausea can be present. ICHD: international classification of headache disorders.

TTH has been present since the first edition of the ICHD (Headache Classification committee, 1988), and its criteria remains relatively unaltered. The main change that has been made is the way in which other headache disorders are ruled out. Table 17 summarizes the main differences between the four editions of the ICHD (Headache Classification committee, 1988; Headache Classification committee, 2004; Headache Classification committee, 2013; Headache Classification committee, 2018). 
Table 17. ICHD criteria for 2. Tension type headache: from the first edition to the third version.

\begin{tabular}{|c|c|c|c|c|}
\hline Criterion & ICHD-1 (1988) & ICHD-2 (2004) & ICHD-3 beta (2013) & ICHD-3 (2018) \\
\hline A & Frequency criterion & Frequency criterion & Frequency criterion & Frequency criterion \\
\hline B & $\begin{array}{l}\text { Headache lasting from } \\
30 \text { minutes to } 7 \text { days }\end{array}$ & $\begin{array}{l}\text { Headache lasting from } \\
30 \text { minutes to } 7 \text { days }\end{array}$ & $\begin{array}{l}\text { Lasting from } 30 \text { minutes } \\
\text { to } 7 \text { days. }\end{array}$ & $\begin{array}{l}\text { Lasting from } 30 \text { minutes } \\
\text { to } 7 \text { days. }\end{array}$ \\
\hline C & 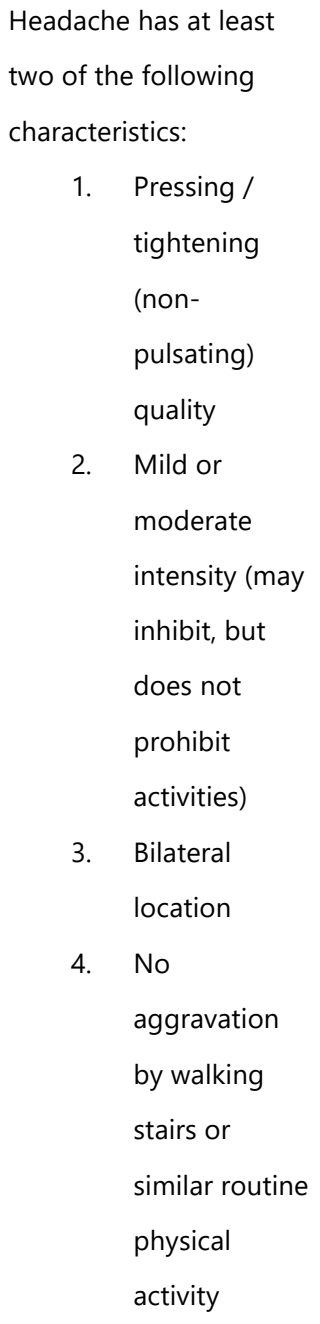 & $\begin{array}{l}\text { Headache has at least } \\
\text { two of the following } \\
\text { characteristics: } \\
\text { 1. } \\
\text { Bilateral } \\
\text { location } \\
\text { 2. } \text { Pressing / } \\
\text { tightening } \\
\text { (non- } \\
\text { pulsating) } \\
\text { quality } \\
\text { 3. Mild or } \\
\text { moderate } \\
\text { intensity } \\
\text { Not } \\
\text { aggravated by } \\
\text { routine } \\
\text { physical } \\
\text { activity such } \\
\text { as walking or } \\
\text { climbing stairs }\end{array}$ & $\begin{array}{l}\text { At least two of the } \\
\text { following four } \\
\text { characteristics: } \\
\text { 1. } \text { Bilateral } \\
\text { location } \\
\text { 2. } \text { Pressing or } \\
\text { tightening } \\
\text { (non- } \\
\text { pulsating) } \\
\text { quality } \\
\text { 3. Mild or } \\
\text { moderate } \\
\text { intensity } \\
\text { Not } \\
\text { aggravated by } \\
\text { routine } \\
\text { physical } \\
\text { activity such } \\
\text { as walking or } \\
\text { climbing stairs }\end{array}$ & $\begin{array}{l}\text { At least two of the } \\
\text { following four } \\
\text { characteristics: } \\
\text { 1. } \\
\text { Bilateral } \\
\text { location } \\
\text { 2. } \text { Pressing or } \\
\text { tightening } \\
\text { (non- } \\
\text { pulsating) } \\
\text { quality } \\
\text { 3. Mild or } \\
\text { moderate } \\
\text { intensity } \\
\text { Not } \\
\text { aggravated by } \\
\text { routine } \\
\text { physical } \\
\text { activity such } \\
\text { as walking or } \\
\text { climbing stairs }\end{array}$ \\
\hline D & $\begin{array}{l}\text { Both of the following: } \\
\begin{aligned} \text { 1. No nausea or } \\
\text { vomiting } \\
\text { (anorexia may } \\
\text { occur) } \\
\text { 2. Photophobia } \\
\text { and }\end{aligned}\end{array}$ & \begin{tabular}{|l} 
Both of the following: \\
$\begin{aligned} \text { 1. } & \text { No nausea or } \\
& \text { vomiting } \\
& \text { (anorexia may } \\
& \text { occur) } \\
\text { 2. } & \text { No more than } \\
& \text { one of }\end{aligned}$
\end{tabular} & $\begin{array}{l}\text { Both of the following: } \\
\begin{aligned} \text { 1. No nausea or } \\
\text { vomiting } \\
\text { 2. No more than } \\
\text { one of } \\
\text { photophobia }\end{aligned}\end{array}$ & $\begin{array}{l}\text { Both of the following: } \\
\begin{aligned} \text { 1. } & \text { No nausea or } \\
& \text { vomiting } \\
\text { 2. } & \text { No more than } \\
& \text { one of } \\
& \text { photophobia }\end{aligned}\end{array}$ \\
\hline
\end{tabular}




\begin{tabular}{|c|c|c|c|c|}
\hline & $\begin{array}{l}\text { phonophobia } \\
\text { are absent, or } \\
\text { one but not } \\
\text { the other is } \\
\text { present }\end{array}$ & $\begin{array}{l}\text { photophobia } \\
\text { or } \\
\text { phonophobia }\end{array}$ & $\begin{array}{l}\text { or } \\
\text { phonophobia }\end{array}$ & $\begin{array}{l}\text { or } \\
\text { phonophobia }\end{array}$ \\
\hline$E$ & $\begin{array}{l}\text { At least one of the } \\
\text { following: } \\
\text { 1. History, physical and } \\
\text { neurological } \\
\text { examinations do not } \\
\text { suggest secondary } \\
\text { disorders } \\
\text { 2. History and/or } \\
\text { physical and/or } \\
\text { neurological } \\
\text { examinations do suggest } \\
\text { such disorder but is } \\
\text { ruled out by appropriate } \\
\text { investigations. } \\
\text { 3. Such disorder is } \\
\text { present, but tension- } \\
\text { type headache does not } \\
\text { occur for the first time in } \\
\text { close temporal relation } \\
\text { to the disorder. }\end{array}$ & $\begin{array}{l}\text { Not attributed to } \\
\text { another disorder }\end{array}$ & $\begin{array}{l}\text { Not better accounted for } \\
\text { by another ICHD } \\
\text { diagnosis }\end{array}$ & $\begin{array}{l}\text { Not better accounted for } \\
\text { by another ICHD-3 } \\
\text { diagnosis }\end{array}$ \\
\hline
\end{tabular}

ICHD: international classification of headache disorders.

Problems with TTH diagnosis

One of the pitfalls of TTH diagnosis is the fact that its classification is more based on what it is not rather than what it is. The ICHD-3 criteria only include bilateral topography and pressing quality as positive features (Headache Classification committee, 2018). Most other criteria refer to the absence of typical migraine features (Figure 7) and the absence of symptoms or signs that suggest other headache disorders. A multicentre 
study of 1832 patients that aimed to validate the ICHD 3-beta criteria found 150 (8.1\%) patients that fulfilled criteria. The authors suggested that the core criteria were based largely on the absence of pulsating headache and the lack of aggravation by routine physical activity (Kang et al, 2018).
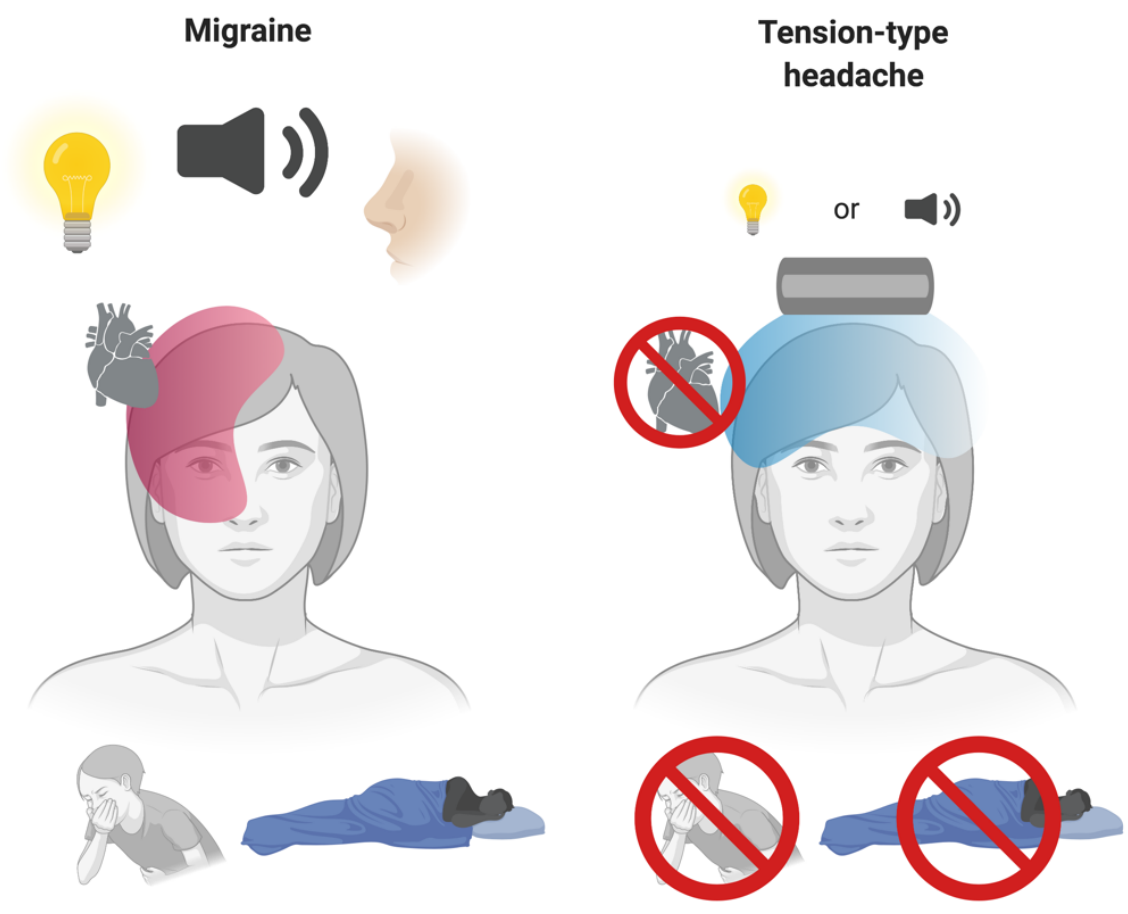

Figure 7. Graphical representation of ICHD-3 criteria for migraine and TTH. Created with BioRender by David García-Azorín.

The phenotype of TTH is relatively unspecific. Many other headache disorders may present with frontal pressing pain: migraine (Kelman, 2007), hemicrania continua (Cittadini et al, 2010), nummular headache (Trigo et al, 2019), new daily persistent headache (Yamani et al, 2019), external-pressure headache (Krymchantowski, 2010), supratrochlear neuralgia (Pareja et al, 2017), supraorbital neuralgia (Caminero et al, 2001), lacrimal neuralgia (Pareja et al, 2013), paroxysmal pressing headache (Pareja et al, 
2019), and the vast majority of secondary headache disorders (Cristal et al, 2011; Headache Classification committee, 2018). If TTH is diagnosed based only on "positive findings," namely the phenotype, it can therefore be misdiagnosed. In contrast, the presence of a single "atypical" feature, or even more, a red flag, may throw into question the TTH diagnosis.

In this study, a simple strategy was adopted: to assess whether the discharge reports included any statement that made TTH diagnosis incompatible. It was observed that in $87.5 \%$ of the reports, there were elements of anamnesis that made the diagnosis of TTH incompatible, while in $21 \%$ of the cases, there were prior history of headache disorders that made the TTH diagnosis incompatible. We classified the discrepancies in the anamnesis into five groups: presence of symptoms that were highly suggestive of another headache disorder, presence of abnormal neurological symptoms or signs, presence of red flags related to the headache itself, systemic symptoms and close temporal relationship to an event able to produce the headache.

One of the most frequent diagnoses in the ED setting is "headache not better specified" (Dermitzakis et al, 2010). This name implies a certain degree of uncertainty, and the patient must be closely monitored in case of a change of the phenotype or presence of new symptoms. However, in our study we specifically selected patients with a definite TTH diagnosis, excluding all those patients with "headache no other specified" or even those patients with "possible TTH" or "probable TTH." We observed that in the 
studied patients, red flags were ignored, reflecting that education on headache disorders should be improved (Gallagher et al, 2005). According to the World Health Organization Atlas of Headache Disorders, education is within the main priorities in headache medicine (World Health Organization, 2011). The opposite approach to the use of red flags is the evaluation of green flags, which could be defined as elements in the anamnesis or prior history that are associated with a higher probability of having a primary headache disorder. The Special Interest Group on Secondary Headache disorders recently proposed a list of green flags that will need further validation to prove their real effectiveness (Pohl et al, 2021). The combination of red and green flags evaluation is the optimal approach for the patient with headache, not only in the ER setting, but also in an outpatient basis.

The consequences of $\mathrm{TTH}$ misdiagnosis are perhaps even more harmful than the misdiagnosis of other secondary headache disorders. When a patient with a secondary headache disorder is classified as TTH, this implies that the underlying condition is benign and that there is no need for further examination. In this study, after re-classifying patients, $30 \%$ of patients received a secondary headache disorder diagnosis, with $6 \%$ of those being high-risk headaches. In a similar study, conducted in the same hospital and including 1120 patients, the percentage of patients with a secondary headache disorder was $24 \%$ and the percentage of those patients with a high-risk headache was 5\% (GarcíaAzorín et al, 2020). 


\subsection{Red flags in cerebral venous sinus thrombosis}

Despite that headache has been relatively well characterized in CVST (Iurlaro et al, 2004; Crassard et al, 2005; Cumurciur et al, 2005; Wasay et al, 2010; Gameiro et al, 2012; Sparaco et al, 2015; Singh et al, 2018), there have been no studies analysing either the presence of red flags in CVST or the role of red flags in its diagnosis. In the current CVST study, the charts of all patients who had a confirmed diagnosis of CVST during the 6-year study period were reviewed. In the present case, the sensitivity may be underestimated because only the information present in the charts and reports, and not in-person interviews by study physicians which may have identified more red flags, was included in the analysis. It is well known that the quality of reports, particularly in the ER setting, is far from being optimal (Noben et al, 2016). This is related with the workload and scarcity of human resources. Electronic health records and pre-defined formulaires could improve and facilitate the history taking and completion of the reports.

The quality of the evidence, and therefore the generalizability of the study, depends on the design (Phillip et al, 2007). Figure 8 summarizes the typical study designs used for this topic of research. In the CVST study, a retrospective review of records was done; however, the purpose was defined a priori, and procedures were designed specifically to assess the frequency and type of red flags in the patient group. In the Covid-19 study, by contrast, patients were directly interviewed after one month of symptoms. Interviews were done over the phone due to the risk of contagion, so certain aspects of the exam were not possible, such as the physical exam. However, thanks to the pandemic, 
telemedicine may become a more widespread option in the research field in future studies (Ganapathy, 2020; Grossman et al, 2020).

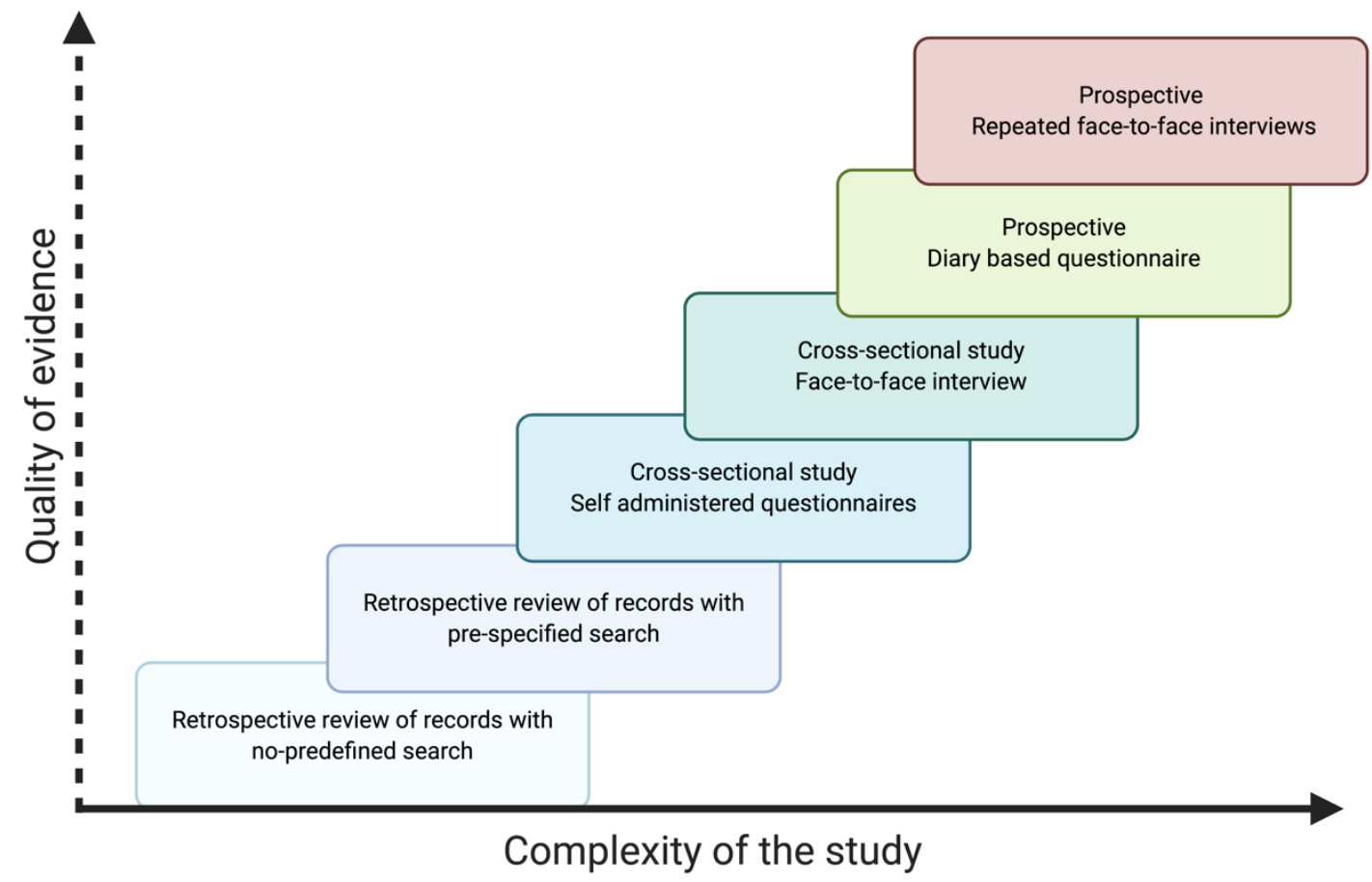

Figure 8. Quality of evidence in studies assessing red flags. Created with BioRender by David García-Azorín.

Another strength of this series is that the number of red flags that were studied was significantly higher than in other published series. For analytic purposes, some authors have merged multiple red flags into one group, such as, "drowsiness, confusion, memory impairment or loss of consciousness" (Dorsi et al, 2003). While this combining of factors may facilitate the statistical analysis, the interpretation may be more complex. Conversely, correcting for multiple comparisons of a high number of red flags makes the analysis even more complicated (Chen et al, 2017). There are, therefore, two possible 
approaches for validating red flags as diagnostic biomarkers: the specific analysis of selected red flags, e.g., thunderclap onset of the headache (García-Azorín et al, 2020); or the validation of several red flags at once (Young et al, 2018; Munoz-Ceron et al, 2019). Each option should be selected depending on the purpose of the study.

The most practical example of the use of red flags is triage systems. Emergency medicine prioritizes attention for the most severe patients (Grudzen et al, 2016). In most cases, the ER triage of patients is done immediately after the arrival of the patient. There are several triage systems, but the most frequently used is probably the Manchester Triage System (Sanchez-Bermejo 2015). Despite being extensively used, it had never been validated in the headache field in adults (Balossini et al, 2013) until recently (GarcíaAzorín et al, 2020). In the specific evaluation of headache, this system considers certain variables that have not been validated as red flags, such as "moderate pain," while in contrast, it neglects most of the typical red flags (Do et al, 2019).

In the interpretation of Figure 5, the higher frequency of abnormal examination in patients with CVST could be explained by the direct lesion on the brain caused by the venous infarcts (Singh et al, 2018). In contrast, the high frequency of "other symptoms" in Covid-19 is likely related to the fact that $>98 \%$ of patients with Covid-19 exhibit systemic symptoms (Guan et al, 2020).

The ICHD-3 criteria for CVST follows the typical diagnostic scheme for most secondary headache disorders, and there are no specific phenotypic requirements related to the headache (Table 18). In other headache disorders, "positive" criteria, such as the 
precipitation of the headache after sitting upright or standing in the case of low cerebrospinal fluid headache (Headache Classification committee, 2018), may help clinicians in the diagnosis and classification. In other cases, such as TTH, the syndrome is defined by the absence of specific features, such as nausea, photophobia and phonophobia or worsening with physical activity (Headache Classification committee, 2018). And last, but not least, in certain disorders such as CVST, the specific phenotype could be defined by the presence of headache-related red flags.

Table 18. International Classification of Headache Disorders, $3^{\text {rd }}$ version, criteria for 6.6.1 Headache attributed to cerebral venous thrombosis.

\begin{tabular}{|c|c|}
\hline Criterion A & Any new headache, fulfilling criterion C \\
\hline Criterion B & Cerebral venous thrombosis (CVT) has been diagnosed \\
\hline Criterion C & $\begin{array}{l}\text { Evidence of causation demonstrated by at least two of the } \\
\text { following: } \\
\text { 1. headache has developed in temporal relation to other } \\
\text { symptoms and/or clinical signs of CVT, or has led to the discovery } \\
\text { of CVT } \\
\text { 2. either or both of the following: } \\
\text { a) headache has significantly worsened in parallel with clinical or } \\
\text { radiological signs or extension of the CVT }\end{array}$ \\
\hline
\end{tabular}




\begin{tabular}{|l|l|}
\hline & b) headache has significantly improved or resolved after \\
& improvement of the CVT \\
\hline Criterion D & Not better accounted for by another ICHD-3 diagnosis \\
\hline
\end{tabular}

CVT: cerebral venous thrombosis; ICHD: international classification of headache disorders.

Despite that fact that the same list of red flags was used across the different studies, in the case of CVST, red flags within the prior medical events category included the use of contraceptive therapy and hormone replacement therapy, pregnancy, and prior history of prothrombotic conditions (McBane et al, 2010), even though those red flags are not consistently included within other published lists of red flags (Do et al, 2019). This technique may overestimate the frequency of red flags because the study focused on red flags that were related to CVST specifically, as prothrombotic conditions (Metha et al, 2019). Nevertheless, CVST should be always included in the differential diagnosis of young patients with new onset headache (Weimar, 2014).

The clinical presentation of CVST and the headache phenotype may be linked with the pathophysiology of the disease. The proper identification of red flags goes beyond the CVST diagnosis; it might alert to the presence of certain complications, such as intracranial hypertension, haemorrhagic transformation or venous infarct (Singh et al, 2018). Figure 9 represents some of the features of CVST pathophysiology and the correlation with some of the most prominent signs and symptoms. 


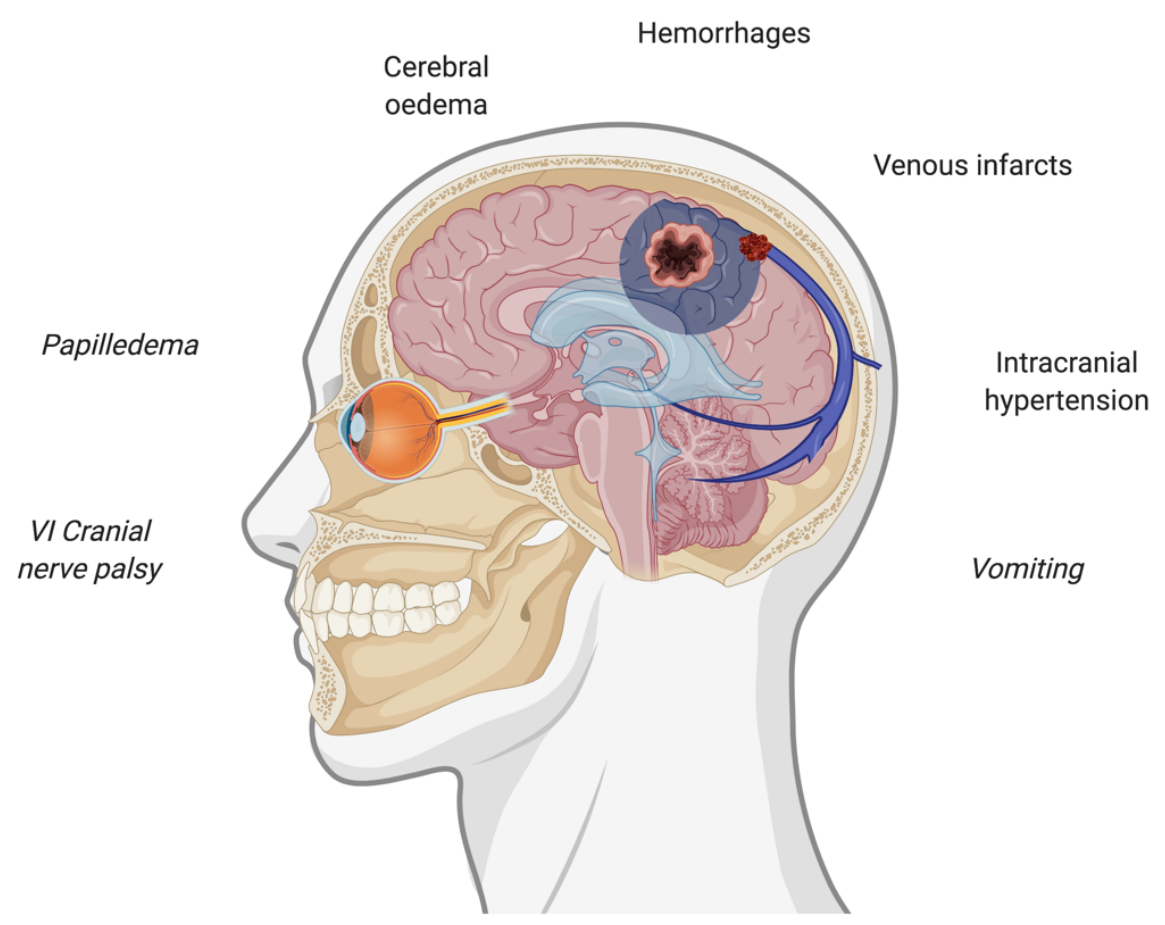

Figure 9. Pathophysiology, symptoms and signs of cerebral venous sinus thrombosis. Created with BioRender by David García-Azorín.

In neurology, one of the best-established dogmas is, "time is brain" (Furlan, 2006; Saver, 2006). The prognosis of stroke patients is highly dependent on the time of ischaemia (Audebert et al, 2014). In the case of CVST, venous infarcts have a different pathophysiology (Ferro et al, 2019), but the management should still be urgent (Saposnik et al, 2011). For that reason, the time between arrival to the ER and the request for imaging exams was analysed. Unfortunately, it was observed that in patients with headache and with no other symptoms, this time interval was longer than in headache plus other symptoms patients. 


\subsection{Headache in Covid-19}

Neurological symptoms are the most frequent non-respiratory symptoms of Covid-19 (Mao et al, 2020; Romero-Sánchez et al, 2020). In the case of headache, the first general series estimated the frequency of headache among Covid-19 patients to be around $12 \%$ (Borges do Nascimento et al, 2020). The estimated frequency in the first neurologic series was slightly higher at 13-14\% (Mao et al, 2020; Romero-Sánchez et al, 2020). The Centers for Disease Control and Prevention of the United States reports a frequency of around 13\% in hospitalized patients as well (Centers for Disease Control and Prevention, 2020). However, the reported frequency in the first headache-specific series was $59-75 \%$ (Poncet-Megemont et al, 2020; Lechien et al, 2020; Sampaio et al, 2020; Caronna et al, 2020). In the current series, the frequency was $24 \%$ (Trigo et al, 2020).

\subsubsection{Strengths of this series}

Within our series of Covid-19 patients, every consecutive patient from the first patient to patient number 2,194 was systematically studied for the presence of headache. Patients were only studied if they had a confirmed diagnosis, which in the case of Covid19 consisted of either real-time reverse transcriptase polymerase chain reaction (RT-PCR) for the viral RNA or of serum IgM + IgA antibodies specific for severe acute respiratory syndrome coronavirus 2 (SARS-CoV-2). Since headache might be an evolving symptom, patients were interviewed one month after onset of the first symptom. Finally, the sources of information in this series included the emergency department reports, the 
primary care charts and the hospital records. Figure 10 depicts the design of the studies that were conducted for characterizing headache in Covid-19 (Trigo et al, 2020).

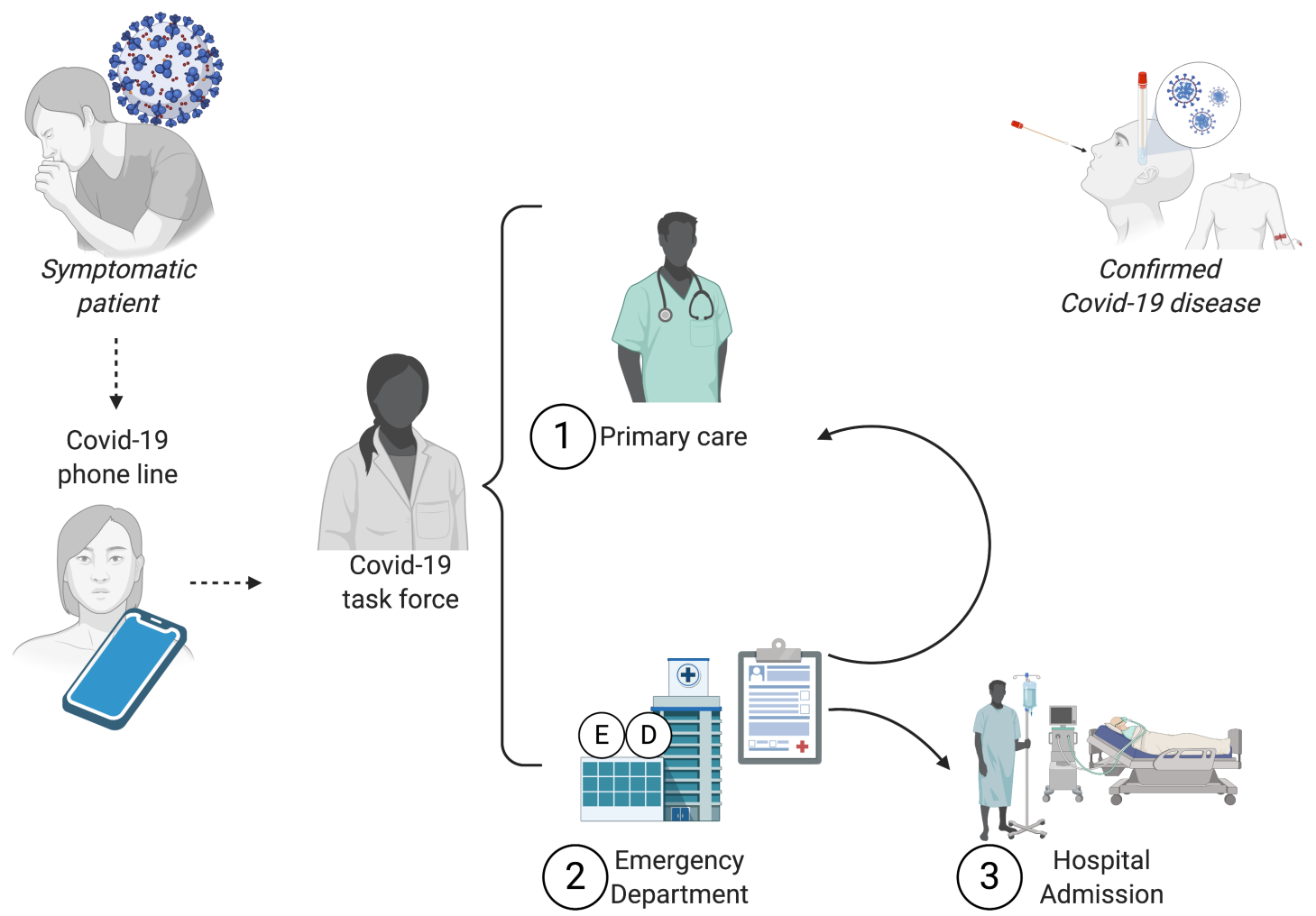

Figure 10. Design of studies assessing frequency of headache in Covid-19 patients in Valladolid. Created with BioRender by David García-Azorín.

The frequencies and types of red flags were studied in patients with Covid-19 who had headache. The Covid-19 headache phenotype is not specific and is typically described as bilateral, predominantly frontal, pressing in quality and intense (Porta-Etessam et al, 2020; Magdy et al, 2020; Membrilla et al, 2020). The ICHD-3 criteria are again relatively unspecific with the only two phenotypic features being diffuse pain and moderate or severe intensity (Table 19). For that reason, patients with headache and Covid-19 were also assessed using the phenotypic criteria for migraine and/or TTH: $50 \%$ of the patients 
fulfilled phenotypic criteria for both systemic viral infection and TTH, and $25 \%$ fulfilled phenotypic criteria for both systemic viral infection and migraine (Trigo et al, 2020).

Table 19. International Classification of Headache Disorders, $3^{\text {rd }}$ version, criteria for 9.2.2: Headache attributed to systemic viral infection.

\begin{tabular}{|c|c|}
\hline A & Headache of any duration fulfilling criterion $\mathrm{C}$ \\
\hline B & $\begin{array}{l}\text { Both of the following: } \\
\text { 1. Systemic viral infection has been diagnosed } \\
\text { 2. No evidence of meningitic or encephalitic involvement }\end{array}$ \\
\hline C & $\begin{array}{l}\text { Evidence of causation demonstrated by at least two of the following: } \\
\text { 1. Headache has developed in temporal relation to onset of the systemic } \\
\text { viral infection } \\
\text { 2. Headache has significantly worsened in parallel with worsening of the } \\
\text { systemic viral infection } \\
\text { 3. Headache has significantly improved or resolved in parallel with } \\
\text { involvement in or resolution of the systemic viral infection } \\
\text { 4. Headache has either or both of the following characteristics: } \\
\text { a) diffuse pain } \\
\text { b) moderate or severe intensity }\end{array}$ \\
\hline $\mathrm{D}$ & Not better accounted for by another ICHD-3 diagnosis \\
\hline
\end{tabular}

ICHD: international classification of headache disorders. 
The usefulness of red flags is also supported by the fact that headache is an early symptom during the course of Covid-19. Headache occurs within the first 24 hours of symptoms in $42 \%$ of patients and within 96 hours in $77 \%$. In fact, headache is the first symptom of the disease in $28 \%$ of patients (García-Azorín et al, 2020) (Figure 11), what would account for the first symptom in at least $5 \%$ of all the infected patients (García Azorín et al, 2020). In light with our results, Covid-19 can be suspected in patients who present to the ER with headache and have red flags.

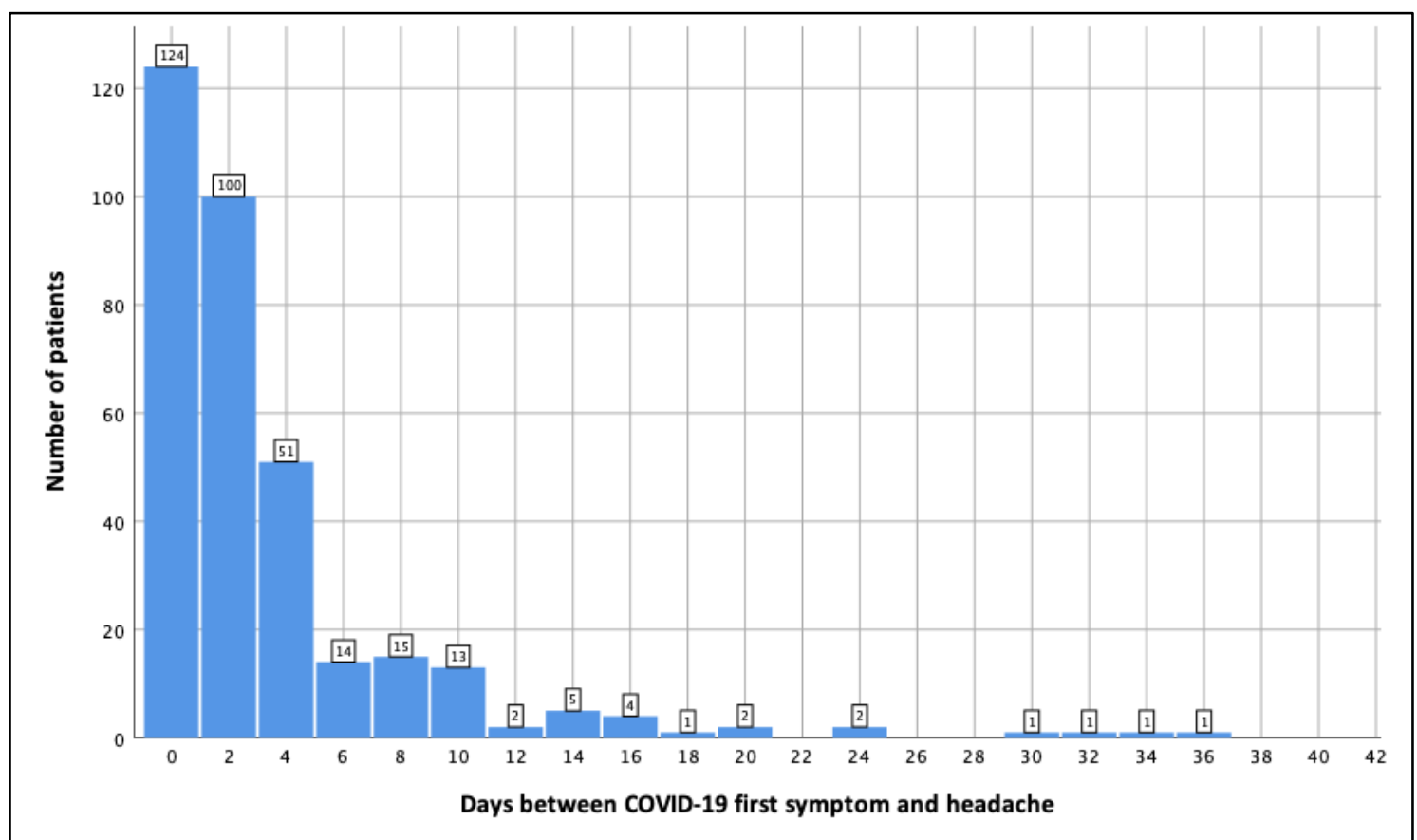

Figure 11. Interval (in days) between the first COVID-19 symptom and the headache onset (n=458). Unpublished data. Created with SPSS by David García-Azorín.

For that reason, every new-onset headache in 2020 should be managed as a potential Covid-19 infection. The research question was: can the presence of Covid-19 be suspected based on the presence of red flags? Knowing that red flags are highly sensitive in Covid-19-related headache, and due to the high prevalence of the disease during the 
pandemic time, we could expect a high negative predictive value. In the case of Covid-19, specific biomarkers that may lead to the diagnosis are available: PCR, serology, thoracic computerized tomography (CT) and/or rapid antigen tests (Ministry of Health, 2020). To be useful, they must be accurately completed and adequately interpreted. PCR tests may be positive in the early stages of the disease, but serology tests may be falsely negative in the first week (Caruana et al, 2020; Ezpeleta et al, 2020). Figure 12 summarizes the interpretation of PCR and serological tests.

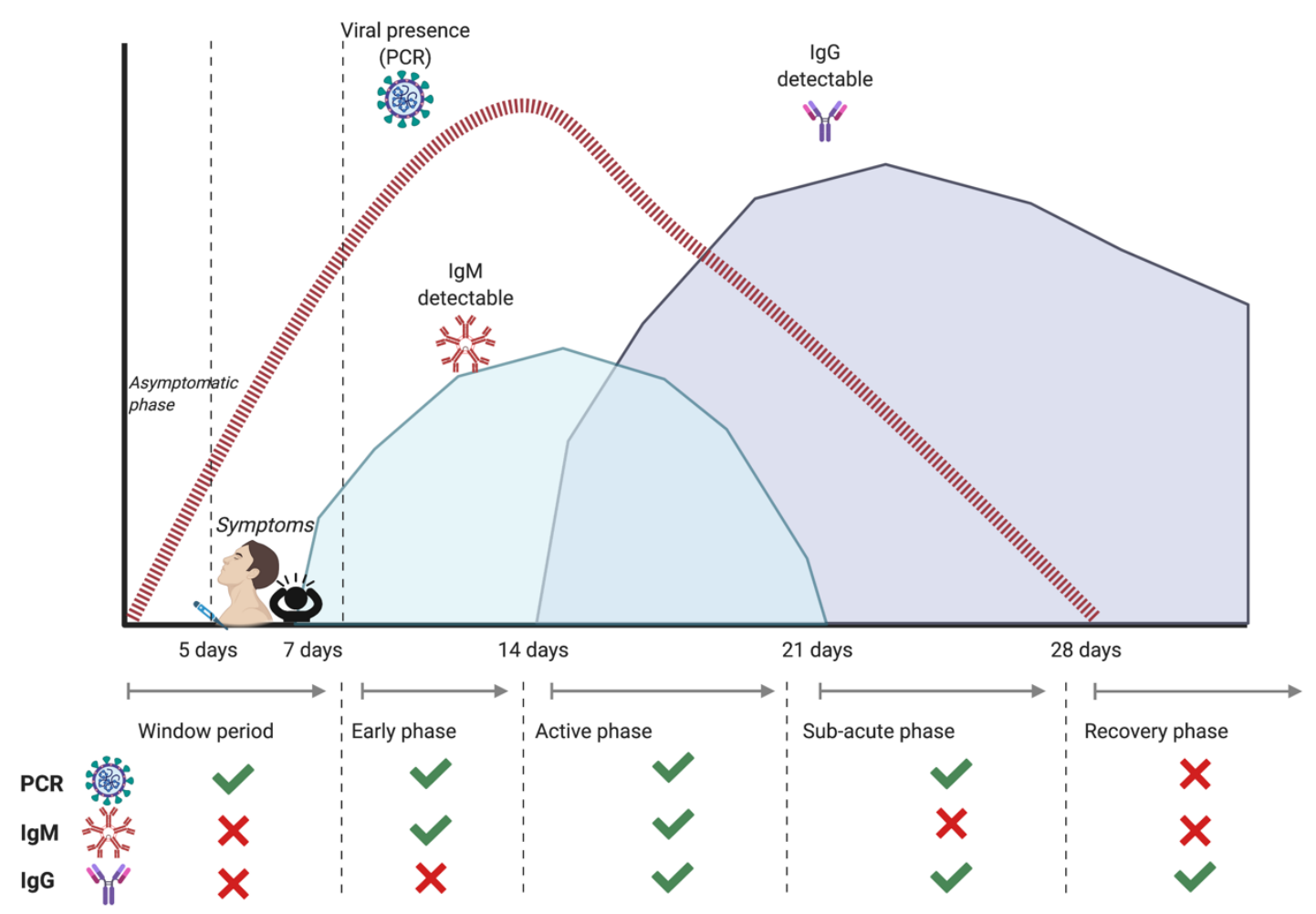

Figure 12. Interpretation of PCR and serological tests to detect severe acute respiratory syndrome coronavirus 2. Adapted from Ezpeleta et al, 2020. Created with BioRender by David García-Azorín. 
One of the few red flags that has been validated is new headache onset after age 50 years (Ramirez-Lassepas et al, 1997; Locker et al, 2006; Munoz-Ceron et al, 2019). The mean age of Covid-19 patients has been highly variable during the pandemic, depending largely on social exposure, the implementation of lockdown, and the presence of outbreaks in nursing homes and schools (National Epidemiologic Surveillance Network, 2020). Despite that, the mean age of Covid-19 patients with headache is around 50 years in most of the headache-specific series, and a significant proportion of those patients had no prior history of headache (Table 20). Since patients with headache tend to be younger than patients without headache, it would not be the best example for age $>50$ years old as red flag (Trigo et al, 2020).

Table 20. Demographic profile of patients included in the published series assessing headache in Covid-19:

\begin{tabular}{|c|c|c|c|c|c|c|}
\hline Author & $\begin{array}{l}\text { García- } \\
\text { Azorín }\end{array}$ & Magdy & $\begin{array}{l}\text { Porta- } \\
\text { Etessam }\end{array}$ & Membrilla & Caronna & $\begin{array}{l}\text { Poncet- } \\
\text { Megemont }\end{array}$ \\
\hline$n$ & 458 & 172 & 112 & 99 & 97 & 82 \\
\hline $\begin{array}{l}\text { Age, years } \\
{[\mathrm{IQR}](\mathrm{SD})}\end{array}$ & 51 [42-61] & 33 [27-42] & 43 (SD: 11) & 43 (SD: 11) & 51 (SD: 15) & 47 (SD: 14) \\
\hline Female sex & $72 \%$ & $63 \%$ & $81 \%$ & $36 \%$ & $67 \%$ & $67 \%$ \\
\hline $\begin{array}{c}\text { Prior } \\
\text { history of } \\
\text { headache }\end{array}$ & $49 \%$ & $53 \%$ & $27 \%$ & $33 \%$ & $\begin{array}{c}20 \% \\
\text { (migraine) }\end{array}$ & NS \\
\hline
\end{tabular}

IQR: inter-quartile range; SD: standard deviation; NS: not specified. 
As was observed with CVST, red flags may be linked with SARS-CoV-2 pathophysiology. Some symptoms such as fever, asthenia or myalgia may reflect the cytokine storm that occurs in the early phases of the infection (Guo et al, 2020; Metha et al, 2020). The frontal topography of the headache could be related to the presence of anosmia (Talavera et al, 2020) and to the adhesion of SARS-CoV-2 to angiotensinconverting enzyme receptors (Xu et al, 2020). Despite that, in this series prior history of headache was relatively high, probably related to the fact that two neurologists with experience in headache disorders directly interviewed the participants. The most frequent headache-related red flags were pattern change, in $49 \%$ of patients, and recent onset, in $42 \%$. Another remarkable headache-related red flag was the fact that $37 \%$ of patients claimed that this was the worst headache they had ever experienced, highlighting how intense this headache may be (Trigo et al, 2020).

7.4.2.

CVST in patients with Covid-19

At the time this study was designed, in March 2020, it was not known yet that arterial and venous thromboembolic events occur more frequently in Covid-19 patients (Logidiani et al, 2020). To date, 31 cases of CVST in Covid-19 have been published, and similarly to this series, all patients with CVST exhibited red flags, even though only 20/31 (64.5\%) presented with headache. Table 21 summarizes these published cases and the red flags that were described. In line with what was observed in the study done in patients without Covid-19, all patients exhibited red flags. 
Table 21. Published cases of CVST in patients with Covid-19 to date.

\begin{tabular}{|c|c|c|c|c|}
\hline Author & $\begin{array}{l}\text { Date of } \\
\text { submission }\end{array}$ & $n$ & $\begin{array}{l}\text { Described } \\
\text { headache? } \\
\text { (Age, years) }\end{array}$ & Red flags present \\
\hline Chougar & 20/04/2020 & 1 & No (72) & $\begin{array}{l}\text { Hemiparesis, altered mental status, } \\
\text { status epilepticus, mild respiratory } \\
\text { symptoms }\end{array}$ \\
\hline Hemasian & $23 / 04 / 2020$ & 1 & No (65) & $\begin{array}{l}\text { Loss of consciousness, suspected } \\
\text { seizure }\end{array}$ \\
\hline Hugues & $26 / 04 / 2020$ & 1 & Yes (59) & $\begin{array}{l}\text { Progressive headache, arterial } \\
\text { hypertension, neurological signs }\end{array}$ \\
\hline Garaci & $27 / 04 / 2020$ & 1 & Yes (44) & $\begin{array}{l}\text { Fever, dyspnoea, altered mental } \\
\text { status, neurological signs }\end{array}$ \\
\hline Dahl-Cruz & $28 / 04 / 2020$ & 1 & Yes (53) & $\begin{array}{l}\text { Seizures, vomiting, fever, } \\
\text { dyspnoea, anosmia, neurological } \\
\text { signs }\end{array}$ \\
\hline Klein & $30 / 04 / 2020$ & 1 & Yes (29) & Seizures, cough, fever \\
\hline Cavalcanti & $01 / 05 / 2020$ & 3 & $\begin{array}{l}\text { 1: Yes (38) } \\
\text { 2: NS (41) } \\
\text { 3: Yes (23) }\end{array}$ & $\begin{array}{l}\text { 1: Altered mental status, vomiting, } \\
\text { fever } \\
\text { 2: Confusion, aphasia, coma } \\
\text { 3: Lethargy, fever }\end{array}$ \\
\hline
\end{tabular}




\begin{tabular}{|c|c|c|c|c|}
\hline Poillon & $11 / 05 / 2020$ & 2 & $\begin{array}{l}\text { 1: Yes (62) } \\
\text { 2: Yes (54) }\end{array}$ & $\begin{array}{l}\text { 1: Fever, dyspnoea, hemiparesis, } \\
\text { altered consciousness } \\
\text { 2: Prior history of cancer, hormone } \\
\text { replacement therapy, headache, } \\
\text { fever, asthenia }\end{array}$ \\
\hline Kananeh & $14 / 05 / 2020$ & 1 & Yes (54) & $\begin{array}{l}\text { Headache, altered mental status, } \\
\text { cough }\end{array}$ \\
\hline Roy-Gash & $28 / 05 / 2020$ & 1 & No (63) & $\begin{array}{l}\text { Aphasia, hemiplegia, fever, cough, } \\
\text { seizures }\end{array}$ \\
\hline Malentacchi & $05 / 06 / 2020$ & 1 & No (81) & $\begin{array}{l}\text { Prior history of cancer and use of } \\
\text { Iglv, altered mental status }\end{array}$ \\
\hline Bolaji & $16 / 06 / 2020$ & 1 & No (63) & $\begin{array}{l}\text { Weakness, fever, dyspnoea, } \\
\text { seizures }\end{array}$ \\
\hline Sugiyama & $23 / 06 / 2020$ & 1 & Yes (56) & Fever, malaise, vomiting \\
\hline Hussain & 04/08/2020 & 1 & No (30) & Seizures \\
\hline Mowla & $27 / 08 / 2020$ & 13 & $\begin{array}{l}\text { Yes } 10 / 13 \\
(83 \%), \\
\text { (mean age } \\
50.9 \pm 11.2 \\
\text { years) }\end{array}$ & $\begin{array}{l}\text { Covid-19 symptoms } 11 / 12 \text { (92\%), } \\
\text { decreased consciousness } 5 / 13 \\
(42 \%) \text {, seizures } 3 / 12 \quad(25 \%) \text {, focal } \\
\text { neurological deficit } 2 / 12(17 \%) \text {, risk } \\
\text { factors } 3 / 12(23 \%)\end{array}$ \\
\hline Hoelscher & 04/09/2020 & 1 & No (54) & Encephalopathy \\
\hline
\end{tabular}

NS: not specified; Iglv: intravenous immunoglobulin therapy. 
7.5. Lessons and tips for the design of future studies assessing red flags in headache

The main element associated with the quality of a study is the design. The introduction and the discussion of an article can be always modified. However, once the study is performed, errors in the design will be echoed in the results. The first step of every project is to decide the optimal research question (Aslam et al, 2010). It is a common mistake pretending to evaluate all the aspects of a disorder at once, in the same study, which cannot be adequate (Mayo et al, 2013). The reason is that the study has to consider all the possible elements that may influence the result and should grant an adequate sample size (Houle et al, 2005; Farrugia et al, 2010). In the case of red flags, researchers should decide whether to evaluate a single, specific red flag or to evaluate all red flags at once. The latter requires a much larger sample size (Whitley et al, 2002), given the vast number of different red flags (Do et al, 2019) and the number of different possible headache disorders (Headache Classification committee, 2018). Broad inclusion criteria are also relevant to ensure a sufficient external validity (Ferguson, 2004).

Headache is a common symptom, both in the ER (Centers for Disease Control and Prevention, National Hospital Ambulatory Medical Care Survey, 2017) and in outpatient clinics (Matías-Guiu et al, 2016). For this reason, reaching a significant sample size would be feasible. However, study staff and researchers would be required on a $24 / 7$ basis, considering that patients with headache do not seek attention at the ER in a uniform pattern (Leicht, 1980; Valade, 2008; Alstadhaug et al, 2008; García-Azorín et al, 2020). Multicentric and multinational design may facilitate recruitment, and at the same time, 
is a sign of external validity, supporting that the findings can be generalized (Enarson et al, 2004).

Red flag evaluation can be done in different ways, as was shown in Figure 8, about the quality of the evidence. However, systematic evaluation, such as by using a validated and standardized questionnaire, produces higher quality data. For research purposes, a face-to-face interview with the patient, as opposed to a survey the patient completes, may be helpful to ensure that patients properly interpret the meaning of each red flag. In addition, patients can ask the provider any questions. The use of headache diaries is always recommended to avoid recall bias (Miller et al, 2020). The counter argument is that these studies should not interfere in the clinical management of patients, since many patients may be suffering from a secondary cause or a debilitating primary headache attack (Minen et al, 2014).

In this field, the optimal study design is either an interventional study, comparing an intervention with the standard-of-care, or a prospective cohort study. In any case, the diagnosis should be done by using the ICHD criteria (Headache Classification committee, 2018), ideally after the evaluation of a neurologist or an expert in headache disorders and after the adequate exclusion of secondary causes. Follow-up for a period of three to six months is desirable, since the adequate diagnosis might not otherwise be reached or since some disorders might present in a pre-clinical phase (Goldstein et al, 2006).

Regarding the statistical methods, missing data must be reported and handled adequately, selecting the method depending on the type of missing data (Donders et al, 
2006; Newgard et al, 2007). Results should be presented together with confidence intervals (Houle et al, 2013), and hypothesis testing must be done both per intention-totreat and per-protocol (Turner et al, 2020). The optimal approach is probably regression analysis, since this type of model can attenuate the possible effect of the different confounders and effect modifiers, as opposed to the direct comparison between groups (Tripepi et al, 2008; Richardson et al, 2018).

Last, but not least, it is always important to replicate the findings, confirming that they are not solely due to chance. This is one of the main shortages of most studies assessing red flags. The International Headache Society created guidelines for controlled trials of acute (Diener et al, 2019) and preventive (Diener et al, 2020) treatment of migraine in adults and children (Abu-Arafe et al, 2019), even though the preceding editions of these guidelines were not systematically followed (García-Azorín et al, 2018). In addition, all results must be published, whether or not the result is negative (DeVito et al, 2019). If the study is properly designed, a negative result is equally valid and contributes to the better understanding of the role of the red flags. The Special Interest Group on secondary headache disorders of the International Headache Society recently summarized the key elements in the design of studies of headache in Covid-19 (García-Azorín et al, 2020). 
VIII. CONCLUSIONS 


\section{Conclusions}

The present study assessed the frequencies and types of red flags in two secondary headache disorders, in which headache is one of the most prominent features, and in a primary headache disorder.

The main conclusions of these studies are:

1. Tension-type headache was over-diagnosed in the emergency department. There were red flags related to prior medical history in a fifth of the patients and red flags related to the clinical presentation in $80 \%$ of patients who received a tension-type headache diagnosis, despite that these red flags would make a tension-type headache diagnosis incompatible. Only a minority of the patients fulfilled the International Classification of Headache Disorders-3 diagnostic criteria for tension-type headache, with most patients being misdiagnosed. The main reason was that diagnosis was based on the clinical phenotype and not on the International Classification of Headache Disorders criteria.

2. All patients with confirmed cerebral venous sinus thrombosis who presented to the emergency room had at least one red flag, which was related to prior medical history, clinical presentation, or an abnormal neurological examination. The evaluation of prior medical history, the anamnesis of the patient, and the physical examination are important to evaluate. Cerebral venous sinus thrombosis must be included in the differential diagnosis of patients with headache and red flags, and adequate imaging modalities should be requested to properly and promptly identify it. 
3. In patients with Covid-19 that described headache, red flags were observed in all cases. The main group of red flags were systemic symptoms, which were present in most cases, and isolated headache was an infrequent presentation. However, red flags concerning the headache were also described by almost all of the patients, despite that there were no specific headache-related red flags. Since red flags related to prior medical history or the presence of neurological symptoms were also common, they should be, as in every patient with headache, systematically evaluated. 
IX. REFERENCES 


\section{References}

1. Aaronson EL, Quinn GR, Wong Cl, Murray AM, Petty CR, Einbinder J, et al. Missed diagnosis of cáncer in primary care: Insights from malpractice claims data. J Health risk Manag 2019;39(2):19-29.

2. Abu-Arafeh I, Hershey AD, Diener HC, Tassorelli C, Clinical Trials Standing Committee and the Child and Adolescent Standing Committee of the International Headache Society. Guidelines of the International Headache Society for controlled trials of preventive treatment of migraine in children and adolescents, 1st edition. Cephalalgia 2019;39(7):803-816.

3. Al-Drawi AS, Wicinski M, Grzesk G, Szadujkis-Szadurska K, Grzesk E, Weclewicz MM, et al. Evaluation of VCAM-1 and ICAM-1 and concentration values of global tests concerning the coagulation system of patients suffering from subarachnoid hemorrhage. Ann Agric Environ Med 2016;23(4):654-659.

4. Aller-Alvarez JS, Quintana M, Santamarina E, Álvarez-Sabin J. Descriptive analysis of neurological in-hospital consultations in a tertiary hospital. Neurología 2017;32(3):152-157.

5. Alstadhaug K, Salvesen R, Bekkelund S. 24-hour distribution of migraine attacks. Headache 2008;48(1):95-100.

6. Amanat M, Thijs RD, Salehi M, Sander JW. Seizures as a clinical manifestation in somatic autoimmune disorders. Seizure 2019;64:59-64.

7. Andersen AM, Ashina H, Iljazi A, Al-Khazali HM, Chaudhry B, Ashina M, et al. Risk Factors for the Development of Post-Traumatic Headache Attributed to Traumatic Brain Injury: A Systematic Review. Headache 2020;60(6):1066-1075.

8. Andersen HH, Duroux M, Gazerani P. Serum microRNA signatures in migraineurs during attacks and pain-free periods. Mol Neurobiol 2016;53(3):1494-1500.

9. Andruchow JE, Kavsak PA, McRae AD. Contemporary emergency department management of patients with chest pain: a concise review and guide for the highsensitivity troponin era. Can J Cardiol 2018;34(2):98-108.

10. Arca KN, Halker Singh RB. The Hypertensive Headache: A Review. Curr Pain Headache Rep 2019;23(5):30. 
11. Argyriou AA, Chroni E, Polychronopoulos $P$, et al. Headache characteristics and brain metastases prediction in cancer patients. Eur J Cancer Care (Engl) 2006;15(1):90-95.

12. Assarzadegan F, Asgarzadeh S, Hatamabadi HR, Shahrami A, Tabatabaey A, Asgarzadeh M. Serum concentration of magnesium as an independent risk factor in migraine attacks: a matched case-control study and review of the literatura. Int Clin Psychopharmacol 2016;31(5):287-292.

13. Aslam S, Emmanuel P. Formulating a researchable question: A critical step for facilitating good clinical research. Indian J Sex Transm Dis AIDS 2010;31(1):47-50.

14. World Health Organization. Atlas of headache disorders and resources in the world 2011, World Health Organization, 2011, Geneva, Switzerland. ISBN: 97892-4-156421-2.

15. Au-Yong A, Coats T. Towards evidence based emergency medicine: best BETs from the Manchester Royal Infirmary. C Reactive Protein and the diagnosis of intracranial infection. Emerg Med J 2007;24(3):218-219.

16. Audebert HJ, Sobesky J. Stroke: "time is brain" after stroke, regardless of age and severity. Nat Rev Neurol 2014;10(12):675-676.

17. Azzopardi E, Lloyd C, Texeira SR, Conlan RS, Whitaker IS. Clinical applications of amylase: novel perspectives. Surgery 2016;160(1):26-37.

18. Balducci N, Morara M, Veronese C, Barboni P, Casadei NL, Savini G, et al. Optical coherence tomography angiography in acute arteritic and non-arteritic anterior ischemic optic neuropathy. Graefes Arch Clin Exp Ophthalmol 2017;255(11):2255-2261.

19. Balossini V, Zanin A, Alberti A, Freund Y, Decobert M, Tarantino A et al. Triage of children with headache at the ED: a guideline implementation study. Am J Emerg Med 2013;31(4):670-675.

20. Bazan R, Almeida LA, Rocha FC, Raffin CN, Fonseca RG. Headache secondary to haemorrhagic stroke resembling paroxysmal hemicrania. Arq Neuropsiquiatr 2008;66(3B):761-762.

21. Berlit P, Fedel C, Tornow K, Schmiedek P. Der bakterielle Hirnabszess-Erfahrungen bei 67 Patienten [Bacterial brain abscess--experiences with 67 patients]. Fortschr Neurol Psychiatr 1996;64(8):297-306. 
22. Blum CA, Winzeler B, Nigro N, Schuetz P, Biethahn S, Kahles T, et al. Copeptin for risk stratification in non-traumatic headache in the emergency setting: a prospective multicenter observational cohort study. J Headache pain 2017;18(1):21.

23. Birk S, Kruuse C, Petersen KA, Tfelt-Hansen P, Olesen J. The headache-inducing effect of cilostazol in human volunteers. Cephalalgia 2006;26(11):1304-9.

24. Boardman HF, Thomas E, Croft PR, Millson DS. Epidemiology of headache in an English district. Cephalalgia 2003;23(2):129-137.

25. Bo SH, Davidsen EM, Gulbrandsen P, Dietrichs E. Acute headache: a prospective diagnostic work-up of patients admitted to a general hospital. Eur J Neurol 2008;15(12):1293-1299.

26. Bolaji P, Kukoyi B, Ahmad N, Wharton C. Extensive cerebral venous sinus thrombosis: a potential complication in a patient with COVID-19 disease. BMJ Case Rep 2020;13(8):e236820.

27. Borges CR, Almeida SM, Sue K, Koslyk JLA, Sato MT, Shiokawa N, et al. Neurosyphilis and ocular syphilis clinical and cerebrospinal fluid characteristics: a case series. Arq Neuropsiquiatr 2018;76(6):373-380.

28. Borges do Nascimento IJ, Cacic N, Abdulazeem HM, von Groote TC, Jayarajah U, Weerasekara I, et al. Novel Coronavirus Infection (COVID-19) in Humans: A scoping review and meta-analysis. J Clin Med 2020;9(4):941.

29. Botta R, Donirpathi S, Yadav R, Kulkarni GB, Kumar MV, Nagaraja D. Headache Patterns in Cerebral Venous Sinus Thrombosis. I Neurosci Rural Pract 2017;8(Suppl 1):S72-S77.

30. Bottiroli S, Allena M, Sances G, De Icco R, Avenali M, Fadic R, et al; COMOESTAS Consortium. Psychological, clinical, and therapeutic predictors of the outcome of detoxification in a large clinical population of medication-overuse headache: A six-month follow-up of the COMOESTAS Project. Cephalalgia 2019;39(1):135-147.

31. Bousser MG, Chiras J, Bories J, Castaigne P. Cerebral venous thrombosis - a review of 38 cases. Stroke 1985;16(2):199-213.

32. Brilla R, Pawlowski M, Evers S. Hemicrania continua in carotid artery dissection symptomatic cases or linked pathophysiology? Cephalalgia 2018;38(2):402-405. 
33. Burish MJ, Rozen TD. Trigeminal Autonomic Cephalalgias. Neurol Clin 2019;37(4):847-869.

34. Burch RC, Rizzoli P, Loder E. The prevalence and Impact of Migraine and Severe Headache in the United States: Figures and Trends from Government Health Studies. Headache 2018;58(4):496-505.

35. Bustamante Maldonado $E$, Marí Alfonso B, Monteagudo Jiménez $M$, Casanovas Martínez A, Jordana Comajuncosa R, Tolosa Viella C, et al. Análisis de una serie de 55 pacientes con arteritis de células gigantes confirmada por biopsia [Analysis of a series of 55 patients with biopsy proven giant cell temporal arteritis]. An Med Interna 2004;21(10):473-476.

36. Buture A, Boland JW, Dikomitis L, Ahmed F. Update on the pathophysiology of cluster headache: Imaging and neuropeptide studies. J Pain Res 2019;12:269-281.

37. Calabrese LH, Dodick DW, Schwedt TJ, Singhal AB. Narrative review: reversible cerebral vasoconstriction syndromes. Ann Intern Med 2007;146(1):34-44.

38. Calvacanti DD, Raz E, Shapiro M, Dehkharghani S, Yaghi S, Lillemoe K, et al. Cerebral venous thrombosis associated with COVID-19. AJNR Am J Neurorradiol 2020;41(8):1370-1376.

39. Caminero AB, Pareja JA. Supraorbital neuralgia: a clinical study. Cephalalgia 2001;21(3):216-223.

40. Campagna G, Prospero Ponce CM, Vickers A, Hong BY, Pellegrini F, Cirone D, et al. Neuro-Ophthalmic Sarcoidosis. Neuroophthalmology 2019;44(5):319-326.

41. Candeloro E, Canavero I, Maurelli M, Cavallini A, Ghiotto N, Vitali P, et al. Carotid dissection mimicking a new attack of cluster headache. J Headache Pain 2013;14(1):84.

42. Canhao P, Ferro JM, Lindgren AG, Bousser MG, Stam J, Barinagarrementeria F, et al. Causes and predictors of death in cerebral venous thrombosis. Stroke 2005;36(8):1720-1725.

43. Capizzano AA, Lai L, Kim J, Rizzo M, Gray L, Smoot MK, et al. Atypical Presentations of Intracranial Hypotension: Comparison with Classic Spontaneous Intracranial Hypotension. AJNR Am J Neuroradiol 2016;37(7):1256-61. 
44. Cardelli P, Hur M, Di Somma S. Biomarkers in Emergency Medicine. Dis Markers 2018;2018::4597489.

45. Caria F, Zedde M, Gamba M, Bersano A, Rasura M, Adami A, et al; Italian Project on Stroke at Young Age (IPSYS) Investigators. The clinical spectrum of reversible cerebral vasoconstriction syndrome: The Italian Project on Stroke at Young Age (IPSYS). Cephalalgia 2019;39(10):1267-1276.

46. Carlsen LN, Munskgaard SB, Nielsen M, Storm Engelstoft IM, Westergaard ML, Bendtsen $\mathrm{L}$, et al. Comparison of 3 treatment strategies for Medication Overuse Headache: A randomized clinical trial. JAMA Neurol 2020;77(9):1-10.

47. Caronna E, Ballvé A, Llauradó A, Gallardo VJ, Ariton DM, Lallana S, et al. Headache: a striking prodromal and persistent symptom, predictive of COVID-19 clinical evolution. Cephalalgia 2020;40(13):1410-1421.

48. Carpenter J, Stapleton S, Holliman R. Retrospective analysis of 49 cases of brain abscess and review of the literature. Eur J Clin Microbiol Infect Dis 2007;26(1):111.

49. Caruana G, Croxatto A, Coste AT, Opota O, Lamoth F, Jaton K, et al. Diagnostic strategies for SARS-CoV-2 infection and interpretation of microbiological results. Microbiol Infect 2020;26(9):1178-1182.

50. Castilla y Leon Department of Health. Guideline on the Sanitary Ordinance. Available on: https://www.saludcastillayleon.es/institucion/es/organizacion/ordenacionsistema-sanitario/guia-ordenacion-sanitaria-castilla-leon/area-saludvalladolid.ficheros/77572-Valladolid\%20este.pdf Accessed on September $6^{\text {th }}$, 2020.

51. Centers for Disease Control and Prevention. National Center for Health Statistics. National Hospital Ambulatory Medical Care Survey: 2017 Emergency Department $\begin{array}{llll}\text { Summary } & \text { Tables. }\end{array}$ https://www.cdc.gov/nchs/data/nhamcs/web tables/2017 ed web tables508.pdf Accessed on October 22, 2020.

52. Cernuda-Morollón E, Larrosa D, Ramón C, Vega J, Martínez-Camblor P, Pascual J. Interictal increase of CGRP levels in peripheral blood as a biomarker for chronic migraine. Neurology 2013;81(14):1191-1196. 
53. Chen PK, Fuh JL, Wang SJ. Cough headache: a study of 83 consecutive patients. Cephalalgia 2009;29(10):1079-1085.

54. Chen SY, Feng Z, Yi X. A general introduction for adjustment for multiple comparisons. J Thorac Dis 2017;9(6):1725-1729.

55. Chen XH, Huang S, Kerr D. Biomarkers in clinical medicine. IARC Sci Publ 2011;(163):303-322.

56. Christiaans MH, Kelder JC, Arnoldus EPJ, Tijssen CS. Prediction of intracranial metastasis in cancer patients with headache. Cancer 2002;94(7):2063-2068.

57. Chou DE. Secondary headache syndromes. Continuum (Minneap Minn) 2018;24(4, Headache):1179-1191.

58. Chougar L, Mathon B, Weiss N, Degos V, Shor N. Atypical deep cerebral vein thrombosis with hemorrhagic venous infarction in a patient positive for COVID19. AJNR Am J Neurorradiol 2020;41(8):1377-1379.

59. Chun $\mathrm{CH}$, Johnson JD, Hofstetter M, Raff MJ. Brain abscess: a study of 45 consecutive cases. Medicine 1986;65(6):415-431.

60. Cittadini E, Goadsby PJ. Hemicrania continua: a clinical study of 39 patients with diagnostic implications. Brain 2010;133(Pt 7):1973-1986.

61. Cortelli P, Cevoli S, Nonino F, Baronciani D, Magrini N, Re G et al. Evidence-based diagnosis of nontraumatic headache in the emergency department: a consensus statement on four clinical scenarios. Headache 2004;44(6):587-595.

62. Costa AC, Satalich JR, Al-Bizri E, Shodhan S, Romeiser JL, Adsumelli R, et al. A tenyear retrospective study of post-dural puncture headache in 32,655 obstetric patients. Can J Anaesth 2019;66(12):1464-1471.

63. Costello F, Zimmerman MB, Podhajsky PA, Hayreh SS. Role of thrombocytosis in diagnosis of giant cell arteritis and differentiation of arteritic from non-arteritic anterior ischemic optic neuropathy. Eur J Ophtalmol 2004;14(3):245-257.

64. Courand PY, Serraille M, Girerd N, Demarquay G, Milon H, Lantelme P, et al. The Paradoxical Significance of Headache in Hypertension. Am J Hypertens 2016;29(9):1109-1116. 
65. COVID-NET: COVID-19 associated hospitalization surveillance network.Centers for Disease Control. Available on https://gis.cdc.gov/grasp/COVIDNet/COVID19 5.html Accessed on November 8, 2020.

66. Crystal SC, Robbins MS. Tension-type headache mimics. Curr Pain Headache Rep 2011;15(6):459-66.

67. Cumurciuc R, Crassard I, Sarov M, Valade D, Bousser MG. Headache as the only neurological sign of cerebral venous thrombosis: a series of 17 cases. J Neurol Neurosurg Psychiatry 2005;76(8):1084-1087.

68. Curone M, Tullo V, Peccarisi C, Bussone G, D'Amico D. Headache as presenting symptom of neurosarcoidosis. Neurol Sci 2013;34(Suppl 1):S183-S185.

69. Dahl-Cruz F, Guevara-Dalrymple N, López-Hernández N. Cerebral venous thrombosis and SARS-CoV-2 infection. Rev Neurol 2020;70(10):391-392.

70. Davenport R. Acute headache in the Emergency Department. J Neurol Neurosurg Psychiatry 2002;72(suppl II):ii33-ii37.

71. Day JW, Raskin NH. Thunderclap headache: symptom of unruptured cerebral aneurysm. Lancet 1986;2(8518):1247.

72. de Bruijn SF, de Haan RJ, Stam J. Clinical features and prognostic factors of cerebral venous sinus thrombosis in a prospective series of 59 patients. For The Cerebral Venous Sinus Thrombosis Study Group. J Neurol Neurosurg Psychiatry 2001;70(1):105-108.

73. de Coo IF, Wilbrink LA, Haan J. Symptomatic Trigeminal Autonomic Cephalalgias. Curr Pain Headache Rep 2015;19(8):39.

74. De Falco FA, Sterzi R, Toso V, Consoli D, Guidetti D, Provinciali L, et al. The neurologist in the emergency department. An Italian nationwide epidemiological survey. Neurol Sci 2008;29(2):67-75.

75. De Marinis M, Welch KMA. Headache associated with non-cephalic infections: classification and mechanisms. Cephalalgia 1992;12(4):197-201.

76. De Reuck J, Van Maele G. Seizures in patients with symptomatic cervical artery occlusion by dissection and by atherosclerosis. Eur J Neurol 2009;16(5):608-611. 
77. Dentali F, Poli D, Scoditti U, Di Minno MND, Siragusa S, Kostal M, et al. Long-term outcomes of patients with cerebral vein thrombosis: a multicenter study. J of Thromb and Haemostasis 2012;10(7):1297-1302.

78. Dermitzakis EV, Georgiadis G, Rudolf J, Nikiforidou D, Kyriakidis P, Gravas I, et al. Headache patients in the emergency department of a Greek tertiary care hospital. J Headache Pain 2010;11(2):123-128.

79. Department of State. Agreement on the human rights and biomedicine. Based on the meeting from April 4, 1997. Oviedo. Spain. Published in the Official Bulletin of State, October 20, 1999, pages 36825-36830. Available on https://www.boe.es/buscar/doc.php?id=BOE-A-1999-20638 Accessed on November 28, 2020.

80. Depreitere B, Bruyninckx D, Güiza F. Monitoring of Intracranial Pressure in Meningitis. Acta Neurochir Suppl 2016;122:101-104.

81. Devenney E, Neale H, Forbes RB. A systematic review of causes of sudden and severe headache (Thunderclap Headache): Should lists be evidence based? J Headache Pain 2014;15(1):49.

82. DeVito NJ, Goldacre B. Catalogue of bias: publication bias. BMJ Evid Based Med 2019;24(2):53-54.

83. Diacinti D, Cartocci G, Colonnese C. Cerebral venous thrombosis: A case series and a neuroimaging review of the literature. J Clin Neurosci 2018;58:142-147.

84. Diener HC, Katsarava Z, Limmroth V. Headache attributed to a substance or its withdrawal. Handb Clin Neurol. 2010;97:589-599.

85. Diener HC, Tassorelli C, Dodick DW, Silberstein SD, Lipton RB, Ashina M, et al; International Headache Society Clinical Trials Standing Committee. Guidelines of the International Headache Society for controlled trials of acute treatment of migraine attacks in adults: Fourth edition. Cephalalgia 2019;39(6):687-710.

86. Diener HC, Tassorelli C, Dodick DW, Silberstein SD, Lipton RB, Ashina M, et al; International Headache Society Clinical Trials Committee. Guidelines of the International Headache Society for controlled trials of preventive treatment of migraine attacks in episodic migraine in adults. Cephalalgia 2020;40(10):10261044. 
87. Do TP, Remmers A, Schytz HW, Schankin C, Nelson SE, Obermann M, et al. Red and orange flags for secondary headaches in clinical practice: SNNOOP10 list. Neurology 2019;92(3):134-144.

88. Dobb B, Cooper J. A pilot survey of decisions by acute medicine staff after thunderclap headache. J R Coll Physicians Edin 2013;43(3):207-214.

89. Donders AR, van der Heijden GJ, Stijnen T, Moons KG. Review: a gentle introduction to imputation of missing values. J Clin Epidemiol 2006;59(10):10871091.

90. Ducros A. Reversible cerebral vasoconstriction syndrome. Lancet Neurol 2012;11(10):906-917.

91. Durand M, Calderwood S, Weber D, Miller SI, Southwick FS, Caviness VS, et al. Acute bacterial meningitis in adults: a review of 493 episodes. N Engl J Med 1993;328(1):21-28.

92. Duvall JR, Robertson CE, Cutsforth-Gregory JK, Carr CM, Atkinson JL, Garza I. Headache due to spontaneous spinal cerebrospinal fluid leak secondary to cerebrospinal fluid-venous fistula: Case series. Cephalalgia 2019;39(14):18471854.

93. Eccles R. Understanding the symptoms of the common cold and influenza. Lancet Infect Dis 2005;5(11):718-725.

94. Edmeads J. Challenges in the diagnosis of acute headache. Headache 1993;30(suppl 2):537-540.

95. Edvardsson B. Symptomatic cluster headache: a review of 63 cases. Springerplus 2014;3:64.

96. Elhfnawy AM, Solymosi L, Sommer C. Carotid dissection presenting as a prolonged cluster-like headache in a patient with episodic cluster headache. BMJ Case Rep 2017;2017:bcr2017220845.

97. Enarson DA, Kennedy SM, Miller DL. Choosing a research study design and selecting a population to study. Int J Tuberc Lung Dis 2004;8(9):1151-1156.

98. Engelter ST, Traenka C, Lyrer P. Dissection of Cervical and Cerebral Arteries. Curr Neurol Neurosci Rep 2017;17(8):59. 
99. English SW, Nasr DM. Thunderclap Headache and Cerebral Vasoconstriction Secondary to Pheochromocytoma. JAMA Neurol 2019;76(4):502-503.

100. Erygit U, Cakmak VA, Sahin A, Tatli O, Pasli S, Gazioglu G, et al. The diagnostic value of the neutrophil-lymphocyte ratio in distinguishing subarachnoid hemorrhage and migraine. Am J Emerg Med 2017;35(9):12761280.

101. Evans RW, Friedman BW. Headache in the emergency department. Headache 2011;51(8):1276-1278.

102. Ezpeleta D, García-Azorín D. Handbook on COVID-19 for Neurologists. 1st edition. Ediciones SEN, Madrid, España. ISBN. 978-84-17372-84-2.

103. Fang $X$, Liang $Y$, Chen $D$, He F, Chen J, Huang F. A study on clinicoradiological characteristics and pregnancy outcomes of reversible posterior leukoencephalopathy syndrome in preeclampsia or eclampsia. Hypertens Res 2017;40(12):982-987.

104. Farooque U, Okorie N, Kataria S, Shah SF, Bollampally VC. Cocaine-Induced Headache: A Review of Pathogenesis, Presentation, Diagnosis, and Management. Cureus 2020;12(8):e10128.

105. Farrugia P, Petrisor BA, Farrokhyar F, Bhandari M. Practical tips for surgical research: Research questions, hypotheses and objectives. Can J Surg 2010;53(4):278-281.

106. Favier I, van Vliet JA, Roon KI, Witteveen RJW, Verschuuren JJGM, Ferrari $\mathrm{MD}$, et al. Trigeminal autonomic cephalgias due to structural lesions: a review of 31 cases. Arch Neurol 2007;64(1):25-31.

107. Fein AS, Ko MW. Neuro-Ophthalmologic Complications of Giant Cell Arteritis: Diagnosis and Treatment. Semin Neurol 2019;39(6):673-681.

108. Ferguson L. External validity, generalizability, and knowledge utilization. J Nurs Scholarsh 2004;36(1):16-22.

109. Ferro JM, Canhao P, Stam J, Bousser MG, Barrinagarrementeria F. Prognosis of cerebral vein and dural sinus thrombosis. Results of the international study on cerebral vein and dural sinus thrombosis. Stroke 2004;35(3):664-670. 
110. Ferro JM, Aguiar de Sousa D. Cerebral venous thrombosis: an update. Curr Neurol Neurosci Rep 2019;19(10):74.

111. Fica C A, Bustos G P, Miranda C G. Absceso cerebral: a propósito de una serie de 30 casos [Brain abscess: about a clinical series of 30 patients]. Rev Chilena Infectol 2006;23(2):140-149.

112. Filler L, Akhter M, Nimlos P. Evaluation and management of emergency department headache. Semin Neurol 2019;39(1):20-26.

113. Fofi L, Orlandi V, Vanacore N, Mizzoni MC, Rosa A, Aurilia C, et al. Headache in chronic cocaine users: A cross-sectional study. Cephalalgia 2014;34(9):671-678.

114. Foroozan R, Danesh-Meyer H, SavinoPJ, Gamble G, Mekari-Sabbagh ON, Sergott RC. Thrombocytosis in patients with biopsy-proven giant cell arteritis. Ophtalmology 2002;109(7):1267-1271.

115. Forsyth PA, Posner JB. Headaches in patients with brain tumors: a study of 111 patients. Neurology 1993;43(9):1678-1683.

116. Friedman BW, Serrano D, Reed M, Diamond M, Lipton RB. Use of the emergency department for severe headache. A population-based study. Headache 2009;49(1):21-30.

117. Friedman BW, Lipton RB. Headache in the emergency department. Curr Pain Headache Rep 2011;15:302-307. doi: 10.1007/s11916-011-0189-z.

118. Friedman DI. The Eye and Headache. Continuum (Minneap Minn) 2015;21(4 Headache):1109-1117.

119. Friedman DI. Headaches Due to Low and High Intracranial Pressure. Continuum (Minneap Minn) 2018;24(4 Headache):1066-1091.

120. Fritz D, van de Beek D, Brouwer MC. Clinical features, treatment and outcome in neurosarcoidosis: systematic review and meta-analysis. BMC Neurol 2016;16(1):220.

121. Fugate JE, Rabinstein AA. Posterior reversible encephalopathy syndrome: clinical and radiological manifestations, pathophysiology, and outstanding questions. Lancet Neurol 2015;14(9):914-925.

122. Furlan AJ. Time is brain. Stroke 2006;37(12):2863-2864. 
123. Gago-Veiga AB, García-Azorín D, Mas-Sala N, Ordás CM, Ruiz-Piñero M, Torres-Ferrus $\mathrm{M}$, et al. How and when to refer patients diagnosed with primary headache and craniofacial neuralgia in the Emergency department or Primary Care: Recommendations of the Spanish Society of Neurology's Headache Study Group. Neurologia 2020;35(3):176-184.

124. Gallagher RM, Alam R, Shah S, Mueller L, Rogers JJ. Headache in medical education: medical schools, neurology and family practice residencies. Headache 2005;45(7):866-873.

125. Gallai V, Sarchielli P, Floridi A, Franceschini M, Codini M, Glioti G et al. Vasoactive peptide levels in the plasma of young migraine patients with and without aura assessed both interictally and ictally. Cephalalgia 1995;15(5):384390.

126. Galvão A, Gonçalves D, Moreira M, Inocêncio G, Silva C, Braga J. Prolactinoma and pregnancy - a series of cases including pituitary apoplexy. J Obstet Gynaecol 2017;37(3):284-287.

127. Gameiro J, Ferro JM, Canhao P, Stam J, Barinagarrementeria F, Lindgren A, et al. Prognosis of cerebral vein thrombosis presenting as isolated headache: early vs. late diagnosis. Cephalalgia 2012;32(5):407-412.

128. Ganapathy K. Telemedicine and neurological practice in Covid-19 era. Neurol India 2020;68(3):555-559.

129. Garaci F, Di Giuliano F, Picchi E, Da Ros V, Floris R. Venous cerebral thrombosis in COVID-19. J Neurol Sci 2020;414:116871.

130. García-Azorin D, Yamani N, Messina LM, Peeters I, Ferrili M, Ovchinnikov D, et al; European Headache Federation School of Advanced Studies (EHF-SAS). A PRISMA-compliant systematic review of the endpoints employed to evaluate symptomatic treatments for primary headaches. J Headache Pain 2018;19(1):90.

131. García-Azorín D, Aparicio-Cordero L, Talavera B, Johnson A, Schytz HW, et al. Clinical characterization of delayed alcohol-induced headache: A study of 1,108 participants. Neurology 2020;95(15):e2161-e2169. 
Guerrero AL, Porta-Etessam J, et al. Estudio sobre el subtriaje del Sistema de Triaje de Manchester en pacientes que acuden a urgencias por cefalea. Neurología 2020, S0213-4853(20)30275-9. doi: 10.1016/j.nrl.2020.06.019.

133. García-Azorín D, González-García N, Abelaira-Freira J, Marcos-Dolado A, Gurrero AL, Martín-Sánchez FJ, et al. Management of thunderclap headache in the emergency room: a retrospective cohort study. Cephalalgia 2021, doi: 10.1177/033310240981721.

134. García-Azorín D, Sierra A, trigo J, Alberdi A, Blanco M, Calcerrada I, et al. Frequency and phenotype of headache in Covid-19: a study of 2194 patients. J Headache Pain 2020, under evaluation.

135. García-Azorín D, Abelaira-Freire J, Rodríguez-Adrada E, González-García N, Planchuelo-Gómez, Guerrero AL, et al. Temporal distribution of emergency room visits in patients with migraine and other headaches. Sci Rep 2020, under evaluation.

136. García-Azorín D, Gantenbein A, Kristoferssen ES, Hansen JM, Nelson S, Obermann $M$, et al. Design of studies of headache in COVID-19: Expert recommendations of the Secondary Headache Special Interest Group of the International Headache Society. Eur J Neurol 2020, under evaluation.

137. García-Iglesias C, Martínez-Badillo C, García-Azorín D, Trigo-López J, Martínez-Pías E, Guerrero-Peral AL. Secondary numular headache: a new case series and review of the literature. Pain Med 2020, accepted.

138. Garrido Cumbrera M, Gálvez Ruiz D, Braçe O, Nieblas Rosado MI, Delgado Dominguez CJ, Colomina I et. al. Impacto y situación de la migraña en España: Atlas 2018. 1st. Ed. Universidad de Sevilla. ISBN: 978-84-472-2832-4.

139. Ghanizada H, Al-Karagholi MA, Arngrim N, Olesen J, Ashina M. PACAP27 induces migraine-like attacks in migraine patients. Cephalalgia 2020;40(1):57-67. 140. Global Burden of Disease 2016 Headache collaborators. global, regional, and national burden of migraine and tension-type headache, 1990-2016: a systematic-analysis for the Global Burden of Disease Study 2016. Lancet Neurol 2018;17(11):954-976. 
141. Global Burden of Disease 2016 Neurology collaborators. Global, regional, and national burden of neurological disorders, 1990-2016: a systematic analysis for the Global Burden of Disease Study 2016. Lancet Neurol 2019;18(5):459-480.

142. Global Burden of Disease 2017 Disease and Injury incidence and prevalence collaborators. Global, regional, and national incidence, prevalence and years lived with disability for 354 diseases and injuries for 195 countries and territories, 1990-2017: a systematic analysis for the Global Burden of Disease Study 2017. Lancet 2018;392(10159):1789-1858.

143. Global Burden of Disease 2019 Diseases and Injuries Collaborators. Global burden of 369 diseases and injuries in 204 countries and territories, 1990-2019: a systematic analysis for the Global Burden of Disease Study 2019. Lancet 2020;396(10258):1204-1222.

144. Global, regional, and national disability-adjusted life-years (DALYs) for 359 diseases and injuries and health life expectancy (HALE) for 195 countries and territories, 1990-2017: a systematic analysis for the Global Burden of Disease Study 2017. Lancet 2018;392(10159):1859-1922.

145. Goadsby PJ, Edvinsson L, Ekman R. Release of vasoactive peptides in the extracerebral circulation of humans and the cat during activation of the trigeminovascular system. Ann Neurol 1988;23(2):193-196.

146. Goadsby PJ, Edvinsson L, Ekman R. Vasoactive peptide release in the extracerebral circulation of humans during migraine headache. Ann Neurol 1990; 28(2):183-187.

147. Goadsby PJ, Edvinsson L. Human in vivo evidence for trigeminovascular activation in headache. Neuropeptide changes and effects of acute attacks therapies. Brain 1994;117(pt3):427-434.

148. Goadsby PJ, Edvinsson L. Neuropeptide changes in a case of chronic paroxysmal hemicrania-evidence for trigemino-parasympathetic activation. Cephalalgia 1996;16(6):448-450. 
149. Goadsby PJ. Reader response: Clinical characterization of delayed alcoholinduced headache: A study of 1,108 participants. Neurology 2020, online ahead of pub.

150. Godkemir MT, Nas C, Godkemir GS. Pentraxin 3 level in acute migraine attack with aura: patient management in the emergency department. Am J Emerg Med 2020;38(1):38-42.

151. Godwin SA, Cherkas DS, Panagos PD, Shih RD, Byyny R, Wolf SJ. Clinical policy: critical issues in the evaluation and management of adult patients presenting to the emergency department with acute headache. Ann Emerg Med 2019;74(4):e41-e74.

152. Goffaux P, Fortin D. Brain tumor headaches: from bedside to bench. Neurosurgery 2010;67(2):459-466.

153. Goldstein JN, Camargo CA, Pelletier AJ, Edlow JA. Headache in the United States emergency departments: demotraphics, work-up and frequency of pathological diagnoses. Cephalalgia 2006;26(6):684-690.

154. Goldust SA, Graber JJ, Bossert DF, Avila EK. Headache in patients with cancer. Curr Pain Headache Rep 2010;14(6):455-464.

155. Good clinical practice: consolidate guideline. In: Proceedings of the International Conference on Harmonisation of Technical Requirements for Registrations of Pharmaceuticals for Human Use, Geneva. International Conference on Harmonisation 1996.

156. Grände PO, Myhre EB, Nordström CH, Schliamser S. Treatment of intracranial hypertension and aspects on lumbar dural puncture in severe bacterial meningitis. Acta Anaesthesiol Scand 2002;46(3):264-70.

157. Grigoriadis E, Gold WL. Pyogenic brain abscess caused by Streptococcus pneumoniae: case report and review. Clin Infect Dis 1997;25(5):1108-1112.

158. Grossman SN, Han SC, Balcer L, Kurzweil A, Weinberg H, Galletta SL, et al. Rapid implementation of virtual neurology in response to the Covid-19 pandemic. Neurology 2020;94(24):1077-1087.

159. Grudzen CR, Anderson JR, Carpenter CR, Hess EP. The 2016 academic emergency medicine consensus conference, shared decision making in the 
emergency department: development of a policy-relevant patient-centered research agenda May 10, 2016, New Orleans, LA. Acad Emerg Med 2016;23(12):1313-1319.

160. Guan W, Ni Z, Hu Y, Liang WH, Ou CQ, He JX, et al. Clinical characteristics of coronavirus disease 2019 in China. N Engl J Med 2020;382(18):1708-1720.

161. Gudmundsson LS, Aspelund T, Scher Al, Thorgeirsson G, Johannsson M, Launer LJ, et al. C-reactive protein in migraine sufferers similar to that of nonmigraineurs: the Reykjavik Study. Cephalalgia 2009;29(12):1301-1310.

162. Guo L, Ren L, Yang S, Xiao M, Chang D, Yang F, et al. Profiling Early Humoral Response to Diagnose Novel Coronavirus Disease (COVID-19). Clin Infect Dis 2020;71(15):778-785.

163. Gürger M, Atescelik M, Yilmaz M, Yildiz M, Ali Kobat M, Demir CF. Can we define migraine patients with blood high-sensitivity C-reactive protein and galectin-3 levels in the emergency department? Arch Med Sci 2018;14(2):307312.

164. Hadidchi S, Surento W, Lerner A, Liu CJ, Gibbs WN, Kim PE, et al. Headache and brain tumor. Neuroimaging Clin N Am 2019;29(2):291-300.

165. Hanly JG, Urowitz MB, O'Keeffe AG, Gordon C, Bae SC, Sanchez-Guerrero J, et al. Headache in systemic lupus erythematosus: results from a prospective, international inception cohort study. Arthritis Rheum 2013;65(11):2887-97.

166. Hatem CF, Yri HM, Sørensen AL, Wegener M, Jensen RH, Hamann S. Longterm visual outcome in a Danish population of patients with idiopathic intracranial hypertension. Acta Ophthalmol 2018;96(7):719-723.

167. Hansen CK, Fisher J, Joyce N, Edlow JA. Emergency department consultations for patients with neurological emergencies. Eur J Neurol 2011;18(11):1317-1322.

168. Hansen CK, Fisher J, Joyce NR, Edlow JA. A prospective evaluation of indications for neurological consultation in the emergency department. Intern J Emerg Med 2015;8(1):74.

169. Harriott AM, Karakaya F, Ayata C. Headache after ischemic stroke: A systematic review and meta-analysis. Neurology 2020;94(1):e75-e86. 
170. Headache Classification Committee of the International Headache Society. Classification and diagnostic criteria for headache disorders, cranial neuralgias and facial pain. Cephalalgia 1988;8(suppl7):1-96.

171. Headache Classification Subcommittee of the International Headache Society. The international Classification of Headache Disorders: $2^{\text {nd }}$ edition. Cephalalgia 2004;24(suppl1):9-160.

172. Headache Classification Committee of the International Headache Society (IHS). The International Classification of Headache Disorders, $3^{\text {rd }}$ edition (beta version). Cephalalgia 2013;33(9):629-808.

173. Headache Classification Committee of the International Headache Society (IHS). The International Classification of Headache Disorders, 3rd edition. Cephalalgia 2018;38(1):1-211.

174. Hemasian H, Ansari B. First case of Covid-19 presented with cerebral venous thrombosis: A rare and dreaded case. Rev Neurol (Paris) 2020;176(6):521523.

175. Hénon H, Lebert F, Durieu I, Godefroy O, Lucas C, Pasquier F, et al. Confusional state in stroke: relation to preexisting dementia, patient characteristics, and outcome. Stroke 1999;30(4):773-779.

176. Henriquez J, Almorox EG, Garcia-Goñi M, Paolucci F. The first months of the COVID-19 pandemic in Spain. Health Policy Technol 2020;9(4):560-574.

177. Heo YE, Kwon HM, Nam HW. Thunderclap headache as an initial manifestation of phaeochromocytoma. Cephalalgia 2009;29(3):388-390.

178. Hoelscher C, Sweid A, Ghosh R, Al Saiegh F, Keppetipola KM, Farrell CJ, et al. Cerebral deep venous thrombosis and COVID-19: case report. J Neurosurg 2020;4:1-4.

179. Houle TT, Penzien DB, Houle CK. Statistical power and sample size estimation for headache research: an overview and power calculation tools. Headache 2005;45(5):414-418.

180. Houle TT, Turner DP, Penzien DB. Type I error in headache research. Headache 2013;53(7):1031-1033. 
181. Hsu YC, Sung SF. Spontaneous vertebral artery dissection with thunderclap headache: a case report and review of the literature. Acta Neurol Taiwan 2014;23(1):24-28.

182. Huang C, Wang Y, Li X, Ren L, Zhao J, Hu Y, et al. Clinical features of patients infected with 2019 novel coronavirus in Wuhan, China. Lancet 2020;395(10223):497-506.

183. Hughes C, Nichols T, Pike M, Subbe C, Elghenzai S. Cerebral venous sinus thrombosis as a presentation of COVID-19. Eur J Case Rep Intern Med 2020;7(5):001691.

184. Hussain S, Vattoth S, Hassan Haroon K, Muhammad A. A case of Coronavirus Disease 2019 presenting with seizures secondary to cerebral venous sinus thrombosis. Case Rep Neurol 2020;12(2):260-265.

185. Hussein A, Shafran S. Acute bacterial meningitis in adults: a 12-year review. Medicine (Baltimore) 2000;79(6):360-368.

186. Iannuzzi MC, Fontana JR. Sarcoidosis: clinical presentation, immunopathogenesis, and therapeutics. JAMA 2011;305(4):391-399.

187. Ing EB, Lahaie Luna G, Pagnoux C, Baer PA, Wang D, Benard-Seguin E, et al. The incidence of giant cell arteritis in Ontario, Canada. Can J Ophthalmol 2019;54(1):119-124.

188. Ioannides MA, Eftychiou C, Georgiou GM, Nicolaides E. Takayasu arteritis presenting as epileptic seizures: a case report and brief review of the literature. Rheumatol Int 2009;29(6):703-705.

189. Iurlaro S, Beghi E, Massetto N, et al. Does headache represent a clinical marker in early diagnosis of cerebral venous thrombosis? A prospective multicentric study. Neurol Sci 2004;25(Suppl3):S298-S299.

190. Jain S, Singhai K, Swami M. Seizure as a primary presentation in opioid withdrawal. Psychiatry Clin Neurosci 2018;72(10):802-803.

191. Jensen RH. Tension-Type Headache - The Normal and Most Prevalent Headache. Headache. 2018;58(2):339-345.

192. Jin D, Lian YJ, Zhang HF. Secondary SUNCT syndrome caused by dorsolateral medullary infarction. J Headache Pain 2016;17:12. 
193. Jordan JE, Ramirez GF, Bradley WG, Chen DY, Lightfoote JB, Song A. Economic outcomes assessment of magnetic resonance imaging in the evaluation of headache. J Natl Med Assoc 2000;92(12):573-578.

194. Kananeh MF, Thomas T, Sharma K, Herpich F, Urtecho J, Athar MK, et al. Arterial and venous strokes in the setting of COVID-19. J Clin Neurosci 2020;79:6066.

195. Karsan N, Bose PR, Thompson C, Newman J, Goadsby PJ. Headache and non-headache symptoms provoked by nitroglycerin in migraineurs: A human pharmacological triggering study. Cephalalgia 2020;40(8):828-841.

196. Kashkoush Al, Ma H, Agarwal N, Panczykowski D, Tonetti D, Weiner GM, et al. Cerebral venous sinus thrombosis in pregnancy and puerperium: A pooled, systematic review. J Clin Neurosci 2017;39:9-15.

197. Kaur A, Singh A. Clinical study of headache in relation to sinusitis and its management. J Med Life 2013;6(4):389-394.

198. Kefella H, Luther D, Hainline C. Ophthalmic and neuro-ophthalmic manifestations of sarcoidosis. Curr Opin Ophthalmol 2017;28(6):587-594.

199. Kelman L. Pain characteristics of the acute migraine attack. Headache 2006;46(6):942-953.

200. Kermani TA, Schmidt J, Crowson CS, Ytterberg SR, Hunder GG, Matteson $E L$, et al. Utility of erythrocyte sedimentation rate and C-reactive protein for the diagnosis of giant cell arteritis. Semin Arthritis Rheum 2012;41(6):866-871.

201. Kim K, Cho J, Moon J, et al. What factors determine the need for lumbar puncture in patients with fever and headache? Singapore Med J 2017;58(10):618-622.

202. Kim BS, Kim SK, Kim JM, Moon HS, Park KY, Park JW, Sohn JH, Song TJ, Chu MK, Cha MJ, Kim BK, Cho SJ. Factors Associated with Incidental Neuroimaging Abnormalities in New Primary Headache Patients. J Clin Neurol 2020;16(2):222229.

203. Kirsch CFE. Headache Caused by Sinus Disease. Neuroimaging Clin N Am 2019;29(2):227-241. 
204. Klein DE, Libman R, Kirsch C, Arora R. Cerebral venous thrombosis: A typical presentation of COVID-19 in the young. J Stroke Cerebrovasc Dis 2020;29(8):104989.

205. Komro J, Findakly D. Cerebral Venous Sinus Thrombosis in Adults with Prothrombotic Conditions: A Systematic Review and a Case from Our Institution. Cureus 2020;12(4):e7654.

206. Kong $X$, Chen J, Jiang $H$, Li Q, LV Y, Huang $Y$, et al. Testing of diagnosis criteria of tension-type headache: A multicenter clinical study. Cephalalgia 2018;38(12):1833-1840.

207. Kraemer M, Lee SI, Ayzenberg I, Schwitalla JC, Diehl RR, Berlit P, Bosche B, Katsarava Z, Obermann M. Headache in Caucasian patients with Moyamoya angiopathy - a systematic cohort study. Cephalalgia 2017;37(5):496-500.

208. Krief P, Silver A, Eberhard A, Maytal J. Fifteen-year-old girl with systemic lupus erythematosus and unilateral cerebellitis. Lupus 2010;19(8):981-984.

209. Krymchantowski AV. Headaches due to external compression. Curr Pain Headache Rep 2010;14(4):321-324.

210. Kuchar E, Miskiewicz K, Nitsch-Osuch A, Szenborn L. Pathophysiology of clinical symptoms in acute viral respiratory tract infections. Adv Exp Med Biol 2015;857:25-38.

211. Kwon PM, Evans RW, Grosberg BM. Cerebral Vascular Malformations and Headache. Headache 2015;55(8):1133-1142.

212. Lai SL, Chang YY, Liu JS, Chen SS. Cluster-like headache from vertebral artery dissection: angiographic evidence of neurovascular activation. Cephalalgia 2005;25(8):629-632.

213. Lai J, Harrison RA, Plecash A, Field TS. A Narrative Review of Persistent Post-Stroke Headache - A New Entry in the International Classification of Headache Disorders, 3rd Edition. Headache 2018;58(9):1442-1453.

214. Lambru G, Trimboli M, Tan SV, Al-Kaisy A. Medullary infarction causing coexistent SUNCT and trigeminal neuralgia. Cephalalgia 2017;37(5):486-490.

215. Lance JW. Headache. Ann Neurol 1981;10(1):1-10. 
216. Landtblom AM, Fridriksson S, Boivie J, Hillman J, Johansson G, Johansson I. Sudden onset headache: a prospective study of features, incidence and causes. Cephalalgia 2002;22(5):354-360.

217. Larsen EL, Ashina H, Iljazi A, Al-Khazali HM, Seem K, Ashina M, et al. Acute and preventive pharmacological treatment of post-traumatic headache: a systematic review. J Headache Pain 2019;20(1):98.

218. Lassman A, DeAngelis L. Brain metastases. Neurol Clin 2003;21(1):1-23.

219. Lawton MT, Vates GE. Subarachnoid Hemorrhage. N Engl J Med 2017;377(3):257-266.

220. Lebedeva ER, Kobzeva NR, Gilev DV, Kislyak NV, Olesen J. Psychosocial factors associated with migraine and tension-type headache in medical students. Cephalalgia 2017;37(13):1264-1271.

221. Lebedeva ER, Gurary NM, Olesen J. Headache in transient ischemic attacks. J Headache Pain 2018;19(1):60.

222. Lebedeva ER, Ushenin AV, Gurary NM, Gilev DV, Olesen J. Sentinel headache as a warning symptom of ischemic stroke. J Headache Pain 2020;21(1):70.

223. Lechien JR, Chiesa-Estomba CM, Place S, Van Laethem Y, Cabaraux P, Mat $Q$, et al. Clinical and epidemiological characteristics of 1420 European patients with mild-to-moderate coronavirus disease 2019. J Int Med 2020;288(3):335-344.

224. Lee AG, Beaver HA, Brazis PW. Painful ophthalmologic disorders and eye pain for the neurologist. Neurol Clin 2004;22(1):75-97.

225. Lei Q, Lv J, Kang B, Guo H, Fei Y, Chen R, et al. Comorbid SUNCT Syndrome and Opalski Syndrome Caused by Dorsolateral Medullary Infarction. Front Neurol. 2020;11:52.

226. Leicht MJ. Non-Traumatic headache in the emergency department. Leicht. Ann Emerg Med 1980;9(8):404-409.

227. Limper M, Eeftinck Schattenkerk D, de Kruif MD, van Wissen M, Brandjes DPM, Duits AJ, et al. One-year epidemiology of fever at the emergency department. Neth J Med 2011;69(3):124-128. 
228. Linn FHH, Wijdicks EFM, van der Graaf $\mathrm{Y}$, Weerdesteyn-van Vlient FAC, Bartelds AIM, van Gijn J. Prospective study of sentinel headache in aneurysmal subarachnoid haemorrhage. Lancet 1994;344(8922):590-593.

229. Liu IH, Wang AG, Yen MY. Idiopathic intracranial hypertension: clinical features in Chinese patients. Jpn J Ophthalmol 2011;55(2):138-142.

230. Liu Y, Peng X, Weng W, Zhu J, Cao H, Xie S. Efficacy of ventriculoperitoneal shunting in patients with cryptococcal meningitis with intracranial hypertension. Int J Infect Dis 2019;88:102-109.

231. Locker TE, Thompson C, Rylance J, Mason SM. The utility of clinical features in patients presenting with with nontraumatic headache: an investigation of adults patients attending an emergency department. Headache 2006;46(6):954-961.

232. Logan SAE, Macmahon E. Viral meningitis. BMJ 2008;336(7634):36-40.

233. Logidiani C, Lapichino G, Carenzo L, Cecconi M, Ferrazzi P, Sebastian T, et al. Venous and arerial thromboembolic complications in COVID-19 patients admitted to an academic hospital in Milan, Italy. Thromb Res 2020;191:9-14.

234. Lv X, Wang G. Review of de novo cerebral arteriovenous malformation: haemorrhage risk, treatment approaches and outcomes. Neuroradiol J 2018;31(3):224-229.

235. Lyngberg AC, Rasmussen BK, Jørgensen T, Jensen R. Has the prevalence of migraine and tension-type headache changed over a 12-year period? A Danish population survey. Eur J Epidemiol 2005;20(3):243-249.

236. Lyngberg AC, Rasmussen BK, Jørgensen T, Jensen R. Prognosis of migraine and tension-type headache: a population-based follow-up study. Neurology 2005;65(4):580-585.

237. Magdy R, Hussein M, Ragaie C, Abdel-Hamid HM, Khallaf A, Hoda I, et al. Characteristics of headache attributed to COVID-19 and predictors of its frequency and intensity: a cross sectional study. Cephalalgia 2020;40(13):14221431. 
238. Malentacchi M, Gned D, Angelino V, Demichelis S, Perboni A, Veltri A, et al. Concomitant brain arterial and venous thrombosis in a COVID-19 patient. Eur J Neurol 2020;27(9):e38-e39.

239. Mao L, Jin H, Wang M, Hu Y, Chen S, He Q, et al. Neurologic Manifestations of Hospitalized Patients with Coronavirus Disease 2019 in Wuhan, China. JAMA Neurol 2020;77(6):683-690.

240. Markey KA, Mollan SP, Jensen RH, Sinclair AJ. Understanding idiopathic intracranial hypertension: mechanisms, management, and future directions. Lancet Neurol 2016;15(1):78-91.

241. Martami F, Jahromi SR, Togha M, Ghorbani Z, Seifishahpar M, Saidpour A. The serum level of inflammatory markers in chronic and episodic migraine: a casecontrol study. Neurol Sci 2018;39(10):1741-1749.

242. Martín-Dávila P, Blanes M, Fortún J. Immunosuppression and infection in transplant recipients. Enferm Infecc Microbiol Clin 2007;25(2):143-154.

243. Marrodan M, Bensi C, Alessandro L, Muggeri AD, Farez MF. Chronic and Subacute Meningitis: Differentiating Neoplastic From Non-Neoplastic Etiologies. Neurohospitalist 2018;8(4):177-182.

244. Matsumoto H, Hanayama H, Sakurai Y, Minami H, Masuda A, Tominaga S, Miyaji K, Yamaura I, Yoshida Y, Hirata Y. Investigation of the characteristics of headache due to unruptured intracranial vertebral artery dissection. Cephalalgia 2019;39(4):504-514.

245. Matías-Guiu JA, Porta-Etessam J, García-Azorín D, Martín-Sánchez FJ. Analysis of in-hospital consultations between the emergency department and the on-call neurologist due to headaches. Neurologia 2016;31(8):577.

246. Mayo NE, Asano M, Barbic SP. When is a research question not a research question? J Rehabil Med 2013;45(6):513-518.

247. McBane II RD, Tafur A, Wysokinski WE. Acquired and congenital risk factors associated with cerebral venous sinus thrombosis. Thrombosis Res 2010;126(2):81-87.

248. Mea E, Savoiardo M, Chiapparini L, Casucci G, Bonavita V, Bussone G, et al. Headache and spontaneous low cerebrospinal fluid pressure syndrome. Neurol Sci 2007;28(Suppl 2):S232-S234. 
249. Mehta A, Chilakamarri P, Zubair A, Kuruvilla D. Chiari Headache. Curr Pain Headache Rep 2018;22(7):49.

250. Mehta A, Danesh J, Kuruvilla D. Cerebral Venous Thrombosis Headache. Curr Pain Headache Rep 2019;23(7):47.

251. Mehta P, McAuley DF, Brown M, Sanchez E, Tattersall RS, Manson JJ, et al. COVID-19: Consider cytokine storm syndromes and immunosuppression. Lancet 2020;395(10229):1033-1034.

252. Mekinian A, Maisonobe L, Boukari L, Melenotte C, Terrier B, Ayrignac X, et al. Characteristics, outcome and treatments with cranial pachymeningitis: A multicenter French retrospective study of 60 patients. Medicine (Baltimore) 2018;97(30):e11413.

253. Menal Muñoz P, Saez Valero E, Muñoz Jalle E, Gimeno Peribañez MJ. Cefalea hemicraneal secundaria a una malformación arteriovenosa gigante [Hemicranial headache secondary to a giant cerebral arteriovenous malformation]. Med Clin (Barc) 2016;146(11):518.

254. Michailidou D, Rosenblum JS, Rimland CA, Marko J, AhIman MA, Grayson PC. Clinical symptoms and associated vascular imaging findings in Takayasu's arteritis compared to giant cell arteritis. Ann Rheum Dis 2020;79(2):262-267.

255. Miller VE, Faurot KR, Palssson OS, Maclntosh BA, Suchindran C, Honvoh G, et al. Comparing prospective headache diary and retrospective four-week headache questionnaire over 20 weeks: Secondary data analysis from a randomized controlled trial. Cephalalgia 2020;40(13):1523-1531.

256. Minen MT, Loder E, Friedman B. Factors associated with emergency department visits for migraine: an observational study. Headache 2014;54(10):1611-1618.

257. Ministry of Health. Technical documents. Hospital management of COVID19. Version March 19, $2020 . \quad$ Available on https://www.mscbs.gob.es/profesionales/saludPublica/ccayes/alertasActual/nC ov-China/documentos/Protocolo manejo clinico ah COVID-19.pdf. Accessed on May $21^{\text {st }}, 2020$. 
258. Morgestern LB, Luna-Gonzales H, Huber JC, Wong SS, Uthman MO, Gurian $\mathrm{JH}$ et al. Worst headache and subarachnoid hemorrhage: prospective, modern computed tomography and fluid analysis. Ann Emerg Med 1998;32(3):297-304.

259. Mose LS, Pedersen SS, Debrabant B, Jensen RH, Gram B. The role of personality, disability and physical activity in the development of medicationoveruse headache: a prospective observational study. J Headache Pain 2018;19(1):39.

260. Moulin S, Leys D. Stroke mimics and chameleons. Curr Opin Neurol 2019;32(1):54-59.

261. Mowla A, Shakibajahromi B, Shahjouei S, Borhani-Haghighi A, Rahimian N, Baharvahdat $\mathrm{H}$, et al. Cerebral venous sinus thrombosis associated with SARSCoV-2; a multinational case series. J Neurol Sci 2020;419:117183.

262. Munoz-Ceron J, Marin-Careaga V, Peña L, Mutis J, Ortiz G. Headache at the emergency room: Etiologies, diagnostic usefulness of the ICHD 3 criteria, red and Green flags. PLoS ONE 2019;14(1):e0208728.

263. Munksgaard SB, Bendtsen L, Jensen RH. Treatment-resistant medication overuse headache can be cured. Headache 2012;52(7):1120-1129.

264. National Epidemiologic Surveillance Network. Daily report on the COVID19 situation. Report number 31, March 14 ${ }^{\text {th }}, 2020$. Available on https://www.isciii.es/QueHacemos/Servicios/VigilanciaSaludPublicaRENAVE/Enf ermedadesTransmisibles/Documents/INFORMES/Informes\%20COVID-

19/Informe\%20n-\%2031.\%20Situación\%20de\%20COVID-

19\%20en\%20España\%20a\%2014\%20de\%20mayo\%20de\%202020.pdf Accessed on June $2^{\text {nd }}, 2020$.

265. National Library of Medicine. National Center for Biotechnology Information. PubMed.gov. Available on https://pubmed.ncbi.nlm.nih.gov/?term=migraine\&size=200. Accessed on November 11, 2020.

266. Nelson S, Taylor LP. Headaches in brain tumor patients: primary or secondary? Headache 2014;54(4):776-785. 
267. Nesher R, Mimouni MD, Khoury S, Nesher G, Segal O. Delayed diagnosis of subacute angle closure glaucoma in patients presenting with headaches. Acta Neurol Belg 2014;114(4):269-272.

268. Newgard CD, Haukoos JS. Advanced statistics: missing data in clinical research--part 2: multiple imputation. Acad Emerg Med 2007;14(7):669-78.

269. Nicolosi A, Hauser W, Musicco M, Kurland L. Incidence and prognosis of brain abscess in a defined population: Olmsted County, Minnesota, 1935-1981. Neuroepidemiology 1991;10(3):122-131.

270. Nye BL, Ward TN. Clinic and emergency room evaluation and testing of headache. Headache 2015;55(9):1301-1308.

271. Nikiforow R. Headache in a random sample of 200 persons: A clinical study of a population in Northern Finland. Cephalalgia 1981;1(2):99-107.

272. Noben CY, de Rijk A, Nijhuis F, Kottner J, Evers S. The exchangeability of self-reports and administrative health care resource use measurements: assessment of the methodological reporting quality. J Clin Epidemiol 2016;74:93106.e2.

273. Nordhaug LH, Hagen K, Vik A, Stovner LJ, Follestad T, Pedersen T, et al. Headache following head injury: a population-based longitudinal cohort study (HUNT). J Headache Pain 2018;19(1):8.

274. Nozaki K, Scott TF, Sohn M, Judson MA. Isolated neurosarcoidosis: case series in 2 sarcoidosis centers. Neurologist 2012;18(6):373-277.

275. Olesen J, Steiner T, Bousser MG, Diener HC, Dodick D, First MB, et al. Proposals for new standardized general diagnostic criteria for the secondary headaches. Cephalalgias 2009;29(12):1331-1336.

276. Olesen J. Problem areas in the International Classification of Headache Disorders, $3^{\text {rd }}$ edition (beta). Cephalalgia 2014;34(14):1193-1199.

277. Olesen J. International Classification of Headache Disorders. Lancet Neurol 2018;17(5):396-397.

278. Olofsson IA, Kogelman L, Rasmussen A, Erikstrup C, Sórensen E, Paarup $\mathrm{HM}$, et al. Prevalence and socio-demotraphic characteristics of persons who have never had a headache among healthy voluntary blood donors - a populationbased study. Cephalalgia 2020;40(10):1055-1062. 
279. Osbun JW, Reynolds MR, Barrow DL. Arteriovenous malformations: epidemiology, clinical presentation, and diagnostic evaluation. Handb Clin Neurol 2017;143:25-29.

280. Paradowska-Stankiewicz I, Piotrowska A. Meningitis and encephalitis in Poland in 2014. Przegl Epidemiol 2016;70(3):349-357.

281. Pareja JA, Cuadrado ML. Lacrimal neuralgia: so far, a missing cranial neuralgia. Cephalalgia 2013;33(14):1198-1202.

282. Pareja JA, López-Ruiz P, Mayo D, Villar-Quiles RN, Cárcamo A, GutiérrezViedma Á, et al. Supratrochlear Neuralgia: A Prospective Case Series of 15 Patients. Headache 2017;57(9):1433-1442.

283. Pareja JA, Álvarez M, Cárcamo A, Liaño T, Rodríguez-Caravaca G, Cuadrado ML. Paroxysmal pressing headache: A new short-lasting headache. Cephalalgia 2019;39(7):921-926.

284. Pareja Grande JA, Caminero AB, García Azorín D, Ordás Bandera C, Santos Lasaosa S. On: Cefaleas Trigémino-Autonómicas. On: Santos Lasaosa S, Pozo Rosich P. Manual de práctica clínica en cefaleas. Recomendaciones diagnósticoterapéuticas de la Sociedad Española de Neurología 2020, p165-190. Ed. Luzán 5. ISBN: 978-84-18420-19-1.

285. Parikh R, Mathai A, Parikh S, Sekhar GC Thomas R. Understanding and using sensitivity, specificity and predictive values. Indian J Ophtalmol 2008;56(1):45-50.

286. Park KI, Chu K, Park JM, Kim M. Cluster-like Headache Secondary to Cerebral Venous Thrombosis. J Clin Neurol 2006;2(1):70-73.

287. Pascual J, Iglesias F, Oterino A, Vázquez-Barquero A, Berciano J. Cough, exertional, and sexual headaches: an analysis of 72 benign and symptomatic cases. Neurology 1996;46(6):1520-1524.

288. Pascual Gómez J. On: Tratado de Neurología Clínica, 2009. Ed. Ars Médica. ISBN: 978-849-751-395-1.

289. Pascual J. CGRP antibodies: the Holy Grail for migraine prevention? Lancet Neurol 2015;14(11):1066-1067. 
290. Perry JJ, Stiell IG, Sivilotti ML, Bullard MJ, Lee JS, Eisenhauer M, et al. High risk clinical characteristics for subarachnoid hemorrhage in patients with acute headache: prospective cohort study. BMJ 2010;341:c5204.

291. Pfund Z, Szapáry L, Jászberényi O, Nagy F, Czopf J. Headache in intracranial tumors. Cephalalgia 1999;19(9):787-790.

292. Piantanida E, Gallo D, Lombardi V, Tanda ML, Lai A, Ghezzi F, et al. Pituitary apoplexy during pregnancy: a rare, but dangerous headache. J Endocrinol Invest 2014;37(9):789-797.

293. Phillip D, Lyngberg A, Jensen R. Assessment of headache diagnosis. A comparative population study of a clinical interview with a diagnostic headache diary. Cephalalgia 2007;27(1):1-8

294. Pohl H, Do TP, García-Azorín D, Hansen JM, Kristoffersen ES, Nelson SE, et al. Green flags and headache. A concept study using the Delphi method. Headache 2021, doi: 10.1111/head.14054.

295. Poillon G, Obadia M, Perrin M, Savatovsky, Lecler A. Cerebral venous thrombosis associated with COVID-19 infection: Causality or coincidence? J Neuroradiol 2020;S0150-9861(20)30167-X.

296. Polkowska A, Toropainen M, Ollgren J, Lyytik ainen O, Nuorti JP. Bacterial meningitis in Finland, 1995-2014: a population-based observational study. BMJ Open 2017;7(5):e015080.

297. Polmear A. Sentinel headaches in aneurysmal subarachnoid haemorrhage: what is the true incidence? A systematic review. Cephalalgia 2003;23(10):935941.

298. Poncet-Megemont L, Paris P, Tronchere A, Salazard JP, Pereira B, Dallel R, et al. High prevalence of headaches during Covid-19 infection: A retrospective cohort study. Headache 2020;60(10):2578-2582.

299. Pradeep S, Smith JH. Giant Cell Arteritis: Practical Pearls and Updates. Curr Pain Headache Rep 2018;22(1):2.

300. Prakash S, Rathore C, Makwana P, Dave A. A Cross-Sectional Clinic-Based Study in Patients With Side-Locked Unilateral Headache and Facial Pain. Headache 2016;56(7):1183-1193. 
301. Prakash S, Rathore C. Side-locked headaches: an algorithm-based approach. J Headache Pain 2016;17(1):95.

302. Radojicic A, Vukovic-Cvetkovic V, Pekmezovic T, Trajkovic G, ZidvercTrajkovic J, Jensen RH. Predictive role of presenting symptoms and clinical findings in idiopathic intracranial hypertension. J Neurol Sci 2019;399:89-93.

303. Ramanayake RPJC, Basnayake BMTK. Evaluation of red flags minimizes missing serious diseases in primary care. J Family Med Prim Care 2018;7(2):315318.

304. Ramirez-Lassepas M, Espinosa CE, Cicero JJ, Johnston KL, Cipolle RJ, Barber DL. Predictors of intracranial pathologic findings in patients who seek emergency care because of headache. Arch Neurol 1997;54(12):1506-1509.

305. Ramírez-Moreno JM, Ollero-Ortiz A, Gómez-Barquero MJ, Roa-Montero A, Constantino Silva AB, Hernández Ramos FJ. Longitudinal study of in-hospital consultations with neurology in a tertiary hospital. A health care activity on the increase. Neurologia 2013;28(1):9-14.

306. Rassmussen BK, Jensen R, Schroll M, Olesen J. Epidemiology of headache in a general population - A prevalence study. J Clin Epidemiol 1991;44(11):11471157.

307. Rassmussen BK, Olesen J. Symptomatic and nonsymptomatic headaches in a general population. Neurology 1992;42(6):1225-1231.

308. Richardson AM, Joshy G, D'Este CA. Understanding statistical principles in linear and logistic regression. Med J Aust 2018;208(8):332-334.

309. Robart HA, Brennan PJ, Fife KH, Romero JR, Griffin JA, McKinlay MA, et al. Enteroirus meningitis in adults. Clin Infect Dis 1998;27(4):896-898.

310. Rodríguez S, Calleja S, Morís G. Cluster-like headache heralding cerebral venous thrombosis. Cephalalgia 2008;28(8):906-907.

311. Rodriguez Cruz PM, Pérez Sánchez JR, Cuello JP, Sobrino García P, Vicente Peracho G, Garcia Arratibel A, et al. Workload of on-call emergency room neurologists in a Spanish tertiary care centre. A one-year prospective study. Neurología 2014;29(4):193-199. 
312. Rojo Alvaro J, Toni M, Ollero M, Pineda J, Munárriz P, Anda E. Analysis of a series pheochromocytoma cases over 15 years. An Sist Sanit Navar 2012;35(2):199-205.

313. Romero-Sánchez CM, Díaz-Maroto I, Fernández-Díaz E, Sánchez-Larsen A, Layos-Romero A, García-García J, González E, et al. Neurologic manifestations in hospitalized patients with COVID-19: The ALBACOVID registry. Neurology 2020;95(8):e1060-e1070.

314. Romoli M, Jelcic I, Bernard-Valnet R, García-Azorín D, Mancinelli L, Akhvlediani T, et al. A systematic review of neurological manifestations of SARSCoV-2 infection: the devil is hidden in the details. Eur J Neurol 2020;27(9)17121726.

315. Rostami R, Mittal S, Rostami P, Tavassoli F, Jabbari B. Brain metastasis in breast cancer: a comprehensive literature review. J Neurooncol 2016;127(3):407414.

316. Roy AG, Vinayan KP, Kumar A. Idiopathic intracranial hypertension in pediatric population: case series from India. Neurol India 2013;61(5):488-490.

317. Roy-Gash F, De Mesmay M, Devys JM, Vespignani H, Blanc R, Engrand N. COVID-19-associated acute cerebral venous thrombosis: clinical, CT, MRI and EEG features. Crit Care 2020;24(1):419.

318. Rudolf J, Dermitzakis EV, Kyriazopoulou E, Nikiforidou D, Gravas I, Papadopoulos $\mathrm{V}$, et al. Workload of the emergency room neurologists and the neurological inpatient department in a Greek tertiary care hospital. Clin Neurol Neurosurg 2010;112(4):332-335.

319. Rushton JG, Rooke ED. Brain tumor headache. Headache 1962;2:147-152.

320. Russo A, Silvestro M, Cirillo M, Tessitore A, Tedeschi G. Idiopathic hypertrophic pachymeningitis mimicking hemicrania continua: An unusual clinical case. Cephalalgia 2018;38(4):804-807.

321. Saadatnia M, Pirhaji Z. Factors Influencing the Incidence of Papilledema in Patients with Cerebral Venous Thrombosis. Adv Biomed Res 2017;6:165.

322. Saber JL. Time is brain - quantified. Stroke 2006;37(1):263-266.

323. Salvarani C, Brown RD Jr, Hunder GG. Adult primary central nervous system vasculitis. Lancet. 2012;380(9843):767-777. 
324. Salvarani C, Brown RD Jr, Christianson T, Miller DV, Giannini C, Huston J $3 r d$, et al. An update of the Mayo Clinic cohort of patients with adult primary central nervous system vasculitis: description of 163 patients. Medicine (Baltimore) 2015;94(21):e738.

325. Samaie A, Asghari N, Ghorbani R, Arda J. Blood magnesium levels in migraineurs within and between the headache attacks: a case control study. Pan Afr Med J 2012;11:46.

326. Sampaio Rocha-Filho PA, Magalhaes JE. Headache associated with COVID19: Frequency, characteristics and association with anosmia and ageusia. Cephalalgia 2020;40(13):1443-1451

327. Sanchez-Bermejo. Encuesta a los profesionales de enfermería españoles sobre el triaje en los servicios de urgencias hospitalarios. Emergencias 2015;27(2):103-108.

328. Sánchez del Río González M, Medrano Martínez V, Pozo Rosich P, Ruiz Álvarez L, Torres Ferrús M. In: Capítulo 2. Fisiopatología, métodos diagnósticos, criterios de derivación y criterios de hospitalización. In: Santos Lasaosa S, Pozo Rosich P. Manual de práctica clínica en cefaleas. Recomendaciones diagnósticoterapéuticas de la Sociedad Española de Neurología 2020, p58. Ed. Luzán 5. ISBN: 978-84-18420-19-1.

329. Saposnik G, Barrinagarrementeria F, Brown RD, Bushnell CD, Cucchiara B, Cushman M, et al. Diagnosis and management of cerebral venous thrombosis. A statement for healthcare professionals from the American Heart Association/American Stroke Association. Stroke 2011;42(4):1158-1192.

330. Saver JL. Time is brain--quantified. Stroke 2006;37(1):263-266.

331. Saylor D, Steiner TJ. The global burden of headache. Semin Neurol 2018;38(2):182-190.

332. Schankin CJ, Ferrari U, Reinisch VM, Birnbaum T, Goldbrunner R, Straube A. Characteristics of brain tumour-associated headache. Cephalalgia 2007;27(8):904-911.

333. Schievink WI, Karemaker JM, Hageman LM, van der Werf DJ. Circumstances surrounding aneurysmal subarachnoid hemorrhage. Surg Neurol 1989;32(4):266-272. 
334. Schievink WI. Misdiagnosis of spontaneous intracranial hypotension. Arch Neurol 2003;60(12):1713-1718.

335. Schuetz P, Aujesky D, Müller C, Müller B. Biomarker-guided personalised emergency medicine for all - hope for another hype? Swiss Med Wkly 2015;145:w14079.

336. Schytz HW, Birk S, Wienecke T, Kruuse C, Olesen J, Ashina M. PACAP38 induces migraine-like attacks in patients with migraine without aura. Brain 2009;132(Pt 1):16-25.

337. Schytz HW, Schoonman GG, Ashina M. What have we learnt from triggering migraine? Curr Opin Neurol 2010;23(3):259-265.

338. Schytz HW, Ashina M, Magyari M, Larsen VA, Olesen J, Iversen HK. Acute headache and persistent headache attributed to cervical artery dissection: Field testing of ICHD-III beta. Cephalalgia 2014;34(9):712-716.

339. Schytz HW, Olesen J. Laboratory tests of headache disorders - dawn of a new era? Cephalalgia 2016;36(13):1268-1290.

340. Sendama W, Musgrave KM. Decision-making with D-Dimer in the diagnosis of pulmonary embolism. Am J Med 2018;131(12):1438-1443.

341. Sha DJ, Qian J, Gu SS, Wang LN, Wang F, Xu Y. Cerebral venous sinus thrombosis complicated by seizures: a retrospective analysis of 69 cases. J Thromb Thrombolysis 2018;45(1):186-191.

342. Shigematsu K, Shimamura O, Nakano H, Watanabe Y, Sekimoto T, Shimizu $\mathrm{K}$, et al. Vomiting should be a prompt predictor of stroke outcome. Emerg Med J 2013;30(9):728-731.

343. Shinohara Y. Hemorrhagic stroke syndromes: clinical manifestations of intracerebral and subarachnoid hemorrhage. Handb Clin Neurol 2009;93:577-94.

344. Singh $\mathrm{H}$, Sethi S, Raber M, Petersen LA. Errors in cancer diagnosis: current understanding and future directions. J Clin Oncol 2007;25(31):5009-5018.

345. Singh Rai G, Rai T, Jain L, Mohan Vyas M, Roshan R. Evaluation of CT and MRI findings among patients presented with chief complaint of headache in Central India. J Clin Diagn Res 2016;10(2):TC:21-25.

346. Singh RJ, Saini J, Varadharajan S, Baburao Kulkarni G, Veerendrakumar M. Headache in cerebral venous sinus thrombosis revisited: exploring the role of 
vascular congestion and cortical vein thrombosis. Cephalalgia 2018;38(3):503510.

347. Singhal AB, Hajj-Ali RA, Topcuoglu MA, Fok J, Bena J, Yang D, Calabrese LH. Reversible cerebral vasoconstriction syndromes: analysis of 139 cases. Arch Neurol 2011;68(8):1005-12.

348. Sigurdardottir B, Björnsson O, Jónsdőttir K, Erlendsdóttir $H$, Gudmundsson S. Acute bacterial meningitis in adults: a 20-year overview. Arch Intern Med 1997;157(4):425-430.

349. Smetana GW, Shmerling RH. Does this patient have temporal arteritis? JAMA 2002;287(1):92-101.

350. Smith GCS, Pell JP. Parachute use to prevent death and major trauma related to gravitational challenge: systematic review of randomized controlled trials. BMJ 2003;327(7429):1459-1461.

351. Sobri M, Lamont AC, Alias AN, Win MN. Red flags in patients presenting with headache: clinical indications for neuroimaging. $\mathrm{Br} J$ Radiol 2003;76(908):532-535.

352. Song JX, Lin XM, Hao ZQ, Wu SD, Xing YX. Ocular manifestations of internal carotid artery dissection. Int J Ophthalmol 2019;12(5):834-839.

353. Sordo L, Indave BI, Barrio G, Degenhardt L, de la Fuente L, Bravo MJ. Cocaine use and risk of stroke: a systematic review. Drug Alcohol Depend 2014;142:1-13.

354. Sparaco M, Feleppa M, Bigal ME. Cerebral venous thrombosis and headache - a case series. Headache 2015;55(6):806-814.

355. Steiner TJ, Stovner L, Katsarava Z, Láinez JM, Lampl C, Lantéri-Minet M, et al. The impact of headache in Europe: principal results of the Eurolight project. J Headache Pain 2014;15(1):31.

356. Steiner TJ, Stovner $\amalg$, Jensen R, Uluduz D, Katsarava Z; Lifting The Burden: the Global Campaign against Headache. Migraine remains second among the world's causes of disability, and first among young women: findings from GBD2019. J Headache Pain 2020;21(1):137.

357. Struyf T, Deeks JJ, Dinness J, Takwoingi Y, Davenport C, Leeflang MM, et al. Signs and symptoms to determine if a patient presenting in primary care or 
hospital outpatient settings has COVID-19 disease. Cochrane database syst rev 2020;7(7):CD013665.

358. Sturzenegger M. Headache and neck pain: the warning symptoms of vertebral artery dissection. Headache 1994;34(4):187-193.

359. Sugiyama Y, Tsuchiya T, Tanaka R, Ouchi A, Motoyama A, Takamoto T, et al. Cerebral venous thrombosis in COVID-19-associated coagulopathy: A case report. J Clin Neurosci 2020;79:30-32.

360. Suri H, Dougherty C. Presentation and Management of Headache in Pituitary Apoplexy. Curr Pain Headache Rep 2019;23(9):61.

361. Suwanwela N, Phanthumchinda K, Kaoropthum S. Headache in brain tumor: a cross-sectional study. Headache 1994;34(7):435-438.

362. Tabibian S, Motlagh H, Naderi M, Dorgalaleh A. Intracranial hemorrhage in congenital bleeding disorders. Blood Coagul Fibrinolysis 2018;29(1):1-11.

363. Talavera B, García-Azorín D, Martínez-Pías E, Trigo J, Hernández-Pérez I, Valle-Peñacoba G. Anosmia is associated with lower in-hospital mortality in COVID-19. J Neurol Sci 2020;419:117163.

364. Tentschert S, Wimmer R, Greisenegger S, Lang W, Lalouschek W. Headache at stroke onset in 2196 patients with ischemic stroke or transient ischemic attack. Stroke 2005;36(2):e1-3.

365. Terni E, Giannini N, Chiti A, Gialdini G, Orlandi G, Montano V, et al. Cerebral sinus venous thrombosis: clinical and pathogenetic perspectives from Tuscany. Blood Coagul Fibrinolysis 2015;26(5):505-508.

366. Thakkur KT, Albanese E, Giannakopoulos P, Jette N, Linde M, et al. Chapter 3: Neurological Disorders. Headache Disorders, In: Patel V, Chisholm D, Dua T, Laxminarayan R, Medina-Mora ME. Mental, Neurological, and Substance Use Disorders: Disease Control Priorities, Third Edition (Volume 4). Whashington (DC): The International Bank for Reconstruction and Development / The World Bank; 2016, 2015. p99-108. Disease Control Priorities. Third Edition. World Bank Group. ISBN: 978-1-4648-0428-1. doi: 10.1596/978-1-4648-0426-7_ch3.

367. Thakur KT, Wilson MR. Chronic Meningitis. Continuum (Minneap Minn) 2018;24(5, Neuroinfectious Disease):1298-1326. 
368. Thigpen MC, Whitney CG, Messonnier NE, Zell ER, Lynfield R, Hadler JL, et al. Bacterial meningitis in the United States, 1998-2007. N Engl J Med 2011;364(21):2016-2025.

369. Tietjen GE, Khubchandani J, Herial N, Palm-Meinders ICH, Koppen H, Terwindt GM, et al. Migraine and vascular disease biomarkers: A populationbased case-control study. Cephalalgia 2018;38(3):511-518.

370. Timóteo Â, Inácio N, Machado S, Pinto AA, Parreira E. Headache as the sole presentation of cerebral venous thrombosis: a prospective study. J Headache Pain 2012;13(6):487-90.

371. Toom K, Braschinsky M, Obermann M, Katsarava Z. Secondary headache attributed to exposure to or overuse of a substance. Cephalalgia 2020:333102420942238. doi: 10.1177/0333102420942238.

372. Tripepi G, Jager KJ, Dekker FW, Zoccali C. Linear and logistic regression analysis. Kidney Int 2008;73(7):806-810.

373. Tsai LK, Jeng JS, Liu HM, Wang HJ, Yip PK. Intracranial dural arteriovenous fistulas with or without cerebral sinus thrombosis: analysis of 69 patients. J Neurol Neurosurg Psychiatry 2004;75(11):1639-1641.

374. Tsushima Y, Endo K. MR imaging in the evaluation of chronic or recurrent headache. Radiology 2005;235(2):575-579.

375. Trigo J, García-Azorín D, Martinez Pias E, Sierra Á, Chavarría A, Guerrero AL. Clinical characteristics of nummular headache and differentiation between spontaneous and posttraumatic variant: an observational study. J Headache Pain 2019;20(1):34.

376. Trigo J, García-Azorín D, Planchuelo-Gómez A, García-lglesias C, DueñasGutiérrez C, Guerrero AL. Phenotypic characterization of acute headache attributed to SARS-CoV-2: An ICHD-3 validation study on 106 hospitalized patients. Cephalalgia 2020;40(12):1432-1442

377. Tuka B, Helyes Z, Markovics A, et al. Alterations in PACAP-38-like immunoreactivity in the plasma during ictal and interictal periods of migraine patients. Cephalalgia 2013;33(13)1085-1095. 
378. Turner DP, Deng H, Houle TT. Statistical Hypothesis Testing: Overview and Application. Headache 2020;60(2):302-308.

379. United States. National Library of Medicine, ClinicalTrials.gov. Available on https://clinicaltrials.gov/ct2/results?cond=migraine \&term $=\&$ cntry $=\&$ state $=\&$ city $\underline{=\& \text { dist }}=$ Accessed on November 11, 2020.

380. Valade D. The emergency headache center at the Lariboisière Hospital: 7 years with more than 70,000 patients. Intern Emerg Med 2008;3(suppl1):S3-S7. 381. Valentinis L, Tuniz F, VAlent F, Mucchiut M, Little D, Skrap M, et al. Headache attributed to intracranial tumours: a prospective cohort study. Cephalalgia 2010;30(4):389-398.

382. van de Beek D, de Gans J, Spanjaard L, Weisfelt M, Reitsma JB, Vermeulen M. Clinical features and prognostic factors in adults with bacterial meningitis. $\mathrm{N}$ Engl J Med 2004; 351(18):1849-1859.

383. Van de Beek D, Cabellos C, Dzupova O, Esposito S, Klein M, Kloek AT, et al. ESCMID guideline: diagnosis and treatment of acute bacterial meningitis. Clin Microbiol Infect 2016;22(suppl 3):S37-S62.

384. Vazquez-Barquero A, Ibáñez FJ, Herrera S, Izqueirdo JM, Berciano J, Pascual J. Isolated headache as the presenting clinical manifestation of intracranial tumors: a prospective study. Cephalalgia 1994;14(4):270-272.

385. Verma R, Sarkar S, Garg RK, Malhotra HS, Sharma PK, Saxena S. Ophthalmological manifestation in patients of tuberculous meningitis. QJM 2019;112(6):409-419.

386. Von Elm E, Altman DG, Egger M, et al. The Strengthening the Reporting of Observational Studies in Epidemiology (STROBE) statement: guidelines for reporting observational studies. PLoS Med 2007;4(10):e296.

387. Vukovic Cvetkovic V, Strineka M, Knezevic-Pavlic M, Tumpic-Jakovic J, Lovrencic-Huzjan A. Analysis of headache management in emergency room. Acta Clin Croat 2013;52(3):281-288.

388. Wakerley BR, Tan MH, Ting EY. Idiopathic intracranial hypertension. Cephalalgia 2015;35(3):248-261. 
389. Wall M, Kupersmith MJ, Kieburtz KD, Corbett JJ, Feldon SE, Friedman DI, et al; NORDIC Idiopathic Intracranial Hypertension Study Group. The idiopathic intracranial hypertension treatment trial: clinical profile at baseline. JAMA Neurol 2014;71(6):693-701.

390. Wang $H Z$, Simonson TM, Greco WR, Yuh WT. Brain MR imaging in the evaluation of chronic headache in patients without other neurologic symptoms. Acad Radiol 2001;8(5):405-408.

391. Wang JZ, Vyas MV, Saposnik G, Burneo JG. Incidence and management of seizures after ischemic stroke: Systematic review and meta-analysis. Neurology 2017;89(12):1220-1228.

392. Wasay M, Kojan S, Dai Al, Bobustuc G, Sheikh Z. Headache in cerebral venous thrombosis: Incidence, pattern and location in 200 consecutive patients. J Headache Pain 2010;11(2):137-139.

393. Wei JH, Wang HF. Cardiac cephalalgia: case reports and review. Cephalalgia 2008;28(8):892-896.

394. Weimar C. Diagnosis and treatment of cerebral venous and sinus thrombosis. Curr Neurol Neurosci Rep 2014;14(1):417.

395. Wicinski M, Al Drawi AS, Malinowski B, Stolarek W. Evaluation of Vascular Endothelial Growth Factor and selected parameters of coagulation and fibrinolysis in a group of patients with subarachnoid hemorrhage. Biomed Res Int 2019;2019:8759231.

396. Wilne SH, Ferris RC, Nathwani A, Kennedy CR. The presenting features of brain tumours: a review of 200 cases. Arch Dis Child 2006;91(6):502-506.

397. Whitley R, Soong S, Linneman CJ, Liu C, Pazin G, Alford C. Herpes simplex encephalitis. Clinical Assessment. JAMA 1982;247(3):317-320.

398. Whitley E, Ball J. Statistics review 4: sample size calculations. Crit Care 2002;6(4):335-41.

399. Xu H, Zhong L, Deng J, Peng J, Dan H, Zeng X, et al. High expression of ACE2 receptor of 2019-nCoV on the epithelial cells of oral mucosa. Int J Oral Sci 2020;12(1):8. 
400. Yamada SM, Tomita Y, Murakami H, Nakane M, Yamada S, Murakami M, et al. Headache in patients with chronic subdural hematoma: analysis in 1080 patients. Neurosurg Rev 2018;41(2):549-556.

401. Yamani N, Olesen J. New daily persistent headache: a systematic review on an enigmatic disorder. J Headache Pain 2019;20(1):80.

402. Yazar HO, Yazar T, Aygün A, Kaygisiz S, Kirbas D. Evaluation of simple inflammatory blood parameters in patients with migraine. Irish J Med Sci 2020;189(2):677-683.

403. Yilmaz N, Yilmaz M, Sirin B, Yilmaztekin S, Kutlu G. The relationship between levels of plasma-soluble urokinase plasminogen activator receptor (suPAR) and presence of migraine attack and aura. J Recept Signal Transduct Res 2017;37(5):447-452.

404. Yilmaz DY, Armagan HH, Karaman K, Sirin FB, Bozkurt F, Karaibrahimoglu A, et al. Clinical use of copeptin in migraine patients admitted to the emergency department. Am J Emerg Med 2020;39(9):1910-1914.

405. Yip VCH, Wong HT, Yong VKY, Lim BA, Hee OK, Cheng J, et al. Optical Coherence Tomography Angiography of Optic Disc and Macula Vessel Density in Glaucoma and Healthy Eyes. J Glaucoma 2019;28(1):80-87.

406. Yri HM, Jensen RH. Idiopathic intracranial hypertension: Clinical nosography and field-testing of the ICHD diagnostic criteria. A case-control study. Cephalalgia 2015;35(7):553-562.

407. Yucel Y, Tanriverdi H, Arikanoglu A, Varol S, Kaplan I, Akil E, et al. Increased fibrinogen, D-dimer and galectin 3 levels in patients with migraine. Neurol Sci 2014;35(4):545-549.

408. Zagami AS, Goadsby PJ, Edvinsson L. Stimulation of the superior saggital sinus in the cat causes release of vasoactive peptides. Neuropeptides 1990;16(2):69-75.

409. Zarranz Imirizaldu JJ. In: Neurología. $6^{\text {th }}$ edition. Ed. Elsevier, 2018. ISBN: 978-8491-130-710.

410. Zhao T, Wang G, Dai J, Liu Y, Wang Y, Li S. Cases of visual impairment caused by cerebral venous sinus occlusion-induced intracranial hypertension in the absence of headache. BMC Neurol 2018;18(1):159. 
411. Zhu K, Born DW, Dilli E. Secondary Headache: Current Update. Headache 2020;60(10):2654-2664.

412. Zoons E, Weisfelt M, de Gans J, Spanjaard L, Koelman JH, Reitsma JB, et al. Seizures in adults with bacterial meningitis. Neurology 2008;70(22 Pt 2):2109-15. 


\section{5}


X. APPENDIX 


\section{Supplementary appendix}

\section{APPENDIX I: Ethics review board approvals}

Ilospital Clínico San Carlos

Informe Dictamen Protocolo Favorable

C.P. - C.I. $14 / 425-E$

14 de octubre de 2014

\section{CEIC Hospital Clínico San Carlos}

Dra. Mar García Arenillas

Presidenta del CEIC Hospital Clínico San Carlos

\section{CERTIFICA}

Que el CEIC Hospital Clínico San Carlos en su reunión del día 08/10/2014, acta 10.1/14 ha evaluado la propuesta del promotor/investigador referida al estudio:

Título: "Herramienta clínica de ayuda diagnóstica de patología de alto riesgo vital en los pacientes atendidos por cefalea en un Servicio de Urgencias"

Que en este estudio:

- Se cumplen los requisitos necesarios de idoneidad del protocolo en relación con los objetivos del estudio y están justificados los riesgos y molestias previsibles para el sujeto.

- Es adecuado el procedimiento para obtener el consentimiento informado.

- La capacidad del investigador y los medios disponibles son adecuados para llevar a cabo el estudio.

- El alcance de las compensaciones económicas previstas no interfiere con el respeto de los postulados éticos.

- Se cumplen los preceptos éticos formulados en la Declaración de Helsinki de la Asociación Médica mundial sobre principios éticos para las investigaciones médicas en seres humanos y en sus posteriores revisiones, así como aquellos exigidos por la normativa legal aplicable en función de las características del estudio.

Es por ello que el Comité informa favorablemente sobre la realización de dicho proyecto por el Dr. David García Azorín como investigador principal en el Servicio de Neurología del Hospital Clínico San Carlos.

Lo que firmo en Madrid, a 14 de octubre de 2014

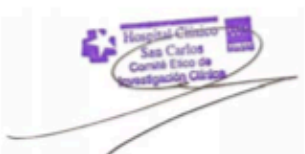

Dra. Mar García Arenillas

Presidenta del CEIC Hospital Clínico San Carlos

$$
\text { Doctor Martín Lagos, s/n. Madrid } 28040 \text { Madrid España }
$$



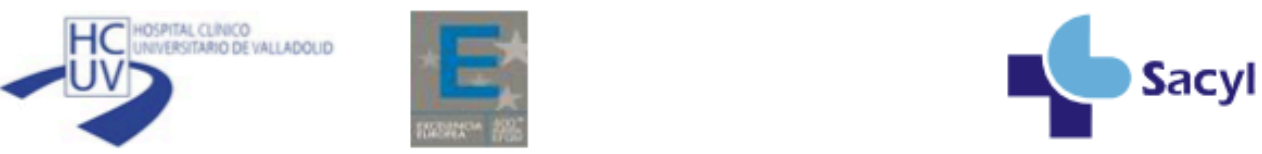

Avda. Ramón y Cajal, 3 - 47003 Valladolid Tel.: $983420000^{-}$- Fax 983257511

gerente.hcuv@saludcastillayleon.es

\section{COMITÉ de ÉTICA DE LA INVESTIGACIÓN CON MEDICAMENTOS ÁREA DE SALUD VALLADOLID}

Valladolid a 8 de abril de 2020

En la reunión del CEIm ÁREA DE SALUD VALLADOLID ESTE del 8 de abril de 2020, se procedió a la evaluación de los aspectos éticos del siguiente proyecto de investigación.

\begin{tabular}{|l|l|l|}
\hline PI 20- & CARACTERIZACIÓN DE LA CEFALEA RE- & I.P.: DAVID GARCÍA \\
1738 & LACIONADA CON LA ENFERMEDAD CO- & AZORÍN \\
& VID19 & EQUIPO: CARLOS DUE- \\
& & ÑA, SANTIAGO JUA- \\
& & RROS, LUISA HURTADO \\
& & REBOLLO, ÁNGEL L \\
& & GUERRERO PERAL \\
& & NEUROLOGÍA \\
\hline
\end{tabular}

A continuación, les señalo los acuerdos tomados por el CEIm ÁREA DE SALUD VALLADOLID ESTE en relación a dicho Proyecto de Investigación:

Considerando que el Proyecto contempla los Convenios y Normas establecidos en la legislación española en el ámbito de la investigación biomédica, la protección de datos de carácter personal y la bioética, se hace constar el informe favorable y la aceptación del Comité de Ética de la Investigación con Medicamentos Área de Salud Valladolid Este para que sea llevado a efecto dicho Proyecto de Investigación.

Un cordial saludo.

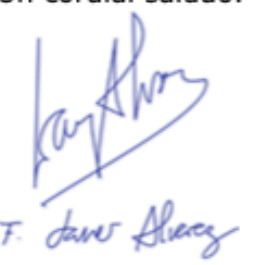

Dr. F. Javier Álvarez.

CEIm Área de Salud Valladolid Este

Hospital Clínico Universitario de Valladolid

Farmacología, Facultad de Medicina, Universidad de Valladolid,

c/ Ramón y Cajal 7,47005 Valladolid

alvarez@med.uva.es,

jalvarezgo@saludcastillayleon.es

tel.: 983423077 
APPENDIX III: Questionnaire used in the studies

CUADERNO RECOGIDA DE DATOS

\begin{tabular}{|c|c|}
\hline VARIABLES & RESP. \\
\hline Número de Registro: & \\
\hline NHC: & \\
\hline Fecha de filiación: dd/mm/aaaa hh:mm & \\
\hline Fecha de nacimiento: $\mathrm{dd} / \mathrm{mm} / \mathrm{aaaa}$ & \\
\hline Sexo (1 mujer, 2 varón). & \\
\hline Nacionalidad: (1 español, 2 otras) (anotar cual) & \\
\hline $\begin{array}{l}\text { ¿Tiene alguna enfermedad o tratamiento que condicione inmunosupresión? } 1 \text { si, } 2 \\
\text { no, cuál? }\end{array}$ & \\
\hline ¿Tiene algún antecedente oncológico? 1 si, 2 no, cuál? & \\
\hline TRATAMIENTO ACTUAL & \\
\hline ¿Toma anticoagulantes? 1 si, 2 no. Indicad: ACO; NACO; HBPM. & \\
\hline ¿Toma antiagregantes? 1 si, 2 no. Especificar tipo y dosis: & \\
\hline ¿Toma anticonceptivos? 1 si, 2 no & \\
\hline $\begin{array}{l}\text { ¿Ha consumido o hay signos de intoxicación por alcohol, cocaína, heroína, } \\
\text { cannabis, éxtasis u otra droga? Especificar tipo. Pregunta: Ha consumido usted } \\
\text { algún tóxico? }\end{array}$ & \\
\hline ¿Consume alcohol de manera regular? 1 si, 2 no & \\
\hline ANAMNESIS: & \\
\hline ¿Cuántos minutos ha tardado su cefalea en alcanzar la máxima intensidad?: & \\
\hline ¿El dolor ha aparecido al realizar algún esfuerzo?: 1 si, 2 no ¿Qué esfuerzo? & \\
\hline $\begin{array}{l}\text { ¿Ha empeorado su dolor de cabeza progresiva y constantemente desde que } \\
\text { comenzó? } 1 \mathrm{si}, 2 \text { no }\end{array}$ & \\
\hline ¿Ha tenido episodios previos como éste? 1 si, 2 no ¿Cuántos? & \\
\hline $\begin{array}{l}\text { ¿El dolor de cabeza aparece tras cambiar de postura desde estar tumbado a estar } \\
\text { de pie o al revés? } 1 \mathrm{si}, 2 \text { no Especificar. }\end{array}$ & \\
\hline ¿Le aparece dolor de cabeza al tocarse o rozarse la cabeza? 1 si, 2 no & \\
\hline ¿Se ha golpeado la cabeza en los últimos 2 meses? 1 si, 2 no Cuándo? & \\
\hline $\begin{array}{l}\text { Desde que comenzó el dolor de cabeza, ¿̇ha tenido algún episodio de pérdida de } \\
\text { conciencia? } 1 \text { si, } 2 \text { no }\end{array}$ & \\
\hline $\begin{array}{l}\text { ¿Es despertado por el dolor de cabeza durante la noche? (especificar que NO se } \\
\text { despierta por otro motivo y tiene cefalea) } 1 \text { si, } 2 \text { no }\end{array}$ & \\
\hline $\begin{array}{l}\text { ¿Le duele la cabeza cuando come algún alimento especial, está estresado o tiene } \\
\text { la menstruación? } 1 \text { si, } 2 \text { no Especificar. }\end{array}$ & \\
\hline ¿Del 1 al 10 que intensidad máxima diría que tiene su dolor? & \\
\hline SÍNTOMAS ACOMPAÑANTES: & \\
\hline ¿Ha tenido náuseas coincidiendo con el dolor de cabeza? 1 si, 2 no & \\
\hline ¿Ha vomitado desde que le duele la cabeza? 1 si, 2 no & \\
\hline ¿Coincidiendo con el dolor de cabeza le molesta la luz? 1 si, 2 no & \\
\hline ¿Coincidiendo con el dolor de cabeza le molesta el ruido? 1 si, 2 no & \\
\hline ¿Coincidiendo con el dolor de cabeza le molestan los olores? 1 si, 2 no & \\
\hline
\end{tabular}




\begin{tabular}{|c|c|}
\hline $\begin{array}{l}\text { ¿Coincidiendo con el dolor de cabeza se le pone el ojo rojo, le llora el ojo, se le } \\
\text { hincha el párpado, le cae moquillo, nota las fosas nasales ocupadas o se encuentra } \\
\text { muy intranquilo? } 1 \text { si, } 2 \text { no Especificar. }\end{array}$ & \\
\hline $\begin{array}{l}\text { ¿Ha visto lucecitas o alguna otra cosa poco antes de que comenzase a dolerle la } \\
\text { cabeza? } 1 \text { si, } 2 \text { no Especificar }\end{array}$ & \\
\hline $\begin{array}{l}\text { Cuando le está doliendo la cabeza, ¿̇le molesta especialmente al caminar? } 1 \text { si, } 2 \\
\text { no }\end{array}$ & \\
\hline ¿Ha tenido temperatura $>37,5$ ㅇ? 1 si, 2 no & \\
\hline $\begin{array}{l}\text { Preguntar a testigo: ¿Se ha quedado como desconectado, con la mirada perdida, } \\
\text { ha hecho movimientos de chupeteo o toqueteando cosas con las manos o ha } \\
\text { llegado a convulsionar? } 1 \mathrm{si}, 2 \text { no. Especificar. }\end{array}$ & \\
\hline ¿Le ha dolido el cuello? 1 si, 2 no & \\
\hline ¿Ha perdido la fuerza en alguna extremidad? 1 si, 2 no Especificar & \\
\hline $\begin{array}{l}\text { ¿Ha notado hormigueo o que tuviera alguna parte del cuerpo dormida como } \\
\text { anestesiada? } \quad 1 \text { si, } 2 \text { no. Especificar. }\end{array}$ & \\
\hline $\begin{array}{l}\text { ¿Ha tenido problemas para decir lo que quería decir, para entender lo que le } \\
\text { decían o para pronunciar bien? } 1 \text { si, } 2 \text { no Especificar. }\end{array}$ & \\
\hline $\begin{array}{l}\text { ¿Ha tenido visión borrosa, doble, pérdida de visión u otros problemas visuales? } 1 \\
\text { si, } 2 \text { no Especificar. }\end{array}$ & \\
\hline $\begin{array}{l}\text { ¿Ha estado tan adormilado que fuese difícil que respondiese a lo que se le decía? } 1 \\
\text { si, } 2 \text { no }\end{array}$ & \\
\hline ¿Se ha comportado de manera claramente extraña? 1 si, 2 no Especificar. & \\
\hline EXPLORACIÓN: & \\
\hline Focalidad neurológica? 1 si, 2 no & \\
\hline Qué focalidad? & \\
\hline Signos meníngeos? 1 si, 2 no & \\
\hline Rigidez de nuca? 1 si, 2 no & \\
\hline Realizado fondo de ojo? 1 si, 2 no; Edema de papila: 1 si, 2 no & \\
\hline Tensión arterial a la llegada a urgencias $(\mathrm{mmHg})$ : & \\
\hline Temperatura a la llegada a urgencias ( $(\mathrm{O})$ : & \\
\hline Frecuencia cardiaca a la llegada a urgencias (Ipm): & \\
\hline Nivel de conciencia a la llegada a urgencias (GCS): & \\
\hline Arterias temporales patológicas?: 1 si, 2 no & \\
\hline Alteración pupilar: 1 si, 2 no. Especificar & \\
\hline
\end{tabular}




\section{HOJA DE INFORMACIÓN AL PACIENTE}

\section{Estudio: "HERRAMIENTA CLÍNICA DE AYUDA DIAGNÓSTICA DE PATOLOGÍA DE ALTO RIESGO VITAL EN LOS PACIENTES ATENDIDOS POR CEFALEA EN UN SERVICIO DE URGENCIAS".}

\section{INTRODUCCION}

Nos dirigimos a usted para informarle sobre un estudio de investigación que estamos realizando en pacientes que son atendidos por episodio de dolor de cabeza en el Servicio de Urgencias y en el que se le invita a participar. El estudio ha sido aprobado por el Comité Ético de Investigación Clínica del Hospital Clínico San Carlos.

Nuestra intención es tan solo que usted reciba la información correcta y suficiente para que pueda evaluar y juzgar si quiere o no participar en este estudio. Para ello lea esta hoja informativa con atención y nosotros le aclararemos las dudas que le puedan surgir después de la explicación. Además, puede consultar con las personas que considere oportuno.

\section{DESCRIPCIÓN GENERAL DEL ESTUDIO.}

El dolor de cabeza es un motivo de consulta frecuentes en los Servicios de Urgencias, y en ocasiones con consecuencias fatales. Por ello, estamos desarrollando un estudio con el objetivo de identificar una escala de datos clínicos que nos ayude a identificar si tiene o no una patología de riesgo vital en los pacientes atendidos por cefalea un Servicios de Urgencias Hospitalario.

\section{PROCEDIMIENTO}

El estudio consiste en una entrevista estructurada que consta de preguntas sobre sus datos demográficos, tratamientos farmacológicos, enfermedades previas y datos clínicos del episodio urgente. Se le practicará un fondo de ojo y una ecografía para medir el diámetro de la vaina del nervio óptico. Además, tras el alta, a los 30 días, un investigador contactará con usted mediante una llamada telefónica con el fin de conocer su situación de salud. No se va a realizar ningún procedimiento invasivo que no fuera a realizar en función de su problema de salud.

\section{BENEFICIOS Y RIESGOS DERIVADOS DE SU PARTICIPACIÓN EN EL ESTUDIO.}

Los participantes que intervengan en el estudio se les someterá a una valoración global integral pero es posible que no se obtenga ningún beneficio para su salud por participar en el mismo. No se espera a priori que los pacientes estén sometidos a ningún riesgo importante como consecuencia de la participación en el estudio. 


\section{PARTICIPACIÓN VOLUNTARIA.}

Debe saber que su participación en este estudio es voluntaria y que puede decidir no participar o cambiar su decisión y retirar el consentimiento en cualquier momento, sin que por ello se altere la relación con su médico ni se produzca perjuicio alguno en su tratamiento.

\section{CONFIDENCIALIDAD.}

El tratamiento, la comunicación y la cesión de los datos de carácter personal de todos los sujetos participantes se ajustará a lo dispuesto en la Ley Orgánica 15/1999, de 13 de diciembre de protección de datos de carácter personal. De acuerdo a lo que establece la legislación mencionada, usted puede ejercer los derechos de acceso, modificación, oposición y cancelación de datos, para lo cual deberá dirigirse a su médico del estudio.

Los datos recogidos para el estudio estarán identificados mediante un código y solo su médico del estudio/colaboradores podrán relacionar dichos datos con usted y con su historia clínica. Por lo tanto, su identidad no será revelada a persona alguna salvo excepciones.

El acceso a su información personal quedará restringido al médico del estudio/colaboradores, al Comité Ético de Investigación Clínica y personal autorizado por el grupo de estudio, cuando lo precisen para comprobar los datos y procedimientos del estudio, pero siempre manteniendo la confidencialidad de los mismos de acuerdo a la legislación vigente.

\section{COMPENSACIÓN ECONÓMICA.}

Su participación en el estudio no le supondrá ningún gasto.

\section{PREGUNTAS/INFORMACION}

Si usted o tiene cualquier pregunta sobre el estudio, contacte con el Investigador Principal de su Centro.

Al firmar la hoja de consentimiento adjunta, se compromete a cumplir con los procedimientos del estudio que se le han expuesto. 
Informed consent form

FORMULARIO DE CONSENTIMIENTO INFORMADO

Estudio: "HERRAMIENTA CLÍNICA DE AYUDA DIAGNÓSTICA DE PATOLOGÍA DE ALTO RIESGO VITAL EN LOS PACIENTES ATENDIDOS POR CEFALEA EN UN SERVICIO DE URGENCIAS".

Yo

He leído la hoja de información que se me ha entregado.

He podido hacer preguntas sobre el estudio.

He recibido suficiente información sobre el estudio.

He hablado con

Comprendo que mi participación es voluntaria.

Comprendo que puedo retirarme del estudio:

1. Cuando quiera

2. Sin tener que dar explicaciones

3. Sin que esto repercuta en mis cuidados médicos

Presto libremente mi conformidad para participar en el ensayo

Fecha

Firma del participante

Fecha

Firma del investigador 
Estudio: "HERRAMIENTA CLÍNICA DE AYUDA DIAGNÓSTICA DE PATOLOGÍA DE ALTO RIESGO VITAL EN LOS PACIENTES ATENDIDOS POR CEFALEA EN UN SERVICIO DE URGENCIAS".

Yo en calidad de

de

He leído la hoja de información que se me ha entregado.

He podido hacer preguntas sobre el estudio.

He recibido suficiente información sobre el estudio.

He hablado con.

Comprendo que mi participación es voluntaria.

Comprendo que puedo retirarme del estudio:

4. Cuando quiera

5. Sin tener que dar explicaciones

6. Sin que esto repercuta en mis cuidados médicos

En mi presencia se ha dado a toda la información pertinente adaptada a su nivel de entendimiento y esta de acuerdo en participar. Y Presto libremente mi conformidad para que participe en el ensayo.

Fecha

Firma del participante

Fecha

Firma del investigador 


\section{APPENDIX V: Suplementary table about severity of Covid-19 disease}

Severity of Covid-19 disease according to the American Thoracic Society guidelines for community-acquired pneumonia.

\begin{tabular}{|c|c|}
\hline Severity & Description \\
\hline Mild illness & $\begin{array}{l}\text { Patients with uncomplicated upper respiratory tract viral } \\
\text { infection symptoms and have non-specific symptoms such } \\
\text { as fever, fatigue, cough (with or without sputum } \\
\text { production), anorexia, malaise, muscle pain, sore throat, } \\
\text { dyspnea, nasal congestion, diarrhea, nausea or vomiting } \\
\text { or }\end{array}$ \\
\hline Pneumonia & $\begin{array}{l}\text { Presence of pneumonia but no signs of severe pneumonia } \\
\text { and no need for supplemental oxygen. } \\
\text { CURB scale } \leq 1 \text {. }\end{array}$ \\
\hline $\begin{array}{l}\text { Severe } \\
\text { pneumonia }\end{array}$ & $\begin{array}{l}\text { Confirmed respiratory infection, plus one of the following: } \\
\text { 4) Respiratory rate }>30 \text { breaths/min. } \\
\text { 5) Severe respiratory distress. } \\
\text { 6) SpO } 2 \leq 93 \% \text { on room air. }\end{array}$ \\
\hline $\begin{array}{l}\text { Acute } \\
\text { respiratory } \\
\text { distress } \\
\text { syndrome } \\
(\text { ARDS) }\end{array}$ & $\begin{array}{l}\text { Onset: within } 1 \text { week of a known clinical insult or new or } \\
\text { worsening respiratory symptoms. } \\
\text { Chest imaging (radiograph, CT scan, or lung ultrasound): } \\
\text { bilateral opacities, not fully explained by volume overload, } \\
\text { lobar or lung collapse, or nodules. } \\
\text { Origin of pulmonary infiltrates: respiratory failure not fully } \\
\text { explained by cardiac failure or fluid overload. Need } \\
\text { objective assessment (e.g. echocardiography) to exclude } \\
\text { hydrostatic cause of infiltrates/oedema if no risk factor }\end{array}$ \\
\hline
\end{tabular}




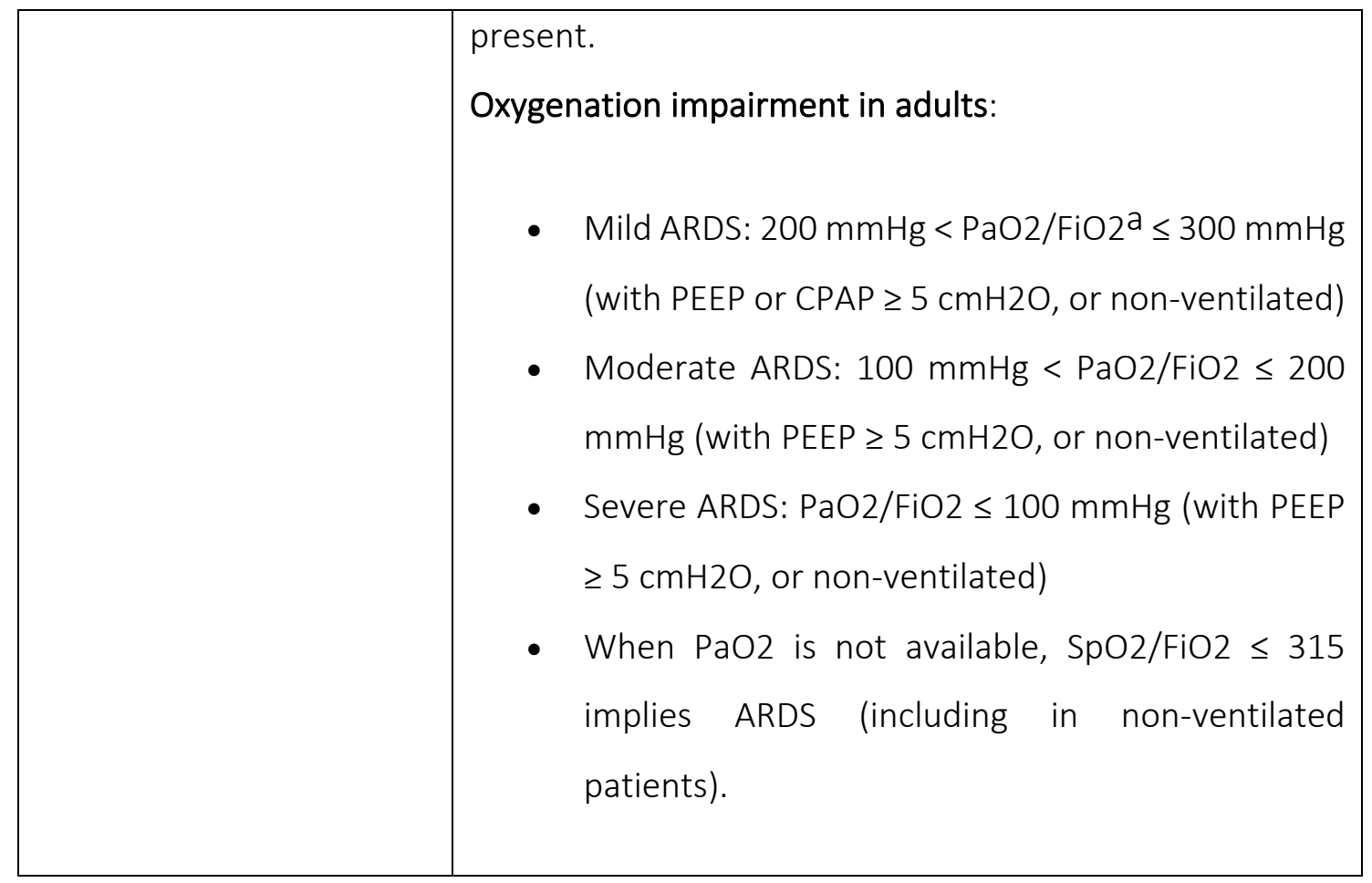

Sp: Saturation percentage. ADRS: Acute Distress Respiratory Syndrome. CT: Cranial Tomography. PaO2: Partial pressure of Oxygen. FiO2: Fraction of inspired Oxygen. PEEP: Positive end-expiratory pressure. CPAP: Continuous positive airway pressure.

\section{Adapted from:}

33. Metlay JP, Waterer GW, Long AC, et al. Diagnosis and treatment of adults with community-acquired pneumonia: an official clinical practice guideline of the American Thoracic Society and Infectious Disease Society of America. Am J Respir Crit Care Med 2019;200(7):e45-e67. 


\section{Figures legends:}

Figure 1: The cover of the International Classification of Headache Disorders, $1^{\text {st }}$ edition, 1988 (left), first page of the International Classification of Headache Disorders, $3^{\text {rd }}$ version, 2018 (right).

Figure 2. Main groups of red flags.

Figure 3. Work-up of patients with red flags.

Figure 4. Common elements in the design of the three studies.

Figure 5. Frequency of red flags in CVST, Covid-19 and TTH groups separated by category of red flag.

Figure 6. Number of publications per year related to migraine (blue) or tension-type headache (TTH) (orange) indexed in PubMed.gov from inception to November 11, 2020. Figure 7. Graphical representation of ICHD-3 criteria for migraine and TTH.

Figure 8. Quality of evidence in studies assessing red flags.

Figure 9. Pathophysiology, symptoms and signs of cerebral venous sinus thrombosis.

Figure 10. Design of studies assessing frequency of headache in Covid-19 patients in Valladolid.

Figure 11. Interval (in days) between the first COVID-19 symptom and the headache onset $(n=458)$.

Figure 12. Interpretation of PCR and serological tests to detect severe acute respiratory syndrome coronavirus 2. Adapted from Ezpeleta et al, 2020. 


\section{Tables legends:}

Table 1. Studies analysing the main reasons for consulting the on-call neurologist in the emergency department setting.

Table 2. Main groups of the International Classification of Headache Disorders.

Table 3: Core criteria for secondary headache disorders.

Table 4. ICHD-3 criteria for 9.2.2 Headache attributed to systemic viral infection.

Table 5. Major groups and/or subgroups of the ICHD-3 classification that include high-risk headache disorders.

Table 6. Frequency of headache in the well-known series of cancer patients.

Table 7. Frequency of headache in the well-known series of central nervous system infections.

Table 8. Main characteristics of a biomarker.

Table 9. Studies evaluating laboratory biomarkers for the diagnosis of headache.

Table 10. Main red flags of headache disorders.

Table 11. Main red flags of headache disorders and the groups or subgroups of the related secondary headache disorders.

Table 12. Studies in which red flags have been validated.

Table 13. Strengths and limitations of red flags as headache-related biomarkers.

Table 14. Common elements of the inclusion and exclusion criteria of the studies.

Table 15. Evaluation of sensitivity and specificity of a test.

Table 16. ICHD-3 criteria for 2. Tension type headache.

Table 17. ICHD criteria for 2. Tension type headache: from the first edition to the third version. 
Table 18. International Classification of Headache Disorders, $3^{\text {rd }}$ version, criteria for 6.6.1 Headache attributed to cerebral venous thrombosis.

Table 19. International Classification of Headache Disorders, $3^{\text {rd }}$ version, criteria for 9.2.2: Headache attributed to systemic viral infection.

Table 20. Demographic profile of patients included in the published series assessing headache in Covid-19:

Table 21. Published cases of CVST in patients with Covid-19 to date. 
